\title{
Clarifying the Conflict Between Modern Science and Natural Right
}

by

\author{
Tyler Chamberlain
}

A Thesis submitted to the Faculty of Graduate and Postdoctoral Affairs in partial fulfillment of the requirements for the degree of

Doctor of Philosophy

in

\section{Political Science}

Carleton University

Ottawa, Ontario

(C)2018

Tyler Chamberlain 


\section{$\underline{\text { Table of Contents }}$}

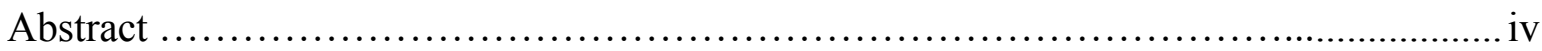

Acknowledgements............................................................

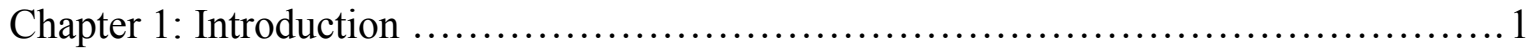

Chapter 2: The Good as the End of Platonic Natural Inquiry .......................... 30

The Developmental Interpretation and Its Problems ........ 30

Phaedo ................................................ 37

Republic ............................................ 71

Conclusion ......................................... 88

Chapter 3: Wisdom and Final Cause: Aristotelian Science ............................... 90

Physics .............................................. 91

Metaphysics ........................................... 126

Natural Inquiry and Natural Right ...................... 143

Concluding Remarks on Platonic-Aristotelian Science....... 147

Chapter 4: Descartes: Certainty for the Sake of Utility ....................................152

Descartes' Philosophical Project ..........................154

Descartes' Open Attack on Ancient Philosophy ...............180

Descartes' Veiled Attack on Ancient Philosophy .............191

The Role of Metaphysics in Descartes' System .............. 209

Technological Mastery or Explanatory Power? .............216

Technological Mastery versus Knowledge of Nature? .......228 
Chapter 5: Baconian Mastery and Observation

The Machiavellian Roots of Mastery ......................234

Baconian Ends and Attunements .......................... 243

Bacon's Refutation of Ancient Science and Philosophy ..... 256

Bacon's Ontology of Nature ............................... 264

The Experimental Method ............................... 274

Science, Politics, or Both? ............................. 285

Concluding Remarks on Cartesian-Baconian Science ..........291

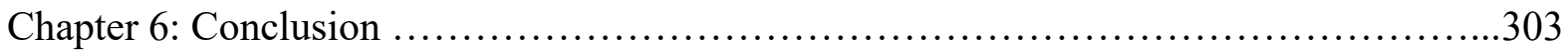

The Relationship Between Ancient and Modern Science ....307

The Emergence of Modern Science ..........................317

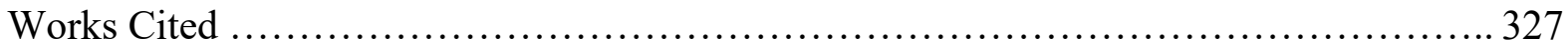




\section{$\underline{\text { Abstract }}$}

This dissertation explores the troubled relationship between natural right and modern science. It proceeds by comparing the ancient (Plato and Aristotle) and modern (Descartes and Bacon) conceptions of natural inquiry, through the categories of aims and attunements. I argue that whereas the aim of Platonic and Aristotelian science was wisdom of the whole, which attuned it to the ultimate causes of everything, the aim of Cartesian and Baconian science was the ability to control nature which attuned it to repeatable laws of behavior. The modern focus on matter and its laws turned science away from ultimate causes so that such questions came to be regarded as unscientific. Thus the conflict is between competing conceptions of science, not simply inadequate observations of the ancients having been corrected by the more careful observations of the moderns.

The benefit of using these categories to compare ancient and modern conceptions of science is that it provides the basis by which natural right might be shown to be consistent with the successes of modern science and technology. Thinking of modern science as asking different questions of nature than ancient science allows for the possibility that its different answers do not necessarily contradict its claims. The upshot of natural right, the possibility of which this thesis explores, is that opens up two primary directions for future research. First, asking the "purpose," or "why," questions that natural right encourages could shed new light on a number of policy debates. Any policy issue that requires an answer to the question "What is $\mathrm{X}$ for?" is made very 
difficult by the modern reticence to derive moral principles from the nature of the world. Basing the answers to these questions on a firmer ground than convention might open up paths to fresh insight. Second, natural right contributes to methodological debates within political science regarding the value-neutrality of the discipline. Its implied criticism of positivist and behavioralist methods can offer a different perspective than many contemporary poststructuralist and non-foundational approaches. 


\section{$\underline{\text { Acknowledgements }}$}

If it takes a village to raise a child, the same can be said for a dissertation. Although the title page bears my name, the insight, support, and encouragement of many others have made this project possible. My supervisor, Professor Waller Newell, helped to shape my initial set of concerns into a functional argument; without his guidance, especially, in the early stages of this dissertation, this already ambitious project would have been difficult to bring to fruition. The other two members of my committee, Professors Marc Hanvelt and Geoff Kellow, provided valuable feedback that has greatly improved the final project. Other teachers and colleagues who have provided valuable insight and encouragement include Tom Darby, Ron Dart, Calvin Townsend, Myron A. Penner, and Paul Chamberlain.

Finally, the biggest sacrifices have been made by my family - extended but especially immediate - and to them my greatest thanks is due. Both sets of parents - Paul and Gail Chamberlain, and Garth and Robynne Healey - know what doctoral research entails and have thus been exceptionally understanding while simultaneously proving that there is light at the end of the tunnel. From enduring cross-country moves, to proofreading drafts and putting up with my often busy evenings and weekends, my wife Raechel has been both the means whereby and the purpose for which this project has been completed. My eldest daughter Cadence is just beginning her formal education as I come to the end of mine, and her joy and passion for 
learning have inspired and encouraged me throughout the writing process. Finally, to Sophia: may the thoughts in these pages embody your namesake. 


\section{INTRODUCTION}

Natural right, the view that what is right is inherent in and given by nature, was the cornerstone of classical political philosophy. The central claim of works like Plato's Republic and Aristotle's Politics and Nicomachean Ethics was that justice is a matter of nature rather than convention. This presupposes the claim that nature, or the cosmos, can provide moral guidance. In other words, the just and the good can be discovered by contemplating the nature of what is. ${ }^{1}$ However, this view of nature is widely thought to conflict with the discoveries of modern science, which depicts nature as a purposeless flux of matter in motion, from which no "oughts" can be derived. ${ }^{2}$

This project will examine the precise nature of this conflict. It will problematize the prevailing view - namely that scientific discoveries themselves have disproven natural right - by drawing attention to key differences between some ancient and modern conceptions of science.

The approach to scientific inquiry taken by Plato and Aristotle sought wisdom of the whole and was for that reason attuned to ultimate causes and, in the last analysis, the good itself. Aristotle's definition of wisdom in Metaphysics is illuminating: "what is called wisdom is

\footnotetext{
${ }^{1}$ Charles Taylor succinctly expresses this view: "And for Plato, and this whole mode of thought in general, the cosmos exhibits the order which we should exemplify in our own lives, both individually and in societies" (Taylor 2007: 60). See also Michael Sandel (2009: 184-207), George Grant (1973: 207-210), and Alasdair MacIntyre (1984: 148-164).

${ }^{2}$ David Hume is often to be the originator of the is-ought distinction and so-called naturalistic fallacy, though it arguably draws more from Kantian categories than Humean ones. Cf. Arnhart (1999: 69-83). See also MacIntyre on Aristotle's supposed commission of the naturalistic fallacy: "Aristotle's initial arguments in the Ethics presuppose that what G.E. Moore was to call the "naturalistic fallacy' is not a fallacy at all and that statements about what is good...just are a kind of factual statement” (MacIntyre 1984: 148).
} 
concerned with first origins and causes" (981b). Plato's theory of the forms can be understood in this light, namely as his attempt to articulate that which is responsible for the world's being the way it is. Through an analysis of the Phaedo and the Republic it will be argued that not only does the theory of the forms contain ontological import, it is also bound up with Plato's entire philosophical method, down to his epistemology and philosophy of education. That the form of the Good is the ground of being determines the structure of knowledge, proper education, and, therefore, Platonic philosophical inquiry as a whole. Philosophy, qua the study of being, is therefore for Plato an inexorable ascent from observable phenomena to the Good as the cause of all that is. This is borne out in the Republic in the symbols of the cave and divided line, and in the Phaedo in Socrates' autobiographical turn from Anaxagorian natural philosophy to the study of the forms as ultimate causes. Scientific knowledge of something, therefore, includes knowledge of what is good for it.

Much of what can be said about Plato's forms can be said about Aristotle's doctrine of causality - indeed it will be argued below that Platonic forms and Aristotle's four causes are answers to the same question. Aristotle's scientific and philosophic method, which consisted of identifying the four causes of each thing, is not just an epistemological or methodological convenience. It is inextricably bound up with his ontological claim that the ultimate and most general cause is "the good, or that for the sake of which" (Metaphysics 982b). Aristotelian natural inquiry does not content itself with knowledge of laws of behavior and the material constituents of things, but strives for knowledge of forms and purposes.

The ancient study of being, I will argue, sought the most general causes of things, which for both Plato and Aristotle were inherently normative. The best way of life and the related matter of the best regime are tied to nature and can only be apprehended by properly 
contemplating the nature of what is. Natural right, in other words, goes hand in hand with the Platonic-Aristotelian study of nature. ${ }^{3}$

Certain theorists of early modern science turned this approach on its head. Coming to the conclusion that the ancients' lofty goal of wisdom had proved unattainable, these early moderns lowered their expectations in order to render them attainable. This study will look to Rene Descartes and Francis Bacon as representatives of this novel approach. Instead of wisdom, they sought control of nature, and adopted the methods best suited to attain manipulability. Rather than seeking wisdom of the general causes of things, their conception of science attuned itself to observable patterns of behavior, namely the "laws of act" (Bacon 2000: 1.51) ${ }^{4}$ and the material bodies that are governed by them. The notions of form and formal cause, so essential to Platonic and Aristotelian inquiry, are discarded as a mere chimera. Francis Bacon writes:

"We should study matter, and its structure, and structural change, and pure act, and the law of act or motion; for forms are figments of the human mind, unless one chooses to give the name of forms to these laws of act" (Ibid.).

These newfound laws of act refer to knowledge of the effects that can be reliably expected to follow from given material and efficient causes acting upon pre-existing initial conditions. They increase man's power over nature by allowing for greater manipulation of the initial conditions of bodies, which then behave according to the foreknown laws of nature. It will be argued that because the overriding aim of Cartesian and Baconian science was the ability to manipulate nature, the scientific knowledge that their methods produced was restricted to matter and laws of motion. The claim that there is a normative ground behind these brute facts is not so much refuted as simply ignored out of existence. Because natural right was bound up with

\footnotetext{
${ }^{3}$ My designation of a single "Platonic-Aristotelian" study of nature should not be taken to imply a minimizing of their real disagreements. The closing section of the third chapter will clarify the way in which we can think of the similarities and differences between Plato and Aristotle.

${ }^{4}$ All references to the body of The New Organon are to book and aphorism number.
} 
the classical belief that the fundamental ground of being was the Good, the ignorance of such fundamental principles renders natural right seemingly unnecessary or unscientific.

Demonstrating this will involve addressing the motivations of early modern thinkers; a restatement of my central claim is that the social and political intentions of Bacon and Descartes influenced their scientific work, as opposed to the perhaps more intuitive claim that their social aims followed from their empirical beliefs about the world. This is all to say that the study of competing conceptions of science is in actuality a study of competing political projects, or at the very least a study of the emergence of a radically new social project to manipulate human and non-human nature. The political nature and implications of the project of mastery are explicitly articulated by Bacon, particularly in The New Atlantis. ${ }^{5}$ Descartes, who shares Bacon's aim of mastery, refrains from stating this objective in political terms, preferring instead to focus on apolitical benefits like medicine and mechanics. However, insofar as both thinkers propose a new relationship between man and nature, patterned after the aim of utility, their shared aim of mastery can be characterized as a socio-political project.

The problem of natural right is an important one, both philosophically and politically. A persistent theme in the history of modern philosophy has been the question of how to reconcile the seeming materialism and determinism of modern science with the need for an objective and transcendent (or at least trans-subjective) ground for moral and political order. In order to stress the importance of this question, and to differentiate this study from other approaches, two wellknown solutions to this difficulty will be briefly discussed: Hobbesian social contract theory and Kant's Transcendental Idealism.

In many respects Thomas Hobbes was the first thinker to consider the political implications of the new science. Nature was a realm governed by mechanistic laws of cause and

\footnotetext{
${ }^{5}$ The New Atlantis is briefly discussed in the concluding chapter of this dissertation
} 
effect. Natural bodies behave according to the laws of force, resistance, and motion, and men in the state of nature behave according to the same laws. Being essentially atoms writ large, individuals in the state of nature collide and sometimes react violently with each other. Every aspect of human experience is thus explainable and reducible to deterministic physical processes, from initial sense perceptions to the ultimate passions including the fear of violent death. Every human motivation, and therefore action, is subject to the non-teleological laws of cause and effect that had been posited by natural scientists.

Justice, Hobbes knew, could have no place in such a world. His solution was to create an artificial island in the midst of it, by social contract or human convention. Men, the atomistic individuals living in the state of nature, can consent to binding principles of justice, although such principles are just and binding by convention only, and not by nature. There is then a clear distinction between the natural world as revealed by modern science, and the artificial world of politics in which principles of justice are binding and order is possible. Natural men in the natural state enact binding rules by which to live in order to curb the violence, disorder, and perpetual threat of death that naturally hangs over every man like the sword of Damocles. These rules, arising out of contract, remove men from nature and place them under the care of a powerful Leviathan, which Hobbes calls an "Artificial Animal” (Hobbes 1987: 81).

One important qualifier is necessary; Hobbes calls the agreed-upon rules of justice Laws of Nature, which seems to call into question the distinction between nature and artifice. They are artificial insofar as they are only binding upon consent - men are under no obligation to other men in the state of nature, indeed they have a natural right to anything they think may ensure their preservation, up to and including theft and murder. However, these laws are rooted in nature insofar as their purpose is to prevent the one thing that is most fearful for men in the state 
of nature, namely death. Men everywhere fear death as the ultimate evil, so the principles of justice to which they ought to agree are those that will most successfully prevent death - that is, the ones that satisfy men's natural need for self-preservation.

For our purposes, all that need be established is that because of the mechanistic determinism of the natural world as revealed by modern science, Hobbes was forced to relegate justice to an artificial sphere untainted by science. Science demonstrated that justice and morality were alien to nature, and could be saved only by transplanting them into the sphere of the artificial.

Another prominent approach to resolving the tension between modern science and a transcendent moral ground was taken by Immanuel Kant. Garret Thomson begins his introduction to Kant with the following problematic:

"The first Critique tells us that we live in a mechanical, spatio-temporal world. The second Critique tells us that we are free, moral beings. How can the two be reconciled? This is part of the problem of the whole modern period: how can physics be reconciled with morality and religion (Thomson 2000: 1).

Just as Hobbes' work largely revolves around the distinction between the natural and the artificial, Kant's solution to this problem was to establish a distinction between the phenomenal and noumenal worlds. All experience and a priori knowledge can only be of the phenomenal world, not the noumenal world of things in themselves. The phenomenal world is the world as known through human philosophy and natural science, and it is the world governed by the impersonal laws of nature discovered by Galileo, Bacon, Newton, and others. It is the world of appearances (gr. phainonenon = "thing appearing to view") as opposed to the world of which nothing can be seen or thought. Moreover, because modern science was thought to have demonstrated that the world is a machine operating according to deterministic laws, the 
phenomenal world is the realm of necessity, while moral freedom is restricted to the world of noumena.

However, the categories, among which are space and time, are not things in themselves, but instead act as filters of our experience, ensuring that all that we can know is the world as interpreted by them. The noumenal world, then, is beyond all categories of experience; it is nothing but a limiting concept about which nothing can be meaningfully said. That is, all that we can truly know is that the phenomenal world is governed by impersonal laws that leave no room for God, human freedom, or the soul, all three of which Kant thought were indispensable for morality.

These metaphysical concepts are beyond the world of phenomena and all possible categories of experience, and cannot be known by pure reason. They are also required in order for morality to be a meaningful concept, since if we are not free then we cannot possibly be morally responsible agents. In similar fashion, the reality and immortality of the soul, as well as the existence of God, are required in order to properly ground morality, but only exist in the noumenal world. They must be accepted, but cannot be grounded in pure speculative reason. Kant's famous solution was to postulate the reality of these three notions, recognizing that while we have no theoretical justification for believing them to be true, they are simply beyond the categories of possible experience. In Kant's words, “[t]hese postulates are not theorerical dogmas but presuppositions having a necessary practical reference" (Kant 1997: 110). The fact that pure reason - physics - cannot know them does not entail that they are false. Metaphysics, while beyond the knowability of the phenomenal world known by physics, is left untouched by physics. It is therefore not contrary to pure reason to postulate their truth as part of practical reason. 
Kant therefore reconciles modern science with an authoritative ground for morality and political order by demarcating physics from metaphysics such that the scientific understanding of the world is compatible with metaphysical truths regarding God, moral freedom, and the soul. Natural science does not disprove them because they exist in the noumenal world that cannot be touched by physics.

The precise nature of the phenomenal and noumenal worlds, or whether they are even two distinct worlds at all, is the subject of a vast and enduring literature. It does not help that Kant himself left the question unclear. The two-world interpretation sees the noumenal world as the world out there, ${ }^{6}$ that exists in and for itself, and would continue to exist if mankind ceased to exist. Phenomena, on the other hand, are the mental representations of reality in the mind of the perceiver, and are thus ontologically separate from noumena. All that one can know, in this view, is the mental representation of the noumena, which is a mental construct. In contrast, the one-world interpretation refuses to grant distinct ontological status to the phenomenon, preferring to think of it as the same world experienced through the categories. Knowledge of the phenomena is a type of knowledge of things in themselves, but only a knowledge of them as through a filter. Men can only have knowledge of noumena by way of the categories that organize experience, and can have no knowledge of the world unfettered by such organization.

The nature of the two worlds, or two aspects of the same world, is crucial for understanding Kant's solution to the problem at hand. It is not enough to insist that knowledge of freedom is sufficient to ground moral responsibility; one must also have reasons for supposing that real, tangible individuals in the midst of the phenomenal, deterministic world have said freedom. This is the reasoning given by proponents of the one-world interpretation of

\footnotetext{
${ }^{6}$ However, one must be mindful of the spatial connotations of this phrase, recognizing that such designations do not apply to noumena.
} 
transcendental idealism, in the hopes that it will reduce the gulf between the phenomena and noumena. One of the benefits of this view is that it does not force us to think of our freedom as only existing in our "noumenal" self instead of our phenomenal self. It is hard to see how the freedom of my noumenal self gives my phenomenological body the freedom to act morally in the world of experience, if they are two distinct entities. Thomson expresses the point thusly: "we should avoid attributing to Kant an ontological dualism. Phenomena and noumena are not two kinds of things. Noumenal causes are not in addition to phenomenal causes. Rather they are two ways of seeing the same thing" (Thomson 2000: 60). That is, we are not part noumenal being that is free and part phenomenal being that is determined; rather, we can regard our actions in either way. Phenomenologically, we must regard our actions as determined, but as per the postulates of practical reason we can also regard our actions as being noumenally free.

Moreover, because the postulates of practical reason pertain to noumena, which are untouched by science, there is no necessary contradiction between the phenomenal and noumenal aspects. ${ }^{7}$

It is worth noting that the one-world interpretation of Kant was not the one held by his immediate successors. ${ }^{8}$ The one-world view has been discussed at greater length because it seems to be the best candidate for reconciling modern science with the requirements for moral and political order. However, both interpretations of Transcendental Idealism assert that the phenomenal world is governed by the materialistic and deterministic laws of modern natural science such that moral freedom and responsibility are relegated to the strictly unknowable world of the noumena.

As stated above, the difficult relationship between morality and modern science is a recurring theme in the history of modern political theory. This brief discussion of Hobbes and

\footnotetext{
${ }^{7}$ For other one-world interpretations of Kant, see Allison (2004) and Bird (2006).

${ }^{8}$ The earliest review of the first Critique, by Christian Garve, held to the two-world interpretation. It is reprinted in Sassen (2000).
} 
Kant leaves many other notable proposals by the wayside, although it was perhaps enough to reveal some commonalities to the various modern approaches to this difficulty. Both Hobbes and Kant, in their own ways, simultaneously concede to modern science that it is incompatible with a transcendent moral ground while locating morality in a sphere beyond and untouched by science. That is, they both concede to modern science that it has disproven the classical basis for moral and political order, and are thus forced, as if post-hoc, to save morality by finding a place for it that is untouched by science. Insofar as Hobbes and Kant are indicative of the general modern tendency, that tendency is to take for granted that science has demonstrated that justice and purposiveness have no part in the natural world. By contrast, natural right situates moral knowledge squarely within scientific inquiry. These modern solutions do not critically examine the assumptions of modern scientific knowledge itself, but instead capitulate to it and define morality according to its terms.

It is beyond my purposes to comprehensively discuss the strengths and weaknesses of this approach, although it should be noted that the decision to locate morality, and indeed the entirety of metaphysics, beyond what is properly knowable contributed in part to the eventual emergence of Nietzsche's radical perspectivism and distrust of transcendent morality as a whole. ${ }^{9}$ Once morality is pushed beyond the realm of the scientifically and rationally knowable, it can only be retained, Nietzsche reasonably concluded, by sheer force of will.

The dominant modern answers to this question, then, have shown themselves to be unsatisfactory. More recently, there have been numerous attempts to look to classical philosophy for answers; it is to this trajectory that the present project belongs. As indicated above, Plato and Aristotle reconciled descriptive knowledge with ethics under a broad

\footnotetext{
${ }^{9}$ Although I disagree with the argument of MacIntyre's After Virtue on a number of important points, I share his belief that Nietzsche's thought was made possible by the failure of the modern project to sufficiently ground morality.
} 
conception of natural inquiry that moved seamlessly from sensible to intelligible objects. While there are different sections of Plato's divided line, it is a single ascent to the top, and one method of inquiry by which one ascends. Similarly, for Aristotle, although there are four causes, there is one single mode of inquiry that knows them all. The ancient approach does not make the familiar modern distinctions between physics and metaphysics or science and philosophy, such that one single study of nature reveals both descriptive and moral knowledge - indeed, moral knowledge ultimately is descriptive knowledge.

Recent decades have seen a sizeable literature on the relationship between classical philosophy and modern science. One influential school is the work of Ethical Naturalists like Larry Arnhart and Roger Masters. Ethical Naturalism seeks an almost-complete synthesis of Darwinian biology and classical natural right (Masters 1989, 1990; Arnhart 1998). Masters perhaps provides the clearest overview of this project, which "[makes] it possible to view human politics from a perspective consistent with both the tradition of Western political philosophy and the findings of contemporary biology" (Masters 1989: 196). His perspective consists of the attempt to "provide the basis for an empirical analysis of the origins of the centralized or bureaucratic state, allowing a basic issue in political philosophy to be treated as a question for scientific analysis" (Ibid.: 203). He concludes that such a method can point us toward "the discovery of natural standards of justice [i.e. natural right]," and ultimately, to something akin to the Aristotelian teaching on natural justice (Ibid.: 204, 205).

Richard Hassing (1997), by way of friendly criticism of Ethical Naturalism, provides a similar answer to the question of classical philosophy and modern science. While hopeful that modern science need not necessitate the complete rejection of natural right, Hassing is wary of Ethical Naturalism's claim that a complete synthesis between modern science and classical 
thought is possible. He proposes "regional teleology," according to which teleology, and therefore natural right, can be retained in the biological sciences despite being refuted in physics and chemistry. To say nothing of this characteristically modern division of inquiry into distinct fields, this solution fails to account for the way in which the final causality operative over living things is made possible by the broader order governing the entire cosmos. Moreover, despite the differences between Hassing and Ethical Naturalism, Ethical Naturalism shares with Hassing the distinction between biological sciences, in which teleology can be maintained, and the other sciences, in which teleology is untenable. For this reason, all of the above depart significantly from the classical formulation of natural right, in which the good for man is only intelligible in light of the good of the whole. Once conceding the impossibility of a teleological understanding of the cosmos, as Hassing and the Ethical Naturalists do, the very foundation for a teleological science of man vanishes.

Arnhart, Masters, and Hassing all ground their discussion in the context of Leo Strauss' Natural Right and History. In the introduction to that book Strauss briefly contemplates the status of natural right in the wake of modern science, only to set the question aside in favour of the historical analysis that comprises the body of his argument. However, despite his setting the question aside, he insists that "an adequate solution to the problem of natural right cannot be found before this basic problem [i.e. the victory of modern science] has been solved" (Strauss 1999: 8). In order to avoid their shared project of regional teleology - albeit recognizing their differences - it is necessary to point out that Strauss himself does not explicitly concede cosmic teleology to modern science, as do the ethical naturalists.

The loss of natural right, Strauss claims, can be attributed to the "victory of modern natural science" (Ibid.: 8). As a result of this victory, cosmic teleology seems to have been 
refuted by modern science, which leaves us with two options. One can either eradicate teleology from all levels of nature, down to life itself, or one can distinguish between non-teleological natural science and teleological human science. The first option is generally chosen by positivists ${ }^{10}$, although it is impossible to account for purposes and intentionality purely mechanistically. The second option, that of regional teleology, is the one taken by Arnhart, Hassing, and modern Thomists. As Strauss claims, it is a modern distinction that departs from the comprehensive view of the whole shared by Plato and Aristotle. Strauss closes by calling for an adequate solution to this problem, but does not attempt to provide one. The implication, however, is that neither of these strategies is sufficient to ground natural right. That is, in the absence of cosmic teleology, Strauss seems to think that classical natural right cannot be maintained.

While the surface reading of this passage indicates that Strauss concedes cosmic teleology to science, a closer look reveals that he does no such thing. He heavily qualifies the claim that modern science has decided in favour of the mechanistic view. In truth, his only admission is that it seems to have been so decided (Ibid.: 7-8). He is thus not nearly so quick to concede cosmic teleology to science as it first appears. It is only the vaguer statement about "the victory of modern science" that he refrains from qualifying. However, it is not obvious that "the victory of modern natural science" is meant to be synonymous with "modern science deciding in favour of a mechanistic universe." Indeed, the "victory of modern science" can plausibly be read as the sociological fact that modern science seems to have refuted cosmic teleology, not the ontological fact that modern science has in fact shown cosmic teleology to be impossible. It may be, then, that his intention in this passage is not to incline the reader to adopt either regional

\footnotetext{
${ }^{10}$ By positivists, I am referring to adherents of the fact-value distinction who restrict what we can know to the realm of objective, or positive, facts and relegate questions of value or purpose to the subjective realm of opinion. Positivist natural and social science aims for value-neutrality on this basis.
} 
teleology or to accept a completely mechanistic cosmos. A possible Straussian answer to the problem he poses might be to examine the status of cosmic teleology itself in the light of modern science. This would avoid the pitfalls of the positivist and Thomist approaches. That is to say, even beginning from Strauss' problematic need not consign one to the limiting project of regional teleology. Both Arnhart and Hassing misinterpret Strauss in this regard, and this misunderstanding leads them to adopt the project of regional teleology. On their own Straussian presuppositions, in other words, their limitation of teleology to specific regions of the cosmos is unnecessary.

Waller Newell’s essay “Did Plato Believe in his own Metaphysics?” (Newell 2010) is helpful in this regard. It persuasively presents the argument that Plato's political teaching - i.e. what Hassing, Arnhart and Masters might call regional teleology - can only be correct if Plato's larger cosmology as a whole is correct. ${ }^{11}$ An alternative, though not necessarily contradictory, way of making the same point is found in Voegelin's "Right by Nature" (Voegelin 1978a), in which he argues that for Aristotle, the virtue of phronesis acts as the mediator between the order of the cosmos and particular instances of natural right. That is, the act of practical judgement is simply the application of cosmological principles to local and particular situations. This can only be the case, of course, if there really is an order and purpose to the entire cosmos. All of this is to say that there are good grounds for rejecting the self-imposed limitation of regional teleology. Only after clearing the ground of this objection to a more complete teleology can my project proceed.

One final classically-inspired approach is Alasdair MacIntyre's attempted revival of Aristotelianism in After Virtue. While not specifically concerned with the quarrel between ancient and modern science, MacIntyre is nonetheless committed to the belief that modern moral

\footnotetext{
${ }^{11}$ I.E.: "Platonic rhetoric and metaphysics are indissolubly and organically linked" (Newell 2010: 230).
} 
philosophy has failed us, and that a return to Aristotelian virtue ethics is of practical as well as theoretical importance. However, his ability to articulate an Aristotelian response to modernity is hampered by his failure to step outside of the limitations of modern natural science. He abandons Aristotle's derivation of the virtues from biology, instead grounding them in a sociological account of human lives (MacIntyre 1984: 162-163, 186-187). The difficulty he has in avoiding the charge of relativism, ${ }^{12}$ ironically the very problem of modernity he sought to overcome, can be traced to his inability to fully rise above the modern conception of science, which bars him from deriving ethics from the nature of man. ${ }^{13}$

MacIntyre and the Ethical Naturalists share a reticence to step outside of the bounds of modern science, which limits the extent to which their projects can effectively challenge the reductionism that so often accompanies it. This dissertation agrees with Hassing, MacIntyre, and the Ethical Naturalists that classical political philosophy can help us in the modern age to reconcile science and morality; it disagrees with all of them, however, insofar as they concede the modern conception of science. The primary objective of this dissertation is to address this weakness. Their diagnosis of modern political thought and life is helpful, as is their project of reviving classical political thought. It therefore will attempt to address this weakness by highlighting some key themes in formulations of modern science, and how these dictates what can and cannot be known. By paying attention to the conception of science that has made it so difficult to salvage objective morality, this project will provide a lens through which the possibility of reconciling natural right to modern science can be maintained. To reiterate, it is

\footnotetext{
${ }^{12}$ See Wachbroit (1983).

${ }^{13}$ I provide a more detailed analysis of this problem in "MacIntyre's Unsuccessful Aristotelianism: An Oakeshottian Critique of After Virtue." Unpublished paper presented at the Aristotle and the Peripatetic Tradition conference; Dominican University College, Ottawa, ON: October 2014.
} 
not the discoveries of modern science that conflict with natural right, but fundamental changes in the modern conception of scientific inquiry.

The chief body of scholarship this project is engaging, and to which it aims to contribute, is the aforementioned set of approaches to reviving classical natural right. It takes their shared limitation, namely conceding to modernity its conception of science, as its starting point and foil. The explicit argument of the following chapters will focus on Plato, Aristotle, Descartes, and Bacon in the service of this broader objective. The purpose of the individual chapters is not primarily to contribute to the literature on their respective thinker, though we will see that placing each of them in comparative perspective will shed light on their respective philosophies. To this end, debates in the relevant literature will be addressed when they shed light on the aims and attunements of science, but they will be secondary to the broad goal of comparing ancient and modern conceptions of science in light of the place of natural right today.

The meaning of "natural right" is not altogether clear or uncontested. By natural right, this project refers to what has elsewhere been called "classic natural right" (Strauss 1999), as opposed to modern natural right. The meaning of natural right in this sense can be made clear by way of comparison with modern natural right. The clearest presentation of classic natural right is in book $\mathrm{V}$ of Nicomachean Ethics, where Aristotle distinguishes between natural and conventional justice. That is, what is "naturally just has the same power everywhere, and is not affected by whether it seems so to people or not" (1134b). The opposite is true for things that are just only in the conventional sense: they only make a difference if and where they are established by people. In the political context, Voegelin suggests that natural right pertains to essentials and conventional right pertains to "essentially indifferent matters" like traffic regulations, measures, 
and the like (Voegelin 1978a: 57). Strauss similarly defines classic natural right against the backdrop of convention:

"the distinction between nature and law (convention) retains its full significance for Socrates and for classic natural right in general. The classics presuppose the validity of that distinction when demanding that the law should follow the order established by nature (Strauss 1999: 121).

Natural right, as used in this project, refers to the belief that there are some things that are right by nature, whether or not such rightness is recognized or legislated by men (or God). There is a best regime according to nature, and some habits, practices, and ways of life are by nature better than others. Within this broad definition there are many disagreements, largely concerning the content of natural right. For example, Voegelin's analysis of the passage from Nicomachean Ethics quoted above argues that natural right is primarily a political concept, and only pertains to other areas of life by resemblance (Voegelin 1978a 56-57), whereas Arnhart applies it without hesitation to the three distinctly non-political human relationships: parent-child, man-woman, and master-slave (Arnhart 1998: ch. 5-7). Such debates are not relevant to the question of this project, which is whether anything, political or otherwise, can be right or wrong according to nature.

What is called modern natural right is best understood by looking to Thomas Hobbes. Hobbes attempted to balance a political order that is based on natural human fears with the radical doctrine that moral and political duties were only legitimate under conditions of consent. This tension was briefly mentioned above in reference to the question whether Hobbes' laws of nature should be understood as natural or artificial; it is the attempt to make them both that typifies modern natural right. George Grant gives a persuasive account of the natural-ness of modern natural right in English-Speaking Justice, the third chapter of which emphasizes the connections between nature and politics in Locke and Kant (Grant 1985: 13-33), but the fact is 
that consent, agreement, or convention remain indispensable components to modern natural right. It remains true that according to modern natural right, nothing is truly right by nature; unless human agreement or contract establishes moral and political duties there are no such duties. Although nature can be used to judge conventions after the fact as being suitable solutions to the problems inherent in the state of nature, the fact that nothing is morally binding by nature entails a qualitative difference between classic and modern natural right, such that the natural-ness of the latter may be called into question.

Classic natural right is thus distinct from modern natural right on the basis of the latter's re-introduction of convention. This project is concerned only with the viability of classic natural right, and thus will refer to it simply as natural right.

Although this work is unabashedly theoretical, it nevertheless addresses an issue of real policy significance. The loss of natural right has had profound implications for the moral and political life of the contemporary west. A number of current debates and problems have only arisen because of the loss of natural right. For example, the ethical debates surrounding genetic engineering, not to mention the extreme example of transhumanism, bring us into murky waters because nature no longer gives an answer to the question, "What is a human being?" The limits and possibilities inherent in the bodily existence of Homo Sapiens, from which pre-modern thinkers received their moral bearings, are no longer authoritative. This leaves any opposition to the technological mastery of human nature without a persuasive response to the alluring promises of increased health, capabilities, and even immortality.

Even two of the most persuasive critics of the march toward further genetic control, Michael Sandel and Jürgen Habermas, fail to provide ontologically satisfying answers to the 
question, "Why should we refrain from modifying the human genome in the name of utility?" Instead, each offers his own version of utilitarian pleas for moderation.

Sandel's The Case Against Perfection: Ethics in the Age of Genetic Engineering makes a distinction between genetic engineering for therapeutic versus enhancement purposes (Sandel 2009a). This distinction relies on a pseudo-teleological concept of "normal" health, such that a treatment is justified insofar as it returns the patient to his or her "normal" state of health, but not if it increases his or her "natural" powers or abilities in any way. This concept, of course, requires something akin to Aristotle's notion of formal cause, which as we will see is closely related to final cause. However, Sandel makes no attempt to argue for this Aristotelian metaphysics, which renders his distinction somewhat arbitrary, and therefore unconvincing. The only part of his argument likely to convince a modern liberal is his utilitarian claim that increased genetic enhancement is likely to limit the role in society of responsibility, humility, and solidarity, which are vital to maintaining a healthy political community (Ibid.: 85-92).

Habermas, on the other hand, is open about his lack of metaphysics. Indeed, his entire postmetaphysical ethical project seeks to replace ontological foundations for freedom and equality with the intersubjectivity of communication and discourse. The model of communication in the ideal speech situation posits a collection of persons in egalitarian relationships reaching a consensus, in which each person is responsible for his or her ethical selfunderstanding. The basis of Habermas' critique of genetic engineering is that it destroys the egalitarian foundations of discourse. "For," he writes,

"as soon as adults treat the desirable genetic traits of their descendants as a product they can shape according to a design of their own liking, they are exercising a kind of control over their genetically manipulated offspring that intervenes in the somatic bases of another person's spontaneous relation-to-self and ethical freedom" (Habermas 2003: 13). 
That is to say, his postmetaphysical defense of liberal politics requires an ethical selfunderstanding of the human species that allows for "symmetrical relations between free and equal human beings" (Ibid.: 23). However, as he argues, making parents responsible for their children's genetic make-up, and thereby putting them in a privileged ethical relationship to them, will drastically undermine this ethical self-understanding. It is at this point, namely when "the ethical self-understanding of language using agents is at stake in its entirety," that even Habermas' respect for pluralism reaches its limit (Ibid.: 11).

However convincing Habermas' explicitly postmetaphysical argument against genetic engineering is, and it certainly does provide a persuasive account of the dangers it poses to liberal politics, it nevertheless fails to truly substantiate the crucial difference between therapeutic and enhancement treatment, or negative and positive eugenics. He distinguishes between the two on the basis of whether or not the treatment would be subject to general consent (Ibid.: 52). However, this merely pushes the question back one step, and possibly even begs the question, for the "logic of healing," from which is derived the point at which consent can be assumed, is undoubtedly drawn from the distinction between therapy and enhancement. Habermas' difficulty in articulating a strict line at which genetic engineering constitutes a threat to the "ethical self-understanding of the human species" is a result of his attempt to formulate his position without reference to natural right.

To conclude this point, it is worth quoting at length from Beyond Therapy: Biotechnology and the Pursuit of Happiness, the 2003 report issued by The President's Council on Bioethics:

But although the distinction between therapy and enhancement is a fitting beginning and useful shorthand for calling attention to the problem (and although we shall from time to time make use of it ourselves), it is fully inadequate to the moral task....[T]here are difficulties owing to the fact that both 'enhancement' and 'therapy' are bound up with, and absolutely depend on, the inherently complicated idea of health and the alwayscontroversial idea of normality....But there are notorious difficulties in trying to define 
'healthy' and 'impaired,' 'normal' and 'abnormal' (and hence, 'super-normal'), especially in the area of 'behavioral' or 'psychic' functions and activities....If one follows the famous World Health Organization's definition of health as 'a state of complete physical, mental, and social well-being,' almost any intervention aimed at enhancement may be seen as health-promoting, and hence 'therapeutic,' if it serves to promote the enhanced individual's mental well-being by making him happier.

Yet even for those using a narrower definition of health, the distinction between therapy and enhancement will prove problematic. While in some cases - for instance, a chronic disease or a serious injury - it is fairly easy to point to a departure from the standard of health, other cases defy simple classification. Most human capacities fall along a continuum, or a 'normal distribution' curve, and individuals who find themselves near the lower end of the normal distribution may be considered disadvantaged and therefore unhealthy in comparison with others. But the average may equally regard themselves as disadvantaged with regard to the above average. If one is responding in both cases to perceived disadvantage, on what principle can we call helping someone on the lower end 'therapy' and helping someone who is merely average 'enhancement'? In which cases of traits distributed 'normally' (for example, high or IQ or cheerfulness) does the average also function as a norm, or is the norm itself subject to alteration? (The President's Council on Bioethics 2003: 14-16)

The authors of the report go on to give further reasons for their wish to move beyond the therapy vs. enhancement distinction, but the above analysis is telling. There seems to be no way of defining "normality" or objective health. In language more familiar to Plato or Aristotle, they might have said that there is no identifiable form of a healthy human being, no set of necessary and sufficient conditions that would demarcate therapy from enhancement. But this is just what natural right would provide. If true, natural right would provide the ontological basis for such a distinction. Genetic engineering is not the only policy question of relevance to natural right. Indeed, any policy or legislative issue that requires an answer to the question "What is $\mathrm{X}$ for?" is made virtually insoluble by the modern reticence to derive moral principles from the nature of the world.

A final implication of the possibility of natural right concerns the methodology of political science itself. The positivism of modern natural science has become prominent in the various social sciences as well. These approaches aspire to describe the objective facts concerning the world of human interaction, and leave values out of the equation. Their goal is 
often to discover and describe impersonal laws of society and politics, the knowledge of which can then be used by planners and policy-makers to produce peace and prosperity. ${ }^{14}$ Though there are a myriad of critical, post-positivist, and postmodern reactions to positivist political science methodologies (Roseneau 1991; Smith, Booth, and Zalewski 1996; Cox 1981; Lapid 1989), the natural right framework implies a distinct methodological approach to the study of political phenomena. Instead of drawing a sharp distinction between facts and values, with the former being objective and the latter being merely subjective, natural right allows for the answering of so-called "value-questions" by way of objective facts about the world. The comparative study of constitutions, to take but one example, would then include everything now included under the rubric of positive description of facts as well as an analysis of how closely each regime is suited to the natural needs and desires of its subjects.

However, the articulation of a natural right-inspired methodology of political science goes beyond the argument of this study, which is concerned only with the possibility of reconciling natural right to modern science. The policy and methodological implications of natural right are mentioned here only to illustrate what is at stake in the debate concerning natural right, and to accentuate the political import of the scientific themes in this study. This comparison of ancient and modern thinkers is not undertaken for its own sake, so to speak, but with a view to the possibility of bringing the natural right framework to bear on contemporary issues of policy and research methodology.

\footnotetext{
14 A few quotations from positivist political scientists will suffice to display this inclination:

"Theories are general statements that describe and explain the causes or effects of classes of phenomena. They are composed of causal laws or hypotheses, explanations, or antecedent conditions. Explanations are also composed of causal laws or hypotheses, which are in turn composed of dependent and independent variables" (Van Evera 1997: 7-8).

"Scientific research is designed to make descriptive or explanatory inferences on the basis of empirical information about the world" (King, Keohane, and Verba: 1994: 7).
} 
Finally, the central argument of this dissertation raises a number of questions which cannot be fully answered but must be acknowledged. The most important of these concerns the proper implications to be drawn from my claim that it is particular conceptions of science that conflict with natural right. The varieties of disagreement are placed in three categories: empirical progress, incommensurability, and compatibility. The framework of aims and attunements suggests that modern science should not simply be thought of as empirical progress over ancient science, but this still leaves open the possibilities of modern science being either incommensurable or compatible with its premodern counterpart. The point on which this question hinges is whether modern scientific methods are best thought of as substitutions for or mere restrictions of ancient science. If Cartesian-Baconian science is conceived of as a substitution of Platonic-Aristotelian science we are confronted with a choice between opposed and incompatible methodologies and presuppositions. On the other hand, if Descartes and Bacon simply restricted the bounds of the scientifically knowable - say, from four causes to two - then there remains the possibility of combining the modern empirical insight into the material and efficient causes of natural phenomena with the ancient insight into the formal and final causes of all things. The concluding chapter will briefly review what is at stake in each of these options before provisionally accepting the restriction, or "compatibility," thesis.

There are two concluding methodological considerations. My method is primarily exegetical. I am seeking to answer my research question by analyzing some of the texts that have come to define modern scientific inquiry. However, I am not merely engaging in the history of ideas. My primary purpose is not, at least intrinsically, to answer pressing questions 
that are of concern to Plato scholars, for example. ${ }^{15}$ The hope is that by shedding light on the various ways science has been defined and understood throughout the ages, current debates about the relationship between science and political thought can be clarified. That is, this project will discuss the work of Plato, Aristotle, Bacon, and Descartes in order to answer a specific question that is relevant today, namely the place, or lack thereof, of questions of morality and purpose in scientific inquiry. While this dissertation will not necessarily argue that the study of the natural world can offer moral or political instruction, it will articulate and defend a set of categories through which the natural right framework might be pursued in the age of science. In other words, this study serves as the clearing in which this question can be explored at greater length and, hopefully, with greater success.

Second, a quick defense of my choice of thinkers is in order. While Plato and Aristotle are fairly obvious choices for chief representatives of classical inquiry, the choice is nevertheless intentional. It is not uncommon for interpreters to draw attention to the differences between them, ${ }^{16}$ especially in regard to the role of empirical evidence and the study of the natural world. Plato can be said to have ignored the material world whereas Aristotle paid more attention to it. ${ }^{17}$ An implication of my analysis, however, will be that the two thinkers' disagreements - real though they are - take place within the context of shared aims and attunements of intellectual inquiry. Each of them begins from looking at the visible world around them, and proceeds from this to the invisible world of ultimate causes. While the emphasis on their similarities has

\footnotetext{
${ }^{15}$ However, the work of interpreting these four thinkers in light of the categories of aims and attunements will lead us into the territory of scholarly debates. These will be addressed and certain positions will be staked out and defended when required.

${ }^{16}$ Hans-Georg Gadamer traces this oppositional interpretation of Plato and Aristotle to Galileo: "Here for the first time one becomes conscious of a real opposition between Plato and Aristotle: Plato's extended application of the mathematical, hypothetical procedure to dialectic could serve to legitimate Galileo's physics whereas Aristotle's authority only stood in the way of unprejudiced inquiry into nature" (Gadamer 1980: 195).

${ }^{17}$ The following chapters will show that there is something to this view, insofar as Plato's immaterial forms explain visible phenomena whereas Aristotle gives causal power to matter. However, the problem arises when we collapse this difference into a simplistic dichotomy that ignores their significant agreement.
} 
perhaps been the minority view, it has had its fair share of support. For example, Robert Turnbull and M.J. Cresswell have argued that Aristotle's natural philosophy owes a significant debt to the natural philosophy of Plato's Phaedo (Turnbull 1958; Cresswell 1987).

The choice of Bacon and Descartes is perhaps more controversial, as it leaves out worthy thinkers like Hobbes, Galileo, Newton, or even Darwin. Hobbes' absence is especially noticeable, as he is arguably the first thinker to completely think through the implications of the new science for political life. ${ }^{18}$ However, his absence is justified insofar as he himself adds nothing of note to the modern conception of science itself. His materialism, and emphasis on generalizable laws of motion that influence the behavior of bodies, adds nothing essential to Bacon's articulation of the same, such that the basis of modern science can be understood without reference to Hobbes.

However, it is still the case that no study of the place of natural right in the modern world would be complete without reference to thinkers like Machiavelli and Hobbes. For this reason they will be considered according to their relationship with Bacon and Descartes, as both laying the foundation for the new conception of science-as-mastery and articulating visions of what such a politics in the absence of natural right might look like. Nevertheless, the primary argument of this dissertation is best made by way of Bacon and Descartes themselves.

In addition to this defensive justification of privileging certain thinkers, there is a positive justification for emphasizing Bacon and Descartes specifically. These thinkers stand at the beginning of the empiricist and rationalist traditions of modern philosophy, respectively. As with Plato and Aristotle, the disagreements between empiricists and rationalists often dominate the discussion at the expense of their manifold similarities. My analysis will counter this

\footnotetext{
${ }^{18}$ Machiavelli could also lay claim to this title. I have omitted him here because he stands before the thorough articulation of modern science by Descartes, Bacon, Newton, et al.
} 
tendency by drawing attention to the way Bacon and Descartes agree on the fundamental aims and attunements that should guide scientific inquiry. Indeed, the importance of shared aims and attunements is put into sharp focus in the context of their epistemological dispute. The rationalist Descartes derives his laws of nature in a way that would be fundamentally unacceptable to Bacon's empiricism. Despite this difference, however, the crucial fact remains that they both conceived of science as providing knowledge of the behavior of bodies. The value, therefore, in using these two thinkers instead of, for example, Isaac Newton, lies in the fact that their central difference highlights their ultimate similarity concerning aims and attunements of scientific inquiry. The emphasis, despite differences, on the similarities between Plato and Aristotle, on the one hand, and Bacon and Descartes, on the other hand, will highlight the contrasting tendencies of ancient and modern thought, and will therefore draw attention to some important lines of disagreement between ancients and moderns.

To this end, my discussion dovetails with Newell's depiction of the fundamental difference between the ancients and the early moderns (Newell 2013). Platonic and Aristotelian inquiry, which sought wisdom and intelligibility, consisted of bringing one's reason into conformity with the natural order of the cosmos; to think rationally was to submit one's intellect to the order of the cosmos. Modern scientific inquiry, on the other hand, consisted primarily of applying one's reason to the task of mastering and subduing nature. Reason, instead of operating according to nature, is divorced from it and treats it as an object.

The next four chapters will study Plato, Aristotle, Descartes, and Bacon, in that order, with a view to illuminating how each of them conceives of natural science. As explained above, I will argue that Plato's theory of the forms is best understood as his articulation of the view that natural inquiry must lead to ultimate causes. Moreover, as he claims in the Republic, the ultimate 
cause of everything that exists is normative. There can be no consistent and thorough study of the world, according to Plato, that does not result in knowledge of the good.

The third chapter will examine the nature of final causality in Aristotle's Physics and then turn to the broader discussion of wisdom in Metaphysics to argue that for Aristotle, wisdom itself consists of knowledge of the ultimate causes of things such that no scientific inquiry can avoid knowledge of final cause - purpose, or "the good of all that is" (Metaphysics 982b). This chapter will highlight the relevant differences and similarities between Plato and Aristotle, and in so doing, will provide a conclusive statement of what is common in their conceptions of science. The details of this have been discussed above, but suffice to say for now that the emphasis will be on the aim of ancient science - wisdom - and the subsequent attunement - ultimate causes, or that which bears the primary responsibility for each thing's being the way it is. Their shared aims and attunements will also direct us to an important disagreement between them, namely concerning whether matter is an explanatorily useful concept.

The fourth and fifth chapters will follow this pattern. The fourth will examine some of René Descartes' philosophical work, primarily the Discourse on Method, in conjunction with his more scientifically-oriented The World. The emphasis here will be on the importance given to method and so-called "practical knowledge," and how this emphasis led Descartes to adopt the physical views he held regarding, among other things, laws of motion and the corpuscular nature of the universe. The fifth will consist of an interpretation of Francis Bacon's New Organon, with special attention given to his redrawing of the boundaries of scientific inquiry to exclude formal and final causality. Baconian science consists of the identification of impersonal laws of motion and the ways in which they govern the movement of bodies. This chapter, like the third, will include a conclusive statement of the commonalities and differences between these two thinkers. 
It will argue that their conception of science was characterized by radically different aims control over nature - which therefore attuned it to certain types of phenomena - the measurable and therefore predictable and manipulable - and away from others, namely that which bears the most responsibility for a thing's being that way it is.

The final chapter will relate the contrasting theories of science to the overarching goal of this dissertation, which is to problematize the simplistic view according to which the discoveries of modern science have empirically disproven natural right. It will suggest that using the categories of aims and attunements to think about the differences between ancient and modern conceptions of science provides a perspective in which natural right might be rendered consistent with the successes of modern science.

I will conclude by raising two important questions related to my argument. First, I will compare different responses to the situation I describe. As mentioned above, my sympathies lie with the view that a reintegration of modern empirical knowledge with classical insights regarding the ultimate causes being normative and purposive in nature is possible in principle. This will be borne out by Descartes and Bacon themselves, who repeatedly frame their methodology in terms of ignoring formal and final causes as useless while concentrating on material and efficient causality. Although their conceptions of material and efficient causality are different than Aristotle's, they are similar enough that the results of modern science are not inherently incompatible with the doctrine of natural right.

The second question concerns the relation between the aims and attunements of modern science, specifically the matter of which is prior. A central claim of my argument is that the modern social and political project required the methods of modern science, rather than the new discoveries leading to new political goals. This brings the discussion to some brief closing 
comments on the political importance of natural right and of the way in which the argument of this dissertation aims to bolster its case in the modern world. 


\section{THE GOOD AS THE END OF PLATONIC NATURAL INQUIRY}

The purpose of this chapter is to substantiate the claim that according to Plato natural inquiry was for the sake of wisdom of the whole. In practice this meant that in order for a belief to become knowledge, it must grasp the true cause of the thing known. His philosophical exploration of this conception of inquiry culminated in the theory of eternal forms. The primary philosophical importance of this doctrine is its implication that that which has ontological primacy - the Good - is inherently normative. This ontology goes hand in hand with an epistemology in which knowledge of something entails knowledge of the form for which it strives, and ultimately normative knowledge of what the thing is "for." In other words, the ontological claim that the Good bears ultimate responsibility for everything's being the way it is implies the epistemological claim that inquiry must strive for knowledge of the forms as ultimate causes. Thus Plato's ontology and epistemology go hand in hand, and, in turn, shape his model of philosophical inquiry as aiming for knowledge of ultimate causes. This chapter will attempt to justify these claims by analyzing the Phaedo and Republic.

\section{The Developmental Interpretation and Its Problems}

Before turning to these dialogues themselves, it is necessary to consider the claims of a particular approach to the Platonic corpus. A central question in Platonic studies since the nineteenth century has been whether the dialogues exhibit a single Platonic philosophy or the 
development of Plato's thinking throughout his life. The so-called "Unitary" and

"Developmental" interpretations, respectively, have been the main answers to this question. The developmental interpretation gained popularity with the work of Karl Friedrich Hermann in 1839 and was given further impetus by the achievement of stylometric analysis in discovering the dialogues' approximate order of composition. ${ }^{19}$ Stylometry is the linguistic analysis of texts in order to determine authorship and chronology based on changing sentence structures, word usages, and other measurable trends. Necip Fikri Alican states the standard stylometric case for developmentalism:

Usage patterns in relation to certain linguistic elements, usually quantified specifically in terms of the occurrence per page of those elements, invariably point to similarities and differences between dialogues, which can then be grouped or even ranked on this basis (Alican 2012: 156).

Gregory Vlastos has more recently defended developmentalism in Socrates: Ironist and Moral Philosopher (Vlastos 1991). Notable Unitarian's include Friedrich Schleiermacher, Paul Shorey and Paul Friedlander. ${ }^{20}$ In recent years, Charles Kahn (1996) and Catherine Zuckert (2009) have defended different forms of the Unitarian interpretation. ${ }^{21}$

It is not necessary to undertake a study of the full literature on this topic, but some of the main arguments for developmentalism must be investigated, since the truth or falsity of it has

\footnotetext{
${ }^{19}$ Charles Kahn (2002) provides a history of the study of Platonic chronology, including the strengths and limitations of this method. The present recapitulation of this history is indebted to his account.

${ }^{20}$ The case of Schleiermacher is particularly interesting, as he is claimed as the founder of both the developmental and Unitarian readings. Kahn (1996) and Taylor (2002) place him in the Unitarian camp, whereas Zuckert (2009) makes him a developmentalist. This disagreement can likely be traced to Schleiermacher's belief that Plato's dialogues represent the gradual unfolding of a single doctrine known from the beginning by Plato. As Taylor describes Schleiermacher's position: "Schleiermacher presents a strongly Hegelian picture of the development of the corpus. Each dialogue builds on the achievement of its predecessor in the working out of a system whose later stages disclose more clearly and fully what was indeed preconceived, but only in an obscure and undeveloped form" (Taylor 2002: 75). One can see how this interpretation could be described as both developmentalist and unitarian, depending on the judgement of the interpreter. At any rate, the Hegelian lens through which he interpreted the dialogues is certainly foreign to Plato himself.

${ }^{21}$ As we will see shortly, even Kahn accepts a weak form of the "Socratic thesis," namely that in Plato's first dialogue we are shown a historical representation of Socrates, the philosophy of whom is different from the philosophy espoused and promulgated in the later dialogues. To the extent that this is true, Kahn might be better described as a weak developmentalist rather than a full Unitarian.
} 
important consequences for the argument of this chapter. First, the developmental interpretation is a result of modern scholarship. It arose largely because of the rise of modern scientific methods of textual analysis that make possible the task of discovering chronology and therefore authorial development. This, in and of itself, is relevant to this study, since it concerns the status of Plato and Aristotle vis a vis modern science, and more specifically, the claim that classical philosophy has been rendered untenable by modern empirical methods. The developmental approach to Plato is itself largely a product of modern empirical science turned toward the work of an ancient philosopher, and it presupposes the ability of modern quantitative research to produce information not even known to the original author himself. In a study of the relation between ancient and modern thought, then, the claims of modern studies of an ancient thinker are of significant importance.

Secondly, the developmental interpretation has important implications for Plato's theory of the forms. Many developmentalists posit the so-called Socratic thesis, according to which Plato’s early dialogues reveal the historical Socrates himself and not necessarily Plato's own ideas, whereas the middle and late dialogues reveal to us Plato's philosophical vision but not the life of Socrates. The Socrates of the Apology and the Crito does not accept the metaphysics of the Phaedo, and vice versa. If this is true then there is a significantly weaker relationship between Plato's theory of the forms and the activity of ceaseless Socratic inquiry. If developmentalism is false, however, one can plausibly ascribe a much broader epistemological import to the doctrine of forms. In lieu of studying the history of this debate at length, the main claims of Vlastos and Kahn will be presented and compared in order to judge the worth of developmentalism and Unitarianism, respectively.

Vlastos, in Socrates: Ironist and Moral Philosopher, argues for the following position: 
I have been speaking of a "Socrates" in Plato. There are two of them. In different segments of Plato's corpus two philosophers bear that name. The individual remains the same. But in different sets of dialogues he pursues philosophies so different that they could not have been depicted as cohabiting the same brain throughout unless it had been the brain of a schizophrenic. They are so diverse in content and method that they contrast as sharply with one another as with any third philosophy you care to mention, beginning with Aristotle (Vlastos 1991: 45-46).

His claim is quite simple: the philosophy of one set of Plato's dialogues is impossible to reconcile with the philosophy of the other set, and therefore the first set does not contain Plato's philosophy, but that of Socrates. Vlastos sums up the difference between the historical Socrates and the Platonic Socrates with ten theses, some of the important of which are that early Socrates is only a moral philosopher while the later Socrates is also a metaphysician and epistemologist; early Socrates professes his ignorance while later Socrates claims to have knowledge; early Socrates does not have a theory of the forms later Socrates does; and early Socrates does not yet believes in the tri-partite soul of the middle and late dialogues. If this is true, then such things as Socratic ignorance and elenchus are incompatible with the later Platonic doctrines of forms, the tri-partite souls, and the political theory of the Republic. In contrast to Kahn, who shall be examined shortly, Vlastos claims that the fact that the historical Socrates does not develop any metaphysical theories implies a principled reticence to such theorizing, such that the later Socrates' metaphysics constitutes a qualitative break from the thought of the early Socrates. That is, the aporetic conclusion of many of the early dialogues is meant to be taken at face value, as evidence that Plato at this stage either did not know of any satisfactory answer or did not think the search for such answers was desirable.

The lack of forms in early Socrates is, for Vlastos, the most telling difference, and because it is the most relevant for the present study, it is necessary for the reasoning behind it to be examined. Vlastos understands the doctrine of immortal and transmigrating souls to be closely related to the doctrine of forms, and as such treats them together. The main line of 
Vlastos' argument begins from the observation that from the Meno onwards Socrates talks about the soul in the terms of his fleshed-out metaphysics. Vlastos compares the treatment of the soul in the Meno, Phaedo, Phaedrus, and Timaeus with the earlier treatment in the Crito, where Socrates refers to the soul as "that in us, whatever it be" (Ibid.: 55). In the Crito Socrates mentions the soul but goes no further in his analysis of it. As Vlastos writes, "The queries, 'Is the soul material or immaterial, mortal or immortal? Will it be annihilated when the body rots?' are never on his elenctic agenda" (Ibid.). As for the forms themselves, Vlastos insists on a strict difference between the early Socrates' quest for definitions and the later Socrates' analysis of form itself. According to Vlastos, there is a difference between asking "What is the form piety?" and "What is form?" (Ibid.: 58). It is the early Socrates' restraint from asking the second question that prevents him from becoming an ontologist and which constitutes a firm break from his later counterpart. For evidence of this, Vlastos points to the fact that Socrates does not take himself to be opposing the view of the many when he assumes that universal definitions exist; it is only when the later Socrates, the ontologist, posits the existence of immaterial entities called the forms that he is contradicting the view of the many. Vlastos concludes with the following words:

Since Plato is not suggesting that the ontological beliefs of 'the many' have now changed, he must be packing a very different content into the proposition that Forms exist. What this new content is we come to see when he goes to work explaining systematically what [the early Socrates] never tried to do at all: how forms are real - what sort of reality they have (Ibid.: 65-66; emphasis in original).

The thrust of Vlastos' argument for developmentalism is that the early dialogues end aporetically with Socrates refraining from ontologizing in order to focus on moralizing, whereas the middle and late dialogues engage in ontology and, in fact, introduce doctrines completely foreign to the earlier dialogues, including the existence of the forms and the immaterial and tripartite soul. Much could be said about Vlastos' theory, but it is sufficient to note here that the 
textual evidence he gathers is insufficient to prove the incompatibility between early and middle/late dialogues, but, at most, demonstrates a relationship of completion, fulfillment, or even elaboration or interpretation. This is the basis of Kahn's argument for a unitarian interpretation of the Platonic corpus, ${ }^{22}$ which he sums up as follows:

There is obviously a great deal of doctrine in the latter works that is absent from the former. But the argument from silence has no grip on an author as cunning as Plato. As Jaeger pointed out, the developmental interpretation often seems to assume that Plato must put into every dialogue everything that he knows or thinks at the time of writing (Kahn 1996: 40).

As the last sentence indicates, Kahn is aware that Plato often refrains from speaking his complete mind if the purpose of the dialogue is better served that way. Kahn accepts with minor reservations the orthodox dates of composition and accompanying division into early, middle, and late dialogues. His claim is that Plato intentionally withheld the substance of his philosophical vision from his early dialogues and instead chose to reveal it progressively in the Symposium, Phaedo, and Republic. The transition from the aporetic dialogues of definition to abstract ontologizing is better explained as a progressive exposition of a single view than as, contra Vlastos, a change of mind. The early dialogues, Kahn argues, raise questions that are explicitly answered in the middle dialogues, and the middle dialogues explicitly and implicitly refer back to earlier works. In response to Vlastos' claim that the question "What is the form piety?" is categorically different than "What is form?" Kahn points out that the language with which Plato describes the forms is identical to that with which he pursued definitions. ${ }^{23}$ Kahn's conclusion is simply that the obvious reading of the middle dialogues is that Socrates is now answering the questions previously left unanswered. That is, the theory of the forms is the

\footnotetext{
${ }^{22}$ Kahn's book is not explicitly set in opposition to Vlastos, though it does mention Vlastos by name and is intended to refute Unitarianism.

23 "The most striking evidence of this is the fact already mentioned that, in the Phaedo and later dialogues, the technical designation for the Forms is the inverted form of the what-is-X? question, "the very what-X-is", auto to ho esti (Phaedo 75B I, D 2, 78D 4, 92A 9; Rep.VI, 507B 7, and often). The essences of the Euthyphro and the Meno become the Forms of the middle dialogues" (Kahn 1996: 62).
} 
complete answer to the problems of definition. The philosophically satisfactory answer to questions like "[what is] that eidos itself by which all the pious things are pious?" (Euthyphro, 6d) requires eternal forms. In Kahn's view, the early dialogues are anticipatory and preparatory, in that they set the stage for the unveiling of his complete vision of reality. It is only when Athenians had been forced to examine the frailty of their everyday conceptions of beauty, virtue, and courage - as accomplished in the dialogues of definition - that they were ready to receive the complete answer to the questions raised therein. ${ }^{24}$

The purpose of discussing Kahn at length has not been to argue for the truth of his variety of unitarianism, per se, but merely to give weight to the claim that the apparent differences between the early and middle/late dialogues can indeed be reconciled without much trouble. Though I have focused on Kahn's work, Catherine Zuckert's Plato's Philosophers: The Coherence of the Dialogues (2009) accomplishes a reconciliation of its own. Rather than reconciling the apparent differences on the basis of a progressive exposition of a single philosophical position, Zuckert reads the dialogues according to their dramatic dates and sees in them "the problems that gave rise to Socratic philosophy, its development or maturation, and its limitations" (Ibid.: 6). It is not important, for the present purpose, to decide between Kahn, Zuckert, or the myriad of competing unitarian interpretations; all that is necessary at this point is to show that developmentalism is not justified on the basis of the text, or at the very least that developmentalism is not required by the text. Reading Plato's works on their own terms allows

\footnotetext{
${ }^{24}$ Despite arguing against authors like Vlastos who divide the corpus into a "Socratic" period and a truly "Platonic" period, Kahn himself believes that the Apology roughly depicts the historical Socrates and does not contain any of Plato's ideas (Kahn 1996: 88-95). The motive for this in unclear, except for the fact that he believes it to have been composed first. At any rate, this concession means that Kahn does not completely move beyond the Socratic thesis, with the unfortunate consequence that nothing the Socrates of the Apology does or says has much import for the meaning of subsequent dialogues.
} 
the reader to see the depth of Plato's presentation of his ideas, and the way in which he tailored his presentation to specific audiences.

The apparent differences can be reconciled either by focusing on Plato's progressive exposition of his views or by taking note of the dramatic order; indeed a responsible interpretation will be aware of both. It is Vlastos' weakness as an interpreter of Plato that he is seemingly unaware of anything beyond the formal arguments themselves, including the characters making them and the changing socio-political situations in which they are made. He sees Socrates refraining from ontology in a discussion with the unphilosophical Crito and concludes that this Socrates is not concerned with ontology (Vlastos 1991: 55), when the better conclusion would be that Socrates knows that any discussion of the nature of the soul would not serve the purpose of the conversation at hand, which is to soothe his unphilosophic friend.

Having saved the possibility of a unity of the dialogues, we can, as Kahn and Zuckert do, interpret the Socratic conversations of the early dialogues as being motivated by the doctrine of eternal forms. In other words, the Socrates of the Apology, for example, is engaged in the type of natural inquiry later to be expounded in the Phaedo and the Republic. More importantly, we can learn from the similarities between early and late dialogues, confident that Plato composed them with the same philosophical vision in mind.

\section{Phaedo}

The preceding discussion justifies our reading groups of dialogues in their dramatic order, as if they were acts in a single play. The Phaedo is the last scene of Socrates' life. This is an important interpretive detail. Moreover, it is connected dramatically and, most importantly, thematically to the Apology and Crito. In the Apology we see Socrates sentenced to death, in the 
Crito we see Socrates' resolution while awaiting death, and finally in the Phaedo we see Socrates meet his death. In addition to this dramatic relationship, and as if to emphasize the point, the Phaedo includes explicit references to the preceding scenes. Before recounting the conversation with Socrates, Phaedo asks Echecrates if he knew how Socrates' trial went. Echecrates replies by asking why such a long time passed between Socrates' condemnation and death, to which Phaedo answers that the ship to Delos set sail just the day before Socrates' trial, such that they could not execute him until its return.

Phaedo's referencing Socrates' trial is obvious enough, but the mention of the interval between the trial and death of Socrates, as well as his thorough explanation of the embassy to Delos, are thinly-veiled recollections of the opening lines of the Crito, in which Crito brings grim news of the return of the Delian embassy. The extended discussion of the embassy to Delos is intended to bring the Crito back into the mind of the reader. As if this were not enough to solidify the point, Crito himself plays a role in the Phaedo similar to his role in his namesake dialogue. Although now resigned to the fact that Socrates will not attempt to escape, he is still concerned with the needs of the body and treats Socrates' death as a great evil up until the very end. Furthermore, at 60a Crito appears unannounced and unexpectedly into the action of the dialogue, just as he surprises Socrates in the Crito. Later, when Crito returns from taking Xanthippe home, he returns silently and by the time Socrates notices him it is apparent that he had been waiting patiently to say something. Again, this is reminiscent of the Crito.

Plato's purpose in including these overt and covert references to the dramatic precedents is to make the reader mindful of the thematic overlap between these works. This overlap can be found in their different answers to the question, "Why is it better for Socrates to accept his death?" In various ways, each of these dialogues presents a different answer to this question. 
The question is first raised in the Apology at 28b: "Perhaps, then, someone might say, 'Then are you not ashamed, Socrates, of having followed the sort of pursuit from which you now run the risk of dying?" The answer given immediately and throughout the whole dialogue is an appeal to his divine calling. Socrates must continually question the seemingly-wise because it is what the god calls him to do. "I would have done terrible deeds," he argues, "[if] when the god stationed me, as I supposed and assumed, ordering me to live philosophizing and examining myself and others, I had then left my station because I feared death or any other matter whatsoever" (28d-e).

His one departure from this theme occurs near the end. After his conviction and sentencing, he turns his attention to those who voted to save him and returns to the question of why he did not try harder to avoid death. From 40b-42a he proceeds to give a philosophical account of the possible outcomes of death and of the transmigrating soul, similar to that which he will later expound in the Phaedo. The reason for this change of theme is that he now has a new audience, namely those that voted against execution. For the majority of his defense his audience had been the entire city of Athens, including the philosophic as well as unphilosophic elements. Speaking to this general crowd, Socrates justifies his behavior and willingness to die with the language of devotion to gods and common piety. Indeed the main thrust of his speech is that he became a philosopher because the god told him to. Given that Athens had put him on trial for impiety, it is fitting that Socrates would defend his philosophical approach to living and dying by appealing to piety. He only engages in properly philosophic discourse when he has the appropriate audience. This is a common principle in the interpretation of Plato's work, namely that Socrates modifies his speech according to his audience. 
The Crito is more openly an answer to the same question. Indeed, the subtitle, added either by Plato or an early editor, is "On What is to be Done?" That is, it explicitly treats the theme of what must be done in the face of Socrates' death sentence. If Socrates' answer in the Apology is an appeal to piety and devotion to the god, on the basis of the audience, then his answer in the Crito is similarly tailored to his interlocutor. Crito is a neighbour of Socrates, wealthy and of the same age, and therefore not one of his philosophy students. Throughout the conversation he demonstrates his overriding concern with the needs of the body, with opinion over knowledge, and with the beliefs and attitudes of the vulgar many as opposed to the wise few. Nonetheless, he is a good man, loyal to his friends and concerned with one's responsibilities to kin and fellow citizens. At one point he reproaches Socrates for failing in his duty toward his children, and throughout seems intent on fulfilling his duty to Socrates as his close friend.

Crito visits Socrates early in the morning with the hope of persuading him to escape. He repeatedly instructs Socrates to "obey" him and escape (44b, 45a, 46a). Socrates responds first by challenging Crito's emphasis on what the many think is proper by drawing an analogy between body and soul, positing an expert knowledge concerning what is best for each. Obviously one should listen to the expert on questions of bodily health; likewise, the possessor of expert knowledge of what is better and worse for the soul - i.e. justice and injustice - should be followed and the many ignored $(46 b-48 a)$. The conclusion of this argument, namely that living justly is more important than living per se, allows Socrates to lay the foundation for the argument ${ }^{25}$ that will occupy the remainder of the dialogue. Socrates has Crito agree to the premise that justice requires doing what one has agreed to do (49e) before personifying the laws

\footnotetext{
${ }^{25}$ To be precise, what follows is not a dialectical argument so much as a rhetorical or therapeutic attempt to assuage Crito's fears.
} 
of Athens and having them give a plausible account of a tacit social contract. The laws of Athens, Socrates hears them say, gave birth to, educated, and protected him such that his living in Athens constituted a tacit agreement to accept whatever the laws deem just. This contract now requires that Socrates accept the laws' decision to execute him.

This is to say that Socrates' answer to Crito is from the perspective of civic virtue and his duty to the city. He must submit to the city's judgement because his tacit agreement to the social contract obliges him to. Socrates thus brilliantly convinces Crito of the justice of his decision to accept his execution, while at the same time reinforcing the sense of civic duty that makes Crito a good citizen to begin with. It is noteworthy that Socrates conspicuously avoids explicitly agreeing with the argument made by the laws, although he certainly agrees with its conclusion, namely that it is better for him to die at this time. His philosophic argument for this conclusion is the subject of the next act: the Phaedo.

When speaking to members of the Athenian jury, who were primarily concerned with issues of piety and satisfactorily honouring the gods, Socrates defends his willingness to die on the basis of his divine calling; when speaking to Crito, who was concerned with issues of duty to kith and kin, Socrates defends himself by appealing to his duty to obey the laws of Athens as if they were his parents. In the Phaedo, we see Socrates answering the same question. However, because his audience is primarily philosophical, he defends his willingness to die on the basis of philosophical arguments pertaining to the eternal forms and immortal souls.

On the surface, and never forgotten throughout the course of the dialogue, philosophy is the practice of dying, qua separating the soul from the body as much as possible. This provides the answer to the question occupying the Apology and Crito: it is just for Socrates to die at the present time because his physical death will allow him to finally accomplish what he had been 
trying to do for decades, namely unite his soul with the immaterial forms. His bodily death will serve as the consummation of his bodily life by freeing his soul from the shackles of his body. Since his audience is now mostly composed of philosophical friends, this answer ought to be taken as his final and considered answer, as opposed to the dissimulated answers given to the Athenian jurors and to Crito.

However, there are many layers to this dialogue, and his full answer to the question, "What is the meaning and worth of philosophic inquiry?" is not exhausted by his explicit statements, nor even his formal arguments themselves. ${ }^{26}$ The Phaedo is first and foremost an exposition of the meaning and worth of true philosophy. In presenting Socrates' self-professed swan song (84e), the Phaedo is Plato's definitive statement of Socratic inquiry. ${ }^{27}$ It states the aims for which inquiry ought to strive, as well as the method best suited to attain those ends. The logical inadequacy of the arguments for immortality, in particular, has been the subject of much well-deserved scrutiny. ${ }^{28}$ Hans-Georg Gadamer takes their fallaciousness as obvious in his analysis of the Phaedo and rightly looks beyond them to the purposes Plato has them serve in the work as a whole. Gadamer's analysis of this dialogue is particularly interesting for our purposes because he sees Socrates challenging the materialism of second-rate Pythagorean philosophers and, therefore, the scientific materialism that dominates twentiethcentury thought.

\footnotetext{
${ }^{26}$ Without dwelling on Vlastos too much, it is worth pointing out at this juncture that the principal cause of weakness of his interpretation was that he failed to see anything beyond formal arguments. He paid insufficient attention to the setting, context, and intention of each dialogue.

${ }^{27}$ I ignore for now the question of Socrates vs. Plato, in part for reasons stated above pertaining to the weakness of the developmental Socratic thesis. Whether the historical Socrates actually expressed the views contained in the Phaedo does not matter; all that is important is that Plato articulated his vision of the philosophical life through his depiction of Socrates. The depiction of "Socratic inquiry" should be understood as Plato's conception of philosophical inquiry.

${ }^{28}$ As Catherine Zuckert observes: "Readers of Plato seem to agree on very little, but commentators on the Phaedo are virtually unanimous in finding the "proofs" Socrates gives inadequate" (Zuckert 2009: 785).
} 
Gadamer devotes one essay in Dialogue and Dialectic: Eight Hermenuetical Studies on Plato to the Phaedo. More specifically, as the title makes clear, he is interested in the specific role of the proofs therein for the immortality of the soul: “The Proofs of Immortality in Plato's Phaedo" (Gadamer 1980). As mentioned above, he takes it as obvious that the proofs are logically inadequate and that Plato was aware of this and knew what he was doing. The question Gadamer seeks to answer throughout the essay is, "Why did Plato give obviously inadequate proofs?" It is his contention that the weakness of the formal arguments themselves was instrumental to Plato's intention.

Socrates' interlocutors are the Pythagoreans Simmias and Cebes, and Gadamer takes the substance of their arguments as evidence that they have completely rejected the religious and mythical aspects of Pythagoreanism in favor of the mathematical and scientific teachings. Overall, Gadamer convincingly argues, they stand for the height of scientific knowledge of their day, and represent the naturalistic and materialistic critique of religious, mythological, and metaphysical knowledge. In having Socrates converse with such men, the Phaedo "raises the very different question of what may be saved of the ancient religious tradition in an age in which scientific explanation and understanding of nature are in the ascendant and have supplanted the mythological picture of the world" (Gadamer 1980: 21). Moreover, Gadamer goes so far as to contemporize their standpoint: "they therefore genuinely represent the modern scientific enlightenment" (Ibid.: 23). In another passage he refers to their skeptical doubts as "modern" (Ibid.: 25). Gadamer, therefore, as a critic of the enlightenment's positivist conception of science, seems interested in this work because of its ability to speak to modern scientific men just as it spoke to ancient scientific men. 
Plato's intention, he argues, is to defend the plausibility of the ancient religious tradition in the face of materialist and skeptical attacks. The role of the formal proofs of immortality, inadequate though they may be, is to expand on the hypotheses of the forms and immortal souls, rather than to conclusively prove them. This is in keeping with the method of hypothesis discussed near the end of the Phaedo, and about which more will be said later. For now it is sufficient to say that the first three arguments for the immortality of the soul progressively reveal the weaknesses and contradictions inherent in Cebes' and Simmias' position, and frame the discussion in terms of the correct ontology of the soul. The third argument is particularly clear in this aim, as it defines the soul as invisible and immutable (Ibid.: 28).

Gadamer brings his study to a conclusion with the observation that, according to the Phaedo, the claims of naturalistic science - i.e. those pertaining to the coming-to-be and passingaway of visible reality - do not touch the metaphysical hypothesis of the immortality of the soul. He argues that the purpose of the dialogue is thus to demonstrate that materialist scientific claims do not refute religious or metaphysical ideas. In the closing paragraph Gadamer makes explicit what had been implicit up to this point, namely the similarity between Phaedo and the Kantian reconciliation of science and metaphysics:

Kant's own philosophical insight comes very close to that of Plato's dialogue. Kant's critique 'proved' human freedom just as little as Plato proved immortality. But it did prove that the a priori validity of causality underlying all natural science could not disprove our human sense of being free. For Kant freedom was the only rational fact. Plato called that same fact something else: idea (Ibid.: 38).

There is much to be admired in Gadamer's interpretation. First, he is correct to look beyond the weakness of the formal arguments in order to see the purpose behind them. He is aware of the fact that the dialogue is a conversation, and like any conversation, exhibits intentions and motives behind the arguments made. Second, Gadamer is correctly attuned to the fact that the Phaedo serves as a corrective to materialist conceptions of scientific inquiry. 
However, his Kantian interpretation is untenable for two reasons. First, he anachronistically reads early enlightenment thought into Simmias and Cebes, on the one hand, and late enlightenment thought - i.e. Kant - back into Socrates, on the other hand. While Simmias and Cebes may have been materialists of some sort, it is unclear that they would have been comfortable with the Baconian and Newtonian science that Kant was responding to. Moreover, because Gadamer has Socrates conversing with alleged enlightenment materialists, his reading of Kant into the text is likely not faithful to what Plato had in mind.

The second weakness of Gadamer's interpretation is related to the first: the implied distinction between scientific knowledge, which can have no knowledge of the soul or afterlife, and metaphysical knowledge, is not made by Plato. I have discussed the differences between Plato and Kant on this question in the first chapter, and the analysis below will corroborate. The Kantian Socrates is not the Socrates as presented by Plato. As we will see, Plato does indeed think that we can have knowledge of the metaphysical forms. They are not simply postulates of practical reason held in the face of scientific evidence; on the contrary, they are the culmination of a single practice of inquiry. Gadamer's interpretation of the Phaedo, then, points us in the right direction by encouraging us to look beyond the arguments themselves, but ultimately concludes unsatisfactorily that Plato was a proto-Kantian all along.

Despite Gadamer's insight in deriving from it a critique of materialist explanations, it cannot really be said that Plato was in any sense a Kantian, or that he would have agreed with The Critique of Pure Reason had he been given the opportunity to read it. A more faithful interpretation must highlight the extent to which the Phaedo helps us see past modern science while remaining within Plato's own terms and concepts. The present interpretation will attempt to do just that, by reading the text according to Plato's stated intentions, namely as the third 
answer to the question of the Apology and Crito. ${ }^{29}$ In being attuned to this perspective we will see that the answer to this question prompts Socrates to discuss the meaning of the philosophic life, its aims and its methods.

\section{$57 a-70 a$}

I have so far hinted at two themes in the dialogue; as a dramatic continuation of the Apology and Crito it provides Socrates' complete defense of his attitude towards death, but the more fundamental purpose, I claim, is to present Plato's conception of natural and philosophical inquiry. These two themes are related, and the early discussion of the first leads effortlessly into, and culminates in, the second. The movement from the first to the second occurs in three stages, although neither theme is ever completely ignored or forgotten. The first stage of the argument, $57 \mathrm{a}-70 \mathrm{a}$, introduces the characters and has Socrates defend his willingness to die. Socrates' off-hand reference to Aesop reminds Cebes that Evenus had asked him to find out why Socrates was now composing verse, having spent most of his life engaging in the allegedly opposite task of philosophizing. Socrates recounts his dream commanding him to do so and, surprisingly, bids Evenus to follow him in death. Startled by Socrates' suggestion that death might be a good, they have Socrates give an account of what he has just said.

The explanation - it is not an argument, strictly speaking - is straightforward.

Philosophy is nothing but the act of separating soul from body as much as possible in order to contemplate the things that truly are. Bodily needs distract us from contemplation, and the senses can deceive us. Knowledge of things as they truly are, Socrates asserts, requires contemplation by the soul itself of the things themselves. Moreover, death is simply the

\footnotetext{
${ }^{29}$ There is, of course, more to the Phaedo than this aspect alone, but any interpretation of other themes must remain firmly wedded to the surface of the text in order to avoid arbitrariness.
} 
separation of soul from body - that is, the very thing the philosopher has sought his entire life. The discussion culminates in Socrates' description of the opinion that philosophers must have concerning this matter:

[I]f we're ever going to know anything purely, we've got to free ourselves from the body and behold things with the soul herself. And then, as it seems, the thoughtfulness we desire and whose lovers we claim to be will be ours - when we've met our end. (66e)

Shortly thereafter he relates this conclusion to the question at hand: "If this is how things stand, wouldn't it be great unreason, as I was just saying, if such a man should be terrified at death" (68b). Socrates' exoteric point in this first section, then, is that to philosophize is to learn to die, and thus fear of death is inherently unphilosophic.

The first thing to note about this section is the explicit answer to the much-discussed question. Socrates' attitude towards death is justified, and indeed consistent with his life, because the goal of philosophy, he says, can only be accomplished by dying. We can infer that this is much closer to Socrates' final answer from the fact that it implies a particular conception of philosophical inquiry, about which more will be said later. By way of comparison, the Crito certainly does not imply any notion of philosophy in its answer, and the Apology appeals to the philosophic life as being a service to God, but relatively little content is given to what is meant by “philosophy." As we will see below, Socrates' opening discourse in the Phaedo introduces important epistemological and ontological themes that form the basis of his conception of philosophical inquiry.

Second, this exoteric hypothesis becomes the dramatic vehicle by which the other themes are explored. For example, Cebes is partial to Socrates' account of philosophy and death, but desires an argument in favour of its necessary assumption of immortal souls. As the discussion moves away from the desirability of death toward the meaning of philosophy, the initial theme 
remains fundamentally connected theoretically and dramatically, because it is only by way of an exposition of the foreground speech that Socrates is drawn to spell out his method of hypothesis.

Third, the exoteric meaning is not Socrates' overriding concern. There are numerous indications in the text that Socrates is not necessarily committing himself to the strict version of body-soul dualism he depicts. For example, before summarizing the conclusion of the speech, he says that, "the true-born philosophers would be won over to some such opinion as this and so would say something like the following to one another" (66b; italics mine). Socrates seems to be implying merely that something like the following must be the case, or that this is one of many possible explanations for the philosopher's willingness to die. At 67a Socrates explicitly refers to the multiple possibilities after death: "one of two things must follow. Either there's nowhere to attain knowledge, or else it's only for those who've met their end." In neither case, it should be noted, should the philosopher fear death. Socrates' non-committal is corroborated by the fact that this section is replete with blatant exaggerations and heavy usage of Pythagorean terminology in order to satisfy the Pythagoreans Simmias and Cebes. ${ }^{30}$ The clearest example of such exaggeration in order to rhetorically vilify the body is the outlandish claim - contradicted elsewhere by Plato himself - that "all wars come about for the sake of getting money, and we're compelled to get money for the sake of the body" (66d). Not only is this claim experientially untrue, particularly to an educated Athenian writing in the aftermath of the Peloponnesian War and having been raised on Homer's Iliad, ${ }^{31}$ it also is impossible to reconcile with Plato's account

\footnotetext{
${ }^{30}$ On the implications of the Pythagoreanism of this passage compare Catherine Zuckert: "By having Socrates ask with some surprise whether Cebes has not heard similar things from Philolaus, Plato lets the reader know that the account of philosophy as a search for death that Socrates is about to give is not Socratic so much as Pythagorean in origin" (Zuckert 2009: 779).

${ }^{31}$ The Trojan War, in Homer's telling, was fought over a woman, not money. On the causes of the Peloponnesian War see Thucydides' words: "I believe that the truest reason for the quarrel, though least evident in what was said at the time, was the growth of Athenian power, which put fear into the Lacedaemonians and so compelled them into war" (Woodruff 1993: 15-16). Thucydides later points out that most greeks sided with Sparta because they offered
} 
of political decay in book VIII of Republic, in which instability and revolution originally arise out of the injured sense of pride and honour of the guardian class, not the petty acquisitiveness of those ruled by their bellies. At least according to the Republic, then, political instability is caused by part of the soul itself, specifically when it is out of harmony.

That the exoteric arguments are not Socrates' overriding concern is an important point, since it entails that their weakness is not necessarily damaging to his intention. Socrates' true purpose in this opening section is not to persuade them of the justice of his attitude regarding death, but rather to introduce themes and ideas that become crucial for the later formulation of his conception of philosophical inquiry. That is, he is here laying the groundwork by getting Simmias and Cebes to assent to a few important ontological and epistemological distinctions and assumptions, without which the primary teaching of the Phaedo could not be accepted. For example, with his exaggerated claims about the extent to which the body prevents philosophizing he introduces the distinction between visible and intelligible reality (65b-66a), hints at the forms (65e), and briefly claims that we can only know something "purely" by beholding it with the soul itself (66e). Logically speaking, each of these notions can be held without the weakly-defended assertion that after death the soul meets up with good masters. The discussion surrounding that claim, to this point, has merely been the vehicle for introducing these more important foundations.

\section{$70 a-91 c$}

Cebes' reaction to Socrates' hypothesis is one of hopeful acceptance. It is "beautifully put" (69e), he says, but nevertheless stands in need of further proof. The claim that after death 
our souls will be in the presence of good masters and better comrades requires that the soul continues to exist after bodily death, so Socrates proceeds to give in quick succession three arguments for the immortality of the soul. However, here too we see that the explicit theme of the discussion is not Socrates' principal concern. What Socrates ultimately accomplishes in this section is the successful introduction of important ontological concepts, the significance of which will be revealed later. The logical weakness of these arguments, mentioned above, therefore, does not count against the teaching of the Phaedo, since it does not insist on their strength in the first place.

The first argument, from contraries, proceeds as follows. Everything that has a contrary comes to be from its contrary - i.e. whatever comes to be bigger comes to be from the smaller, and vice versa. Moreover, being dead and being alive are contraries. From this it follows that whatever is alive came to be so from what was dead. The fact that the living soul has come to be from the dead soul implies that there are dead souls in Hades waiting to "be alive" again. All of these points added together, it is claimed, produce the conclusion that the soul survives death, and spends the time between its lives in Hades.

The most obvious logical flaw in the argument is that "being dead" is defined as "being in Hades" instead of the perhaps more natural "not existing anywhere." It is only by defining "dead" as "in Hades" that the conclusion follows that between lives our souls are in Hades awaiting life. But this simply begs the question in favour of the preferred conclusion, because the very thing being questioned is whether the soul is in Hades or ceases to exist after death.

The second problem, which underlies the first, is readily apparent when the argument is compared to Aristotle's treatment of contraries. In later chapters more light will be shed on the similarities between the Phaedo and Aristotle's Physics, but suffice it to say that this section 
deals with the problem of change in a way that strongly foreshadows Aristotle's treatment. In book I of Physics Aristotle argues that the three principles of nature are the two opposing contraries "exceeding" and "falling short," and the material substrate of which the contraries are predicated. Nature, at the most basic level, can be understood in terms of contraries acting upon an "underlying thing" (Physics 189a). Socrates has here made use of contraries to explain change but curiously omits the underlying thing. ${ }^{32}$ This is partially to blame for the confusing and muddled account of change. There is no clear account of the soul as being the thing that "bears" the contraries; instead, from the fact that "being dead" comes to be from "being alive" Socrates concludes that a living soul was once a dead soul. Strictly speaking, this does not follow. Moreover, this failure to articulate the role of an underlying substrate is possibly the reason for defining dead as "in Hades." Without isolating the soul as that which undergoes the change from death to life, it is hard to think of it in terms of anything but spatial movement. However, that Socrates is aware of this is demonstrated by the fact that this deficiency is accounted for in the fourth argument for immortality, which is the culmination of Socrates' discussion of causality.

Behind, or rather by way of, this argument for the immortality of the soul, Socrates introduces the object of inquiry according to his conception of inquiry. The similarity with Aristotle's later discussion in Physics is instructive. Knowledge has to do with causes, or the reasons for a thing's being the way it is. Even though Socratic knowledge culminates in knowledge of unchanging reality, it must always begin with our experience of changeable things. "Let us look at all things that have a becoming," Socrates says (70e). Even in this early articulation, knowledge of the purported eternal soul begins with physical change and looks for the causes of such change.

\footnotetext{
${ }^{32}$ Of course, the language of "omission" is anachronistic, as the Phaedo pre-dates the Physics.
} 
No objection is raised against the argument from contraries, although Simmias, as if to buttress it, raises the argument from recollection. He is reminded of the discussion relayed in the Meno, although he needs to be reminded of the details. With Cebes in agreement, Socrates restates this argument, albeit differently in order to emphasize different implications. The key logical steps are as follows. Visible particulars sometimes remind us of invisible universals, which implies pre-existing knowledge of the universal in question. The only way we could have come to such pre-existing knowledge is to have known the universals before birth. This, in turn, implies that our souls existed before we were born.

The obvious weakness of this argument, immediately apparent to Simmias, is that at best it proves that the soul existed before birth, but it does not speak to its existence after death. Socrates responds by enjoining his hearers to combine this argument with the previous one, which proved the soul's existence after death. That is a fair response, but raises the obvious question of why he bothered to even include this argument in an apparent proof of the soul's immortality if it does not have anything new to say on the matter. The second problem is that the inference from recollection to pre-existing knowledge which must have been obtained before birth does not follow. At the very least, there are other explanations for the fact that we have an idea of Equal upon seeing two equal things. Nominalism is a competing explanation, as would be a non-metaphysical theory of logical universals. ${ }^{33}$ Although it is clear why Socrates prefers his own inference, simply asserting it without justification does not a convincing argument make.

\footnotetext{
${ }^{33}$ By nominalism I mean the theory that universals are names imposed by men upon disparate universals. Cf. Hobbes: "...there being nothing in the world universal but names; for the things named, are every one of them Individuall and Singular" (Hobbes 1987: 102).

By a non-metaphysical theory of logical universals I mean something like the following: from seeing multiple particulars bearing some resemblance we recognize a universal predicate - i.e. redness - that truly resides in the particulars but is not a being in the sense that Plato's forms are.
} 
However, as with the argument from contraries, the weakness of this argument is inconsequential to the overriding concern of the passage.

This argument introduces, and quite persuasively so, a number of important aspects of the theory of forms. For instance, Socrates introduces the notion of imitations pointing towards their "originals" (73e) even while falling short of them (74a). Additionally, recollection is framed in terms of a movement from the visible and mutable to the unchanging and intelligible (74b). Finally, Socrates introduces the claim that visible reality partakes of a different kind of being than intelligible reality (74d), which serves to flesh out the point about imitations "falling short" of what they imitate. They "want" (74d) to be the same sort of thing as what they imitate but fall short by their mutability. Perhaps the most important aspect of this initial articulation of the forms is the introduction of technical terminology for the forms at $75 \mathrm{~d}$ : "all those things upon which we set the seal 'that which is'."

Not to be lost in this ontological prioritizing of the immutable forms is the important methodological insistence that the visible world is indispensable insofar as it points us toward the forms: "nor is it even possible to get the notion of it [i.e. form] except from seeing or touching or some other of the senses" (75a). This is important in relation to Plato's point, mentioned above, about inquiry beginning with sensible objects. Despite the ontological pre-eminence of the forms, he continually reminds the reader that the path to knowledge begins with the world of the senses.

As if to emphasize the point that these ontological claims are most important, Plato concludes the discussion of this argument by having Simmias declaring that nothing is more plain to him than the following: "All such things, Beautiful and Good and all the rest you were 
talking about just now, are as much as anything can be" (77a). These ontological insights, not a theory of the soul, appear to be the intended takeaway of this discussion.

Despite Simmias' emphatic approval of what has been said, Cebes is reticent to give up his original doubts regarding the deathlessness of the soul. That is, despite the preceding arguments he is plagued, like a child, by the fear that death will not only mark the end of his body but of his soul as well. The third argument, namely from invisibility, seems therefore aimed at assuaging Cebes' fear of death. The formal argument itself is quite simple. From the fact that forms are both invisible and immutable Socrates derives the premise that whatever is invisible is immutable. From this and the additional premise that the soul is invisible Socrates produces the conclusion that the soul is immutable. Moreover, whatever is immutable cannot be scattered, dissolved, or in any way changed. This argument, like the others, contains poor reasoning, and at least one unjustified inference. From the fact that forms, which are noncomposite, are invisible Socrates cannot logically conclude that every invisible thing is therefore non-composite. It does not necessarily follow and Socrates does not provide any additional reasons for why all things that are not seen are necessarily non-composite and immutable.

Another weakness of the argument from invisibility is that Socrates himself contradicts it. $^{34}$ After briefly stating this argument the discussion reaches the topic of Cebes' fears, particularly that after death his soul might not arrive in Hades. The gist of what is agreed upon here is that the soul that philosophizes rightly will reach the heavens - due to the philosophic soul's being made more like the forms that reside there - while the soul that does not philosophize but is overridingly concerned with the things of the body will be made heavy and unable to rise up to the world of the forms. Socrates describes the body-like soul being "made

\footnotetext{
${ }^{34}$ Of course, this in itself is not a refutation of the argument itself, but it does demonstrate that Socrates did not take it seriously.
} 
heavy" (81c) and becoming "similar in ways and similar in nurture [to body]" (83d). However, this is incompatible with the previous argument that since the soul is invisible it is unchanging. Socrates' encouragement to Cebes to be fearless in his philosophizing effectively undermines the argument from invisibility insofar as it assumes that one's activities in life can change the very nature of one's soul, making it fit for either reincarnation as a beast or into "the class of gods" (82b).

The discussion concerning the argument from invisibility accomplishes two things. First, it clarifies the distinction between the visible and intelligible realms by more firmly wedding it to the analogous distinction between mutable and immutable. In addition, this section includes some highly technical language that now seems more concerned with getting the ontological details right than with rhetorical flourish. One example is the following passage:

And philosophy exhorts her [i.e. the philosophic soul] to gather and collect herself into herself and to trust in nothing but herself and what she perceives herself all by herself of what's itself all by itself among the things that are, and to regard nothing else as true that she investigates through anything that's different from herself and differs under differing conditions (83b).

The emphasis on the thing itself brings to the fore the ontological primacy of the unchanging, as well as the methodological importance of grasping the unchanging thing itself. Moreover, here is stressed the ontological relationship between visible and mutable, on the one hand, and intelligible and immutable, on the other hand. Because of this, this passage reverses, or at least counterbalances, the preceding emphasis on sensory experience. By highlighting the fact that visible things are necessarily mutable and transitory, Socrates can very strongly assert that true philosophy must not get bogged down with the things of the body. Even though knowledge of the forms begins from sensory experience of the many particular objects that imitate their forms, true philosophy consists of rising above the visible as much as possible. 
The argument from invisibility and the moral drawn from it bring into sharp focus what I suggested above would be an appropriate subtitle for the Phaedo: "the meaning and worth of philosophic inquiry." This passage in particular stresses the importance of philosophizing rightly (82c). That is to say, it is not enough simply to philosophize; philosophizing in the correct manner is necessary. The close relationship between the meaning of philosophy and its importance is demonstrated by the fact that the ontological distinctions between visible and intelligible, mutable and immutable, are conceptually linked to Socrates' encouraging Cebes and Simmias to continue philosophizing. It is the difference between visible/mutable and intelligible/immutable that makes true philosophy so necessary; because true philosophy consists of rising above the ever-changing world of sensory experience - that is to say, because of the ontological categories he has been introducing - it is a worthwhile endeavour.

Not surprisingly, neither Simmias nor Cebes have been persuaded by the first three arguments. They are still plagued by the fear that bodily death may also mark the end of their souls, and each has a different argument for this belief. Simmias wonders whether the soul is itself a kind of tuning, what contemporary philosophers of mind might call an emergent property of the body. In this view, the soul cannot survive after death precisely because death is the decomposition of the body, the fine-tuned composition of which constituted the soul. Cebes rejects this theory but proposes his own objection to Socrates' arguments. While granting that the soul existed before birth, and possibly will also survive after death, he has not been persuaded that the soul, while longer lasting than body, does not itself have a shelf-life, so to speak. The soul might exhaust its power after a certain number of lives, and as long as one is alive there is no way of knowing whether this death will be its last. 
These arguments bring the prison discussion, as well as the surface discussion between Phaedo and Echecrates, to a dark place. The entire crowd, having been at first persuaded by Socrates' arguments but now equally persuaded by these objections, is made "ill at ease" (88c) or as we could also put it, dis-eased - by a condition Socrates diagnoses as misology. Just as the naïve attitude towards men leaves one jaded and resigned to the wickedness of all men, an artless treatment of arguments is bound to shake one's faith in argument itself. The naïve examiner is tempted to "push the blame off himself and onto the arguments," (90d) concluding that nothing can be known and everything is in flux.

This passage marks the transition between the preceding arguments and the upcoming culmination of the dialogue. It highlights what has been important to this point and reminds the reader of important points to be mindful of during the remainder of the Phaedo. Two of these are worth mentioning. First, the importance of philosophizing rightly is once again stressed; now called "the art of arguments" (90b), the lack of it is blamed for the current bout of misology. In rallying his listeners to keep the faith, he admits that up to this point they had not been arguing rightly, but admonishes them to keep the blame on themselves rather than argument itself. ${ }^{35}$ Second, the evil of losing faith in argument is given a more satisfactory explanation than the earlier speculation about reincarnation into beasts. At this crucial point in the dialogue, Socrates describes the evil in ontological terms that can be taken more seriously than the rhetorical points about reincarnation. The true evil of abandoning philosophy is that it goes hand in hand with a primordialist ontology: ${ }^{36}$

\footnotetext{
${ }^{35}$ This admission is one of many indications that Socrates is well aware of the weakness of the first three arguments.

${ }^{36}$ This term is borrowed from Newell: "By contrast, primordialist ontologies such as those of the pre-Socratics and Sophists stress that life is fundamentally characterized by strife, chance, and motion, the concomitant human behavior for which would elevate selfish impulse and the quest for domination over others as the most 'natural' behavior" (Newell 2013: 21).
} 
those especially who've spent their days in debate-arguments end up thinking they've become the wisest of men and that they alone have detected that there's nothing sound or stable - not in the realm of either practical matters or arguments - but all the things that are simply toss to and fro. $(90 \mathrm{c})$

True philosophy is the practice of transcending the visible world and grasping eternal and unchanging Being - indeed argument is the only way of grasping these verities. Philosophy is only possible if there is a stable ground of being, and the converse is also true that in the absence of true philosophy this ground of being will remain concealed. This serves to stress once again the logical relationship between epistemology and ontology in Plato's thought. Epistemological skepticism goes hand in hand with the dangerous ontology of the sophists.

It is because of passages like this that Joseph Cropsey's cosmological interpretation of the Phaedo is difficult to sustain. In Plato's World: Man's Place in the Cosmos (1995) he makes the case for a Platonic cosmology in which nature is indifferent, and even antithetical, to human purposes such that the proper attitude is conquest rather than conformity. For example:

Philosophizing is thus the conquest of nature, an unnatural act.... In general, if it were to be argued that the classical ancients conceived nature as the criterion and incentive of human excellence, while certain moderns invented nature as indifferent or unfriendly to our wellbeing until we learn to exploit it, the argument would not receive unqualified support from Plato (Cropsey 1995: 185-186).

Throughout the Phaedo and other dialogues, the things that are truly - i.e. what can most truthfully be called nature - are not indifferent or unfriendly to human existence in the least. On the contrary, the best and most fulfilling way of life is the one devoted to knowing them. Nature, then, is the standard for human affairs, not the foil. This is precisely the danger to be feared from misology, namely that nature itself - the ground of being, and what truly is - will remain unknown and the standard of human conduct will be ignored. 
Having brought the extreme dangers of misology to light, Socrates now devotes himself to healing his interlocutors - and through this, Plato his readers - of this sickness. ${ }^{37} \mathrm{He}$ summarizes his intellectual development, and by doing so presents a compelling depiction of the philosophical life, even in the absence of absolute certainty. In the following passage of the dialogue Socrates claims that both the cure for misology and the answers to the pressing questions concerning the soul can only be adequately addressed after coming to terms with how to philosophize rightly. In other words, in the culmination of the Phaedo Plato finally presents what he had been preparing the reader for up to this point, namely his conception of philosophical inquiry.

\section{$91 c-118$}

Simmias' argument is handily refuted - by pointing out its contradiction with the argument from invisibility, in the first place, and by arguing that if it is composed of bodily elements it would not be able to rule the body - but Cebes' theory requires a more detailed treatment of the fundamental principles of nature. "What we're searching for is no trivial business," Socrates tells him, "for we must busy ourselves with the cause concerning generation and destruction as a whole" (95e). He embarks on a complicated series of distinctions that culminates in a fourth and final argument for the immortality of the soul but, once again, one gets the sense that the argument itself is not much more than a vehicle for presenting an ontology and conception of philosophy.

\footnotetext{
${ }^{37}$ The language of healing is introduced by Phaedo in his recapitulation to Echecrates, as a form of external commentary on the conversation between Socrates, Simmias, and Cebes. The process of healing also sheds light on Socrates' enigmatic last words: they owe a cock to Asclepius, the god of healing, for having healed his friends of their dangerous misology.
} 
Much like the visible world is the starting point from which knowledge of the forms must begin, Socrates' intellectual life began with the study of the visible world, or as he calls it, "inquiry into nature" (96a). He began as a materialist of sorts, thinking that the ultimate causes of things were their constituent parts, as we grow by way of the material that we eat, and we are made thoughtful by our blood, and so forth. Various difficulties with this view drew him, initially, to the teachings of Anaxagoras, who taught that mind is the cause of all things. However, his initial excitement about Anaxagoras was "swept away" (98b) when even he assigned material causes to all generations and destructions. However, what Anaxagoras seems to have taught Socrates was to look for purposive causes behind the apparent material conditions of change. What Anaxagoras talked about but never carried through, Socrates took to its conclusion. From then on he sought the true causes of things, that is, those arising from mind and what is best. ${ }^{38}$

This is shown in the following manner. Using the example of his own current confinement in prison, Socrates contrasts two possible types of explanation. His sitting in a jail cell can be explained by pointing to the material requirements, namely his muscles and bones being situated in the appropriate manner and location, or it can be explained by pointing to the Athenians' judging it better to condemn Socrates to death and his own judgement that it was

\footnotetext{
${ }^{38}$ Paul Friedlander plausibly suggests that this recounting is not biographical, but is instead Plato's presentation of the development of Greek philosophy: "Certainly, this survey of systems does not correspond to the development of the historical Socrates - and hardly to that of the historical Plato. Socrates did not begin with natural science, and he did not end with the Platonic method. And for Plato, the philosophy of nature was not a beginning but a final, peripheral expansion, however much he may have known earlier about Anaxagoras and Herakleitos. What is described here in the Phaedo is rather the development taken by Greek philosophy from Thales to Plato, again not as a historical account (to which Plato is essentially indifferent), but as the way philosophy discovers itself" (Friedlander 1969: 56).

At the risk of anachronism, it may be said that there is a crude analogy between this sketch and Hegel's Phenomenology of Spirit, insofar as each describes several layers of development. While, on the surface, Socrates' description of his path to true causality is an individual journey, it equally describes the realization of true philosophy itself as well as the necessary process anyone must undergo on the path to knowledge. For the last layer, note the similarity between Socrates' beginning with analysis of the visible world and moving from there to forms and the process of recollection whereby experience of the visible world calls us to grasp the immaterial forms themselves.
} 
better to remain in prison, to converse with his friends and students, and so on. The first kind of explanation appeals to what he calls "conditions," whereas it is only the second kind of explanation - namely that which looks to "an opinion about what's best" (99a) - that is given the status of cause. This suggests that the material requirements of his sitting in a cell conversing with his friends are not as causally responsible as are mind and opinions about better or worse.

We can infer from Socrates' treatment of Anaxagoras that although he did not think Anaxagoras went far enough, he did agree with the project of identifying mind as the cause. How Socrates interprets this project, namely as the search for "in what way it's best for [each thing] either to be or to undergo or do anything whatsoever" (97c), must be taken to be the framework for his second sailing.

So, according to Socrates, the proper "inquiry into nature" looks something like the following. What one is ultimately looking for are those true causes that are responsible for each thing's being the way it is. The material conditions, properties, and constituents may be useful information, but at best they are simply the conditions underlying true causes. Material conditions and elements are never truly responsible for a thing's being the way it is. Moreover, the true causes will always pertain to what is best for each thing. What the natural inquirer must look for is the purpose for each thing's being the way it is, just as Socrates' present situation was caused by an opinion about what was best.

In the previous chapter much was made of the distinction between regional and cosmic teleology. This issue will be dealt with more fully in the chapter on Aristotle, but here Plato seems to indicate that such a distinction is untenable. At $98 \mathrm{~b}$ he mentions in the same breath, "the best for each" and "the good common to all" as if each is required by the other. The implication is that Socratic inquiry into nature will proceed seamlessly from identifying the 
normative cause of each thing to grasping the cosmic principle of order that governs all. This is borne out later; immediately after distinguishing between causes and conditions ${ }^{39}$ Socrates criticizes those who seek out the causes of the earth's placement in the centre of the cosmos without concern for how these things are best, and posits that "it's the good-and-binding that truly binds and holds all things together" (99c). This is as strong a statement as there can be that Socratic natural inquiry treats of regional as well as cosmic teleology in the same breath. ${ }^{40}$ Having presented his theory of causality, Socrates shows how he actively "busied [himself] with the second sailing in search of the cause" (99d). Always cognizant of his inability to know things with certainty, he inquired into the causes of nature and the cosmos by positing hypotheses and following them through to their conclusions. This is one of Socrates' many reminders of the provisional nature of knowledge, and serves as a corrective to Vlastos' earlier claim that the Socrates of Plato's middle and late dialogues professed true knowledge of his objects of inquiry. On the contrary, this central aspect of Socratic inquiry is explicitly made out to be hypothetical at best and therefore a ceaseless activity. Socrates, here in particular, is emphatically not a dogmatist. In order to avoid "soul-blindness" (99e) from looking at things themselves, he examines arguments as a way toward knowledge of causes, provisional though that knowledge may be. His method is one of positing a hypothesis that seems plausible and examining all things in its light to test its explanatory power.

Not surprisingly, the hypothesis he has put down is the theory of forms that has been progressively revealed in the first three arguments for immortality. It is at this point that the real

\footnotetext{
${ }^{39}$ It should be pointed out that "condition" is my term, not Plato's. I have substituted it in place of the awkward "that without which the cause wouldn't be a cause" (99b).

${ }^{40}$ This is another point at which Cropsey's claim that the Phaedo presents nature as inhabitable and hostile to human concerns is difficult to square with Socrates' words themselves. It is noteworthy that Larry Arnhart, in a review of Cropsey's book, counts it as supportive of his distinction between regional and cosmic teleology. That is, for both Arnhart and Cropsey, there is no "good-and-binding" that orders nature in the best way possible (Arnhart 2009).
} 
import of the forms is revealed: no longer are they the basis for the dubious proofs of immortality, they are now set forth as the true causes of all visible and experiential phenomena. ${ }^{41}$ If this is true, then a beautiful thing is not beautiful because of the arrangement of color, or whatever, but because this thing participates in the Beautiful Itself by Itself. The colors, and all other material constituents are simply the conditions by which it is made beautiful, but cannot be thought of as causes in the true sense. As Socrates states simply and clearly, "it's by the Beautiful that all beautiful things are beautiful" (100d). We can infer from this that it is by the Just that all just things are just, it is by the Big that all big things are big, and so forth. While Socrates does not expand the thought here, the implication for natural inquiry is obvious: everything in the world is the way it is because of the forms in which it participates. Inquiry must seek the forms as causes and not erroneously ascribe causality to material constituents. Material elements are important, and in Plato's view even necessary, but knowledge of the material conditions of things is not knowledge of why things are the way they are, and therefore is not really knowledge at all. Socrates draws the discussion of causality to a close by contrasting his mature theory of causality with his young opinions of the causes of smallness and largeness. Whereas he initially thought small things were small primarily because of their material constituents, he now asserts that the quantity of material composing a body is a mere condition, and that "the littler is littler by nothing but Smallness and is littler because of this, because of Smallness" (101a). Later, and as a summation of his theory of nature: "And you'd shout bigtime that you don't know any other way each thing comes into being except by participating in the particular Being of each form in which it participates" (101c).

\footnotetext{
${ }^{41}$ The crucial introduction of forms as hypothesis occurs as 99b: “And I'll go back to those much-babbled-about things and take my beginning from them, putting down as hypothesis that there's some Beautiful Itself by Itself and a Good and a Big and all the others. If you give me those and grant that they are, I hope, from them, to show you the cause and to discover how soul is something deathless."
} 
At 102b Socrates turns his method of hypothesis to Cebes' objection, and by doing so offers the fourth and final argument for the immortality of the soul. Having clarified the causal relationship between particular things and their forms, Socrates is able to distinguish between forms and the things which partake of them, as fire is hot but is not Hotness Itself. A distinction is made between things which necessarily participate in a certain form and those that do not - for example, fire always partakes of the Hot whereas a rock may participate in the Hot at one time and the Cold at another. This allows for the possibility of particular things being unchanging in certain respects while remaining particular things rather than forms. The crucial premise is then introduced, namely that the soul is of this category of things, namely that it necessarily participates in the form of the Living. Just as fire is necessarily hot, the soul is necessarily alive. That is, if the soul always brings life to bear on whatever it occupies, which Cebes accepts, then it cannot admit of the contrary of life, which is death. From all this it follows that the soul itself is immortal, being incapable of admitting death while remaining a soul, in the same way that fire cannot admit coldness while remaining fire.

Upon hearing this argument Cebes, who had earlier been described by Simmias as "the mightiest of men when it comes to distrusting arguments" (77a), appears convinced and ready to leave the matter alone. However, like the first three arguments, this one is unsatisfactory, and for similar reasons. The crucial premise in this argument is that the soul cannot admit death - that is, that it is in the same category of beings as fire in that it necessarily participates in its form (105e). However, this is not sufficiently proven. Nothing in this passage eliminates the possibility that the soul brings life to bear on whatever it touches but is nevertheless capable of dying. Instead of conclusively proving that the soul is immortal, the argument from causality 
completes the exposition of Socratic natural inquiry, and by so doing cures his interlocutors of their misology.

When Socrates begins the argument by claiming that contraries cannot abide one another, an unnamed interlocutor reminds us of the first argument from contraries, which appears to contradict to what has just been said. This not-so-subtle evocation of the first argument highlights the connection between it and the present argument, in particular the way in which it completes the project introduced by the first. Moreover, this completion could only have been accomplished by utilizing the ontological categories and distinctions, culminating in the theory of forms, introduced and clarified by the second and third arguments. The first argument frames the discussion by declaring that the object of philosophical inquiry is causality. It is not immediately apparent that the early discussion of "all things that have a becoming" and change between contraries (70e) is in truth a discussion of causality, but two observations make this plausible. First, Aristotle's sustained discussion of these very issues is central to his investigations into the nature of causality, and because there is good reason to suppose that his discussion was in part a continuation of Plato's it makes sense to read causality into the Phaedo. Second, and more telling, the direct link drawn between Socrates' final discussion of causality and the first argument is evidence of a common theme. Since contraries and becoming are drawn up into a discussion of causality in the fourth argument, we are justified in seeing intimations of causality in the first.

As pointed out above, the major weakness of the argument from contraries was that, by not articulating the role of the underlying substrate that undergoes the change from one contrary to the other, it was unable to adequately account for the soul's change from death into life in anything other than spatial terms. This resulted in an arbitrary definition of dead as "in Hades" 
such that the argument assumed what it was purported to prove, namely that the soul goes to Hades after death. The second and third arguments go on to introduce and clarify the ontological categories required in order to adequately account for change between contraries. As we saw, Plato does this by gradually introducing his theory of forms in ways that emphasize the ontological distinction between underlying things and the forms - i.e. the development of the concept of contraries - that they resemble by participating in them. The fourth argument, having access to Socrates' developed ontology and theory of causality, revisits the theme of the first. As we see from the complicated distinctions between "contrary things" and "contraries themselves," $103 \mathrm{~b}$ ) on the one hand, and things which always contain certain contraries and things that do not, on the other hand, the original confusion is replaced with technical clarity. Socrates and Cebes now agree that there is a difference between contraries and things, whereas their earlier discussion made no such distinction. The result is that fire is understood as made hot by Hotness Itself, and even though fire is necessarily hot, it itself is not Hotness Itself. Moreover, even though the argument regarding the soul's immortality does not follow, it is nevertheless rendered clearer, and its ontological status is well-understood. The soul is to Life as fire is to Hotness, that is, it is an underlying thing that necessarily participates in the form of life and never abides the opposite of life: death.

The philosophical accomplishment of the argument, then, was to relate the theory of forms, as developed in arguments two and three, to the question of causality raised at the beginning of the explicitly dialectical portion of the discussion. From the standpoint of the entire dialectical section ${ }^{42}$ we see that the guiding question, to which all four proofs of immortality were subordinate, was "Why are things the way they are?" Socrates is explicit about this in his

\footnotetext{
${ }^{42}$ By "entire dialectical segment" I mean the large portion stretching from Cebes' question about the immortality of the soul to the beginning of Socrates' myth: 70a-107b.
} 
biography and description of his second sailing, but the bookend discussions of causality indicate that this was the principal theme throughout. The way to answering this is by way of the theory of forms, albeit in a hypothetical and provisional manner. In other words, natural inquiry consists in seeking out the forms that are responsible for each thing's being the way it is.

Since the reason for his interlocutors' misology was an artless treatment of arguments, the foregoing articulation and demonstration of proper philosophizing serves to cure them. Echecrates, whose interjections throughout the dialogue are helpful indications of the mood Plato sought to convey, had been cured even before the argument from causality (102a), Cebes now completely trusts the argument, and Simmias, albeit with some reservations, admits that he is "certainly not in a position to be distrustful any longer, given what's being argued" (107a). At the very least, he agrees with Socrates that the matter must be looked into more sufficiently, which indicates that he has recovered his trust in arguments themselves. He seems aware that his failure to be persuaded so far is the fault of his weakness, not any deficiency of arguments themselves. For all practical purposes, then, his misology has been cured as well.

Moreover, Socrates' admission that, even at the conclusion of the dialectical portion of the dialogue, the immortality of the soul has not been sufficiently proven is further evidence that the purpose of the Phaedo is not to prove the soul's immortality, ${ }^{43}$ but to demonstrate the importance of philosophizing rightly, which has been accomplished. The forms have been shown, at least provisionally, to best explain natural phenomena and the orderliness of the cosmos, the outlines of the practice of philosophical inquiry have been set down, including how to move from visible to intelligible beings without getting bogged down in phenomenalism or

\footnotetext{
${ }^{43}$ My claim that the immortality of the soul, as such, is not Socrates' primary concern is at odds with interpreters like Kahn (1996) and Gadamer (1980) who argue that Socrates accepted it as true despite the weak proofs, on one hand, as well as David Bolotin (1987), on the other hand, according to whose interpretation Socrates is making a point of denying the soul's immortality. In my view, the soul's immortality is inconsequential, as evidenced as early as $67 \mathrm{a}$, which hints that the true philosopher need not fear death whether or not his soul is immortal.
} 
materialism, and the resulting demonstration of an artful treatment of arguments restored his hearers' trust in argument. To reinforce his last point home, Socrates' dying wish is to sacrifice a cock to Asclepius, the god of healing. The various references to healing misology throughout the discussion make the meaning of this request clear: Socrates considers his friends healed.

To recap the argument so far, the Phaedo is Plato's articulation of the meaning and worth of philosophical inquiry. The fictionalized Socrates' intellectual development began with his Anaxagorian "inquiry into nature" (96a) and culminated in his hypothesizing the theory of eternal forms in order to account for the "cause concerning generation and destruction as a whole" (95e). Each thing that exists is the way it is because of the forms in which it participates - that is, the forms are the causes of everything in the material world. The implication is that only those scientific explanations that grasp the forms, and presumably the relationship between forms and particulars, can rightly be spoken of as real explanations. Moreover, in the process of articulating this theory of natural inquiry, Socrates has expressed to his interlocutors the value of such inquiry, insofar as he restores their faith in logical argument. That is, the meaning and worth of philosophical inquiry are intimately related - it is only by demonstrating how dialectic can lead to knowledge of the true causes of visible phenomena that Socrates can cure misology. In the course of his treatment of misology, Plato has Socrates introduce some important ontological categories and distinctions, the technicalities of which are important for the present purpose. The most important are those pertaining to the theory of forms: the distinction between immutable ideas known through intellection and mutable objects known through the bodily senses, the different ways of being appropriate to forms and their objects, and the like. A strong implication of these explicit notions is the link between immutability, incorporeality, and invisibility. 
Precisely because the forms are invisible and non-material can they be unchanging. The precise way in which visible particulars "fall short" of the being of the forms is not clearly laid out, although a number of possibilities suggest themselves, all of which are potentially compatible. First, the impermanence of material objects could signify an ontological shortcoming, for not "being" consistently or reliably is surely a lesser mode of being than remaining the same always. Second, since the forms are causes, they are ontologically prior to the visible objects. A being that depends on another being for its existence and characteristics surely has a lesser mode of being than that on which it depends. Ultimately, since Socrates' ontological reflections are intentionally hypothetical and speculative, the precise details are not the main point. The overriding concern throughout is that something like a theory of forms must be true; at no point does Socrates commit himself to a precise theory. All that is important for his purpose is to establish the broad strokes of what such a theory must explain. ${ }^{44}$

Finally, the Phaedo hints at a single principle that explains everything, calling it the Good-and-Binding, without giving much detail. Socrates fulfills Anaxagorian inquiry by explaining everything in terms of what is best; things are the way they are because it is better for them to be so. Socrates' imprisonment is the result of the jury's decision that it was best for him to die and his own decision that it was best for him not to escape from prison. Human action is relatively easy to explain in terms of opinions of better or worse, equally so for a Baconian as well as a Platonist. What Socrates does not immediately show in the Phaedo is how such moral explanations can be rendered intelligible in the non-human world - but this is indeed the central problem with which teleological science must come face to face. Socrates does not explicitly

\footnotetext{
${ }^{44}$ Gadamer articulates this point quite well: "Could it be that Plato's liberality ultimately extended so far that he not only let different theories stand about the relationship of the ideas to the numbers and to things but even accepted Aristotle's disputing of the independent being of the ideas as well? For it is certain surely, and not seriously doubted by anyone today, that from early on Aristotle was critical of Plato's doctrine of the ideas but nonetheless was, and remained, a Platonist into his late works" (Gadamer 1986: 14; my emphasis).
} 
provide normative content to his explanation of why, for example, beautiful things are beautiful. At 100c: "it's not beautiful because of any other single thing than this: because it participates in that Beautiful" (my emphasis). The closest he comes to providing moral explanations for natural phenomena is treating Good as a cause of good things analogous to Beautiful and Big (100b). However, if this is the extent of the moral-causal framework, only the goodness of things has a purposive or normative cause, not their bigness or beauty. This leaves unexplained how the entire world can be ordered "in just the way which was best" (97c).

The sketchily-introduced concept of "the Good-and-Binding" (99c) serves to provide the basis for a normative causal account of all phenomena. The full import of a concept such as the Good remains to be explored in the Republic, but a few cursory remarks can be gleaned from the discussion in the Phaedo. First, it is set apart from other forms, and even though they are causes of their respective particulars the Good-and-Binding's causal power pertains to everything. At 99c it is described as holding things together. Recall, other forms exercise their causal power over single things, and by giving certain things their characteristics. Here, the Good-andBinding seems to hold sway over multiple things, or rather by governing the relations between things. This contrast is made plain by Socrates' reference to both "the best for each" and "the good common to all" (98b). From this passage, it would seem that the brief introduction of an architectonic cause serves to orchestrate the many private goods into a single common good. Moreover, because the architectonic cause is explicitly good, indeed it is the Good, everything under its care can be explained normatively. The form of the Beautiful makes beautiful things beautiful - which is in itself not a moral explanation - but the Good-and-Binding can be invoked in order to explain why it was this particular object that is beautiful instead of that one. This is how every natural phenomenon can be understood and explained normatively. Strictly speaking, 
this is more precise than anything Plato wrote, but it is easy to see how the framework of the Phaedo could be developed in such a direction.

Ontologically speaking, the natural inquiry of the Phaedo's Socrates explains every natural phenomena by reference to the forms in which it participates, and the overall order of the cosmos by reference to the Good-and-Binding that, in a way not explicitly spelled out, orders each thing together toward the common good. Going along with these ontological categories are the following methodological considerations. Knowledge of something is primarily knowledge of final causes, and because the forms are responsible for the character of visible objects inquiry must begin with the sensible world but eventually grasp the forms as causes. Because knowledge must by definition be of the ultimate causes of a thing, and the ultimate causes of a thing are not the constitutive elements of a thing, the inquirer into nature must look for more than material constitution or natural history. Knowing the physical process by which the body appropriates energy and nutrition for food may be useful for the physician or trainer, but it does not scientifically answer the question "why do people grow?" That can only be answered by looking to the Good-and-Binding that orders everything according to what is best. It is in the Republic that Plato explores this further.

\section{$\underline{\text { Republic }}$}

In a word, the Republic is magisterial, being virtually unparalleled in breadth and depth. It engages with topics far beyond the purview of the matter at hand. However, books V-VII, arguably the philosophical centre of the entire dialogue, elaborate on our current theme, namely the idea of the Good and its relation to other forms as well as the material world. This section will focus on the ways in which Socrates elucidates what is left implicit in the Phaedo's fleeting 
mention of the Good-and-Binding. However, one of the issues with which the literature surrounding the Republic is concerned is what to make of the ontological reflections of books $\mathrm{V}$ through VII. The Republic is a work of political philosophy, broadly conceived. Moreover, on a surface reading, the explicit argument begun in book II would seem satisfactorily completed even if the middle three books are not taken into account. Books V-VII are a digression from the so-called "main" line of argument, upon the completion of which Socrates resumes his earlier argument. In addition to the dramatic indication that these books are of a different sort, there are stark thematic differences as well. Relative to the rest of the dialogue, politics here takes a back seat to matters of epistemology and ontology.

Some commentators in the Anglo-American tradition, such as Charles Kahn and Julia Annas, tend to interpret the middle books apolitically by largely ignoring the political implications of the Republic's examination of the Good (Annas 1981; Kahn 1996). Annas' analysis in particular suffers from her desire to extract from the text a complete ontology with more precision than ever intended by Plato. For example, in attempting to remove any potential inconsistency from Plato's account of the relation between the world of forms and the world of visible particulars, she removes all ontological connotations from Plato's usage of "being." When Socrates asserts that only the forms truly "are," Annas takes that to mean that they permanently bear their specific predicate, rather than the ontological claim that they exist in a more fundamental sense than sensible particulars (Annas 1981: 208).

Because Plato's language is not as precise as she would like, she insists, contrary to the obvious meaning of the passage, that "book 5's thesis that knowledge and belief have distinct objects does not in itself commit Plato to thinking that there can be no knowledge [...] of people and actions" (Ibid.: 194). On the contrary, Socrates' very point in this passage is that of 
particular things there can only be opinion, not knowledge. Annas seems to ignore Plato's own insistence that his ontologizing is hypothetical and speculative, not precise and analytical. By removing the ontological reflections from their political context, she is forced to significantly reinterpret the passage in order to make it intelligible. This should not be surprising, as Plato's intention was not to deliver an apolitical account of the relationship between sensible and intelligible, but rather to explain the complex relationship between philosophy and politics.

Kahn, on the other hand, at least offers a fair and reasonable assessment of the Republic's treatment of forms. Even though he largely abstracts from the political context of the Republic, his analysis is helpful insofar as he recognizes the hypothetical nature of the ontological claims. According to his progressive exposition thesis, Symposium-Phaedo-Republic incrementally introduce themes of Plato's ontology. An implication of this thesis is that none of these texts can serve as a stand-alone expression of Plato's precise ontology. Instead, they introduce themes, present important categories and distinctions, and demonstrate what philosophy might look like if Plato's philosophical vision were true. This hypothetical nature is expressed throughout Plato's corpus with qualifications like "some such thing must be the case," and "the wise man would make an argument like the following." 45

Contra Annas, Kahn is comfortable with ambiguities in the text because he recognizes that Plato's purpose was never to remove them. However, the absence of political context from his discussion of the Republic is conspicuous. In his treatment, the Symposium and the Phaedo arguably provide more context for the middle books of the Republic than the books immediately preceding and following them. That is, Kahn allows his interpretation of books V-VII to be set up according to problems posed by external dialogues to a far greater extent than by the problems posed within the Republic itself. While intertextuality is obviously of great

\footnotetext{
${ }^{45}$ Republic 533a; Phaedo 67b.
} 
hermeneutical importance, the primary locus of interpretation must always be the individual text itself, not problems that cross boundaries from text to text. As such, Kahn's interpretation has little to say about the relationship between Plato's ontology and his politics, despite the text's insisting on it. ${ }^{46}$

On the other extreme, Leo Strauss tends to minimize the role of ontology in Plato's dialogues; or more accurately, he downplays Plato's actual commitment to the substantive teachings of the text. The Straussian Socrates is not a teacher of metaphysics or cosmology as much as an exemplar of the philosophical life characterized by the double ignorance of the Apology. One could say that for Strauss, ontological discussions are important insofar as they elucidate the meaning of philosophic activity or, in the case of the Republic, reveal the essence of politics. ${ }^{47}$ On the surface, the Phaedo might count in favour of such a downplaying of ontology, insofar as Socrates' concern was with healing misology rather than proving the deathlessness of the soul. However, the above discussion emphasized the relationship between true philosophy and a particular ontological vision. True philosophy requires that reality at its most fundamental level be unchanging. Strauss, while rightly drawing attention to the socio-political situation authors must face as well as the intrinsic political import of all philosophizing, can be said with some justice to understate Plato's commitment to his ontology qua ontology.

Between the extremes of Annas and Kahn, on the one hand, and Strauss, on the other, are Voegelin and Gadamer, despite very real differences of interpretation. Both are committed to the thesis that the ontology, and supervening characterization of philosophy, of books V-VII must be

\footnotetext{
${ }^{46}$ A response on behalf of Kahn might be that Kahn's purpose was merely to discuss how the forms are articulated in the Republic, rather than to describe their political implications. Even still, this does not acquit Kahn entirely. Because the distinction between visible particulars and invisible forms is introduced to elucidate the central problem of why philosophers must be kings, the political goals of the Republic can never be bracketed off, as if they are conceptually irrelevant to the meaning of the forms.

${ }^{47}$ For example, Strauss' discussion of book VI of the Republic in The City and Man says nothing about the Sun, the Divided Line, or the Idea of the Good. The most important teaching of the book, instead, pertains to the difficulty of bringing philosophy and the city together (Strauss 1978: 122-124).
} 
read within the political context of the rest of the dialogue, and vice versa. Voegelin, for his part, is of the mind that the ontology of the Good forms the heart of the Republic because it is precisely the idea of the Good which must be embodied in moral and political life. This explains, moreover, why the idea of the Good is only intelligible in relation to the philosophers who are able to attain it. In other words, Plato is not ontologizing for ontology's sake - rather, he is simultaneously articulating the good that must be embodied in human history as well as the noble minds who are fit to work toward its embodiment. Neither project can truly be understood without reference to the other. ${ }^{48}$ All this is to say that Voegelin interprets the ontology of books V-VII through the lens of the political project of the dialogue in such a way as to emphasize the compatibility - at least in potentia - of philosophy and politics.

Gadamer, on the other hand, interprets the middle books in such a way that philosophy and politics are in fundamental opposition. He says the following about the alleged conflict between theory and the world of appearances and conventional power structures:

[T]here appears to be no doubt that Plato has this conflict in mind in all of its sharpness and that he displays it negatively by the very impossibility of his utopian "solution" - the conflict, that is, between knowledge of the truth, to which the theoretical life is dedicated, and actual political life (Gadamer 1986: 69).

Gadamer goes on to qualify the relationship between philosophy and politics somewhat, to the effect that the two are not completely irreconcilable. For example, he utilizes the allegory of the cave to show why rulers despise the theoretical life, rather than the more radical claim that theory and ruling are wholly at odds (Ibid.: 74). Nonetheless, the divergence from Voegelin is clear: Plato spends so much time contemplating the Good in order to point out the reasons for its political impossibility.

\footnotetext{
${ }^{48} \mathrm{Cf}$. "The right order of man and society is for Plato an embodiment in historical reality of the idea of the Good, of the Agathon. The embodiment must be undertaken by the man who has seen the Agathon and let his soul be ordered through the vision, by the philosopher. Hence, at the centre of the Republic...Plato deals with the rule of the philosopher and the vision of the Agathon" (Voegelin 2000a: 101).
} 
Because the treatments of politics and ontology are woven together to such an extent, the middle books of the Republic must be read as being intrinsically ontologically interesting, as well as having direct political import. The present project is primarily concerned with more deeply understanding the ontological implications of the forms and their place within scientific inquiry, but this important point must not be left by the wayside. It is certainly no coincidence that Plato chose a work devoted to politics in which to articulate the Good. This, in and of itself, would be enough to substantiate the claim that natural right is a central Platonic doctrine - that is, Plato's chief political teaching is that the cosmos is a moral order to which cities and souls must conform. ${ }^{49}$ This fact should also serve to remind the reader of the moral and political meaning of the work of the scientist. In the Republic as well as the Phaedo the forms are constantly described as being causally prior to visible objects - indeed the claim that kings must philosophize is based on a definition of philosophy according to which the world is understood as being caused by the Good. What our contemporaries call natural science culminates in the knowledge that makes one fit to rule cities.

Strictly ontologically-speaking, the Republic fills in a number of the gaps left open by the Phaedo, most of which pertain to the idea of the Good..$^{50}$ Here Socrates expands on his epistemology by articulating why knowledge can only be of eternal forms, and his ontology by discussing what the Good is and what it does. Moreover, in doing so he clarifies the relationship between his ontology and epistemology. However, the Good is still only known by way of analogies, as if by reflection. The Good, that is, can be looked at but never fully apprehended. This is in keeping with Plato's overall hypothetical approach to the forms. He is aware that

\footnotetext{
${ }^{49}$ I here remain agnostic regarding the Voegelin-Gadamer debate about the compatibility of the Good with actual cities. Both of them would agree that the ideal city is patterned after the Good.

${ }^{50}$ Cf. Gadamer (1986: 26): "[T] he work on the polis [the Republic] (which is every bit as much on the psyche) and then, later, the Timaeus, adhere to, and articulate, the program projected in the Phaedo's flight into the logoi (statements)."
} 
dialectic points to something like what he calls the Good, and that there must be some unifying principle behind the multiplicity of forms - which are themselves unifying principles behind the multiplicity of particular things.

\section{Epistemology}

In the Phaedo, Socrates explains why knowledge of causes must point to the forms. Because visible particulars participate in and imitate their forms, they are in a very real sense caused by them. However, this leaves open the possibility that one can still know visible objects in their own right. For example, a materialist could know of a flower that it is beautiful, just not why it is beautiful. Here Socrates denies even this possibility, by insisting that mutable objects are so fleeting that knowledge of them is downright impossible.

At 474a, Socrates has just unveiled his third wave of political reform, namely the proposal that philosophers should rule. Just as each of the first two waves called forth the next, ${ }^{51}$ the third wave calls forth a full examination of the nature of philosophy and, by extension, the philosopher. The philosopher is provisionally defined as one who readily "taste[s] every kind of learning," much to Glaucon's chagrin, since such a definition would seemingly apply to mere lovers of sights and sounds (475c-e). Socrates then clarifies his definition by isolating "lovers of the sight of the truth" (475e; my emphasis), which leads into a technical discussion of the difference between forms and particulars. Lovers of the forms are philosophers, whereas lovers of the "apparitional many" (476a) are not. The man who sees many fair things but does not realize they are mere likenesses of the Fair itself cannot be said to know, insofar as he mistakes the likeness for the thing itself. Thus, only perceiving the visible particulars, he merely opines,

\footnotetext{
${ }^{51}$ That is, gender equality and the de-eroticization of education required the abolition of the family, and the abolition of the family requires tremendous oversight by wise guardians to ensure beneficial mating and breeding.
} 
while the man who sees both the particulars and the form knows. The remainder of the passage is designed to articulate the ontological basis for such a claim. It must be noted, however, that it is addressed to the man of opinion, and is designed merely to "soothe and gently persuade" him, not necessarily to deductively prove beyond the shadow of a doubt. ${ }^{52}$

Socrates claims that knowledge depends on what is and ignorance depends on what is not. In other words, what is can be known and what is not cannot be known. He then sets down a middle category on which opinion depends, namely what both is and is not. The three ontological categories - is, is not, and is-and-is-not - are linked to their epistemological counterparts - knowledge, ignorance, and opinion - by way of "powers" (477c). Powers are distinguished from each other according to that on which they depend and what they accomplish. Because knowledge and opinion accomplish different things - knowing and opining, respectively - they must also depend on different things. In other words, because knowledge and opinion are both powers that accomplish different things, it follows that they therefore depend on different things. It is implied that ignorance is the third power, depending on what is not and producing falsehood. This is the thrust of Socrates' view that the epistemological categories of knowledge, opinion, and ignorance depend on different ontological categories, specifically "that which unchangingly is," "that which is and is not," and "that which is not."

There are then three levels in this ontological hierarchy, with corresponding epistemological designations: what is (knowledge), what both is and is not (opinion), and what is not (ignorance). The forms are shown to be what unchangingly is. Because they are unchanging, what the mind apprehends about them is always true. That is, the beautiful always

\footnotetext{
52 "What if the man of whom we say that he opines but doesn't know, gets harsh with us and disputes the truth of what we say? Will we have some way to soothe and gently persuade him, while hiding from him that he's not healthy?" (476d) Given the political dimension of the discussion, Socrates is evidently primarily concerned with a political solution to the problem of unawareness of the forms, rather than ontological precision.
} 
is beautiful, and never is not so. They are therefore the only things of which knowledge can be had, since knowledge must by definition be infallible and unchanging. In other words, knowledge can never be false, and a belief about something that is constantly changing will at one time be true and at another time false.

What is and is not, unsurprisingly, is shown to be the world of changing particulars. All things in the visible world participate in their forms for a duration but suffer change in their own time. Moreover, temporality is not the only way in which particulars fail to universally instantiate their forms. Socrates here seems to imply that perspectivism obtains in the visible world: "Now, of these many fair things, you best of men...is there any that also won't look ugly? And of the just, that won't look unjust? And of the holy, and that won't look unholy?" (479b) Because of the nature of the visible world, appearances can be deceiving. Thus, for example, even the most beautiful human being might have a "bad side," from which they appear ugly. So, since mutable things imitate their forms only from certain points of view, and even then only periodically, they both are and are not. Again, unstated but implied is that ignorance depends on what is not entirely, i.e. non-being. Because what never is never imitates a form at all, one cannot even hold opinions about it.

Socrates concludes this discussion by reminding Glaucon, and the reader, of the political agenda behind this discussion. He takes himself to have adequately demonstrated that the unphilosophical beliefs of the many, insofar as they fail to grasp the forms, "roll around somewhere between not-being and being purely and simply" (479d). This effectively relates the preceding discussion to the sociological distinction between philosophers and non-philosophers, and moves toward a justification of philosopher-kings. Moreover, Plato's use of "nomima" to 
designate the beliefs of the many accentuates the intended criticism of actual politics. ${ }^{53}$ Not only does Socrates take himself to be describing the beliefs of the many as opinion, but the very conventions and laws - i.e. nomos - that form the basis of Greek political order fail to grasp true being.

Here Socrates has, in one sense, developed the epistemological project initiated in the Phaedo, insofar as he has further tied knowledge to the forms. No new ontological categories have been introduced; instead, new implications have been drawn from existing categories, implications that could only have been brought to light in the political context of the Republic. By introducing the political dimension that was absent from the Phaedo, Socrates here highlights the impermanence of the visible world, and the ensuing difficulties in knowing it. Because the purpose of this passage is to uncover the identity of the philosopher-king who will be wise enough to pattern the city after the timeless form of justice, it begins by distinguishing lovers of mere sights and sounds from lovers of the sight of the truth - i.e. those who grasp the forms. Again, this distinction furthers, without at all negating, what he began in the Phaedo. There, Socrates allows a materialist to at least know that a flower is beautiful, but here he will not even grant that belief the status of knowledge. The materialist, here called a mere lover of sights and sounds, cannot even have knowledge that a flower is beautiful, because the flower is not beautiful from every perspective and will not remain beautiful forever. Because the belief is of an impermanent flower, it cannot be knowledge at all, by definition. As a result of this development, the epistemological role of the forms is brought into clearer focus. Here, more than before, they are the sole object of inquiry, insofar as they alone represent unchanging being.

As stated at the beginning of this chapter, its goal is to establish the claim that a requirement for beliefs to become knowledge is that they grasp the forms. It has been shown

\footnotetext{
${ }^{53}$ This insight is borrowed from Allan Bloom's textual note to 479d (Plato 1991: 461n41).
} 
from the Phaedo how wisdom, conceived as grasping ultimate causes, must be of the forms as causes; Plato here emphasizes this requirement by approaching it from a different angle, or with a different rhetorical purpose. By exploring the relationship between knowledge and the forms with a view to articulating the importance of philosopher-kings, he further strengthens the relationship between the two, going so far as to insist that knowledge can only be of the forms. This is somewhat stronger than the initial view that knowledge of the true cause must involve the forms. The forms, here, are not only the ultimate causes, but the only things that can be known at all.

\section{Ontology}

An additional claim of this chapter is that all of the forms ultimately point toward the Good in such a way that it is the ultimate cause of everything. In other words, if knowledge of causes requires the forms, and all of the forms point toward the Good, then a causal explanation of anything at all must point toward the Good. This is simply another way of expressing the point that Socratic natural inquiry is conducive to natural right. Not only does everything have a particular "good" that is given to it by nature, but it is the job of scientific inquiry to discover that good.

The importance of the forms has been sufficiently discussed. Plato's conception of the Good must now be fleshed out; doing so will fill in some of the gaps left by the Phaedo. After refuting Adeimantus' empirical objection that so-called philosophers are politically useless (487b-502a), Socrates engages him in the investigation of the greatest objects of study - i.e. the forms - the greatest of which is the idea of the Good. Although the discussion with Adeimantus avoids ontological themes, it nevertheless introduces some points that will become important 
later on. The Good is the greatest study because, Socrates argues, it is the Good to which everything else refers. Nothing else is worthwhile on its own, but only insofar as it is good (505b). ${ }^{54}$ Everything is subordinate to, and serves, the Good, not the other way around.

Here the discussion is only in the realm of psychological motivation, ${ }^{55}$ but the point can easily be carried over into the realm of ontology. While the political context of the Republic inclines Socrates to contrast the Good with pleasure and prudence, instead of scientific materialist explanations as in the Phaedo, there is thematic overlap between the two works. In both dialogues the Good is invoked as the true cause of human behavior, despite each dialogue using a different concept as a foil: in the Republic the Good is contrasted with pleasure and prudence, and in the Phaedo the Good is contrasted with materialist explanations. ${ }^{56}$

It is only with Glaucon's return to the conversation at 506d that ontological questions reemerge. He urges Socrates to investigate the idea of the Good as extensively as he did the other virtues, although Socrates is allegedly unable to do so. Instead, he describes the Good by way of analogy with a "child of the good," namely the sun (506e); in so doing, he reveals a number of its important features. It is telling that he begins the ontological treatment of the Good by recapitulating what they had previously agreed to regarding forms and particulars. Although no explicit connection is initially established between the forms and the Good, it is clear that Plato wanted the reader to have his theory of forms in mind.

After reminding us of forms and particulars, he posits a third class of thing, between eyes and visible things, which is required in order for eyes to see visible things, namely light. Properly-functioning eyes can fail to see what is right in front of them so long as light is not

\footnotetext{
${ }^{54}$ That is, pleasure is only worthwhile if it is good, and prudence is only worthwhile if it serves the good, and so on. 55 "Now this [i.e. the Good] is what every soul pursues and for the sake of which it does everything" (505e).

${ }^{56}$ While beyond the scope of this project, an argument can be made that because the ontology of materialism provides the basis for setting pleasure-seeking as the ultimate goal of life, even these two foils are not that different.
} 
present; from this fact Socrates designates light as what makes our eyes see. Insofar as light is a product of the sun, it is the sun itself which gives the power of being seen to all visible objects. Finally, the sun is also the cause of the very existence of all visible things, insofar as it is the source of energy on which all earthly things depend. Thus, the sun is the cause of both the existence and knowability ${ }^{57}$ of all visible objects. As the sun is to the visible objects, so is the Good to the eternal forms, which is to say that the Good is the cause of the forms' existence and of their being known. As the sun gives the eyes the power to see visible objects, the Good gives the mind the power to intellectually grasp the forms.

The Good's being the cause of the forms leads into a central ontological claim, namely that it is "beyond being" (509b). This is Socrates' manner of indicating that the Good is more primary, logically and ontologically, than the class of forms, which have already been classified as true being. "Beyond being" is not meant to suggest that the Good does not exist, because it clearly does; however, it is in a different manner than the forms, just as they are in a different manner than the manifold sensible objects. It is not one member of a class of things, as are both sensible objects and forms, but is the single principle and cause of the existence of everything else. As an epistemological first principle is categorically different than the logical deductions that follow from it, so is the fundamental principle of being categorically different than the many things contingent upon it.

That "beyond being" means something like "a thing that $i s$, albeit in a different way than other things" is corroborated by a later passage in which Socrates indicates that dialectic - the art of separation - comes to know the Good in just the same way that it comes to know other objects. The "in just the same way," as Gadamer points out, is an important qualifier, insofar as

\footnotetext{
${ }^{57}$ Strictly speaking, knowledge is a misleading term with which to describe the mind's relationship to visible objects, as per the discussion at 474d-480a.
} 
it moderates our interpretation of "beyond being" (Gadamer 1986: 84). The Good may not "be" in the same way as the forms, being their uncaused cause, but that must not be taken to mean that it does not exist at all. It is something, and it can be known dialectically, at least in principle.

Finally, and hinted at so far, the Good is simultaneously analogous to the sun as well as its cause. This dual relationship is indicated by the logic of the passage as well as Socrates' explicit statement that the sun is "an offspring of the good begot in proportion with itself" (508b). That is, it is caused by the Good insofar as the Good is the cause of everything, but its function in the cosmos with regard to visible objects parallels the Good's relationship to the eternal forms.

Seth Benardete's interpretation of this passage (Benardete 1989: 157-162) illuminates some of the implications of this duality. The central problem he attempts to sort out is what follows from the Good's being the cause of the sun as well as its analogue "beyond being." If the sun is but an image of the Good then each would prevail over separate portions of the divided line: the sun over the visible realm and the Good over the intelligible realm. However, if the sun is an offspring of the Good then the visible and invisible realms are under its causal influence. The difficulty, according to Benardete, resides in the fact that the sun, insofar as it is an image, oversees the realm of opinion, while the Good oversees the realm of knowledge; but if the sun is an offspring of the Good then the Good would be the cause of both knowledge and opinion, with the result that both are equally intelligible and capable of being known.

Benardete's solution to this complexity is twofold. First, he invests heavily in Socrates' disclaimer that his account of the sun might be incomplete or even fraudulent, which allows for 
the possibility that Socrates is intentionally misspeaking or withholding his real beliefs. ${ }^{58}$ Second, he suggests that this account of opinion - i.e. as being under the reign of the sun as offspring of the Good - is only intended to explain how opinion appears to itself - i.e. as the truth. "The sun," he writes, "though it points to the cave, does not acknowledge the cave" (Ibid.: 158). That is, this account of opinion as being under the indirect reign of the Good has the appearance of knowledge, or of being intelligible. It is left to the allegory of the cave to correct this misrepresentation and properly account for the untruth and ultimate unintelligibility of opinion.

Benardete's interpretation of this difficult passage, though careful and insightful, seems to be unnecessarily complex. The central difficulty he sees is that if the sun is an offspring of the Good then the Good is simultaneously the cause of knowledge and opinion. This is a problem because if knowledge and opinion are products of the Good then both are equally intelligible. However, this conclusion is not required by the text. Benardete fails to properly account for the three-fold hierarchy of being comprised of visible objects, forms, and the Good. ${ }^{59}$ Because visible objects are incomplete and changing imitations of the forms, it is possible to conceive of them as indirectly caused by the Good, insofar as their immediate causes are caused by the Good, without implying, as Benardete wants to, that they be capable of being known. This seems to be the very argument of the closing passage of book $\mathrm{V}$, which has been discussed above. Ironically, this interpretation is implied by Benardete's own illustrative diagram (Ibid.: 157):

\footnotetext{
58 “'I could wish,' I said, 'that I were able to pay and you were able to receive it itself, and not just the interest, as is the case now. Anyhow, receive this interest and child of the good itself. But be careful that I don't in some way unwillingly deceive you in rendering the account of the interest fraudulent"' (507a).

${ }^{59}$ Technically, there are more levels here, including images and shadows, at the bottom, and mathematical objects, situated between sensible objects and forms. But the point can be made with reference to these three.
} 


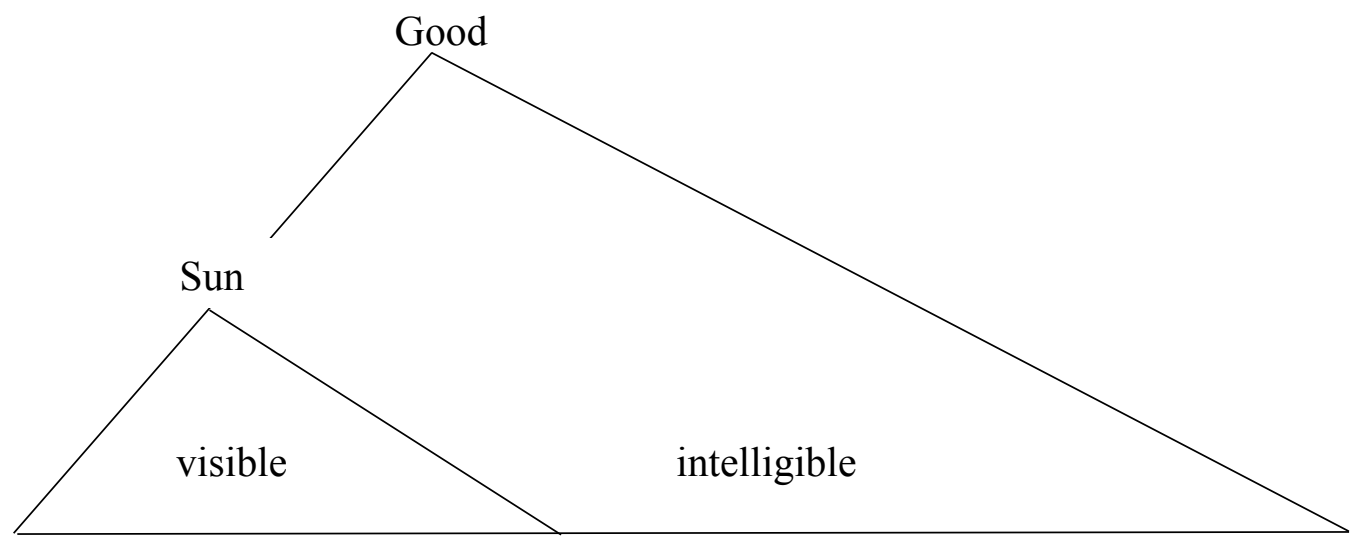

According to this figure, the Good is only indirectly the cause of the visible objects of opinion; it is precisely the indirectness of the Good's causality over the visible realm that allows for it to remain unintelligible opinion - that is, opinion itself, not simply as it appears to itself. Therefore, we can think of the sun as both image and offspring of the Good without entailing the intelligibility or knowability of opinion, which allows us to maintain that natural inquiry must look to the Good as the ultimate, albeit indirect, cause of everything's being the way it is. This seems to be the explicit upshot of this passage.

What is more, a number of illuminating points are unstated but implied by the discussion with Glaucon. The introduction of the Good as the single principle of being that everything else points to will become a major theme in western metaphysics. The point is that ontological dualism is ultimately incoherent, and that at some point being must be characterized by unity and simplicity. The central insight is that any state of affairs in which there is a plurality of objects points beyond itself to a more fundamental reality in which they exist. Only a single, simple, thing can be a first principle of being.

The precise character of the principle, however, is not made clear by this logical necessity. Plato's reason for choosing Good as his arche is hinted at before Glaucon even engages Socrates in this discussion. The preceding non-metaphysical discussion of the Good 
with Adeimantus shows why a normative principle was required. At the psychological level of motivation, Socrates claims, everything is done for the sake of the Good. That is, the Good is the cause of every action, and even other motives or causes are ultimately referred to the Good. Given Socrates' belief in the congruence between soul and cosmos, it makes sense to refer all causes generally to the Good. It is not only causes of human behavior, then, that appeal to the Good, but of non-human behavior as well. This possibility is explicitly taken up again by Aristotle, as we shall see in the next chapter.

Despite the intentional lack of precision, we can summarize the relevant aspects of the Good in the following manner. It is the single principle of being that is responsible for the forms' existence and intelligibility. Logic dictates that there be a single principle beyond the many forms, and such a principle is normative because all causes and explanations ultimately refer to the Good. Everything that is said ultimately appeals to some standard of goodness, and the only explanation that does not point beyond itself is "because it is good thus." 60 The relevant implications for natural inquiry are that everything exists and is made intelligible by the Good, and therefore that all explanations - of both human and non-human things - must terminate in the Good.

Finally, causal knowledge of generation and decay - that is, natural inquiry - is referred to the Good throughout the dialogue, both implicitly and explicitly. First, insofar as the Good is the cause of the sun, it is also the cause of everything the sun does. Second, Socrates draws attention to the way in which the prisoners in the cave mistakenly attribute causes to the shadows on the wall. The implication is that the sun - in this case standing in as an image of the Goodis the true cause of what they saw in the cave. "Once seen," Socrates says, "it must be concluded that [the idea of the good] is in fact the cause of all that is right and fair in everything - in the

\footnotetext{
${ }^{60}$ Cf. Aristotle, Physics (198b).
} 
visible it gave birth to light and its sovereign; in the intelligible, itself sovereign, it provided truth and intelligence" (517c). Later, the dialectical man is he "who grasps the reason for the being of each thing" (534b) - dialectic being the mode of thought by which one ascends to knowledge of the Good. Both the logic of the passage and Socrates' explicit statements indicate that knowledge of causes involves the Good. Not simply worthwhile for its own sake, it is what allows the inquirer into nature to properly understand the "reason for the being of each thing" $(534 b)$.

\section{$\underline{\text { Conclusion }}$}

The vocabulary with which this project interprets the difference between ancient and early modern conceptions of science is that of aims and attunements. Each method of scientific inquiry has a particular goal, and the goals specific to each determine the phenomena to which they are attuned. Plato, we have seen, prioritized wisdom over utilitarian objectives. Natural inquiry, in the Phaedo, and the Republic, must look to and result in knowledge of the general principles governing the cosmos. He develops this aim in such a way that it is fulfilled by grasping the ultimate causes of everything. That is, Platonic natural inquiry is attuned to, or looks for, whatever is most responsible for the world's being the way it is. This led him away from materialist explanations and patterns of efficient cause and effect in favour of the immaterial forms and ultimately the idea of the Good. In other words, his theory of forms is the answer to the questions posed by natural inquiry; every sensible thing is the way it is because it participates in certain forms. The corollary of this is that the sensible world can only truly be understood in light of the immaterial forms. The aim of wisdom thus attuned Plato to the forms 
as ultimate causes of everything that is - this is to say that his theory of forms is a scientific theory.

However, Plato was aware of possible competing aims of inquiry, one of which was repeatable patterns that can be exploited for private and public utility. His implicit critique of this aim was that it remained ignorant of true causes, not that it necessarily resulted in incorrect empirical information. In the allegory of the cave, the prisoners are said to esteem those adept at predicting patterns of behavior in the absence of knowledge of ultimate causes (516c-d). That is to say, in the cave a primitive form of positivist science is the model of inquiry. The behavior of the shadows is taken to be the object of inquiry, and the fact that the shadows are caused by real objects remains hidden by the specific aim of their inquiries, which is limited to information that can be directly used. This oft overlooked implication of the cave allegory becomes the foil against which Socrates articulates his vision of natural inquiry, which involves looking beyond the behavioral patterns of sensible appearances to their true causes. 


\section{WISDOM AND FINAL CAUSE: ARISTOTELIAN SCIENCE}

The previous chapter argued that Plato thought of scientific investigation, or "inquiry into nature" (Phaedo, 96a), as the search for ultimate causes. An adequate explanation of phenomena should go beyond mere predictive efficacy to knowledge of what is most responsible for the phenomenon's being the way it is (Republic, 516c-d). Such knowledge is properly called wisdom, and it is what sets the philosopher apart and makes him (or her) fit to exercise political authority. According to the terminology of this study, the aim of Platonic natural inquiry is wisdom, and it is therefore attuned to ultimate causes. This chapter will demonstrate that, despite some important differences, Aristotelian natural inquiry can be characterized similarly.

In the context of the overall purpose of this study, Aristotle presents the most difficulty. There are strong prima facie reasons for believing that Aristotle's scientific work has been rendered unbelievable by modern science. For example, Samir Okasha's Philosophy of Science, A Very Short Introduction contains 5 non-trivial references to Aristotle or Aristotelianism. In each case, the phrase describing Aristotle's relationship to the findings of modern science is one of the following: at odds with, alternative, conflicted thoroughly with, refuted by, or downfall (Okasha 2002: 3-7). Even still, this chapter will form an important part of the argument that where Aristotelian conclusions appear to conflict with those of modern science, the conflict is due to their differing conceptions of natural inquiry. It will proceed by analyzing the discussion of motion in the Physics, before turning to the Metaphysics for a discussion of the nature and importance of ultimate causes. It will conclude by comparing the Platonic and Aristotelian 
conceptions of scientific inquiry, drawing attention to important similarities as well as differences.

\section{Physics}

Aristotle's Physics is a study of motion. Its namesake - physis - is greek for nature, which Aristotle describes as "a certain source and cause of being moved and of coming to rest" (192b). ${ }^{61}$ A work devoted to physis, naturally, will be devoted to uncovering and investigating motion and rest. ${ }^{62}$ To that end, the book defines motion, analyzes that in which motion occurs i.e. place and time - and culminates in an argument for an unmoved mover. However, before turning his attention to motion as such, the first two books of the work serve as a prolegomena of sorts, introducing necessary concepts and presuppositions pertaining to the basic constituents of nature and the meaning and kinds of causality. It is in these first two books that Aristotle articulates his aims and attunements. The third book, in which Aristotle attempts to define motion, reveals how his aims and attunements - that is, his conception of scientific inquiry translate into an understanding and explanation of natural phenomena as being fundamentally goal-oriented.

The notion that nature is goal-oriented is the central insight of the Physics, and so final causality will be the lens through which the text is interpreted. In order to answer the questions of what final cause is and how it operates, a number of other issues must first be addressed, including Aristotle's broader doctrine of causality, the relationship between all four causes, and the relationship between chance and purpose. Having addressed these issues the central question

\footnotetext{
${ }^{61}$ Throughout this chapter, Bekker pagination will be used to indicate references to passages in Aristotle. 184a$267 \mathrm{~b}$ refers to the Physics, and 980a-1093b refers to the Metaphysics. Unless otherwise specified, all references are from Joe Sachs' translations (Sachs 1995; Aristotle 2002).

62 "Since nature is a source of motion and of change, and our pursuit is for nature, we must not let what motion is remain hidden" (220b).
} 
of final causality can be addressed. Aristotle's conclusion is that final causes, or natural ends, play an active role in bringing about and determining change in nature; indeed, final cause is architectonic, in that it gathers together and governs the operations of all the other causes. Because natural ends are thus an intrinsic part of natural change, it is the task of the Aristotelian study of nature - i.e. science - to discover the natural ends toward which things are aimed, and in which they achieve the good particular to them.

\section{Aristotle's Doctrine of Causality}

The doctrine of causality is the foundation of Aristotelianism. See, for example, the opening statements of his Politics ${ }^{63}$ and Nichomachean Ethics, ${ }^{64}$ which frame the respective investigations in the context of causality, and especially final cause. By "causality" Aristotle does not mean simply the direct influence of one object on another. By "cause" he means any possible answer to the question "why?" To know the cause of a thing is to have "taken hold of the why of it" (194b). However, before the "why" of a thing can be asked, one must know what constitutes a thing in the first place. This is the subject of Physics book I, but it is not a mere preface to the discussion of causality in book II; the question of the fundamental constitution of things is in the context of the possibility of change itself, change being a necessary precondition of causality. Against his predecessors, Aristotle rejects the extreme positions that either nothing is in motion or that everything is in constant flux. That is, he sought to allow for a world with being as well as becoming, motion as well as rest. His solution follows a complex line of

\footnotetext{
63 "Since we see that every city is some sort of partnership, and that every partnership is constituted for the sake of some good (for everyone does everything for the sake of what is held to be good), it is clear that all partnerships aim at some good, and that the partnership that is most authoritative of all and embraces all the others does so particularly, and aims at the most authoritative good of all. This is what is called the city or the political partnership" (1252a).

64 "Every art and every inquiry, and similarly every action as well as choice, is held to aim at some good" (1049a).
} 
argument, in which he proves that the fundamental building blocks of the world are contraries. Any change is from not- $\mathrm{X}$ into $\mathrm{X}$, or from $\mathrm{X}$ into not- $\mathrm{X}$, and therefore at least some sets of contraries must be said to exist. Furthermore, all contraries can be reduced to a more fundamental set of contraries, namely "exceeding" and "falling short" (189b). Big and small, light and dense, educated and uneducated are all various articulations of the more fundamental opposition between exceeding and falling short. ${ }^{65}$

However, in the transition from one contrary to the other, there must be something that persists and makes the transition from one contrary to the other. "The underlying thing," as Aristotle calls it at this point of his argument, is that upon which the contraries act (189a). The man who becomes educated underlies the change and persists throughout it, although he now has the term "educated" predicated of him as opposed to the contrary "uneducated." Between the underlying thing and the two contraries, there are thus three principles of nature. The contrary into which the underlying thing changes is the form, the underlying thing is eventually given the name material, and the contrary from which the material has come is first called privation, but becomes the basis of the more adequate notion of potency. Privation is so open-ended that it becomes causally indeterminate, and indeed Aristotle himself is not quite sure whether it should be treated as a principle of nature at all. He vacillates from sentence to sentence:

Hence there is a way in which the starting points are $t w o$, and another in which they are three; and there is a way in which they are contraries, as if one were to speak of the educated and the uneducated, or the hot and cold, or the concordant and the discordant, but another in which they are not, since it is impossible for contraries to be acted upon by one another (190b; my emphasis).

Thomas Aquinas, summarizing Aristotle, perhaps put it best: "Privation is a per accidens principle...but the other two are per se principles" (Aquinas 1998: 21).

\footnotetext{
${ }^{65}$ When these contraries are later developed into the categories of form and potency, potency corresponds to falling short and form corresponds to exceeding.
} 
The material in its pre-formed or pre-articulated state is only incidentally opposite to its eventual form. The fact that the uneducated man suffers from a deprivation of education is true but virtually meaningless, as he also suffers from a deprivation of wings or of the ability to prove logical contradictions. It is true but offers no scientific knowledge of how or why the change occurs. Aristotle alerts his reader to this fact in a curious way that has confused most translators. In an apparent summary of the results of the previous chain of argument, he writes the following:

But in this way what is does come into being, in the same way as if animal were to come from animal, or a certain animal from a certain animal, for example, if a dog were to come into being [from a dog, or a horse] from a horse (191b).

The words in square brackets are not in any of the original manuscripts, but have been added by confused translators in the attempt to make this sentence intelligible. However, as David Bolotin argues, this is a mistake (Bolotin 1998: 14-15). So long as material, form, and privation are taken as the three principles of nature, there is nothing to prevent a dog coming into being from a horse. Privation is so open-ended that it can lead to almost anything, as a man is presumably deprived of many things in addition to what he eventually becomes, or can potentially become.

Aristotle resolves this difficultly by clarifying what he had meant all along by privation: "another [way to go] is that it is possible to mean these things in respect to potency as well as to their being-at-work" (191b). The concept of potency narrows down the endless possibilities implied by mere privation, and avoids the absurdity of a horse giving birth to a dog. The semen of a horse is deprived of the form of dog, but it does not have the potency to become a dog.

"Being-at-work," in Metaphysics 1048a, is contrasted to potency as that which a thing is when it is fully itself. A block of wood is potentially a statue, but when the statue has been fully carved - i.e made actual - we can speak of its being-at-work. The main idea seems to be that whenever something is truly, and not just potentially, it is fully at work being itself. When 
Aristotle speaks of "things in respect to potency as well as to their being-at-work," he is replacing open-ended privation, and its implication that matter simply takes on whatever form happens upon it, with the idea that matter exists as potency for a limited range of fulfillments, or forms. Each particular kind of matter is potentially some things but not others. We can then clarify Aristotle's teaching on this matter by saying that the three principles of nature are form, matter, and potency (which resides in matter and partially determines the forms it can take).

At this point, it is worth mentioning competing interpretations of the form-matter relationship. A natural reading of the text - or at the very least a linguistic adoption for the purpose of simplicity - would indicate that matter and form are related as thing and property. The material is the stuff that takes on the properties predicated of it. William Charlton, however, proposes an alternative reading of forms as concrete instantiations, and therefore of matter and form being related as "constituent to thing constituted" (Charlton 1970: 71). He marshals textual evidence from Aristotle's corpus to the effect that Aristotelian forms are not Platonic abstract objects but refer to actual beds, statues, and such. Moreover, thinking of forms as concrete fulfillments of the potencies of material, rather than abstractions predicated of neutral material, makes sense of Aristotle's vacillation regarding whether there are two or three principles of nature. Insofar as the underlying thing and the two opposites are conceptually distinct, there are three principles. But insofar as the material is in reality the same thing as the form - i.e. the actual table in front of us - then the principles are two. We will revisit this in the discussion of the Metaphysics.

Given Aristotle's conceptual reliance on matter in order to explain change, by way of the potencies inherent in different materials, it makes sense to think of forms, as Charlton does, as more concrete than abstract. However, since Aristotle's intention is to grasp the conceptual 
nature of change, rather than its outward, or empirical aspects, the traditional language will be retained here for our purposes. It may very well be that, in truth, there are two principles of nature, as Charlton maintains, but the perspective according to which there are three - i.e. the one attuned to the logical character of change - seems more faithful to Aristotle's purpose in writing the Physics.

Potency is a different kind of principle than material and form, as it reaches out toward form and seeks its own eventual destruction. A thing, properly understood, is what happens when potency gives way to form; this entails that a thing is a unity of material and form. This doctrine, which came to be known as hylomorphism, was simultaneously a critique of the materialist pre-Socratics as well as Platonic idealism. Nature is not merely matter, as some preSocratics believed, but neither can a full understanding of the cosmos be had by ignoring the importance of matter, as Aristotle thought his master had done.

The precise character of form will be given in the discussion of the causes themselves, but the preliminary definition of it is that which is predicated of an object. The definition of material, on the other hand, is not as simple. The Aristotelian concept of pure material, in the absence of any form, strictly speaking, refers to something that does not exist. Any matter that exists in the real world is of a certain kind, and bears some attributes instead of others. Wood is never pure and undifferentiated wood, but is always oak, or birch, or maple, or some other kind of wood; that is to say, it always participates in some particular form. Material in the precise meaning here intended refers to a state of pure potency with no actuality; that is to say, stuff which does not partake of any form whatsoever. Aristotle insists that it can be known only through analogy, "as the formless is before taking on its form" (191a). It is later described simply as the "that out of which" something has come into being (194b). 
The question of the causes, then, is simply "Why does this particular thing consist of this particular matter and this particular form?" According to Aristotle, the various answers to this question can be grouped into four categories:

1. That out of which a thing has come (material cause)

2. What it is for it to be (formal cause)

3. That from which the first beginning of change or rest is (agent of motion/efficient cause)

4. That for the sake of which (final cause)

For everything that exists, an answer can be found for each of these four aspects. Each thing, by virtue of being a thing, consists of matter and form, as was demonstrated in book I, so any adequate scientific knowledge must speak to these. However, in the case of natural as well as artificial change, there must have been something which sparked the movement or change into the thing presently before us and, what is controversial to modern readers, genuinely scientific questioning must seek the end for the sake of which the present motion was brought about. Moreover, as if to remove all doubt about what he means by "that for the sake of which," Aristotle insists on using normative language to explain his intention: at one point he likens the end to "the best thing...the good itself" (195a), and at another point, "because it is better thus" (198b). In Aristotle's common example of a statue, the material cause is bronze, the formal cause is the shape of the statue, the cause of the motion is the sculptor, and the final cause is the sculptor's desire for beauty, or to honour the gods, or some other such aim. To reiterate, in order for knowledge of something to be complete, it must know all four of these answers to the question "why?"66

Julius Moravcsik has argued that Aristotle is here working out a theory of adequate explanations, rather than merely causes. He makes distinctions between explaining something by reference to causal factors, function, and purpose, and points out that Aristotle's theory

66 "[S]ince there are four causes, it belongs to the one who studies nature to know about all of them" (198a). 
encapsulates all of the above. Because of this, he writes, "it is quite misleading to refer to the theory of aitiai as a doctrine of causes. It is, rather, a theory about the structure of explanations" (Moravcsik 1974: 3). On the conceptual question of the meaning of Aristotle's theory, Moravcsik is correct. Aristotle's intention is to uncover all of the ways in which the "why" of a thing can be accounted for, and these include the material constitution of a thing as well as its purpose. One has not fully explained something unless all of the above are accounted for. However, Moravcsik seems to assume a limited definition of "cause" that restricts it to the contemporary positivistic notion of efficient cause. When he contrasts a causal explanation with a functional or purposive explanation, it seems that he is referring to the independent variable that set the phenomenon in question into motion; in other words, the modern understanding of what it means to be a cause.

It would have been better to argue that Aristotle's theory of causality is a theory of adequate explanations and thus expand the concept of causality instead of conceding to modern thought its restricted definition. Positing such a distinction between the efficient cause of something and its purpose or function ignores the complex relationship between the telos of a motion and its actualization. Indeed, as will be argued below, it is impossible to fully understand Aristotle's doctrine of final causality without accounting for its causal role (i.e. efficient cause) in motion and change. The interesting question that Moravcsik's argument precludes is how form and purpose can be causes alongside the efficient cause; indeed this is the first major question Aristotle poses to "those who posit the forms" (Metaphysics, 988b):

But most of all, one might be completely at a loss about what in the world the forms contribute to the perceptible things, either to the everlasting ones or to the ones that come into being and perish. For they are not responsible for any motion or change that belongs to them (991a). ${ }^{67}$

\footnotetext{
${ }^{67}$ Aristotle's nuanced relationship with Plato's theory of forms will be explored below.
} 
Formal cause, which we will see is conceptually bound up with purposive explanations, is meant to shed light on the efficient causal explanation of each thing. The fact that some articulations of the theory of forms do not, according to Aristotle, counts against their favour. For this reason Moravcsik's argument, while useful insofar as it reminds us of the breadth of Aristotle's search for explanations, does not go far enough by failing to call such explanations causes.

The question of how the causes work together to bring about an object is never given a clear answer by Aristotle - or rather, it is given more than one answer. One thing that seems clear is that material and formal cause are brought together by the efficient cause; in the case of the statue, the bronze is shaped into a statue by the sculptor. Moreover, Aristotle writes that in some cases the form, end, and mover coincide, such that the form acts as both the purpose of the change and the mover (198a). This should not be taken as a simple conflation of three causes into one, since each occupies a unique place in the totality of explanations. For example, the form of a thing and its purpose might be identical, but a complete understanding requires a distinct conception of how forms and purposes serve as causes. Similarly, the efficient cause of something must bear at least some resemblance to the thing brought about. This is the point of Aristotle's example of human procreation: a man who is the efficient cause of a new human is not identical with the form into which the embryo develops, though he resembles the form and is the same as it in species. So while we should not say that the form itself is itself the initiator of the change from potency to actuality, we can say that the form coincides with, or is the same in species as, the final and efficient causes of motion. ${ }^{68}$ From this coincidence of the causes we can

\footnotetext{
${ }^{68}$ Phillip Wicksteed and Francis Cornford's translation conveys this relationship in the following helpful manner: "But in many cases three of these 'becauses' coincide; for the essential nature of a thing and the purpose for which it is produced are often identical (so that the final cause coincides with the formal), and moreover the efficient cause
} 
gather that any explanation that ignores, for example, formal and final causes, is missing part of what Aristotle thought must be accounted for in any such explanation. Aristotle concludes this discussion by arguing that an adequate explanation of motion must give all four senses of "the why" (198b).

However, the causes seem to be differently arranged in the constitution of artificial things. As far as man-made objects are concerned, the final cause is in the mover's mind, and is what compels him to bring together material and form. The sculptor, because of his desire to honour a god, shapes the unformed bronze into the form of a statue. This is an instance in which the end does not reside in the form, but rather in the mind of the mover. This difference in the arrangement of the causes reflects Aristotle's earlier distinction between natural and artificial things, wherein natural things have in themselves the sources of motion and rest, and artificial things have no such innate impulse of change, but require the agency of an extrinsic mover to move from potency to actuality (192b). However, Aristotle insists numerous times that art imitates nature, which would imply that the causes of artificial things should be analogous to the causes of natural things (194a, 199a). How can Aristotle's belief that art imitates nature be reconciled with the fact that causality operates differently in the natural and human realms? In order to answer this question, we must turn to his examination of the relationship between chance and purpose.

\section{Accidental Versus Essential Causes}

The third chapter of book II presents the four causes, as well as the various ways they act as causes. Aristotle follows this, in chapters four through seven, by posing the problem of events 
that do not seem to be caused by anything in particular, but appear to have come about by chance or fortune. His ultimate concern is the view of his predecessors that the entire cosmos came to be by chance, and is still governed by it. The local patterns we observe in the life-cycle of birth, reproduction, and death, are just that - local patterns within a broader cosmos of chance and fortune. This is a potential impasse because he has just argued that in tracing back the "why" to the four previously mentioned causes one has indeed given complete knowledge of the thing in question. If, however, there are some things that do not owe their existence to any purpose, or a "because it is better thus" (198b), then Aristotle's causal model fails. And it certainly does appear that many things are not the result of order or purpose.

To understand Aristotle's solution to this problem, as well as the main alternative approaches found in the secondary literature, a few central terms must be defined. Nature, in this context, refers to "things always happening in a certain way...[or] for the most part" (196b); that is, a process that is natural will exhibit an intelligible orderliness, always occurring in the same, or a similar, manner. An example of a natural process might be the life cycle of living things: all of them are born and then die, and usually leave genetically similar offspring behind; like begets like. Similarly, the falling of heavy objects is a repeatable phenomenon, and is thus considered a natural phenomenon. In addition, natural processes, as Aristotle has previously argued, always happen for the sake of something; a natural motion is one governed by the end for which it strives.

There is also a distinction between per se causes and per accidens causes. A per se, or essential, cause is one that acts for the sake of the cause in question, as a house is the proper effect of a house builder, whereas the housebuilder is only a per accidens cause of a bird building its nest in the chimney. The bird building a nest in the chimney is, however, per se an 
effect of its natural inclination to build nests for its young. It just so happened that it built its nest in that particular chimney. Per se effects, like natural processes, always happen for the sake of something. The housebuilding art is for the sake of houses, as the bird builds nests for the sake of its young. Per accidens effects, on the other hand, are not for the sake of anything. There is no broader purpose to account for a particular bird choosing a particular chimney, or for the fact that the builder of this house happens to be white, or musical, or any other incidental predicate.

With these preliminary definitions in mind, Aristotle's usage of chance and fortune becomes intelligible. Per se causes and effects are natural causes and effects, in which the effect is proper to the cause and is that for the sake of which the cause acted. On the other hand, an effect can be said to have been caused by chance if it is not the end for which what caused it had aimed. That is, things come about by chance insofar as they are incidental by-products of causes acting for the sake of something else. If a man happens to look down at the precise moment at which a $\$ 100$ bill is in front of him, it can be said that he found it by chance. His looking down was not for the purpose of finding the money, because he did not know it was there. Rather, his looking down for the sake of, perhaps, ensuring that his shoes were tied resulted in something outside the purview of his intention. Because chance events are incidental, and do not follow repeatable patterns, chance accounts for the anomalies, aberrations, or anything that departs from the usual patterns of the world. Aristotle categorizes genetic defects this way, as well as hot days in winter and cold days in mid-summer.

Moreover, fortune is nothing but a subset of chance: chance events that occur in the realm of human affairs. The man finding $\$ 100$ is fortunate, but a hailstorm in August is by chance. What is common to both, however, is that they are incidental effects of causes which were for 
the sake of something else. The significance of this definition of chance is that it entails that chance requires for its existence a broader framework of final causality. If chance occurrences are by-products of causes for the sake of ends, those end-driven causes are more fundamental: "[i]t is clear that fortune is an incidental cause among things proceeding from choice, which in turn are among those for the sake of something (197a).

As we saw, Aristotle began this entire discussion of chance and fortune in response to some of his predecessors, who claimed that the cosmos arose by chance, and is still governed by it. If this is true, as Aristotle recognized, it would invalidate his ontological prioritizing of purpose over chance. His refutation of this primordialist ontology consists of a reversal of the chance-order relationship, according to which chance is by definition derived from the broader network of order and final causality. A chance event, in other words, requires a per se cause that was directed for the sake of something. The most fundamental order of causality, therefore, is that which is aimed at particular ends.

However, while this refutes the ontological primordialism of the pre-Socratics, it is not universally thought to have refuted their historico-scientific claim that the cosmos arose by chance. There are two competing interpretations of the meaning of Aristotle's argument. The first, which could be called the natural reading of the text, claims that Aristotle truly meant that order and final causality are chronologically as well as ontologically prior to chance. This is the view defended by Richard Hassing and Joe Sachs, among others. The alternative view, defended by David Bolotin, is that Aristotle only claimed ontological priority for final causality, but not chronological priority. ${ }^{69}$ That is to say, in Bolotin's view, the pre-Socratics were correct in their

\footnotetext{
${ }^{69}$ In most cases, it is unfair to begin by describing one view as the natural reading of the text, as this can reflect a conscious or unconscious bias in its favour. However, Bolotin himself is aware of the counter-intuitive nature of his interpretation; indeed his book is based on the premise that Aristotle included statements with which he disagreed (Bolotin 1998: 5).
} 
belief that the cosmos is a product of chance. The central question, therefore, is whether purpose is the physical, or chronological, cause of the cosmos, in addition to being necessary for making the cosmos intelligible.

Sachs does not make a distinction between the chronological and ontological priority of final causality. His refusal to distinguish between them is due to his belief that they cannot be separated. His statement that chance events "can only be understood in light of the ends things aim at by nature," which indicates ontological priority, is immediately followed by the claim that "[a]11 events and all motions are rooted in the potencies present by nature in things" (Sachs 1995: 72). This recalls Aristotle's ontology in book I in which different materials have different potencies, with potencies partially determining the forms they take on. In fact, Aristotle's language implies that unformed matter, or pure potency, actively reaches out for, or desires, the form that can fulfill its potency. He introduces the term "potency" as being logically bound up with "being-at-work," with the implication that potency is an active principle and takes part in the natural motions of the material. In his glossary of key terms, Sachs defines potency as " $\mathrm{t}] \mathrm{he}$ innate tendency of anything to be at work in ways characteristic of the kind of thing it is; the way of being that belongs to material" (Ibid.: 252). ${ }^{70}$ This understanding of potency foreshadows Aristotle's introduction of teleology in book II, especially his view that form - i.e. that for which the potencies inherent in matter strive - can act as a final as well as efficient cause. If form is an agent of change for the sake of an end, and potency actively stretches out towards form, then the teleological causal logic informs all natural change. The meaning of Sachs' statement, then, is that all events or motions, chronologically speaking, require for their existence the active desire of potency for its end/form. All change, physically speaking, is a product of end-directed action.

\footnotetext{
${ }^{70}$ See also the opening line of Metaphysics: "All human beings by nature stretch themselves out towards knowing" (980a 21). That is, human beings, by virtue of their natural senses and capacity for wisdom, possess the potential for wisdom. This potency actively "stretches out" towards that which it potentially is.
} 
Thus, in Sachs' view, Aristotle's intended meaning is that no change or motion ever arises without purpose, order, or final causality, including the coming together of the cosmos itself. ${ }^{71}$

Richard Hassing, in his introduction to Final Causality in Nature and Human Affairs, takes roughly the same position. In discussing Aristotle's treatment of the chance-order relationship, he writes that "it makes no sense to speak of per accidens causes and effects in nature without acknowledging the prior or antecedent reality of per se causes and their effects, without which the accidental could not exist" (Hassing 1997: 17; my emphasis). Hassing goes on, however, to clarify that this need not imply that the prime mover, or any transcendent intelligence, has chosen the particular effects of the movement of the cosmos. It is consistent with Aristotle's chance-order relationship that the natural, that is per se, causes are extremely general, and largely indeterminate of the ultimate effects. That is, the particular character of the cosmos, including the seasons and the biological constitution of living things, may indeed be the results of chance, qua incidental effects of more fundamental, but general, per se causes. ${ }^{72}$ Despite this qualification, Hassing maintains that per se causes are ontologically as well as chronologically prior, such that the first links in the causal chain that generated the cosmos are end-directed, intelligible, and orderly.

While Sachs and Hassing are essentially commenting on Aristotle's argument in order to reach their conclusions, Bolotin's argument requires a more delicate treatment of the text. As opposed to Hassing and Sachs, Bolotin explicitly makes a distinction between chronological

\footnotetext{
${ }^{71}$ It should be pointed out that Sachs' interpretation of potency as an active principle washes over the distinction between natural and violent motions, and as such is uncommon in the literature. Sachs' emphasis on the potency's actively stretching out towards form gives it more efficient causal power than, for example, Ross, who represents the more common view of potency as requiring an additional source of change. For example: "But neither can we explain [change] by potentiality alone. Nothing is promoted from potentiality to actuality without the agency of something actual" (Ross 1964: 177).

72 "We could say, following Aquinas, that, in this type of theory, there would be material and efficient causes that produce general effects, but particular effects (for example, 'the heavens,' or the biosphere) would be unexplained since they would not proceed per se from their causes" (Hassing 1997: 18).
} 
priority and ontological priority. The primary reason for his inability to accept that Aristotle claimed chronological priority for final causality was that it would require, in his view, that there be a divine intelligence outside of nature. He infers this from Aristotle's statement that "so that if chance is responsible for the heavens as much as possible, it is necessary that intelligence and nature have a prior responsibility, not only for many other things, but also for this whole" (Bolotin 1998: 39). By this he takes Aristotle as claiming that the broad network of final causes that is ultimately responsible for the incidental causes we call chance requires the purposes of an intelligence. The problem with this, however, is that it would fail to explain the very problem with which the Physics is attempting to explain, namely natural change. By reducing all natural change to the purposes of intelligence, Aristotle would effectively negate his earlier claims that art imitates nature. On the contrary, if nature is simply a manifestation of art, albeit the artifice of a divine mind, then natural change, as such, does not exist. Moreover, it would not truly explain how allegedly natural processes can act for a purpose - for example, how the development of an embryo culminates in a full-grown human being.

Bolotin's solution is to suppose that the world chronologically arose by chance but that "mind must still be a prior cause of it" (Ibid.: 41). That is to say, it may be true that while chance is chronologically prior to purpose, mind is nevertheless ontologically prior, by virtue of being required in order to render the cosmos intelligible. Taking his cue from a passage in the Metaphysics ${ }^{73}$ Bolotin argues that Aristotle thought that "being in the paramount sense is what is true, or what is understood by some mind;" (Ibid.) in other words, the conceptual priority of mind to chance is ontological priority. Because being is what is understood, the fact that what happens in the cosmos can be made intelligible entails that mind and purpose are conceptually

\footnotetext{
73 "And so it is clear that the things that are in the figures in potency are discovered by being drawn into activity, and the cause that is contemplative thinking is the being-at-work of them; therefore the potency comes from a being-atwork, and for this reason it is only those who make a construction who know it" (1051a 34-1051b 6; my emphasis).
} 
prior. This is to say that chance is chronologically prior to purpose, although it is not fully understood - and therefore real - until it is made intelligible by minds, in this case the minds of natural philosophers like Aristotle. The ends to which natural beings are directed, therefore, are imposed by human conceptual categories.

There are a number of problems with Bolotin's approach to this question, the most important of which is that he seems to have unnecessarily assumed that mind must be the source of the purpose that gave rise to the cosmos. He points to a passage in which Aristotle writes that "if chance is responsible for the heavens as much as possible, it is necessary that intelligence and nature have a prior responsibility" (198a). As we have seen, Bolotin takes this to mean that if there is any chronologically prior cause than chance, it must be mind as well as nature. This inference, however, is not required by the text itself. In other places where Aristotle makes the same point, he writes "nature or intellect" (196a, 198a; emphasis in original). The fact that Aristotle evidently treats nature and intellect as either/or concepts instead of both/and might imply that they are both of the category of causes that act for purposes, but not, as Bolotin assumes, that they always act coterminously or that anything that acts for a purpose must be a mind. Thus when Aristotle writes that nature and intellect are prior to chance, he may simply be making the point that final causality is prior to chance, and that final causality can result from either nature or from mind. Because Bolotin's entire reinterpretation of Aristotle's causality is a product of his understanding of the mind-nature relationship, clearing up this confusion allows one to reject his distinction between chronological and ontological priority, and therefore accept the natural reading of Aristotle's words. That is, final causality is both ontologically and chronologically prior to chance, and to whatever extent chance is responsible for the cosmos, order and purpose are more fundamental. 


\section{Natural and Artificial Change}

The preceding discussion of accidental and essential causes and effects has attempted to clarify Aristotle's vagueness with respect to the proper relationship between natural and artificial change. It was noted that he described causality as it pertains to artificial objects differently than as it pertains to natural objects. In the case of artificial objects, the end is located in the mind of the mover, and not in the matter itself, whereas the end of natural change resides in the matter itself, and is brought about, at least in part, because of the inherent striving, or being-at-work, of the potency of the material. This difference between natural and artificial causality is made all the more curious because Aristotle goes on to say that artificial change imitates natural change, which seems strange given the differing composition of each. The fundamental question at the heart of Aristotle's doctrine of causality, then, is "which of these models of causality is more fundamental?" His resolution of the problem of chance and fortune, according to which accidental causes are embedded within a broader network of essential causes, provides clues for a successful resolution of the current impasse. There are two ways in which the model of an ontologically prior level becoming the stratum in which an ontologically derivative layer is embedded can be applied to the alleged tension between artificial and natural causality.

The first is in the chance-order relationship. Chance causality is embedded within an ontologically prior order of final causes. Accidental causes and effects are different than essential causes and effects, but not in such a way that renders them incommensurable with essential causes. Rather, they operate within the larger context of essential causality, not outside of it altogether.

Second, fortune is a subspecies of chance. Chance causes are incidental causes of effects that happened for the sake of something else; this type of incidental cause is found throughout 
nature, from inclement weather that happens to spoil crops to a creditor happening upon his debtor in the marketplace. Fortune, however, is the name given to incidental causes and effects within the realm of human choices and purposes, so the creditor seeing his debtor is fortunate, whereas the early rains are not. Fortune thus being an incidental cause in the realm of human affairs, must operate within the confines of chance, which is incidental cause in natural affairs. That is to say, the incidental causes of human things are part of the larger framework of incidental causes of natural things.

Because chance and fortune are here treated as similar, if hierarchical, there must not be any real tension in how they operate. Moreover, if human incidental causes are subordinate to natural incidental causes, it follows that human essential causes must be subordinate to natural essential causes. Human causality is a subset, and thus a part of, natural causality more broadly; it is embedded within it. If this is true of incidental causes, it must be true of essential causes too, for incidental causes are a part of the network of essential causes. Incidental effects are nothing but unintended (in the case of fortune) or extrinsic (in the case of chance) effects of the four essential causes (material, efficient, formal, final).

To explicitly answer the question at hand (i.e. whether natural or artificial causality is more fundamental), just as chance is embedded within a larger framework of order and purpose, and incidental human causality is embedded within a larger framework of natural incidental change, artificial causality more broadly is embedded within a larger body of natural causality. That is to say, artificial change, in which the end is in the mover instead of the material, is embedded within the ontologically prior occurrence of natural change, in which the end is present in the material and acts as the efficient cause. 
How can this be? How can these two models of causality be embedded, if they have different relationships between the causes? Put simply, it is because humans themselves are natural beings. There is no such thing as pure art or convention; the artificial is ontologically and chronologically derived from the natural. Human beings themselves, including all of their conventions and extrinsic ends and purposes, are part of the natural telos of the cosmos. Human ends and purposes, therefore, can only be understood in light of the natural ends for which they are fitted. This entails that even the purposes they impose on nature are products of natural final causality.

Let us return to Aristotle's favorite example of the bronze statue. While the cause of the bronze's being shaped into a statue was the sculptor acting for the sake of his desire to honour a god, the chain of causality does not stop there. It goes beyond the realm of natural change, and can be traced back to the potency of human beings to live together in political community, which for Aristotle included religious as well as strictly political life. The cause of the statue, qua artificial object, is the sculptor's desire to honor a god, but the cause of the statue, qua part of the human world of political and religious life, is the form of the good life. Recalling the above discussion of the coincidence of the causes, we can think of the form of the good life as coinciding with the efficient cause that compels the material - i.e. the citizen - to contribute to the life of the polis. As W.D. Ross puts it, "the final cause is the same plan [i.e. the form] considered as not yet embodied in the particular thing but aimed at by nature or by art" (Ross 1964: 74). Ross goes on to illustrate the coincidence of final and efficient cause: "the quality and size which accompany a thing's attainment of its complete development are included in its form and operate as a final and thereby as an efficient cause" (Ibid.: 75). So while the form of the good life does not literally become the direct efficient cause that makes a man sculpt a statue, his 
desire to create a statue - which is the efficient cause - must necessarily contain the idea, or form, of the statue. This is what Aristotle means when he writes that "that whence the motion first is [i.e. the efficient cause], is the same in form with these [i.e. formal and final cause]" (198a).

The embeddedness of human causes within natural causality permeates artificial change, such that all art can be traced further back to nature. That is, every artificial motion, in which the end - that is, the desire to bring about a certain end - is external to the thing changed, is ultimately the result of a network of ontologically prior natural motions, in which the material of the thing in motion plays more of a causal role, by way of its potency for some forms over others. ${ }^{74}$ The difference between natural and artificial causality can be reconciled with Aristotle's dictum that art imitates nature in the following manner: natural change is ontologically prior to artificial change and displays characteristics of purpose and intentionality despite the absence of an ordering intelligence, and artificial change imitates this appearance of intentionality by being explicitly end-directed by minds. This is likely what Aristotle meant with the following words:

And in general, art in some cases completes what nature is unable to finish off, but in others imitates nature. If then, what comes from art is for the sake of something, it is clear that what comes from nature is too, for the series of things from art, and from nature are alike, each to each, in the way that the later things are related to the earlier (199a).

The question of Aristotelian final causality can be resolved, then, in the following manner: final cause, qua the end for which all change occurs, coincides with the efficient cause

\footnotetext{
${ }^{74}$ The precise nature of potency is a subject of some debate, as mentioned above. Ross represents the majority view in conceiving of potency as simply determining what changes are possible in a given material, but not as an active principle of motion itself (Ross 1964: 176-178). Sachs disagrees with this view, and instead sees in Aristotelian potentiality an active principle of motion: "A potency in its proper sense will always emerge into activity when the proper conditions are present and nothing prevents it" (Sachs 1995: 252). Though Sachs' view is more amenable to the argument of this project, even Ross' view admits the key difference under discussion: artificial change in which the principles of change are external to the thing changed versus natural change in which the thing itself is more determinative of the precise nature of the change.
} 
of change. The end of the change bears similarities to the form to which it is directed, since it aims for it, and the nature of the change is partially determined by the potency of the pre-formed material. It follows from this relationship of causes that change cannot be understood without reference to final cause, though they all play an important role in nature.

We are now in a position to comment on Aristotle's conception of science. It has been demonstrated that a faithful account of Aristotle's doctrine of causality asserts the primacy of final causes, and that even artificial change, in which final cause seems only indirectly related to the actual change - by acting on the human source of change - can ultimately be accounted for in terms of natural change, in which the end directly acts as the agent and determinant of change. Moreover, it is clear that Aristotle thought that any knowledge of nature must know all of the causes: "since there are four causes, it belongs to the one who studies nature to know about all of them" (198a). The proper objects of science, qua the study of nature, therefore include observable phenomena like visible properties and chronological cause and effect, but also inprinciple unobservables like form, pre-formed material itself and the potencies proper to it, but most importantly, the goods proper to each thing and for which they strive. The distinction, common to many modern accounts of science, between observable and unobservable, is nowhere to be found in Aristotelian science. Rather than designing his inquiries around the aim of manipulability, by way of empirical observation of stable laws of behavior, Aristotle inquired into whichever causes bore the most responsibility for the change in question. This, as has been shown, led him to treat order and purpose as the most fundamental causes of the natural and human worlds. 


\section{Motion}

Let us now turn to the main topic of the Physics: motion itself. The parameters of this discussion have been firmly defined by the preceding discussion in a number of ways. First, Aristotle's goal in studying motion is not merely to predict or understand the patterns of motions, or to discern how individual motions come to be. These investigations would fall under the categories of material and efficient causation, which we have seen is not his primary target. Instead, the primacy of final cause entails that the study of motion must culminate in knowledge of either the purpose of motions, how motion is subservient to purposes, or the relationship between motion and the good. Second, all of the important aspects of his theory of motion have been introduced and cursorily defined, including potency and being-at-work. Third, motion, as Aristotle understood, was not limited to mere change of place. The English words motion and change are both designated by the greek kinêsis, which points to Aristotle's broader conception of motion as encompassing local motion as well as alteration, growth, decay, and so on. The conclusion of books I-II that final cause ultimately holds sway over both natural and artificial change indicates the direction his analysis of motion will take, since motion quite literally is change. The discussion of motion reveals the way in which Aristotle's conception of inquiry frames the scope and conclusion of his investigations. Because his aim is wisdom of the most responsible causes, not the ability to predict the behavior of motions, very little time is spent analyzing motions; instead, he focuses on analyzing the intrinsic character of motion itself. $^{75}$

His definition of motion brings the above considerations together. The most basic fact about motion is that it is conceptually bound up with natural goods or ends. In many ways, the discussion of motion does no more than flesh out the implications of books I-II. Because motion is intrinsically end-directed, the Physics is, at its core, a study of natural ends. Motion is always

\footnotetext{
${ }^{75}$ The novelty of defining motion as such is noted by Remi Brague (1990: 1-2).
} 
toward a specified end or goal, not just open-ended movement or transition from one place or condition to another. The latter, motion as mere movement or open-ended transition, is closer to the modern, Cartesian view, which is essentially circular. ${ }^{76}$ As Remi Brague notes, it is nearly impossible to give a non-circular definition of motion, which perhaps begins to account for the dearth of attempted definitions. However, the argument of this thesis entails that modern thinkers' abstention from defining motion had more to do with their lack of concern for anything that did not provide predictive or utilitarian value. Brague quotes the Logique de Port-Royal: "to whom was it [this definition] ever useful for explaining any of the properties of motion?"

(Brague 1990: 2). One does not require an ontological theory of motion in order to predict and harness the power of individual motions. Even still, it is notable that, as far as Brague can tell, not a single definition of motion has been proposed that differs from Aristotle's in any meaningful way (ㅎid.).

The central concepts involved in the definition of motion are being-at-work, being fully active, and being potentially. The full import of these and other Aristotelian concepts will be addressed in the later discussion of the Metaphysics; here they will be briefly defined and their relation to motion clarified. Being-at-work has been alluded to above as what it is for a thing to be, and it was initially placed opposite potency. In book I being-at-work refers to a thing that has fully reached its potential, as a block of wood that has been carved into a statue is "at work" as a statue, whereas it was previously only potentially a statue. The meaning of the terms carries over into the present discussion of motion, although more nuance is added. In book III a completed thing is called fully active whereas potential things still exist only as potential. But here

\footnotetext{
${ }^{76}$ However, circular definitions are not solely the claim of modern thinkers. Thomas Aquinas criticizes the traditional interpretation of Aristotelian motion for defining motion by way of "elements that are posterior to motion" (Aquinas 1999: 146). In addition to being incorrect simply, such interpretations miss Aristotle's intention, which was to define motion by elements that are prior to, or more fundamental than, it.
} 
Aristotle suggests that each of them has a being-at-work particular to it, instead of only the fully active, as it was in book I; that is, even the potentially existing has a being-at-work that is proper to it. The being-at-work of the fully active is its thinghood, or what-it-is-for-it-to-be; the beingat-work of the potential thing, on the other hand, is motion, or what one could clumsily call whatit-is-for-it-to-become. Having briefly introduced the main concepts, Aristotle's definition itself can begin to make sense: "the being-at-work-staying-itself of what is potentially, whenever, being fully at work, it is at work not as itself, but just as movable, is motion" (201a).

The central idea is that motion has to do with the being-at-work of potency, or what the potency does qua potency. Having mentioned above Aristotle's clarification of being-at-work such that it belongs to both the fully active and the potential, there are three separate thoughts contained within this definition. For the purpose of clarity, each will be discussed in turn before combining them to present the full import of the definition. ${ }^{77}$

"The being-at-work-staying-itself of what is potentially..."

Being-at-work and being-at-work-staying-itself, while carrying different sets of nuances, mean roughly the same thing. Suffice to say for now that what was said above regarding beingat-work holds true here for being-at-work-staying-itself, namely that it refers to what it is for a certain thing to be, either as fully active or as potential. We see here that motion arises out of things that exist as potency, and pertains to the essence of potency. Insofar as it is the very being-at-work-staying-itself of potency, and the very meaning of what it is to exist potentially, motion is intrinsic to potency. In other words, motion seems to be the very "what-ness" of potency; it is what potency does or is that makes it a potency.

\footnotetext{
77 The following exposition is indebted to Brague (1990).
} 
“...whenever, being fully at work...”

This clause introduces a distinction between potency at work and potency not at work, or active versus inactive potency. This distinction can be paraphrased as the distinction between actually becoming versus possessing the capacity to become. A potency is fully at work when the transformation is currently in progress, or when it is actively taking on the goal for which it strives. A healthy man who keeps to a strict diet and fitness regime has the potency to become sick even though the potency is not currently active - the man is not currently becoming sick. On the other hand, a sick man who is undergoing treatment for his illness and is getting better each day has an active potency for health - he is actively reaching his potential. This provides clarification to the first clause in the definition insofar as it asserts that simply possessing a particular potency does not a motion make. Just as a stable ice cube is not in motion towards liquid water unless it is melting, a potency must be actively at work in order for motion to be said to exist.

\section{“...it is at work not as itself, but just as movable."}

The final clause draws on Aristotle's earlier discussion of incidental versus intrinsic causes and effects. An intrinsic effect is the effect for the sake of which the action was undertaken, and the incidental effect is anything else that may have followed. It is the same with causes; the cause for the sake of which an effect happens is intrinsic and all others are incidental. Bill the carpenter is the intrinsic cause of a table, and if Bill is bald then the bald man is an incidental cause of the table, for although the man who built the table was bald, it was not by means of his baldness that the table was built, but by his possession of the carpenter's art. A graduate student is the intrinsic cause of a chapter on Aristotle, whereas if he happens to have 
blonde hair a blonde-haired man is an incidental cause of the same chapter. Whatever it is that makes a cause the cause of the particular effect is the intrinsic cause; anything else in the cause that is incidental to its role as cause is merely incidental to the effect. In regards to motion, Aristotle argues that it must not simply be that in which the potency resides that is actively at work, but the potency qua potency must be at work as the intrinsic cause.

Broken down into its three constituent clauses, this statement connects motion to potency. Whenever potency, as such, is fully at work, there is motion. When the buildable is being built, there is a motion called building. When the growable is growing, there is a motion called growth, and so forth. Aristotelian motion, then, can be described as potential which is in the process of being fulfilled, although it should be stressed that Aristotle avoids circularity by shying away from discussing motion in terms of progress towards a goal, or movement from potentiality to actuality. The motion consists in the nature of potency itself, whenever it is fully at work, hence my above term, what-it-is-for-it-to-become. Aristotle repeats his definition in various places, each time making the same point: "the being-at-work-staying-itself of whatever is only potentially, just as such, is motion," "the being-at-work-staying-itself of a potency, as a potency, is motion," "motion is the being-at-work-staying-itself of the movable, as movable" (201a, 201b, 202a).

Motion is the activity of potency, or in other words, it is what potency does as potency. Since we know that a potency is always for something specified, ${ }^{78}$ motion is thus necessarily tied to specific ends, goals, or teloi. Each motion, therefore, is the being-at-work of a potency toward its goal. The obvious implication of this is that nature, being a source of motion, is end-directed and that truly scientific explanations must reveal the end towards which the potency strives. Any

\footnotetext{
${ }^{78}$ Recall the above transition from privation to potency, for the reason that privation is too open-ended to be explanatorily useful (191b).
} 
explanation that does not refer to the telos of the potency does not adequately explain the motion ontologically, but merely describes its behavior as if it was a brute fact.

The justification of this definition is twofold. First, as already stated, it is primarily a fleshing out of the principles of nature and of the relationship between the causes as articulated in the first two books of the Physics. As long as nature is composed of contraries acting upon an underlying thing and the causes are as described, motion must be as here depicted, that is, as the being-at-work of a potency.

Second, Aristotle does provide a brief post hoc justification. The basic point is that neither potential being as such nor fully active being is being-moved, and the only remaining option is that motion is "a certain being-at-work, but incomplete" (201b); neither being-at-work nor potency, but rather the being-at-work of potency. Potency by itself would never move toward its goal, but fully active being has already reached its goal; a middle term is required in order to bridge the gap. In other words, the work proper to potency is the fulfillment of that which it has the potential to become. The "necessary condition of being moved" (201b), to use Aristotle's criteria for a definition of motion, is a potency doing what is appropriate to it qua potency. This seems to Aristotle to be the only logically satisfactory way of locating motion between inactive potency, on the one side, and complete being-at-work, on the other; "difficult to bring into focus, but possible to be" (202a).

I have hinted at two possible interpretations of Aristotle's account of motion: the circular and the non-circular. Aquinas refers to commentators that introduce circularity, and Sachs discusses David Ross' description of Aristotelian motion as “actualization” (Aquinas 1999; Sachs, nd). These are variations of what Sachs calls the "standard account of Aristotle's view of motion" (Sachs, nd). Most likely due to the strangeness of Aristotle's stated definition, 
conceiving of motion as the transition, or movement, from potential to actual seems plausible enough. However, as Brague, Sachs, and Aquinas correctly point out, defining motion as a certain movement or transition is no definition at all, but at best is a clarifying description. Given Aristotle's insistence that a definition of motion must provide a "necessary condition of being moved" (201b), the non-circular definition, which locates the basis of motion in the beingat-work of the potency instead of the basic fact of movement or transition, must be closer to Aristotle's intent.

Two final points must be made. First, the definition of motion does not in any way depend on the content imputed to the material and efficient causes. That is, the ontological claim that motion is the being-at-work of active potency, which potency is situated in the material, is not contingent upon any particular findings related to the composition of the material itself. Whether all material is composed of four elements or $118^{79}$ has no bearing on the ontological structure of motion that Aristotle presents. In the opening pages of the Physics, Aristotle articulates his method of discovering the ultimate causes of natural phenomena, which leads him to highlight form and potency as the contraries that act upon underlying matter, as well as the role of final cause in orchestrating the network of causality that obtains in the natural world. In other words, the search for ultimate causes led Aristotle to final causality, or the good for which each thing strives and the mode of being most proper to it. This division of being into potency and being-at-work, as we saw, is the ontological basis for motion-as-active-potency. That is, Aristotle's definition of motion arises out of his conception of natural inquiry, insofar as the search for ultimate causes led him to define motion in such a way. This is corroborated by Aristotle's half-hearted allusions to the four alleged elements of his time. He never commits

\footnotetext{
${ }^{79}$ The International Union of Pure and Applied Chemistry (IUPAC) formally verified elements number 113, 115, 117, and 118 on 30 December 2015, per an official IUAC press release: http://iupac.org/cms/wpcontent/uploads/2016/01/IUPAC-Press-Release 30Dec2015.pdf.
} 
himself to the theory that all matter is composed of earth, water, air, and fire, as if to indicate that its truth or falsity is of no relevance to him. See, for example, the following passages:

But all those concerned about nature set down as underlying the infinite some other nature from among the so-called elements, such as water or air or what is between these (203a; my emphasis).

And further, the changes of place of the simple natural bodies, such as fire and earth and things of that kind, give evidence not only that place is something, but also that it has some power (208b; my emphasis).

And one must state the nearest causes: What is the material? Not fire or earth but the material peculiar to each thing (Metaphysics 1044b).

The qualifiers "so-called" and "things of that kind" indicate that his purpose is not to provide any insight into whether fire, earth, water, and air are the fundamental building blocks of matter, especially given the fact that there seems to be no rhyme or reason behind which of the particular elements are named in each discussion. Moreover, as the $208 \mathrm{~b}$ passage demonstrates, the particularities of the "simply natural bodies" serve neither as premise nor conclusion to his arguments. Rather, they seem to be used primarily as heuristic devices by which he can situate his argument with reference to earlier thinkers as well as use concepts familiar to educated readers of his day. Indeed, in the third quoted passage above, the four elements actually seem to impede scientific explanations, rather than enable them. His point is that even if "fire or earth" are the ultimate materials out of which a thing is composed, the more adequate material explanation will point to the "nearest" cause, i.e. the composite material that is particular to the thing in question. This is because the potencies which allow us to understand the changes that are possible for each thing belong to the composite materials more than the simple elements. That is to say, knowing that something is composed of flesh and bone tells us more about its potencies than simply knowing that it is composed of a certain ratio of earth, water, air, and fire. 
Thus, there is no reason why replacing the four elements of fourth century BCE parlance with the 118 elements of contemporary chemistry would affect his ontological claims in any meaningful way. The obvious implication is that empirical discoveries pertaining to the particular content of the material and efficient causes, playing no role in the formulation of this definition of motion, seemingly can have no bearing on whether or not it is plausible.

Second, the distinction between the natural and human worlds, stressed so strongly by Richard Hassing and Ethical Naturalists alike, has no basis in the text. Hassing, Masters, Arnhart and most other contemporary Aristotelians have decided to save teleology in human affairs by divorcing it from cosmic teleology. Strauss rightly points out that this dualistic cosmology of a clean break between man and nature is a modern invention that "presupposes a break with the comprehensive view of Aristotle as well as that of Thomas Aquinas" (Strauss 1999: 8). Both Hassing and Arnhart adopt versions of this dualism, although Arnhart tries, unsuccessfully, to introduce a third position that is neither reductionist nor dualistic. ${ }^{80}$

The most promising articulation of dualism is that of Allan Gotthelf (2012), in part because it highlights the observational aspect of Aristotle ${ }^{81}$ and emphasizes the possible correspondence with modern discoveries. In responding to the charge that Aristotle is a mere "armchair theorist" lacking in empirical sensitivity, Gotthelf argues that not only was Aristotle an extremely careful observer, his true greatness lies in "his use of data so organized to understand the world of animals, to explain why animals are as they are" (Gotthelf 2012: 379; my emphasis). The italicized words express Aristotle's concern for teleological explanations,

\footnotetext{
${ }^{80}$ He adopts the term "emergentist evolution," according to which human life and purposes operate according to purposes that emerge out of lower levels of biological and physical reality. These lower levels have no teleological or purposive principles. Although he thus avoids completely divorcing man from nature, insofar as man arises, or emerges, out of nature in this framework, the result is the same: non-teleological nature inhabited by teleological man (Arnhart 2000: 264).

${ }^{81}$ The earlier statement that Aristotle's definition of motion was not arrived at empirically should not be taken to imply that Aristotle's scientific activity floated free of observation of the material world. His method is to begin with objects of ordinary experience, and attempt to explain how or why they are such as they are.
} 
albeit limited to the biological sciences. Life itself, Gotthelf understands Aristotle to be saying, is teleological; all living things have goods proper to them and are internally organized in such a way as to realize them (Ibid.: 386). Gotthelf implies that teleological explanations are necessary because reducing biological explanations to physics and chemistry is "not enough" (Ibid.: 389). This can only be the case if physics and chemistry are themselves non-teleological. This desire to avoid reductionism, which is borne out of a desire to save Aristotelian biology, effectively divorces Aristotelian biology from the more fundamental layers of causality that make it possible, as discussed above.

Be that as it may, Gotthelf articulates a vision of teleological biology that, based on the end-directedness of life, can stand in relative isolation from the presence or absence of cosmic teleology. Specifically, Gotthelf claims that the end-directedness of living things can be explained by the modern discovery of DNA, insofar as DNA coding gives unity, direction, and stability to the development of living things by front-loading, as it were, the goal of the plant or animal's growth (Ibid.: 390). In the terminology of the Physics, DNA is the mechanism by which the potency in the material causes it to reach out toward its end. This is not to say that Aristotle can be credited with the discovery of DNA or modern genetics, ${ }^{82}$ but that his observational insight that living things seem to grow towards a certain goal with relative uniformity has been confirmed - or at least not denied - by modern discoveries; the corollary of this is that modern genetics would appear to confirm the end-directedness of living things.

Arnhart and Masters's Ethical Naturalism, Hassing's regional teleology, and Gotthelf's approach can all be grouped under the broad heading of dualism. Gotthelf provides a useful summary of the position below:

\footnotetext{
${ }^{82}$ Gotthelf refers to the physicist and biologist Max Delbrück's suggestion that Aristotle be given a Nobel prize posthumously "for the discovery of the principle implied in DNA" (Gotthelf 2012: 88).
} 
Final causality is the mode of causation that characterizes human action, and it extends throughout the living world. I believe, too, that it is the goal directed character of life-and the biological basis of that goal-directed character-which provides the foundation for the very concept of value. Understanding final causality is thus essential to understanding man's nature as the distinctive biological entity he is, and to understanding a great part of the natural world of which he is a part, and how his good is to be found in that world (Ibid. 2012: 67).

The main point is that final causality only operates in the living world - that is, within the purview of biology - and distinguishes biological reality from the rest of nature. The obvious benefit of the dualistic approach is that, if true, it pre-empts the claim that Aristotle's findings conflict with modern science. There seems to be a certain plausibility to the claim that DNA, by front-loading the end goal of organic growth from conception, is the mechanism that drives the end-directedness that Aristotle saw at work. In fact, Thomas Nagel, despite having no explicit intention of reviving Aristotle, resorts to teleology to account for what the non-teleological explanations of conscious life with a moral sense fail to explain (Nagel 2012). In other words, if dualism is an acceptable interpretation of Aristotle it would seem to solve the central problem of natural right vis-à-vis modern science.

An initial response to dualism can be found by looking to Aristotle's treatment of the relationship between human and non-human change. While the logic of causality proper to each species of change is different - with change in the human world being driven by an external efficient cause, as opposed to the internal efficient cause of non-human change - which lends initial plausibility to dualism, the two species of change can in fact be quite easily reconciled. As we noted above, Aristotle often embeds one type of cause within another more fundamental framework of causes. Chance is embedded within the more fundamental layer of final causes, and fortune is a further subspecies of chance. Artificial causes more generally are embedded within natural causes such that if there were no natural final causes then there could be no artificial, or human, final causes either. Art, rather than transcending, emerging from, or being 
distinctive of nature, imitates or completes it. "If," Aristotle writes, "what comes from art is for the sake of something, it is clear that what comes from nature is too, for the series of things from art and from nature are alike, each to each, in the way that the later things are related to the earlier" (199a).

The ultimate similarity in the structure of causality holds for the discussion of motion as well. A natural motion like rain comes about when the potency of the clouds to precipitate is at work; an artificial motion like opening an umbrella to avoid the rain comes about when the natural potency of humans for warmth and comfort is at work. In each case the most fundamental potency at work is that of a natural thing. The desire to separate natural from human purposes does not hold up to textual scrutiny, insofar as the potencies which drive motion are, by definition, end-directed in both the human and non-human world. ${ }^{83} 84$

Even assuming that the dualism of Ethical Naturalists and Gotthelf departs from Aristotle, what is the problem? Contemporary Aristotelians should be satisfied with biological teleology, given the historic aversion to purposes in modern science, they might claim. However, the truth is that restricting teleology to biology is ontologically impossible. Once it is conceded that matter, motion, and chemical bonds can be explained non-teleologically, it is hard to see how DNA, to use Gotthelf's example, cannot be reduced to such non-teleological laws. This is one of Arnhart's weaknesses in Darwinian Natural Right: even if it makes sense to describe living things according to their ends, if all living things are constructed out of nonteleological matter, the ends that living things allegedly strive towards can be no more than

\footnotetext{
${ }^{83}$ One must not confuse purposiveness with intentionality or consciousness, as Aristotle never meant to infuse the natural world with spirits or feelings. The language of "striving" or "reaching out towards form" is metaphorical, as is the modern scientific language of natural things "obeying" natural laws. The principal difference between things striving for their proper place and obeying external laws is the question of whether the impulse for motion comes from within (as with Aristotelian potencies) or from without (as in Baconian or Cartesian laws of motion externally determining the behavior of matter.

${ }^{84}$ For example, David Furley has argued that Aristotle intended to explain even rainfall teleologically (Furley 1985).
} 
linguistic constructs or post hoc rationalizations of behaviors that have proven to be successful.

Darwin's theory of evolution, for this very reason, has been said to explain how non-teleological

matter can behave according to stable laws so as to give the appearance of design or purpose. ${ }^{85}$

In sum, if purposes seem to emerge from non-purposive matter and natural laws, purpose can

either be used to explain nature all the way down, as Aristotle does, or it must be written off as

an illusion, as modern materialism does. Nature has given us no reason to maintain such a

dualism, insofar as organic matter is constructed out of and requires inorganic matter.

So far, the analysis of the Physics has been intended to demonstrate that because

Aristotle's aim was wisdom, he attuned himself to whatever was most responsible for the

phenomena. In book II he tells us that "we do not yet know each thing until we have taken hold

of the why of it (and to do this is to come upon the first cause)" (194b); in book III he writes that

an explanation must provide the "necessary condition" (201b) of the phenomenon in question,

referring to whatever is ontologically prior. That is, one has knowledge of something to the

extent that he or she knows what is ontologically prior, or is more truly. Motion is understood in

light of the potency of which it is the being-at-work. Potency, for its part, insofar as it is latent in

the material cause, is drawn up and set into action by the final cause, which is the most

${ }^{85}$ This is admitted by critics and allies of Darwin alike. See the concluding lines of Darwin's On the Origin of Species:

It is interesting to contemplate an entangled bank, clothed with many plants of many kinds, and birds singing about on the bushes, with various insects flitting about, and with worms crawling through the damp earth, and to reflect that these elaborately constructed forms, so different from each other, and dependent on each other in so complex a manner, have all been produced by laws acting around us. These laws, taken in the largest sense, being Growth with Reproduction; Inheritance which is almost implied by reproduction; Variability from the indirect and direct action of the external conditions of life, and from use and disuse; a Ratio of Increase so high as to lead to a Struggle for Life, and as a consequence to Natural Selection, entailing Divergence of Character and the Extinction of less-improved forms. Thus, from the war of nature, from famine and death, the most exalted object which we are capable of conceiving, namely the production of the higher animals, directly follows. There is grandeur in this view of life, with its several powers, having been originally breathed into a few forms or into one; and that, whilst this planet has gone cycling on according to the fixed law of gravity, from so simple a beginning endless forms most beautiful and most wonderful have been, and are being, evolved. (Porter \& Graham 1993: 215).

Likewise Michael Behe, a prominent figure in the Intelligent Design movement, describes Darwin's theory as an explanation of "how unintelligent forces may mimic intent" (Behe 2007: 158). 
fundamental of the causes. In this manner, Aristotle's aim of wisdom culminates in his description of all motions as expressing the being-at-work of a potency striving for its end, or good. Moreover, the above exposition makes the implications for natural right obvious. The goods appropriate to each thing, including man and political orders, are given by nature. Ways of life and political regimes can therefore be judged according to how well they put into motion the ends appropriate to them. Principles of political right are natural, not conventional, as are rules of morality and right conduct.

\section{$\underline{\text { Metaphysics }}$}

The Physics articulates and demonstrates the methodology of Aristotelian science, or how the "why" of a thing can be discovered. We have seen how the four causes, brought together by the final cause, explain the central physical category of motion, namely by reference to the end for which the potencies inherent in each thing move or change. That is to say, the Physics discusses the things to which Aristotelian inquiry is attuned - namely ultimate causes - for the purpose of attaining wisdom. It does not go into detail regarding the question of why wisdom pertains to ultimate causes or why it is preferable to technical - that is, productive or useful knowledge. That task is reserved for his later work, the Metaphysics. This section will flesh out the preceding interpretation of the Physics in a few important ways: it will discuss Aristotle's definition and defense of wisdom, it will analyze the basis of Aristotle's belief that wisdom necessarily refers to ultimate causes, and it will explore his treatment of Plato's theory of forms. The closing discussion of Plato's forms will bring the discussion of Aristotelian science to completion, insofar as the forms occupy the role in each philosopher's thought of ultimate causes. Aristotle clarifies his master's theory of the forms, but never rejects the idea that the 
form of something is ultimately responsible for its being the way it is. This has implications for the doctrine of natural right insofar as forms provide objective standards of flourishing that things, people, and cities ought to attain.

\section{Wisdom}

Joe Sachs translates the first sentence of the Metaphysics as "[a]11 human beings by nature stretch themselves out toward knowing" (980a21), using "stretch themselves out toward knowing" in place of the usual "desire to know." ${ }^{86}$ The imagery is of a newly-sprouted seedling reaching up out of the soil in the direction of sunlight and, awkwardness of the rendering aside, it accurately conveys the role and activity of the human potency for wisdom. Whereas "desiring" may simply refer to an inactive potency for knowledge, "stretching out toward" knowledge suggests that the potency for knowledge is fully at work, not inactive. The crucial difference between inactively desiring and actively stretching out towards is that one may desire something without doing anything to attain it, whereas stretching out towards something implies actively attaining it, or at least striving to attain it. That man's potency for knowledge is active rather than inactive is indicated by our love of the senses; with every act of seeing we bear witness to our love of knowing things for their own sake (980a).

This brief association of seeing with knowing is left aside, however, as sense perception is then made into the first step in the path from seeing to knowing. Sense perception produces memory, which in turn produces experience of particular examples. Knowledge and art come about when meditation on many particulars produces a universal judgment about similar particular cases. This initial definition of knowledge is well within the Platonic tradition that

\footnotetext{
${ }^{86}$ W.D. Ross: "All men by nature desire to know" (Aristotle 1924).

Hugh Tredennick: “All men naturally desire knowledge” (Aristotle 1933).
} 
knowledge can only be of universals, not particulars - although Aristotle does not yet mean the forms specifically. The most accurate and reliable information about particular cases is not knowledge, whatever else it may be. Knowledge, at this point, identifies similarities between particulars, recognizing them as "being of one kind" (981a).

The next step in the argument occurs when possessors of art - i.e. knowledge of universals - are said to be wiser than mere possessors of experience, for the reason that they know the causes of things. This modifies the previous definition of knowledge as pertaining to universals; it now pertains to the causes of things. The logical relationship between universals and causes is left implicit in the text, although it foreshadows the eventual conclusion that one of the four causes of things - thinghood - is the universal articulation of the thing. ${ }^{87}$ This further differentiates knowledge from experience, in that knowers know why a thing is whereas possessors of experience know merely what or that a thing is.

Aristotle completes his definition of wisdom by adding to it the knowledge of origins and sources, which themselves modify the understanding of cause. Both "source" and "origin" imply ontological priority. Book $\mathrm{V}$, which is essentially a glossary of key terms, offers six definitions of " $\operatorname{arch} \vec{e}$ " - the term rendered by Sachs as both source and origin - each of which converges on the common idea of "the first thing from which something is or comes to be or is known" (1013a). There are two things of note in this definition. First, one of the definitions of archē is normative: "that from which each thing might best come into being" (1013a). This continues the theme of the good being ontologically prior to individual phenomena. Second, "that from which a thing is first known" is a source as well, echoing Plato's teaching about the Good as being the cause of the being and intelligibility of all things. Aristotle does not here

\footnotetext{
${ }^{87}$ While Aristotle's developed concept of form is not simply a universal class or definition, this is certainly part of what a form is, as will be shown below.
} 
commit himself to a specific source of being, though he appears to insist that whatever it is will bear responsibility for the existence of all things as well as the fact that we can come to know them. He unites these two observations in his summary of the definition of archē: "for the good and the beautiful are sources of both the knowledge and motion of many things: (1013a).

Wisdom has thus far been defined as knowledge of universals, causes, and sources. Chapter two extends the argument by clarifying the precise kind of sources and causes of which wisdom is the knowledge. It provides an ontological ground for knowledge of causes, establishes the necessary normative component of such knowledge, and argues for the precedence of contemplative over productive knowledge. Aristotle accepts as generally correct the common opinions regarding the wise man, ${ }^{88}$ namely that he has "universal knowledge" of the "first things" and "insight into causes" (982a). These "first things," moreover, are both more knowable and exist for their own sake. This invokes the notion of priority that is at once ontological and epistemological. The first thing, which is the cause or source, does not depend on anything else for its being or motion, whereas everything that exists is contingent upon it. Dependent things are known partly by coming to know the things by which they exist, and the thing that is known entirely by reference to itself - i.e. the first thing - is therefore most knowable. In other words, the first things, which are therefore the true causes and sources, are known by and for their own sake, not for the sake of anything else. More specifically, knowledge of purposes fits this qualification: "the most ruling of the kinds of knowledge, or the one more ruling than what is subordinate to it, is the one that knows for what purpose each thing in general must be done" (982b). The purpose is for its own sake because, by definition, it cannot be for the sake of anything else, or else that thing would be the purpose. In order to

\footnotetext{
${ }^{88}$ The only modification Aristotle makes is to change the relative qualities of the opined wise man into superlative qualities, such as from having more precise knowledge to having the most precise knowledge. See Benardete (1978: 211).
} 
remove all doubt, he specifies that by "purpose" he means "the good of each thing, and in general the best thing in the whole of nature" (982b). This completes Aristotle's argument for the claims that wisdom is of the most originary sources and causes - what I have referred to as ultimate causes - and that the most ultimate cause is normative. To sum up: what is most known for its own sake is most knowable, and the purpose for which each thing should be done is most known for its own sake.

Finally, Aristotle is concerned to impress upon the reader that this is not to be pursued because of any perceived utilitarian value. Indeed, wisdom is explicitly contrasted with knowledge of what might be useful for acting. Experience is knowledge of particulars, and art consists in the generalization from observed particulars to the universal causes that underlie each set of particulars. Experience may be more amenable to action, since action takes place in the world of particulars, but it does not bring about wisdom insofar as it fails to give a reasoned account of the general causes that underlie the particulars (981a). Knowledge of the good, or purpose, of each thing is that to which no cause can be prior; it is therefore "he most ruling kind of knowledge" (982b).

His analogy of knowledge either ruling or obeying is meant on two levels; on the one hand, it is a way of expressing logical priority, but, it also indicates the proper real-world relationship between the different types of knowledge. For example, Aristotle solidifies his distinction between experience and art by pointing to the relationship between a master craftsman and his manual labourer. The manual labourer has a wealth of carpentry experience, but only the master possesses the art required to command the particular tasks of the labourer. The master thus rightfully directs his labourer's activities, as he possesses the knowledge that ought to rule that of his labourer. A similar relationship is described in the Politics' discussion 
of natural slavery ${ }^{89}$ Art, qua knowledge of causes, therefore ought to command experience.

After Aristotle has generalized the experience-art dichotomy into the distinction between productive and contemplative arts, the conclusion is reached that the contemplative arts ought to command and direct the productive arts. The contemplative arts seek knowledge for its own sake, and are therefore not subordinate to anything else, while the productive arts seek knowledge only for extrinsic purposes. They do not command, but must obey and be directed by knowledge of the purposes they ought to serve.

\section{Priority}

Discussed above, but not fully elaborated, is the concept of ontological priority. While Plato does not use the language of logical or ontological priority, this is what he has in mind when he hypothesizes the forms as ultimate causes. He posits them as answers to the question of what is responsible or to blame for the being and intelligibility of each thing; the good itself, in turn, is his attempt to answer the same question for the forms themselves. The being and intelligibility of the visible phenomena is contingent upon the prior existence of the forms - in that way, the forms are logically prior to or more primary than the visible particulars that imitate them. Aristotle, by contrast, is explicit about the importance of ontological priority in scientific explanations. The Metaphysics is littered with examples of priority (as well as the related terms primary and preceding) being used in the service of tracking down explanations or ultimate causes. See, for example, the following lines from 988b, 997a, and 1003b:

For in one sense the most elementary thing of all would seem to be that out of which things first come into being by combination.

\footnotetext{
${ }^{89}$ See especially 1254b: "Accordingly, those who are as different [from other men] as the soul from the body or man from beast - and they are in this state if their work is the use of the body, and if this is the best that can come from them - are slaves by nature. For them it is better to be ruled in accordance with this sort of rule, if such is the case for the other things mentioned."
} 
But now if the knowledge of thinghood and that about these principles are different, which of them are more authoritative and more primary?

And knowledge is always chiefly about what is first, on which other things depend and through which they are named.

The point is the same as it is in Plato: all contingent things are known or explained by reference to the ontologically prior things upon which they are contingent. The four causes, discussed above, are in effect the four ways of isolating what is ontologically prior to, and therefore responsible for, the thing in question.

The eleventh chapter of book $\mathrm{V}$ is devoted to defining the correlated concepts of preceding and following. After pointing out some of the more mundane modes of preceding and following - such as in time, power, or order in the chain of causation - he turns his attention to "things [that] are called preceding and following...in accordance with nature and thinghood" (1019a). This kind of priority, namely having to do with physis and ousia, refers to "things that are capable of being without other things, while those things are not capable of being without them" (1019a; emphasis in original). It is certainly worth emphasizing that Aristotle insists that Plato himself made this same distinction; he does not specify where, most likely because it permeates the Platonic corpus in the same way as it does Aristotle's writing.

This brief definition tells us that something is ontologically prior, preceding, or more primary ${ }^{90}$ if it is capable of being without the things to which it is prior, but this should not be rendered merely chronologically. In other words, ontological priority should not be confused with chronologically priority, which distinction is borne out by the text. As mentioned above, Aristotle lists a number of kinds of precedence before turning to those pertaining to thinghood, only one of which is chronological. Ontological priority is far more complex than a simple

\footnotetext{
${ }^{90}$ These are all terms that are seemingly used interchangeably.
} 
question of which came first. The four causes themselves demonstrate this in a number of revealing ways. The end, which absolutely works as a cause, only fully comes about after the motion of which it was a cause. ${ }^{91}$ Similarly, pure unformed material, or pure potency lacking any attributes or actualities, never exists at all, but is still a cause. Since the pure material cause never truly exists in unadulterated form it is not chronologically prior to anything, but it is still ontologically prior.

Phil Corkum replaces the standard interpretation of Aristotle's notions of ontological priority and independence, ${ }^{92}$ which he thinks gets hung up on the issue of chronological priority, ${ }^{93}$ with a more nuanced articulation (Corkum 2008). Corkum begins by positing that any articulation of ontological independence must satisfy what he calls the "asymmetry thesis," which holds that substances are independent from non-substances while non-substances are dependent upon substances (Ibid.: 67). The standard interpretation of Aristotelian ontological independence ${ }^{94}$ is that ontological independence is the capacity for independent existence: " $\mathrm{A}$ is ontologically independent from B just in case A can exist without B" (Ibid.: 71). On the surface this is a natural reading of $1019 \mathrm{a}$, where Aristotle defines precedence as "capable of being without other things" (emphasis in original). However, and for reasons similar to those given above, Corkum persuasively argues that such a simplistic view does not satisfy the asymmetry thesis.

\footnotetext{
${ }^{91}$ One could reply that although the end was not fully active in time before the motion that brought it about, it was there in potency, such that it truly is chronologically prior to the change. This, however, is a category mistake. The "that-for-the-sake-of-which" (or end) which caused the motion was the not-yet-existing actual thing, not simply the potential for something else to become it. Cf. 1048b: "such as losing weight, for the thing that is losing weight, when it is doing so, is in motion that way, although that for the sake of which the motion takes place is not present." ${ }^{92}$ Independence is, strictly speaking, a different category than priority, although the logical relationship between the two is clear: in order for something to be prior it must also be independent. Thus the following discussion of ontological independence will have direct bearing on ontological priority. What holds for independence will hold for priority.

${ }^{93}$ Corkum's concern is not with chronological priority, per se, but with the capacity for independent existence. However, the capacity for independent existence raises the same problems as chronological priority, in that what has the capacity for independent existence can exist in time before other things that cannot exist without it.

${ }^{94}$ The designation of this view as the standard one is Corkum's.
} 
Using substances and attributes, Corkum demonstrates that there are many B's (attributes) without which A's (substances) cannot exist. For while it is possible for Callias to exist without some particular attributes, such as generosity (in which case Callias is ontologically independent of the attribute of generosity), it is impossible for Callias to exist without propria, defined as "necessary but inessential properties" (Ibid.: 72; emphasis in original), such as visibility. So even though Callias is a substance and visibility is an attribute, he does not possess the capacity to exist independently of it. Similarly, many of these attributes can exist without Callias - generosity, risibility, and visibility can all exist in a universe without the individual Callias. It seems, therefore, that ontological-independence-as-capacity-for-independentexistence does not satisfy the asymmetry thesis.

Corkum therefore proposes an alternative articulation of ontological independence: "A is ontologically independent from B just in case A admits of the ontological status of a being independently of standing in some tie to B" (Ibid.: 77; emphasis in original). On the next page he refines the statement: "A admits of the ontological status of a being independently of standing in some tie to any B whatsoever" (Ibid.: 78). This articulation defines ontological independence as being "classified as beings independently of standing in any tie to anything else" (Ibid.: 78). In other words, a substance is ontologically independent from its attributes because it does not have being in virtue of any of them, whereas attributes have being only in virtue of the substances of which they are attributes. Of note is the implication that this holds even for propria like visibility; Callias, as a bodily substance, cannot exist without the attribute of visibility but he is not a substance on the basis of visibility, whereas the attribute of visibility always requires a substance in which it can be instantiated. 
Corkum admits that his analysis does not provide a full account of what it might mean for something to depend on something else for its ontological status (Ibid.: 80-81), but his account nevertheless demonstrates how to formulate Aristotle's complex notions of ontological independence and priority. It is not enough to look to which things can empirically exist without other things, or which things empirically occur first in time before other things, as this leads to a confusion in which neither substances nor their attributes are ontologically independent or primary. Instead, the important question is "which things exist in virtue of themselves and which exist only in virtue of their relationships to other things?" In other words, the question is ontological, not empirical.

This ontological question is at the heart of Aristotle's conception of natural inquiry. The search for ontological priority led Plato to hypothesize the forms as ultimate causes, and the very same search leads Aristotle along his inquiry into substances as being ontologically primary. Moreover, Aristotle's discussion of substance (ousia in greek; Sachs renders it in English as “thinghood") requires that he reconsider and clarify ${ }^{95}$ Plato's answer to the same question.

\section{Forms}

Rather than providing a full recapitulation of Aristotle's argumentation leading to his position vis a vis the forms, this section will point out the main threads, in order to demonstrate how Aristotle's nuanced theory of forms both refines Plato's thinking and provides an answer to the question at the heart of his conception of natural inquiry, "what are the ultimate causes of things?"

\footnotetext{
${ }^{95}$ My description of Aristotle's approach to Plato's forms as "reconsider and clarify" is contested, to say the least. In what follows, I hope to lend credence to the view that Aristotle systematizes and refines Plato's hypothesis of the forms, instead of rejecting it outright.
} 
Aristotle's discussion of natural science in the Physics provided an account of the four causes and of the ways in which they operate, namely that natural motion - which is ontologically prior to artificial motion - is a product of the potency of matter to reach a certain form. However, the sustained discussion of the nature of matter and form, upon which the account in the Physics depends, is reserved for the Metaphysics, insofar as it is his work on the principles of first philosophy, or "being as being" (1003a). The aim of the investigation is to uncover "being as being," insofar as it is what exists and is known for its own sake. He eventually locates this in a revised articulation of form, by way of the concept of thinghood, or substance.

The first two chapters of book I, discussed above, argue that wisdom is of first causes and of what is known for its own sake. This unites the previous discussion of ontological priority with the overarching concern for ultimate causes. The search for wisdom is the search for what is most primary as well as for what is more responsible for the world's being the way it is, because they are the same thing. The ultimate causes are one and the same with what is most primary, such that to uncover one is to uncover the other. After some preliminary remarks on earlier thinkers' answers to this question and relevant impasses, book IV begins the investigation in earnest. The kind of knowledge Aristotle seeks is the one that "contemplates what is insofar as it is," or in other words, "the sources and highest causes... [that] belong to nature in its own right" (1003a). What is in its own right is defined in the second chapter as the underlying things of which attributes are predicated. Even though we speak of being in many ways, as walking is healthy, as is a body temperature of $98^{\circ}$ Fahrenheit, they are derivative of something else that is in its own right, namely the medical art. ${ }^{96}$ Similarly, a ball is round, red, and small, but those predicates have being on account of the ball of which they are predicated. This is what

\footnotetext{
${ }^{96}$ The example of the medical art is Aristotle's, but the example of the ball is my own.
} 
Corkum's nuanced version of ontological independence was meant to express, namely that the ball - as underlying thing - is ontologically independent of its predicates because it does not have being on account of them, but they on account of it. The things that have being in the most primary sense, then, are independent things of which others can be attributed. ${ }^{97}$ This, Aristotle writes, referring to "what is first, on which other things depend and through which they are named," is thinghood (1003b).

Chapter eight of the glossarial fifth book is devoted to thinghood and, as such, both draws together what has been said up to that point and sets the stage for where the search for thinghood will lead. Thinghood is given a number of related meanings, including primary underlying things, "that which is responsible for the being of a thing," individual things, and the articulation of "what it is for something to be" (1017b). He distills these into two meanings: "the ultimate underlying thing," and "whatever is a this and separate, and of this sort is the form or 'look' of each thing" (1017b; emphasis in original). These seemingly innocuous definitions in fact say a great deal about the nature of thinghood and form. The first thing to note is that they reiterate the connection between priority and causes, insofar as thinghood is both more primary and responsible for things. Second, the well-known departure from the specifics of Plato's theory of forms is indicated here in embryonic form. ${ }^{98}$ Thinghood, what is in the most ontologically primary sense, is in a "this," a term that Aristotle uses to refer to the many individual perceptible things around us; moreover, this is given the designation of form. Although the full delineation of form comes in later passages, it is here said to be a cause and to have being in the true sense,

\footnotetext{
${ }^{97}$ See also 1028a: "[T] hese are more so, because there is something determinate which underlies them."

${ }^{98}$ It should be said that Aristotle does not reject forms as such, but merely clarifies the way in which they should be thought to exist. Thus, Aristotle does not reject the forms outright, but merely clarifies or modifies what a satisfactory theory of forms would look like. Recall Gadamer's statement from the previous chapter: "For it is certain surely, and not seriously doubted by anyone today, that from early on Aristotle was critical of Plato's doctrine of the ideas but nonetheless was, and remained, a Platonist into his late works" (Gadamer 1986: 14).
} 
which connects it to the Platonic vision, but it also has to do, in a way not yet specified, with individual this-es, a possibility that was not entertained by Plato.

Books VII-VIII constitute a single argument devoted to uncovering precisely what thinghood is. He repeats his claim that "thinghood seems most of all to be the first underlying thing," (1029a) and identifies the three candidates for the first underlying thing: material, form, and what is composed of these two. While recognizing the intuitiveness of positing material as the underlying thing, Aristotle argues that such an answer cannot be sustained. His argument is to the effect that particular things existing on their own - "this-es" - have already been agreed to be thinghood, and these are not pure matter-as-potency but matter that has taken on a form. Thus if thinghood consists of independent things, and independent things are more than material itself, then the material on its own cannot be the underlying thing that is thinghood. Moreover, the third option - namely the composite of form and matter - is clearly derivative of form and matter and cannot be the underlying thing that thinghood requires. This leaves form as the only remaining option, and consequently as the subject for the remainder of book VII.

In the final chapter, Aristotle again connects thinghood to ultimate causes as being the goal of inquiry, in a passage that is worth quoting at length:

$[T]$ herefore, one is inquiring why something is present as belonging to something. (That it is present has to be evident, for if that were not so, one is inquiring after nothing.) For example, "why does it thunder?" is, "why does noise come about in the clouds?," for thus it is one thing's belonging to another that is inquired after. Or why are these things here, say bricks and stones, a house? It is clear, then, that one is looking for what is responsible, which in some cases, as presumably with a house or a bed, is that for the sake of which it is, but in some cases it is that which first set the thing in motion, since this too is responsible for it. But while the latter sort of cause is looked for in cases of coming into being and destruction, the former applies even to the being of something (1041a).

The distinction between sorts of causes refers to the distinction between natural and artificial change that is explored in the Physics. What he here calls the former sort of cause is that of ontologically prior natural change. This is the final cause - "that for the sake of which"- 
and, revealingly in the search for thinghood, "applies even to the being of something." The answer to the question "why are these things here a house" is that "what it is to be a house [i.e. the form of house] belongs to them" (1041b). The passage quoted above also entails that the form, in addition to being the thinghood which he is after, is that for the sake of which the materials in question are a house. The specific mechanism behind this was explored in the discussion of the Physics. What the Metaphysics adds to it is that the form, in addition to being one of the causes, is ontologically most primary. This is what allows Gadamer to describe Aristotle as a Platonist in spite of his divergence from Plato.

However, it is not simply a matter of form and matter combining to create a house. Aristotle demonstrates this with the example of a syllable: a syllable is not merely the letters that constitute it as elements, since "BA" is more than the sum of its parts "B" and "A." Moreover, it cannot be some other material element, because the same argument will apply to any number of material elements. Aristotle, here, does not yet give his specific answer, but he insists that whatever it is that makes " $\mathrm{B}$ " and " $\mathrm{A}$ " into the syllable "BA" will be its thinghood and that which is primarily responsible for the being of it (1041b).

In his summation of book VII, Aristotle writes that "it turned out that neither the universal nor the general class is thinghood [and therefore form]" (1042a). He also qualifies the earlier rejection of the thinghood of material in a way that will become important: "in one sense [thinghood] is the material (and by material I mean that which, while not being actively a this, is a this potentially)" (1042a). Material is thus thinghood in potency, and form is thinghood in actuality. From this point on, being-at-work is used alongside form and almost synonymously with it, because as has been pointed out above, the being-at-work of the fully active thing is its thinghood. Now that we know that the thinghood of something is its form, we can infer that the 
form of something is its being-at-work. The final chapter of book VIII draws the conclusion from these considerations that form is "immediately a particular one and a particular being" (1045b). He clarifies in order to remove all doubt: form is "not in the sense of being in a class of beings or ones, nor of being among things that have being apart from particulars" (1045b).

This is all to say that Aristotle's forms do not have being apart from the particulars. However, given Corkum's articulation of ontological independence, the fact that forms are in particular beings does not render them ontologically dependent on them. What it is for them to be is still ontologically prior to their particular instantiation. The materiality of forms is further indicated by Aristotle's concession that material, too, is thinghood, albeit in a potential sense. The potency of material is to be in a particular state or being-at-work. When the potency of the material has given way to form, it has reached a completed state of being-at-work.

The earlier statements about Aristotle's alleged hylomorphism, in the discussion of the Physics, must now be clarified. A thing, or a this, properly understood, is not a conjunction of matter and form, thought of as two separate components existing simultaneously. Material and form are actually two ways of describing the same thing: before it reached its form it was potential, and after that it is being-at-work as its form. ${ }^{99}$ The form, in other words, pertains to a material's state of having reached the end for which it had a potency. "What is in potency," he writes, "and what is in activity are in a certain way one thing" (1045b). That is, when the material, as such, lacks its form it is potency, but when it has reached it it is fully active being-atwork. Sachs writes in a footnote to the text that the conclusions of book VIII are that "(a) form is not an arrangement of parts but a being-at-work of material that has the potency for it, (b) the

\footnotetext{
${ }^{99} \mathrm{Cf}$. "But as was said, the highest level of material and the form are one and the same thing, the former potentially and the latter actively, so that looking for what is responsible for their being one is like looking for a cause of one thing" (1045b).
} 
thinghood of a thing is its form, and (c) the form itself has an internal form/material structure, and is therefore unified as intelligible material-at-work" (Sachs 1995: 165). ${ }^{100}$

Alexandre Kojève compares Plato and Aristotle on this point with remarkable simplicity. Using his Hegelian terminological framework of eternity, time, and the Concept, he situates Plato and Aristotle as two variants of the same possible relation between "the Concept and Time" (Kojève 1980: 101-116). They represent the position that the Concept, which Kojève identifies with forms, is eternal and relates to eternity. The only difference is that Platonic forms relate to eternity outside of time, whereas the Aristotelian forms relate to eternity in time. That is, for Plato the intelligible ideas that can be spoken and thought have their being outside of temporal reality, and in so doing are free from coming into being and passing away. But for Aristotle, the eternal forms have their being in the real existence of perceptible things that come and go in time. The forms themselves are never created or destroyed, but they are ontologically present in the physical being-at-work of the perceptible "this-es" around us. As Kojève writes:

Aristotle saw Plato's difficulties. And at the same time he made a great discovery. Just like Plato, Aristotle defines the Concept as eternal. That is, he defines it as a relation to something else. And this something else for him, as for Plato, is not time but Eternity. (Episteme exists only in the cosmos in which there are ideas - i.e., eternal entities, having Eternity as their topos.) But Aristotle saw what Plato seems not to have seen; namely, that Eternity is not outside of Time, but in Time. At the very least, there is something eternal in Time (Ibid.: 113).

Aristotle's reason for situating forms in the mechanisms of physical change, rather than floating free of change and mutability as with Plato, can be seen in a preliminary statement on the weakness of the specifics of Plato's theory. Keeping in mind that Aristotle agrees with Plato in positing that forms exist and have explanatory power, he says the following about what can be described as the surface reading of Plato's words:

${ }^{100}$ For more on this interpretation of hylomorphism, see Charlotte Witt (1987). 
One might be completely at a loss about what in the world the forms contribute to the perceptible things, either to the everlasting ones or to the ones that come into being and perish. For they are not responsible for any motion or change that belongs to them. But they don't assist in any way toward the knowledge of the other things either..., nor toward their being, inasmuch as they are not present in the things that partake of them (991a).

He goes on to claim that "to say they are patterns and the other things participate in them is to speak without content and in poetic metaphors" (991a).

I specify that this is directed at a surface reading of Plato's words because, as the previous chapter has shown, Plato was at pains to avoid making dogmatic statements about the precise character of the forms. He never claims that they are more than a hypothesis, and his language is such as to never go beyond claiming that something like the forms must be the case. Indeed, in a later dialogue he himself demonstrated an awareness of the problems inherent in positing the forms. With this in mind, it would be imprudent to take Aristotle as here rejecting Plato's framework, but rather as taking his master's preliminary speculations as an invitation to further exploration, systematization, and even adaptation. After dismissing the surface reading of the theory of the forms as "poetic metaphors," he asks the question that his own articulation of the forms will answer: "For what is the thing that is at work, looking off toward the forms?" (991a) As we have seen, the thing that is at work looking off toward the forms is the material-aspotency. In other words, reintroducing matter into the causal equation allowed Aristotle to solve what he took to be the biggest problem with the specific working out of Plato's hypothesis.

Looking back to Socrates' theory of causality in Phaedo 95e-102a, we recall that he makes a crucial distinction between "genuinely the cause" and "that without which the cause wouldn't be a cause" (99b). The "genuine causes" are the forms and "that without which the cause wouldn't be a cause" is the material. The only true cause of a flower's being beautiful is the form of the beautiful, and the material elements are simply what is put together into a beautiful combination of shape and colour. Aside from being a passive bystander upon which 
the form acts, however, the matter contributes nothing to the beauty of the flower, according to the Socratic schema. It is against those who turn this passage in the Phaedo into a dogmatic doctrine of forms that Aristotle writes the words quoted above, and he is right to point out that as long as matter is a passive bystander it is nigh impossible to account for actual changes taking place in nature. His solution was to grant matter the status of being a genuine cause as well. By giving matter a causal role in natural change, by way of its inherent potencies for some forms over others, it becomes much easier to account for efficient causation.

It is not quite clear how the form of the beautiful can cause matter to grow into a flower and become beautiful, but once the bulb is recognized as having a potency that compels it to grow into a flower, given the proper external conditions, the efficient cause of a flower's being beautiful is immediately evident. Moreover, the potency is not for a universal class of things that the material mystically seeks to imitate, but is for a certain arrangement of itself, or way of being as matter. Such a theory of forms remains true to observed changes in nature, to Plato's belief that scientific explanations must uncover the ultimate causes of a thing's being the way it is, and it is able to sufficiently account for all four kinds of cause.

\section{Natural Inquiry and Natural Right}

These considerations make it clear that Plato and Aristotle defend similar conceptions of natural inquiry. They are both interested in knowing what exists for its own sake, which leads them to the ontologically prior forms. Moreover, both Plato and Aristotle trace ontological priority to moral and political categories. The Good is Plato's form of the forms, as it were, and Aristotle argues that knowledge of purpose is the most ruling kind of knowledge. These theoretical claims are corroborated by the fact that their explicitly political works are grounded in 
these ontological considerations. Plato's discussion of the Good is in the context of defining the best way of life for human beings and determining who should be given political power. Similarly, Aristotle's Politics is little more than an application of the four causes of natural inquiry to political questions. What Aristotle calls knowledge of purpose in the Metaphysics is the doctrine of Natural Right in the Politics.

The specific relationship between the ancient conception of science and the doctrine of natural right can now be explored. Though they are closely connected, they are not the same thing. The latter is the doctrine that some things are right by nature rather than convention, and the former is a particular approach to studying nature. Still, we can say that the ancient study of nature opens up the possibility of the discovery of natural right, even though they are, conceptually speaking, different.

The central claim of the ancient conception of science is that knowledge of purpose is "the most ruling of the kinds of knowledge" (Metaphysics, 982b). Productive knowledge of means is a necessary condition of material subsistence but contemplative knowledge of ends is superior because it grasps what most truly is. This is why the master craftsman rules his labourer (Metaphysics, 981a-b) and why knowledge of the Sun is superior to knowledge of observable patterns in the cave (Republic, 516c-d). We can distinguish between knowledge of means and ends and, at the risk of generalizing, say that ancient science concerned itself with ends and modern science with means. Knowledge of the ends of each thing is worth pursuing for its own sake and is therefore more scientific, according to the ancient conception of science. When it comes to political science, this means that knowledge of laws of social or economic behavior, though important for material well-being and social harmony, are subordinate to knowledge of the purpose of the city or the role each citizen ought to play within it. Political science is 
therefore necessarily a moral science, and Aristotle argues that the ends of politics are given by nature.

The first two chapters of Politics book I demonstrate how the Aristotelian study of political phenomena led to the doctrine of natural right. The opening paragraph is worth quoting in full, as the two chapters we will discuss do little else than interpret it:

Since we see that every city is some sort of partnership, and that every partnership is constituted for the sake of some good (for everyone does everything for the sake of what is held to be good), it is clear that all partnerships aim at some good, and that the partnership that is most authoritative of all and embraces all the others does so particularly, and aims at the most authoritative good of all. This is what is called the city or the political partnership (Politics, 1252a). ${ }^{101}$

Final cause, or that for the sake of which, was central to the inquiry of Physics and Metaphysics, and we see it here as well. The city is defined by its telos, understood in normative terms. Moreover, political rule is distinguished from household or familial rule by the ends specific to each. Ruling a polis is fundamentally different than ruling a household because the end of a household is material subsistence but the end of the polis is the good life. This is a clear example of Aristotle's belief that a scientific understanding of a thing must make reference to its end.

We see Aristotle's understanding of material cause at work in the Politics as well. He treats households and villages as material in one sense, and individual citizens as material in another sense. The household emerges from the unity of man and woman - for the sake of reproduction - and master and slave - for the sake of mutual preservation. All of these partnerships exist for the sake of satisfying bodily needs, and are ruled monarchically. The city emerges when several villages unite and become self-sufficient. This self-sufficiency allows

${ }^{101}$ All Politics references are to Carnes Lord's translation (Aristotle 1985). 
them to focus on living well. ${ }^{102}$ Self-sufficiency and living well, Aristotle then suggests, were the ends of all earlier partnerships, which is to say that they exist in the form of material-aspotency for the city.

That these partnerships stretch themselves out toward the city is accounted for by the nature of individual men. Men are political animals, given the faculty of speech by which we can articulate the pleasant, advantageous, and just. Unstated but implied is that men therefore have a potency for justice, or living well. This natural potency can only be fulfilled, or made atwork, in a partnership that is self-sufficient. This natural potency for a political partnership is present in all pre-political forms of social organization due to this human potency, and is what Aristotle had in mind when he wrote that the city was the end of the household and village.

This analysis of the city follows the program for natural inquiry in the Physics and Metaphysics, paying as it does special attention to the material and final causes. The efficient cause is hinted at, namely the desire of individual households and villages to achieve greater economic security, and the formal cause is discussed later in the analysis of constitutions. This brief summary has been enough to show how Aristotelian science can lead to natural right. Investigating political phenomena through the lens of the four causes allows the intimate relationship between material-as-potency and final cause to explain the existence and purpose of cities. Human beings have a natural potency for partnerships that are constituted for the sake of living well, such that even other partnerships - i.e. households and villages - are only completed when they join together to form a city. The correlate of this is that only social partnerships that are for the sake of living well allow men to be fully at work as what they truly are. Central to Aristotle's theory of potency is that the nature of a thing is defined as what it is "when its coming

\footnotetext{
102 This is reminiscent of Aristotle's argument in Metaphysics that philosophy is superior to the arts concerned with
} survival because the former is done for its own sake whereas the latter is not (Metaphysics, 982b). 
into being is complete" (Politics, 1252b). In other words, men are not truly men until they belong to a city. Political association, which entails the rights and responsibilities of citizenship, is thus a better way of life according to nature. The nature of men as political animals dictates that some ways of life are objectively better than others.

\section{Concluding Remarks on Platonic-Aristotelian Science}

The last two chapters have attempted to obtain from the writings of Plato and Aristotle a shared set of scientific aims and attunements. Despite their differences, Plato and Aristotle articulate a practice of natural inquiry that aims for wisdom and is for that reason attuned to the ultimate causes of phenomena. By "ultimate causes" I mean whatever bears the most responsibility for each thing's being the way it is. In the Phaedo Socrates uses the language of responsibility and blame to describe this idea, and Aristotle's Metaphysics refines this notion into the concept of ontological priority. We saw with the help of Corkum (2008) that ontological priority refers to that which does not depend on anything else. To truly understand something is to know on what it depends, and without which it could not exist.

Plato answers this question with his hypothesis of the forms. The beauty of a flower cannot be scientifically explained simply by pointing to the material and efficient causes leading to its growth, but only by pointing beyond particular instance of the flower to the form of the Beautiful itself, of which the flower is only a partial imitation. We then saw in the Republic how the Good is likewise the explanation of the many forms themselves. Their existence and intelligibility must be explained by something prior, and purposes are the only things beyond which nothing is prior. Recall Socrates' claim that purposive explanations are the only 
explanations that do not require further elaboration. Doing something "because it is better thus" is as far back as explanations can go, so to speak.

Aristotle is within this Platonic tradition when he develops his theory of the four causes to answer the same question. The aim of natural inquiry, for Aristotle as well as Plato, is knowledge of ultimate causes. The four causes - material, efficient, formal, and final - together explain everything that can be known of any object of investigation, and final cause is architectonic among them. Final cause is the primary driver, so to speak, of both natural and artificial change. In natural motions - conceived as the actualization of potency - the material is drawn by its intrinsic potency to a particular end; in artificial motions - conceived as the work of humans - the material is arranged according to an end that exists in the mind of the human agents. In both cases the motions are end-directed. Aristotle drives this point home by explaining motion in ontological terms as the being-at-work of a potency. When we recall that a potency is necessarily for a particular end, or circumscribed range of ends, Aristotelian motion (which encompasses everything that happens in the cosmos) is unequivocally end-directed. For him too, like Plato, scientific explanation must culminate in the ends behind the motion under investigation, as they are what bears ultimate responsibility for things' being the way they are. This is not to imply that Aristotle's answer to the question of ultimate causes is the same as Plato's. His doctrine of causality gives the material a clear role in scientific explanations in a way that the immateriality of Plato's forms did not. This is no small difference, about which more will be said below.

One final similarity that is worth highlighting is that each began with observation of the material world around them. Aristotle is sometimes thought to have corrected his teacher's 
tendency to ignore the material world; ${ }^{103}$ there is something to this characterization so long as we do not exaggerate the extent to which Plato looked beyond the world of visible particulars. ${ }^{104}$ Some of the Platonic passages discussed above problematize the interpretation of Plato as having ignored the physical world. For example, the argument from recollection (Phaedo, 72e-77a) implies that observation of visible particulars plays an important role in leading us to the forms. The result of dialectic is knowledge of the immaterial forms, but such philosophical knowledge is not reached by abstracting from observation of the world, but by reflecting upon it. This is a different approach than Descartes', which ignores sensory information altogether and attempts to attain philosophical knowledge from "the simple consideration of the nature of our minds" (Descartes 1997: 124). The converse is true as well. Though Aristotle begins with observations, he does not limit his knowledge to the observable. The categories of empiricism and rationalism, taken from modern epistemology, cannot be anachronistically applied to premodern thinkers like Plato or Aristotle.

There is one major difference between their conceptions of science that is responsible for their different articulations of the meaning of forms. Plato does not impute causal power to material, preferring instead to call it "that without which the cause wouldn't be a cause" (Phaedo, 99b). For Plato the material is a purely passive recipient of the causal power coming from the forms. Aristotle, however, gives the potencies inherent in matter a central role in change. That is why Aristotle's definition of form involves instantiation in material objects, and ultimately why he articulated the four causes as he did, with the material playing an important role. The universal form of something is never abstracted from its particular instance, but

\footnotetext{
${ }^{103}$ Raphael's famous painting "The School of Athens" is a possible example of this portrayal. Plato is shown pointing to the sky while Aristotle gestures to the physical world around us.

${ }^{104}$ An example of this exaggeration can be found in Peter Lipton's off-hand remark in (2001: 4481) that Plato "disdained" empiricism. While he does not give sensible matter a causal role in scientific explanations he nevertheless insists that the path to knowledge, though it must transcend the sensible realm, must still begin with it.
} 
instead is located in the material thing itself whenever a potency has been reached. In other words, we can say that Aristotle's forms exist in their material instantiations because the matter of which they are composed bears responsibility for their coming to be. Material is not simply "that without which the cause wouldn't be a cause," but is one of the four causes itself. However, we must remember that this disagreement with Plato is not a significant departure from a conception of natural inquiry that aims at wisdom and attunes itself to ultimate causes.

While I do not wish to downplay the differences between their articulations of ultimate causes, the argument of this thesis is that their different answers were nonetheless in response to the same question. The aim of wisdom required asking what the ultimate causes are; Aristotle simply corrected what he saw as his master's neglect of matter. We have seen above that Aristotle explicitly criticizes the surface-level interpretation of Plato's forms that completely dematerializes them and thus renders them unable to account for change in the material world (Metaphysics, 991a). Christopher Bruell takes this criticism of immaterial forms, situated as it is in the first book of the Metaphysics, as a critique of Platonism from a former member of Plato's school (Bruell 2014: 27; See also Annas 1977 and Fine 1995 for treatments of Aristotle's criticism of Platonic forms). The argument of this dissertation is in accord with these commentators' claims regarding Aristotle's criticisms of Platonic forms, and has particular sympathies with Bruell's claim that Aristotle rejected Platonic forms precisely because they provided an inadequate foundation for science (Bruell 2014: 27-29). However, it is important to refrain from inferring from these criticisms a larger criticism of Platonism generally. Aristotle recognizes more than one way of speaking about the forms and thus does not unequivocally attribute the most immaterial version of forms to Plato himself. ${ }^{105}$ For this reason it seems more

\footnotetext{
${ }^{105}$ Cf. Bruell (2014: 21): "At a certain point in this chapter, Aristotle ceases to speak of Plato himself, but rather of his followers, whom he calls here "those who posit the forms."
} 
appropriate to treat Aristotle's criticism of immaterial forms as intended to lead readers away from scientifically unhelpful ways of speaking about forms in favour of materially-grounded alternatives. Again, this is not to deny the real change involved in making the forms inhere in matter, or to suggest that Plato would have agreed with Aristotle's modification, but only that his modification was meant as a better answer to Plato's original question.

This dissertation's project is to compare and contrast Plato and Aristotle with Descartes and Bacon. The above claims concerning the similarities between Plato and Aristotle should be understood in the context of a larger comparison between the themes of ancient and modern conceptions of science. The shared Platonic and Aristotelian aim of wisdom persists despite their differences, real and important though they may be. The following comparison with Descartes and Bacon, who share a different set of aims and attunements, will serve to underscore this fact.

Gail Fine also argues that Aristotle's criticisms of Platonic forms are directed against articulations of Plato's arguments that Plato himself might not himself accept as his own. Nevertheless, she claims, Aristotle does this in order to present his alternative (Fine 1995: 28-29). 


\section{CHAPTER 4 - DESCARTES: CERTAINTY FOR THE SAKE OF UTILITY}

Rene Descartes (1596 - 1650) is often, and with good reason, said to be at the forefront of modern philosophy. ${ }^{106}$ With less frequency he is recognized as one of the intellectual founders of modern science. ${ }^{107}$ With even less frequency are his contributions to modern political theory appreciated. ${ }^{108}$ However, these three aspects of his thought are fundamentally connected; modern philosophy had profound implications for scientific inquiry and therefore constituted a radical social and political project. To separate them out for the purposes of analysis would be to make a "distinction of reason," to use a Cartesian term, rather than a "real distinction" (Descartes 1997: 300-302). Cartesian metaphysics is conceptually bound up with the physics of matter in motion, and both are part of his social and political project, which was to provide a method enabling men to transforming nature to make it serve human interests. The

\footnotetext{
${ }^{106}$ Such a statement is a truism among thinkers as diverse as Hans-Georg Gadamer, Roger Scruton, and Bertrand Russell.

Gadamer: "The first telling example for this sense of the philosophical sciences that dominated modern thinking until Kant and Hegel is reflected most clearly in the works of Descartes" (1981: 156).

Scruton: "Rene Descartes..., the founding father of modern philosophy..." (1984: 29).

Russell: "Rene Descartes... is usually considered the founder of modern philosophy, and, I think, rightly" (1961: 542).

${ }^{107}$ Among others, see (Barbour 1997: 3-32; Butterfield 1965: 122-128; Postman 1993: 34-35).

${ }^{108}$ While Leo Strauss himself did not seem to give Descartes much of an explicit role in the formation of the modern political project, some scholars influenced by Strauss have pursued that interpretation, especially Lampert (1993) and Kennington (2004). Lampert and Kennington's interpretations will be explored in greater depth below, since they draw attention to Descartes' relation to Francis Bacon. The Italian Marxist Antonio Negri sees in Descartes' metaphysics a radically new political ontology that adds "to the constitutive reasons of modern politics (which presents itself in the form of the Absolutist state) an evolutionary project for cultural hegemony and the bourgeois domination of society" (2007: 318). Michael Oakeshott's exposition of "rationalism in politics" demonstrates how Descartes' distinctly modern epistemology - that is, his emphasis on method - provides the basis for modern political thought (Oakeshott 1991). In the same vein, in an unpublished paper I have argued that Hobbesian political thought is grounded in an essentially Cartesian epistemology (Chamberlain 2013).
} 
primary purpose of this chapter will be to illuminate these socio-political implications of Descartes' metaphysics.

We will see that though Descartes does not write much that is explicitly devoted to political matters, his philosophical and scientific meditations were not simply meant as fuel for academic disputations; on the contrary, he hoped that they might facilitate mankind's ability to conquer nature and make it serve human interests. The aim of Cartesian natural science is control, or the ability to manipulate natural processes for human benefit, and that in order to bring this to fruition it is attuned to, and understands nature in terms of, patterns of repeatable behavior to which all matter conforms. That is to say that Descartes is a proponent of mastery. This claim points to a significant disagreement in the literature on Descartes. Many commentators in the Anglo-American, or analytic, tradition of philosophy interpret him as first and foremost attempting to establish certainty in questions of metaphysics and theology, as well as working towards a scientific methodology that can more reliably understand natural processes. Reading Descartes as a metaphysician and scientist, however, conceals the political aspect of his thought, which this chapter aims to bring to the surface. There are other interpreters, many, though not all, of them Thomists or Straussians, who see a deeper objective behind the striving for metaphysical certainty and scientific reliability, namely the desire to master nature and make it susceptible to human control. The argument of this chapter aligns with the second group, insofar as it argues that Cartesian science is attuned to laws of cause and effect that are conducive to the goal of mastery.

In order to fully and persuasively articulate such a program for natural science, Descartes had to offer a novel epistemology, based on certainty for the sake of utility, which gave rise to a new understanding of the traditional metaphysical concepts of mind, body, and nature. On the 
basis of this new epistemology and metaphysics Descartes criticized the claims on which Aristotelian natural inquiry was based and replaced them with surrogates that render nature subject to man's will. This is a strongly Baconian project; indeed Laurence Lampert is not exaggerating when he describes Descartes' project as "Baconian Ends [with] Cartesian Means" (Lampert 1993: 146).

The main texts to be analyzed will be The Discourse on Method and The World. The Discourse was Descartes' first published work, and the one in which his rhetoric is most difficult to disentangle from his genuine teaching. One of his stated reasons for writing it was to make him worthy of the reputation he had acquired; this concern for his reputation demands careful interpretation and an openness to the possibility that some statements in it should not be taken at face value. By contrast, he withheld The World from publication for fear of censure and persecution; indeed it was only published posthumously. It contains Descartes' unguarded presentation of his physics, which is the very reason he chose not to publish it while he was alive. References will be made to his other works and letters when they supplement the arguments of The Discourse and The World.

\section{Descartes' Philosophical Project}

In order to make clear what Descartes hoped to accomplish, it will be helpful to draw attention to the few social conditions to which he alerts his readers. After noting how the content of Cartesianism forms a response to these social conditions, we will be in a position to understand the purpose that he sets for inquiry. ${ }^{109}$ In addition to explaining his method "of

\footnotetext{
${ }^{109}$ Marleen Rozemond begins her 1998 study Descartes' Dualism by observing that "consideration of historical context is very instructive about [Descartes'] views and arguments" (Rozemond 1998: xii).
} 
rightly conducting the reason and seeking for truth in the sciences," ${ }^{110}$ he tells of his reasons for writing the Discourse, and for not publishing The World. At the beginning of part two he makes reference to "the wars which are not yet at an end" (Descartes 1997: 77). This refers to the Thirty-Years War, which was largely fought along religious fault lines. Later, he cites "the longcontinued war" as his reason for settling in Holland (Ibid.: 91). ${ }^{111}$ The immediate relevance of these references is not made explicit in the text, although they shed light on Descartes' ultimate goal, which was to provide a means of settling philosophical disputes with such authority and persuasiveness that there could be no doubt about their truth and, therefore, no legitimate means for dispute.

Timothy Reiss' paper on the socio-political context of Descartes' thought is helpful here. In it he attempts to correct what he takes to be the tendency among commentators to interpret Descartes' philosophy a-historically, as “having sprung fully developed from his subjective brow" (Ibid.: 108). As a corrective, Reiss suggests that Descartes' method was formulated at least in part in order to contribute to the resolution of social problems. For example:

By the end of the 1640s Descartes had an equally clear idea of the consequences of Method applied to political dilemmas. In other words, he thought his Method could order authority in a state society, as well as power relations between sovereign and subjects, and among subjects themselves. It is by no means clear that he did not already think this as he wrote the Discourse (Ibid.: 112).

My interpretation is largely in accord with Reiss', especially concerning the connection between political disagreement and method. Since there seems to be no record of Descartes explicitly confirming such a connection, we are left to make educated guesses. However, the timing of the writing, the obvious contrast between the instability of his social situation and the stability of method, when combined with Descartes' repeated references to the importance of

\footnotetext{
110 This is the second half of the title of The Discourse on Method.

111 Timothy Reiss tentatively dates the writing of part I of The Discourse at precisely the midpoint of the ThirtyYears War, between 1627 and 1637 (Reiss 1991: 112).
} 
utility for scientific and philosophical thinking, make this assumption a plausible one. Reiss makes the following suggestion:

From all of this we may safely assume, since the philosopher himself chose to emphasize the events, that during the writing of the Discourse, the instability of the sociopolitical situation, in 1637 no less than in 1619-20 at the very beginning of his original thinking, could be seen only as counter to the stability desired of Method (Reiss 1991: 113).

Though we get no direct affirmation of this from the pen of Descartes, his occasional interlocutor and fellow proponent of method, Thomas Hobbes, is more explicit. The Epistle Dedicatory to The Elements of Law highlights the political utility of method in an age defined by wars fought over religious disagreements. It makes a distinction between mathematical and dogmatic learning and states that only the former is beyond dispute, for it "consisteth in comparing figures and motion only," whereas with dogmatic learning "there is nothing not disputable, because it compareth men, and meddle with their right and profit" (Hobbes 1994: 19). Lacking the results of his method, he continues, "government and peace have been nothing else, to this day, but mutual fear" (Ibid.: 20). Thus, if government is founded on his principles, which are in turn derived from his mathematical method, peace might be achieved.

The method that Hobbes describes is strikingly similar to Descartes'. Both are based on mathematics, both consist of breaking complex questions down into the smallest possible particulars, and both attempt to provide certain knowledge of matters hitherto subject to doubt and faction. The fact that the only political condition Descartes explicitly makes reference to in the work devoted to revealing the aims and intentions is violence occasioned by theological and metaphysical disagreement adds plausibility to the claim that one of the desired effects of his method was political stability in mind. Similarly, the reason he gave for devoting an entire treatise to proving the existence of God and the soul, namely the Meditations on First Philosophy, was that by grounding such theological issues in his philosophical method all would 
agree to accept them - that is, to minimize theological disagreement. One of his motives, then, seems to have been to make philosophical and theological agreement easier to attain.

The second piece of context given is the condemnation of Galileo, with whom Descartes secretly and to a large extent agreed. A common interpretation of the Galileo affair is that he was put on trial for denying geocentrism. ${ }^{112}$ More recent histories of the event have downplayed the extent to which cosmological beliefs were at issue, and instead point to more general political concerns or Galileo's lack of respect for ecclesial authority. ${ }^{113}$ However, Pietro Redondi offers an explanation of the episode that sheds helpful light on Descartes' concern. ${ }^{114}$ Redondi makes the interesting argument that Galileo was in trouble not for denying geocentrism, but for jeopardizing the metaphysical basis of transubstantiation. By late scholasticism, hylomorphism had transformed from the nuanced relationship between form and matter Aristotle discusses in the Metaphysics into a clear doctrine of matter and form as distinct substances. ${ }^{115}$ One of the central issues of religious dispute at this time was the doctrine of transubstantiation: the belief that the bread and wine of the eucharist become the literal body and blood of Christ. In 1551 the Council of Trent declared that the scholastic understanding of substance and accidents was to become the official explanation of transubstantiation, and that any physics must be able to account for change in substance occurring in the absence of a change in accidents. The new

\footnotetext{
${ }^{112}$ As an indicator of the ubiquity of this interpretation, the textbook Public Policy in Canada mentions this in passing as an obvious historical truth (Miljan 2012: 24). John Brooke and Geoffrey Cantor call "the popular mythology of the Galileo affair" the idea that he was condemned for proposing heliocentrism and thereby defying Church teaching (Brooke and Cantor 1998: 106). The last chapter of Harry Frankfurt (2008), entitled "Truth and Reality: The Galileo Controversy," argues that the issue in questions was whether the earth or the sun was at the centre of the solar system. This view received its first English-language exposition in Andrew Dickson White's now infamous A History of the Warfare of Science with Theology in Christendom (White 1897: 130-170).

113 " [W] hat does the Galileo affair actually reveal? It most certainly demonstrates that powerful organizations often do abuse their power" (Stark 2003: 165).

${ }^{114}$ Redondi's argument is discussed in Lampert (1993: 183-187).

${ }^{115}$ Garber summarizes the scholastic doctrine of substance in (1992: 68-70). Also helpful is Rozemond's discussion of the elements the scholastic doctrine of substance as it relates to Descartes in (1998: 103-111). See especially Rozemond's point about Transubstantiation: "Transubstantiation clearly posed problems for Descartes. Various of his correspondents asked how, on his view of qualities, the miracle of the Eucharist should be understood" (Ibid.: 107).
} 
materialist physics was unable to account for such change. Visible and sensible qualities of each thing are simply epiphenomena of their material constituents, such that any change in underlying substance would require a change in outward or visible accidents. Indeed the very terminology of substance and accidents is misleading in the context of Cartesian physics.

Pope Urban VIII knew of Galileo’s materialist physics, and even made him his official scientist (Lampert 1993: 185). When changing political circumstances forced the Pope to go after Galileo in 1632, despite the fact that he was a known heliocentrist long before, he condemned him only for Copernicanism instead of materialism as a way of reducing his punishment (Ibid.). The implication is that denying the basis of transubstantiation was a far graver heresy than challenging the relationship between the sun and the earth, and the only reason Galileo was charged with the latter was to save him from even worse punishment. In other words, the danger of persecution came not from heliocentrism but from the new materialist philosophy espoused by Galileo and Descartes. ${ }^{116}$

One benefit of Redondi's argument is that it draws a clear enough connection between his ideas and the sources of political disorder that one can clearly understand why Galileo was targeted. The issue raised by heliocentrism, namely whether the earth or the sun is the centre of the solar system, has very little explicit bearing on the theological dispute between catholics and protestants. Transubstantiation, however, and therefore hylomorphism, was at the heart of "the wars which are not yet at an end" (Descartes 1997: 77). The denial of the metaphysical basis of the Catholic doctrine of Transubstantiation is a boon to the Protestants, and was thus understandably treated as a serious threat by the Catholic Church. This makes the reasons for Galileo's trial, and Descartes' worries, intelligible, especially since an argument can be made

\footnotetext{
${ }^{116}$ Similarly, Roger Ariew names atomism as a lasting and important threat to late scholastic and early modern ecclesial authorities primarily because of the challenge it posed for the doctrine of transubstantiation (Ariew 1999: 144).
} 
that Descartes did not actually claim that the earth moves. ${ }^{117}$ If the real problem was not the motion of the earth, but the denial of hylomorphism, then Descartes has a much bigger problem on his hands. He could claim plausible deniability for the motion of the earth, by a clever sleight of hand in The Principles of Philosophy, but the core of his physics of matter in motion is a denial of hylomorphism. His central physical thesis that matter alone is constitutive of all things violates the council of Trent's declaration that substantial and accidental change must be distinguished, insofar as change in the physical properties of matter - i.e. accidental change - is all there is.

Descartes does not specify that heliocentrism is the reason for Galileo's trial, writing only that the church "had disapproved of a physical theory published a little while before by another person" (Ibid.: 110). However, as Redondi suggests, Descartes was aware of the true cause of Galileo's condemnation; though this is not confirmed, it is left open, by Descartes' vague description of Galileo's alleged error. Like the importance attributed to the Thirty Years War, no explicit confirmation is given by Descartes. The argument of this chapter does not hang on the historical matter of what precisely Descartes thought Galileo had been accused of, but looking at the matter in this light - which, given Redondi's argument, seems plausible - puts the focus on Descartes' central physical theories instead of his half-hearted support for heliocentrism.

These two contextual clues provide important insight into what Descartes saw as the problems of his time. Theological disagreements had devolved into geopolitical disorder, and to make matters worse, one of the central theological claims under dispute was based on a physical theory that Descartes believed to be false. What these two contextual clues have in common is

\footnotetext{
${ }^{117}$ Part 2, Articles 24-25 of The Principles of Philosophy argues that motion is best understood in relative terms: "We can say that [the same thing] moves and does not move at the same time. For he who is seated in a ship setting sail, thinks he is moving when he looks at the shore he has left, and considers it fixed, but not if he regards the vessel he is on, because he does not change his position in reference to its parts" (Descartes 1997: 320-321).
} 
that they are both problems of scholastic - that is, Aristotelian - philosophy. ${ }^{118}$ The Discourse's explicit criticism of scholastic philosophy brings these together and highlights the deeper problem with it, namely its complete lack of concern for utility or the human good. He compares ancient philosophy to a magnificent palace built on a foundation of sand and mud: although it extols the virtues and makes profound claims, its weak foundation renders everything dubious and therefore subject to dispute (Ibid.: 76). Ancient philosophy is uncertain because of its weak foundation, and because it is uncertain there neither is nor can be consensus or confidence in its conclusions. Moreover, throughout the early sections of The Discourse there is another benefit of certainty: utility. Interspersed throughout part one are seemingly off-hand remarks linking certainty to utility. ${ }^{119}$ For example: "By their means [i.e. letters] a clear and certain knowledge could be obtained of all that is useful in life," and "I was delighted by mathematics because of the certainty of its demonstrations...but I did not yet understand its true use" (Ibid.: 73, 75; my emphasis). Immediately after comparing ancient philosophy to a castle built upon sand, he tells the reader that "I always had an excessive desire to see clearly in my actions and to walk with confidence in this life" (Ibid.: 77). The implication is that the ancients' lack of certainty rendered all of their thoughts useless. It is this uselessness of philosophy that Descartes hoped to overturn by articulating a metaphysics capable of grounding a set of natural laws that govern all matter, thus allowing humanity to control and manipulate the universe.

\footnotetext{
${ }^{118}$ It may be useful here to distinguish between Aristotle's philosophy and "Aristotelianism." Scholastic philosophy was not a carbon copy of Aristotle's thought, but was clearly influenced by it and saw itself as remaining within Aristotle's categories and concerns. For example, Daniel Garber notes that Descartes' education exposed him to "the Aristotle of the sixteenth-century" (1992: 7).

${ }^{119}$ Cf. John C. McCarthy: “'Utility' and 'certainty' are the two watchwords of Descartes' most programmatic writing, the Discourse on the Method" (McCarthy 1994-1995: 248).

Compare also Blaise Pascal's fragment directed against Descartes: "Descartes useless and uncertain" (Fragment \#78 in Pascal 1952). The simple act of combining these two demonstrates the extent to which Descartes was understood to ground utility in certainty.
} 
There is a still more profound source of the ancients' uselessness than the uncertainty of their philosophy. Even if ancient teachings about form, matter, and final cause were true, Descartes will argue, they provide no relief from the sufferings of life. Uncertainty is one of the problems of Aristotelian philosophy, to be sure, and the one that is most immediately to blame for the religious wars, but Descartes' ultimate goal was to propose a new form of natural science that would allow for endless control and management of nature. In other words, the problem is not simply that Aristotle was wrong; the problem was that even if he were right he would not have discovered anything about nature that was of use.

Method is the single most important descriptor of Cartesianism. The title of his posthumously published Rules for the Direction of the Mind is telling in itself. In it he compares those who seek truth without a definite method to a man who wanders the streets in search of treasure, simply hoping to come upon something a stranger happens to have dropped. Such people may occasionally find the truth by chance, "[b]ut however that may be, it were far better never to think of investigating truth at all, than to do so without a method" (Ibid.: 11). He later describes those who do not follow his method as having "some mental defect" (Ibid.: 26).

The specific method laid out in embryonic form in the Rules and clarified in The Discourse is as follows. The first rule is to "accept nothing as true which I did not clearly recognize to be so" (Ibid.: 82). This involves withholding judgment in matters of doubt and uncertainty, and avoiding prejudice entirely. The second rule is to "divide up each of the difficulties which I examined into as many parts as possible" (Ibid.: 82). The third is to move in order from "the most simple and easy to understand...to knowledge of the most complex" (Ibid.: 82). The fourth and final rule is to "make enumerations so complete and reviews so general that I should be certain of having omitted nothing" (Ibid.: 83). For ease of discussion, they can be 
called, in order, the rule of certainty, the rule of division, the rule of order, and the rule of enumeration. The first three rules constitute the method proper, and the fourth is a means of quality control and proofreading to ensure that no mistakes or oversights have been made in carrying out the first three rules. He summarizes the nature and utility of his method as follows:

$[P]$ rovided only that we abstain from receiving anything as true which is not so, and always retain the order which is necessary in order to deduce the one conclusion from the other, there is nothing so remote that we cannot reach it, nor so recondite that we cannot discover it (Ibid.).

This foreshadows his infamous search for indubitable truths upon which more and more complex conclusions are deduced, and highlights the centrality of certainty and order. The importance of certainty in the Cartesian method is well-known, ${ }^{120}$ but equally important is his claim that all areas of knowledge are related in a definite order: "all those things which fall under the cognizance of man might very likely be mutually related in the same foundation" (Ibid.). This is the reason for his emphasis on foundations; a foundation is important not for its own sake but because the rest of the building depends on it. Philosophical foundations are likewise important because everything else that can be known depends on their certainty. In the preface to The Principles of Philosophy he makes the same point with an analogy of a tree:

Thus philosophy as a whole is like a tree whose roots are metaphysics, whose trunk is physics, and whose branches, which issue from this trunk, are all the other science. They reduce themselves to three principle ones, viz. medicine, mechanics, and morals (Ibid.: 269).

Particular areas of science, which produce the fruits of knowledge, are related to metaphysics in the same way that branches are related to roots and that upper stories are related to foundations, namely, in a relationship of dependence. Moreover, like many relations of dependence, the specific qualities of these sciences, and their potential for fruit, are determined by the metaphysics that grounds them. As will be demonstrated below, many of Descartes'

${ }^{120}$ Recall McCarthy's claim that certainty is one of the two watchwords in The Discourse (McCarthy 1994-1995). 
specific metaphysical claims are such as to make possible a physical theory that would allow men to manipulate natural processes for human gain. The nature of the foundations, that is, has a direct influence on the nature of the scientific claims.

He develops his metaphysics essentially according to the above method, with the additional step of removing from his mind everything that he does not know with certainty. ${ }^{121}$ The set of meditations in which he progresses from prejudice to doubt and finally to certainty ostensibly occurred only once in his life, ${ }^{122}$ though it is recapitulated with slight variations in The Discourse, Meditations, and Principles. It is worth noting that his first written treatise, Rules for the Direction of the Mind, does not contain the infamous extreme skepticism. In that text, he satisfies the rule of certainty by appealing to intuitions, by which he means "the conception which an unclouded and attentive mind gives so readily and distinctly that we are wholly freed from doubt about that which we understand" (Descartes 1997: 9). This is a plausible and reasonably safe foundation for knowledge, to be sure, but it is a far cry from his later standard of absolute indubitability.

The Discourse' recollection of these meditations is the most concise of the three, as its purpose is merely to show the results of his method and to provide a foundation for physics. ${ }^{123}$ It begins by introducing his stringent standard of certainty according to which a belief being subject to one iota of doubt is too much, and suggests that sensory information and the apparent truths of reason sometimes deceive us, as can the intuition that we are awake. However, even if everything we believe is a deception, it remains true that there must be some being who is

\footnotetext{
${ }^{121}$ The reason for this initial step's not being listed in the formal method is likely that it is merely a historical necessity, not a logical one. The only reason he must rid his mind of error is that his mind is filled with the errors of his scholastic education and upbringing. Theoretically someone raised in the absence of prejudice could skip this step, whereas no one can skip the four steps of his formal method.

${ }^{122}$ I.E. during his time in Holland, where he settled in 1628 (Descartes 1997: 91).

${ }^{123}$ The Meditations, by contrast, spends significantly more time discussing theological arguments, and The Principles spends more time on problems discussed in the universities, such as universals and the theory of distinctions.
} 
deceived, thus "I think, therefore I am" (Ibid.: 92). His cogito becomes the indubitable first principle that his method requires, pursuant to the rule of certainty. He then follows rules two and three by proceeding in small steps, starting from the cogito, until he is able to make certain pronouncements on important metaphysical themes. The steps are as follows.

Since the only thing that is absolutely beyond doubt is that he is being deceived, and deception is a mode of mind and not of body, he infers that he is essentially a mind, or "a substance the whole essence or nature of which is to think" (Ibid.: 92). His body, if it is even real, is not essential to his continued existence. Knowing that he exists as a mind, however, does not furnish him with the knowledge of the material world that is required in order to manipulate it. In order to do this he investigates what it was that gave him confidence in the cogito, to see if such confidence could be found in any other beliefs that might prove amenable to action. He could believe in his cogito because he saw "very clearly that to think it is necessary to be," and generalized this into the principle that "the things which we conceive very clearly and distinctly are all true" (Ibid.: 92). He then uses his newfound trust in clear and distinct judgements to construct two arguments for the existence of a perfect $\operatorname{God}^{124}$ who is the author of his mental and sensory faculties and would not allow him to be deceived if he used them properly - by properly,

\footnotetext{
${ }^{124}$ Descartes' more extended discussion in the Meditations includes three arguments for the existence of God, though there is much overlap. The question of whether Descartes' actually proves the existence of God need not be settled here, though E.M. Curley provides a helpful analysis of Cartesian theistic arguments, writing that although they do ultimately fail, they are "better than their reputations" (Curley 1978: 125). Lawrence Nolan (2014: 128) similarly argues that Descartes' theistic arguments are "simple, elegant, and relatively plausible." Curley and Nolan ascertain the arguments' reputations mainly from Descartes' contemporaries including Caterus, Gassendi and Hobbes, but a classic statement of the weakness of Descartes' arguments is given by Kant near the end of his famous argument that existence is not a predicate: "Time and labour therefore are lost on the famous ontological (Cartesian) proof of the existence of a Supreme Being from mere concepts; and a man might as well imagine that he could become richer in knowledge by mere ideas" (Kant : 485-486). Within a page Kant goes on to describe the ontological proof as "unfortunate" (Ibid.: 486). Moreover, because Kant argues that even Descartes' cosmological arguments presuppose the ontological argument (Ibid.: 489), Kant's dismissal of the ontological argument can be taken as a dismissal of all of Descartes' theistic arguments. Peter Van Inwagen articulates a revised version of the ontological proof that he takes to be impervious to Kant's critique of Descartes' original (Van Inwagen 2015: 129157).
} 
it is assumed, he means according to his method. It is worth noting that the first argument begins with the recognition of his own imperfection, which the arguments are meant to overcome.

The first argument begins with what he knows with the most certainty, namely that he exists as a mind that thinks, that is, that has and entertains various ideas. By a creative combination of elements of St. Anselm's ontological argument ${ }^{125}$ and St. Thomas Aquinas' cosmological argument, ${ }^{126}$ Descartes formulates what could roughly be called an ontocosmological argument for the existence of God. Taking from Anselm the premise of our idea of a perfect being, and from Aquinas the premise that imperfect or contingent things must be caused by perfect or self-existent things, Descartes infers the conclusion that "this conception [i.e. of perfection] must proceed from some nature which was really more perfect” (Ibid.: 92-93). This nature, furthermore, "had within itself all the perfections of which I could form any idea" (Ibid.: 93). Such a God would not allow men to be deceived if they followed a careful method and only accepted as true clear and distinct judgements and obvious deductions from them.

On a strictly logical basis it would seem that he has sufficiently grounded reason. However, he goes on to present another argument for God's existence, this time drawn from an analogy with geometric objects. Ostensibly drawing even more on Anselm's ontological argument, according to which the conception of God entails his existence, this argument accomplishes an additional theoretical and rhetorical objective. Upon the completion of the onto-cosmological argument, he concludes that what makes geometrical knowledge certain is the clarity and distinctness with which it is known. For example, we clearly perceive that the three angles of a triangle add up to $180^{\circ}$, and that it cannot be otherwise. However, there is nothing about them, as objects of contemplation, that ensures us of their existence. With God, on the

\footnotetext{
125 (Anselm 1998: 82-104).

126 (Aquinas 1998: 249-255).
} 
other hand, that is not so. We can clearly and distinctly know, from the simple contemplation of his character, that he necessarily exists, just as the angles of a triangle necessarily add up to $180^{\circ}$. Geometrical objects are not part of Anselm's original formulation of the ontological argument, and appear to be Descartes' original contribution. It is no accident that the first thinker to build his philosophical edifice on the sure foundation of mathematics so closely unites geometry with divinity. This parallel between geometric and theological truths, and implicit strengthening of confidence in geometrical knowledge, is important for the scientific knowledge of nature because he will later define body as being essentially geometrical, devoid of essential secondary qualities. Because he here places knowledge of geometrical objects next to godliness, so to speak, he is entitled to enormous confidence in his mathematical analysis of nature.

At this point Descartes has completed his demonstration - concerns about the Cartesian circle notwithstanding - of the existence and goodness of God and the incorporeality of the soul. Moreover, he has placated his earlier doubts by placing such claims on an indubitable foundation and buttressing his faith in clear and distinct judgements by an appeal to God. He summarizes the thrust of his conclusions with the following words: "that all things that we very clearly and very distinctly conceive of are true, is certain only because God is or exists, and that he is a perfect Being, and that all that is in us issues from Him” (Descartes 1997: 95-96).

This account of Descartes' movement from complete scepticism to complete certainty is fairly uncontroversial within much of the literature on Descartes. There is some variety among scholars about how to cash out some of the details, but the general picture is very similar. ${ }^{127}$ There is, however, a tendency among many Descartes scholars to treat the above metaphysical

\footnotetext{
${ }^{127}$ Some of these differences will be discussed below.
} 
and epistemological meditations as having been undergone for their own sake, so to speak. ${ }^{128}$

This approach to reading Descartes treats him as a philosophically important thinker primarily on the basis of his refutation of skepticism and his arguments for mind-body dualism. The present chapter seeks to highlight some limitations of this tendency by providing an account of Descartes' philosophical and scientific writings according to which his philosophical work provides the foundation for his scientific project of mastery. Before doing that, however, more needs to be said about the tendency to treat Descartes as being primarily philosophically interesting because of his metaphysics and epistemology.

We can infer the popularity of this interpretation by looking to its many appearances in influential textbooks in the history of philosophy. Thomas Kuhn insightfully observes that textbooks become the standard-bearers of governing paradigms, simultaneously reflecting and reifying the assumptions that a given field takes for granted:

When the individual scientist can take a paradigm for granted, he need no longer, in his major works, attempt to build his field anew, starting from first principles, and justifying the use of each concept introduced. That can be left to the writer of textbooks. Given a textbook, however, the creative scientist can begin his research where it leaves off (Kuhn 2012: 20).

The role of textbooks that Kuhn describes in the natural sciences, holds true, albeit to a lesser extent, in the humanities as well. Though Descartes scholarship is not singly dominated by one paradigm in the way that Kuhn suggests the natural sciences might be, there is nonetheless an approach to Descartes recounted and taken for granted in enough textbooks that it can be described with justice as paradigmatic.

A notable example is Frederick Copleston's A History of Philosophy, first published in 1963:

\footnotetext{
128 This should not be taken to imply that there is no significant disagreement between interpreters of this mould. The affinity resides in the common claim that Descartes' principal aim was to place knowledge of metaphysical truths on a foundation that could withstand the claims of skepticism.
} 
The fundamental aim of Descartes was, obviously enough, to attain philosophical truth by the use of reason. 'I wished to give myself entirely to the search after truth.' But what he was seeking was not to discover a multiplicity of isolated truths but to develop a system of true propositions, in which nothing would be presupposed which was not self-evident and indubitable. There would then be an organic connection between all the parts of the system, and the whole edifice would rest on a sure foundation. It would thus be impervious to the corroding and destructive effect of scepticism (Copleston 1994: 66).

All of the relevant aspects of this approach to Descartes are present here. Descartes is depicted as being concerned with truth for its own sake, and as establishing a method that would allow him to deduce a complete system of indubitable truths. If the foundation - that is, the cogito ergo sum - is secure, then the entirety of his knowledge would be certain as long as every deduction is as clear and distinct as the truths of mathematics. Constructing such a system was his singular focus, and he had no concern for anything beyond making knowledge certain to all who would reason rightly. ${ }^{129}$

This tendency can be seen in scholarly monographs as well. Most such treatments of Descartes' metaphysics and epistemology look to the Meditations on First Philosophy as their primary source, ${ }^{130}$ for the reason that this work most clearly presents the results of the Cartesian philosophical method, without any of the ambiguities or contextual complications of the Discourse on Method. ${ }^{131}$ Harry Frankfurt's study of the Meditations stresses Descartes' defense

\footnotetext{
${ }^{129}$ Many prominent and widely-read histories of philosophy have given similar readings, especially with the rise of analytic philosophy and its singular focus on explicit arguments and epistemological problems. For example, Bertrand Russell's History of Western Philosophy, first published in 1945, Roger Scruton's Short History of Modern Philosophy (1984), and Anthony Kenny's A New History of Western Philosophy (2012), all present Descartes as primarily interested in resolving the problem of uncertainty.

Russell describes Descartes' use of radical doubt to overcome scepticism and establish certainty "the most important in his philosophy" (Russell 1975: 548). Similarly, Scruton argues that Descartes' contribution to philosophy was "his single-minded search for method in all branches of human enquiry" (Scruton 1984: 29). Anthony Kenny likewise summarizes the relevant lessons of The Discourses: "First: human beings are thinking substances. Second: matter is extension in motion....Descartes reaches these conclusions by the application of a method of systematic doubt" (Kenny 2012: 528).

${ }^{130}$ E.M. Curley half-apologetically laments that his book may be taken as yet "another book on the Meditations" (1978: 235).

${ }^{131}$ Harry Frankfurt's Demons, Dreamers, and Madmen: The Defense of Reason in Descartes' Meditations (1970) is the clearest example of this tendency, though Bernard Williams' Descartes: The Project of Pure Inquiry follows the argument of the Meditations in his presentation of Descartes' project as well.
} 
of reason against the sceptics, and nine of the sixteen chapters are devoted to presenting and drawing out the implications of the method of radical doubt. Frankfurt begins with his understanding of Descartes' goal: “Descartes' aim is to guide the reader to intellectual salvation by recounting his own discovery of reason and his escape thereby from the benighted reliance on his senses, which had formerly entrapped him in uncertainty and error" (Frankfurt 2008: 5). In the penultimate chapter, entitled "The Validation of Reason," he makes the same point in a different way by describing Descartes' aim as defeating the skeptical attempt to undermine reason (Ibid.: 242). The intellectual transformation of the "meditator" is framed as one out of common sense into philosophical erudition (Ibid.: 19, and in passim). Being a capable analytic philosopher, Frankfurt is able to clarify the precise logic of Descartes' individual arguments. An example is Descartes' suggestion that we have no reliable way of knowing whether we are dreaming or awake, hereafter called the dream argument. This is often taken to produce the conclusion that we might possibly be dreaming all of the time, though Frankfurt points out that as written the only valid conclusion one can draw is that we cannot with any certainty distinguish being awake from being asleep (Ibid.: 69-73; Frankfurt cites W.H. Walsh's Metaphysics as an example of this misinterpretation).

Frankfurt's analysis is a fairly clear illustration of some of the tendencies that are pervasive in much Anglo-American commentary on Descartes, which will be explicitly presented below. Within the context of these shared tendencies there remain differences of interpretation, however, which are worth clarifying at this point in the argument. It might be helpful to note two examples of disagreement between scholars who work within this framework. This will help us to resist the claim that there is a single interpretation of Descartes against which I am pushing, but it will also demonstrate the kind of interpretation toward which 
these tendencies incline commentators. The first such disagreement, which was mentioned above, is Frankfurt's interpretation and defense of Descartes' dream argument, contra W.H. Walsh. E.M. Curley, in his turn, is unsatisfied with Frankfurt's reading (Curley 1978: 48-51; Frankfurt 2008: 69-73). The issue at hand is whether the proper conclusion to be drawn from the dream argument is that "we may be dreaming all the time" or that "I can never by any certain indications distinguish being awake from dreaming." ${ }^{, 132}$ Frankfurt does not think the first option follows from Descartes' premises and therefore prefers the second. Curley's response is to the effect that even the second option will not satisfy what he calls the "procedural objection" to the dream argument (Curley 1978: 50-51). ${ }^{133}$ Curley argues that Descartes did not set high epistemic standards of proof for the arguments of the first meditation, and our attempt to make them pass through such hoops is misguided (Curley 1978: 50-51). It is not important for this chapter to take a position on this question, but only to note that the parties to this debate share the assumption that Descartes' purpose is to make reliable metaphysical claims, and that if Descartes is to succeed in this task his explicit arguments themselves must be able to withstand logical scrutiny.

The second set of disagreements concerns how best to resolve the problem of the "Cartesian circle," the name given to Descartes' infamous set of arguments whereby reason demonstrates the existence of God while God justifies our reliance on reason. Louis E. Loeb's contribution to The Cambridge Companion to Descartes, entitled "The Cartesian Circle,"

\footnotetext{
132 These are Frankfurt's formulations (Frankfurt 2008: 72), though Curley states them in a roughly similar fashion (1978: 48-49).

133 "What I [i.e. the fictional procedural objector] meant was that the use of a premise like (i) implies, or presupposes, that the person using it knows it to be true, or at least believes it without questions. If he does not, then he is not entitled to use it. And if (ii) is true, Descartes cannot know (i) or even believe it without question. So he cannot be entitled to use (i)" (Curley 1978: 50).

Premise (i) is that "sometimes we take objects to exist in reality when they exist only in our dreams."

Premise (ii) is that "There is no intrinsic difference between illusory dream experiences and veridical, waking experiences." Both are stated at (Ibid.: 48).
} 
identifies "two broad lines of interpretation" among contemporary scholars: the epistemic interpretation and the psychological interpretation (Loeb 1992: 201). The epistemic interpretation holds that the theistically-inspired arguments for trusting clear and distinct perceptions give us epistemic reasons for trusting them; the psychological interpretation, on the other hand, holds that they remove the reason for doubt by making it psychologically impossible to doubt clear and distinct perceptions. Loeb believes that the psychological interpretation has not been sufficiently elaborated, and devotes the remainder of the chapter to filling in this gap. Again, there is no need to take a side here, though later on I will consider a different solution to the Cartesian circle that takes Descartes' broader socio-political project into account. For now it is important to note the way in which each of these solutions, like the debate concerning the dream argument, takes for granted that the import of Descartes' writing lies in his logical solution to epistemological and metaphysical questions. This ignores another possibility, namely that the metaphysical speculations were meant more to provide a foundation for technological science ${ }^{134}$ than to be truthful or indubitable, per se. This will be proposed in due course.

We are now in a position to formulate what I take to be some of the predominant tendencies in the literature on Descartes' metaphysics, and to shed light on the way in which they obscure the social and political implications of his thought. First, Descartes' purpose in writing the Meditations is taken to be theoretical, not practical (Frankfurt 2008: 23). It is read as a book of logical problems written in response to an intellectual challenge to the possibility of reason.

\footnotetext{
${ }^{134}$ By "technological science" I mean a science whose methods are made to match its goal of the mastery of nature. It is not merely a science that produces knowledge that happens to be useful, but one that judges claims by the criteria of utility. In the language of some theorists, it unites making and knowing in a way foreign to premodern conceptions of science (Grant 1986; Heidegger 1977). Tom Darby describes modern science as "the co-penetration of thought (= perception) and action (= practice)" (Darby 2016: 303). What I take him to mean by this is that the meaning of each is set by the other such that, for example, what we take to be scientifically knowable is defined in terms of what we want to do, and the practical aims we have for scientific knowledge. The conception of science articulated by Descartes and Bacon is technological, I will argue, because its aim of mastery set the terms of what counts as scientific knowledge; the truths it discovers are the truths that are required in order to master nature.
} 
To this end Frankfurt draws out the logical subtleties of skepticism as well as Descartes' refutation of it, characterizing skepticism as a "reductio ad absurdum of the assumption that reason is reliable," and Descartes' logical task as showing "that the skeptic's reductio argument cannot be generated" (Ibid.: 242). The success or failure is thus analyzed according to the rules of logical inference alone.

The second theme is the importance of certainty. In fact, according to Frankfurt Cartesian certainty is elevated above the notion of truth; Descartes is not bothered by the possibility of error, per se, but by the fact that his opinions are now doubtful (Ibid.: 34$)$. Drawing on Descartes' reply to an objection, Frankfurt suggests that Descartes is not concerned with the absolute correspondence of one's beliefs to reality, but rather with the immovable sense of certainty we hope for in our intellectual life (Ibid.: 35). Moreover, it is implied that certainty of this sort can be present even when one is in error: "Being certain of the principle that what is clearly and distinctly perceived is true, however, is not the same thing as knowing it to be true" (Ibid.: 237). In the same vein E.M. Curley writes that Descartes was "concerned with the problem of certainty" (Curley 1978: 9). The commonality here is to depict Descartes as being most interested in achieving certainty in metaphysical and theological matters.

Thirdly, and most important, Descartes' philosophical opponent is said to be the skeptic who would undermine the validity of reason. ${ }^{135}$ Based on a technical reading of the Meditations by itself, this is understandable. This explains the centrality of doubt - beating the skeptic at his own game, so to speak - and the single-mindedness with which Descartes pursues a foundation for reason. Near the end of his study Frankfurt evaluates the success of Descartes' arguments by the criteria of how soundly the skeptic has been refuted. He concludes that although his arguments are not circular in the way often thought - that is, due to the Cartesian circle - they

\footnotetext{
${ }^{135}$ Note, for example, the title of Curley's book: Descartes Against the Skeptics.
} 
still rest on a fundamental circularity by which the validity of reason must be assumed in order to demonstrate its consistency. He nonetheless concludes that this is not as big of a difficulty as it might seem, since "[i]t is difficult to see how any 'solution' of this problem could go further than this" (Ibid.: 246).

Much of this can be accounted for by Frankfurt's claim that the Meditations is to be treated as Descartes' most authoritative work, not the Discourse, and he does not even mention the scientific works (Ibid.: 74). The Meditations certainly is the most technical-philosophical of Descartes' major works, so Frankfurt's view is understandable, though by separating it from the context provided in other works he passes over many important themes. The result of all this is that the Descartes of Demons, Dreamers, and Madmen is a truncated version of the original. The lack of concern for practical issues could be corrected by looking to the context given in the Discourse, as discussed above. Here Frankfurt mirrors Gregory Vlastos' near-sighted approach to Plato, in that they both focus to such an extent on the explicit arguments themselves that they miss the larger context of the works in which they appear. More will be said below about how we should treat Descartes' metaphysical arguments, but for now it is enough to point out this similarity to Vlastos.

Frankfurt's study has been discussed at length here because it is an insightful scholarly exposition of some prevailing tendencies in the commentary on Descartes according to which his primary philosophical project was to defeat the challenge of skepticism and provide a solid foundation for reason, which could then go on to settle disputes regarding God and the immortal soul.

The importance of treating skepticism as the primary antagonist of Descartes is worth explicitly stating. The skeptic denies the possibility of certain or reliable knowledge, and thus 
the response to him must provide certain and reliable philosophical beliefs. This is essentially what Frankfurt's Descartes does, as we have seen. The other candidate for primary opponent of Descartes is scholastic philosophy and science, ${ }^{136}$ which according to the Discourse denies the importance of utilitarian benefits of knowledge. If this, rather than philosophical skepticism, ${ }^{137}$ is Descartes' primary object, then the primary goal of his thinking is to treat nature in a way that allows and encourages control over it. If certainty is required to do this, then the ability to make scientific pronouncements with certainty will be sought, but even then certainty is a means rather than the end. We can therefore say that the tendencies explored here lead to the conclusion that Descartes's objective was certainty; it is by making note of Descartes' putting certainty in the service of utility that we are able to present Descartes as a proponent of the mastery of nature. ${ }^{138}$

That the positing of skepticism rather than scholasticism as the primary opponent leads the interpreter in the direction of certainty instead of mastery can be seen in E.M. Curley's Descartes Against the Skeptics. His first chapter, entitled "The Problem," is a historical review of the prominence of skepticism in the seventeenth century, so accordingly Descartes' primary question was the following: "is it possible to work out a scientific account of the nature of things which will be perfectly general, intelligible to everyone, and perfectly certain?" (Curley 1978: 1). ${ }^{139}$ Curley goes beyond Frankfurt in noticing the foundations for Cartesian physics even in the

\footnotetext{
${ }^{136}$ Scholasticism must be understood as the interpretive tradition of authoritative texts, primarily those of Aristotle. That Descartes sees Aristotelian physics as his primary opponent is evident by is repeated mocking and Aristotle's definition of motion before substituting his own definition (Descartes 1997: 50; 1998: 26).

${ }^{137}$ It is worth pointing out how different scholastic philosophy is from skepticism. We might even think of scholastic philosophy as anti-skepticism, insofar as it is criticized by Descartes as being too quick to accept claims on the basis of tradition and authority. This difference is highlighted by Thomas Hibbs' description of Montaigne's skeptical attack on Aristotle and the scholastic tradition of Aristotelianism: "By attacking the opening of the Metaphysics, Montaigne undoes the very possibility of speculative philosophy. He also thereby undermines the entire commentary tradition that reposes on the assumption that Aristotle's approach simply needs elaboration and clarification" (Hibbs 2017: 48).

${ }^{138}$ We will see below that it is not a simple matter of combining certainty and utility; the emphasis will be placed on "moral" rather than "metaphysical" certainty (Descartes 1997: 95).

139 The extended discussion of skepticism can be found on pp. 9-20.
} 
Meditations, though still within the interpretive framework of science for the sake of certainty, not utility.

Marleen Rozemond's study of Cartesian dualism puts Descartes in the proper context of scholastic philosophy (Rozemond 1998). Her interpretation is closer to the mark than Frankfurt's and Curley's, since it begins from the observation that Descartes was responding to scholastic philosophy, not skepticism, per se. She thereby sheds important light on the meaning of Cartesian metaphysics. Since, she writes, “Aristotelian scholasticism...constitutes the most important aspect of Descartes' historical context....the question where Descartes and the scholastics agreed and disagreed is of great significance" (Ibid.: xii). More to our immediate point, she claims that " $[\mathrm{m}] \mathrm{uch}$ of his argumentation is directed against them, and understanding his target improves our grasp of his arguments" (Ibid.; my emphasis).

Her contribution is to shift the focus of Cartesian scholarship away from the simple fact of the distinction between mind and body to the most interesting and relevant redefinitions of those categories which Descartes effected. Plato, Aristotle, and the scholastics had affirmed the dualism of mental and physical substances, but what Rozemond highlights is Descartes' reinterpretation of the meaning of these substances, for the purpose of founding a mechanistic conception of science. The distinction between primary and secondary qualities, ${ }^{140}$ for example, arose out of a desire to explain sensible phenomena mechanistically. More broadly, the redefinition of the pre-modern notion of the soul into the thinking mind allowed nutrition and growth to be explained materialistically, rather than leaving such natural and bodily functions under the purview of a soul (Ibid.: 62).

\footnotetext{
${ }^{140}$ Primary qualities are those like size, motion, and shape; secondary qualities are those like colour, taste, smell, etc. As we will see in the discussion of The World, secondary qualities are explained reductively by the mechanistic primary qualities.
} 
We will see in what follows that the redefinition of the material world brought about by Descartes' mechanistic theory of matter and separation of mind from matter paved the way for, and served to justify, the new science. Insofar as Rozemond makes this explicit, she draws our attention to the ways in which commentators like Copleston, Frankfurt, and Curley tend to downplay some important implications of Cartesian metaphysics. Even her approach, though, could be extended and further developed by contextualizing this relationship within Descartes' overall goal of rendering nature subject to control, which she does not. Only this will put Descartes' metaphysical and epistemological meditations in their proper context.

There are two reasons for this discussion of the above approach to Descartes interpretation. The first is to provide background and context for the more important and controversial part of my argument pertaining to mastery of nature, and the second is to show connections between what even these approaches accept and the physics of mastery. The depiction of Descartes as being primarily concerned with refuting academic skepticism, and possibly with making scientific statements reliable, renders us liable to miss the socio-political implications of his thought. The remainder of this chapter will be devoted to drawing out the connection between much of what is helpful in the commentators referred to above and Descartes' project of scientific mastery of nature.

Desmond Clarke's study, Descartes' Philosophy of Science, suggests that the "standard interpretation" of Descartes puts too much emphasis on his metaphysics to the neglect of his work as a scientist (Clarke 1982: 1). As a corrective Clarke interprets Descartes' science by downplaying the extent to which it follows from his metaphysics. ${ }^{141}$ This interpretive approach is certainly consistent with Descartes' own words to the effect that his primary concern was with

\footnotetext{
${ }^{141}$ Clarke does not completely sever the connection between physics and metaphysics in Descartes, but does heavily modify the depiction of Cartesian physics simply being deduced wholesale from metaphysical principles (Clarke 1982: 77-104).
} 
physics, ${ }^{142}$ however we will see below that his metaphysics makes important contributions to his physics. An either-or approach is liable to miss important facets of Descartes' thought. This chapter therefore stands in between what Clarke calls the "standard" or "canonical" (Ibid.: 1,2$)$ view's emphasis on metaphysics, on the one hand, and Clarke's overcorrection, on the other.

This is to say that the content of Descartes' metaphysics sets the stage for his physics. Curley highlights some of these prefigurations, drawing special attention to the distinction between primary and secondary qualities ${ }^{143}$ and the definition of body as extended, changeable, and intrinsically unthinking - that is, of a different mode of existence than mind (Curley 1978: 207-234). Rozemond, as we have seen, points to the connection between Descartes' revised account of body and the new science (Rozemond 1998: 62). Much has been written about the relationship between the laws of nature and Cartesian metaphysics (Menn 1990; Schmaltz 2008; Gorham 2005; Hattab 2007, 2007). We will revisit this theme later, though we can say for now that most readers take Descartes at face value when he deduces the laws of nature from God's immutability. ${ }^{144}$

I will further highlight two particular ways that Descartes' metaphysics pertains to the project of conquering nature. The first is that Cartesian mind-body dualism introduces a large gulf between man and nature, insofar as man is essentially mind and nature is essentially body. Throughout the demonstrations body, and indeed the entire material world, is given a lower ontological status by virtue of its dubitability, so much so that the material world is eventually rendered superfluous for human existence, insofar as human existence is essentially of the mind (Ibid.: 92). This reduction in ontological status goes hand in hand with, or at least authorizes, the

\footnotetext{
${ }^{142}$ Indeed, the Discourse was originally written as the preface to a collection of scientific writings. The summary of his metaphysics therein was intended to prepare the reader to accept his scientific findings.

${ }^{143}$ We will have occasion to say more about this distinction in the exegesis of chapters 1-3 of The World.

${ }^{144}$ Desmond Clarke is, unsurprisingly, an exception (Clarke 1982: 91-95).
} 
eventual subjugation of nature to human purposes. If what truly or more certainly exists are immaterial minds who experience pain and pleasure, then superfluous matter can and should be made to conform to their will. ${ }^{145}$

Related to this is the characterization of God as perfectly distinct from matter. ${ }^{146}$ God is perfect, and neither matter nor things composed of mind and matter are perfect, so God is therefore simply immaterial. This is an important move; not only is matter not knowable with the same certainty as mind, its nature admits of imperfection in a way that mind does not. Mind is linked with the nature of God, and matter is linked with God's creation, subject to his power and control.

The second implication of his metaphysics prepares the way for his later claim that material bodies are of an essentially geometrical nature. By geometrical bodies we mean, with Garber, "extended things and extended things alone, the objects of geometry made real" (Garber 1992: 63). Garber offers an extended analysis of Descartes' arguments for the geometrical nature of bodies in Descartes' Metaphysical Physics, though without drawing attention to the implications for mastery. For example, the conclusions he draws from Descartes' doctrine of body are limited to mind's ability to have knowledge of external objects; there is no discussion

\footnotetext{
${ }^{145}$ Rozemond has an insightful discussion of Descartes' separation of body and soul, especially viz a vis the scholastics (Rozemond 1998: 38-63). She points out that Cartesian mind is separated from bodily existence in a way that Aristotelian souls are not.

${ }^{146}$ It can be pointed out with some justice that Christian theologians have always conceived of God as being immaterial. This is true, although the scholastic theological tradition, to say nothing of the Orthodox and protestant traditions, nevertheless insisted upon the claim that God became man through the Incarnation of Jesus of Nazareth, and moreover becomes matter every time the sacrament of eucharist is performed. It is unclear how the gulf Descartes introduces between mind and body could account for such claims. Similarly, it is unclear whether Descartes successfully accounts for the unity of mind and body in human beings. It is for this reason that Pascal his contemporary distinguished between the god of Abraham, Isaac, and Jacob, and the God of the Philosophers (http://www.users.csbsju.edu/ eknuth/pascal.html).
} 
of how matter as extended substance might be more easily manipulated or transformed (Ibid.: $92-93) .{ }^{147}$

Although The Discourse does not explicitly argue for geometrical bodies, The Meditations and Principles treat this doctrine as being entailed by his metaphysics. In The Discourse such explicit arguments are passed over in silence, in lieu of providing the basis for geometrical bodies without spelling out the implications. ${ }^{148}$ Descartes' exact reason for doing so is not important, although it likely has to do with his concern for reputation and avoiding unnecessary disputes. ${ }^{149}$

What The Discourse does make explicit, though, is the greater confidence we are to have in geometrical truths than what we perceive through our senses and imagination. Even after revalidating reason by the goodness and power of God, Descartes insists that sensory information is potentially deceptive. The cognitive faculty that is validated by his metaphysics is the mind's ability to clearly and distinctly apprehend geometrical truths. "We should never allow ourselves," he writes, "to be persuaded excepting by the evidence of our reason." However, he immediately specifies that he is only referring to "our reason and not of our imagination nor of our senses" (Ibid.: 96). In other words, not all of his original doubts have been assuaged. He still cannot trust his senses, and he does not know whether he is dreaming or awake. Only the third doubt, his radical distrust of reason itself, has been satisfied. For even in his dreams, distinct apprehensions of geometrical truths can be trusted, being no more false or untrustworthy simply for appearing to him in a dream. Because body is essentially geometrical extension

\footnotetext{
${ }^{147}$ Gaukroger's discussion of Descartes' theory of matter shares much with Garber's account, in addition to making explicit the connection between matter as extension and space as neutral extension, in opposition to Aristotle's doctrine of absolute place (2002: 97-114).

${ }^{148}$ His single description of body in the Discourse is brief: "a space indefinitely extended in length (Descartes 1997: 94).

${ }^{149}$ Garber notes that though this view had been expressed early and later in his career, it is suspiciously absent from in The Discourse (1992: 64).
} 
devoid of other necessary secondary qualities, it can be apprehended by the mind with certainty. It is noteworthy that the only faculty of mind that is truly proven reliable is the faculty required to know the nature of his particular conception of body.

After thus grounding reason, he summarizes his discoveries in physics, which he describes as being "more useful and more important than all I had formerly learned or even hoped to learn" (Ibid.: 97). However, before exploring his candid presentation of his physics, it will be beneficial to examine his treatment of important Aristotelian doctrines.

\section{Descartes' Open Attack on Ancient Philosophy}

It has been noted that Descartes criticized ancient and scholastic philosophy for its weak foundation and subsequent uncertainty, as well as its failure to sufficiently pursue humanitarian aims. These claims form the backdrop of the Cartesian project to transform nature, but there are additional criticisms of the substantive content of ancient philosophy. The content of Descartes' physics and metaphysics directly, and in some cases explicitly, contradicts principles that play crucial roles in the Aristotelian understanding of nature.

Before demonstrating this, however, it is important to qualify the claim that Descartes definitively broke from Aristotle. Though the central argument of this chapter, and indeed the dissertation as a whole, is that the aims and attunements of modern science are fundamentally different than ancient science, this should not be taken to mean that Descartes did not inherit anything from his predecessors. As examples, Enrique Chávez-Arvizo suggests the following two "standard scholastic metaphysical principles, 'nothing comes from nothing' and 'there must be as much reality in the cause as in the effect of that cause"" (Chávez-Arviso 1997: xvii). Even in his scientific work scholars have located relics from Aristotle. The most well-known example 
is Descartes' belief that there can be no natural vacuum (Descartes 1998: 13-16). Desmond Clarke's study of Descartes' philosophy of science goes so far as to call Descartes "an innovative Aristotelian" (Clarke 1982: 197-206), though we might say that he goes too far. He points to, among other things, Descartes' acceptance of the Aristotelian foundationalist model of scientific knowledge, by which truths are inferred from an intuitive foundation (Ibid.: 199). Despite the fact that "the underlying metaphysical theory of essences and forms is eliminated in favour of observable properties which are explained by matter in motion," Descartes emerges as a “qualified Aristotelian" (Ibid.). Such a statement can only arise out of interpretations of each philosopher that fail to acknowledge precisely what this study seeks to establish. Aristotelian practice is here understood as "the accurate observation of common natural phenomena - rather than...a metaphysics of matter" (Ibid.: 200). Likewise, Clarke minimizes the importance of matter in motion to Cartesian science. It is worth reminding the reader of Clarke's decision to read Descartes' scientific work in isolation from his metaphysical work. An implication of this is that the meaning of certain methodological rules is concealed by this failure to understand the latent metaphysical transformations beneath them. The limitation of Clarke's approach will be made evident by drawing attention to some of the relevant metaphysical disagreements between Descartes and Aristotle.

Throughout Descartes' work there is an explicit attack on Aristotle's theory of causality and the definition of motion derived from it. The prominence given to the rejection of final causes is succinctly described by Gaukroger: "Descartes' attitude to teleology, which is shaped by his commitment to mechanism, is firm and uncompromising, and he does not pursue any part of his natural philosophy in terms of purposes and aims" (Gaukroger 2002: 136). Throughout his writing Descartes openly dismisses final cause as being outside the purview of human 
knowledge, though he frames his rejection of it in terms of Christian humility. Unsurprisingly, The Discourse, with its concern for respectability, does not explicitly reject final cause, although the scientific explanations it contains conspicuously make no reference to it. The explicit treatment of final cause is saved for The Meditations and Principles.

Article 28 of part one of The Principles, entitled "That we must not inquire into the final, but only into the efficient causes of created things," conceives of final causes in theological terms. The final cause is God's reason for creating things the way he did. This discussion occurs immediately after God is described as supreme perfection in contrast with the imperfection and sinfulness of man. The important conclusion to be drawn from the difference between God and man is that "we should not take so much upon ourselves as to believe that God could take us into His counsels," by telling us his reasons or purposes (Ibid.: 287-288). Instead, we must be content to think of God as the efficient cause of all created things, and keep our investigation to the effects and patterns of behavior we observe. In contemporary terms, such laws are "brute facts," the reasons for which we cannot see. The fourth meditation contains the same points, with the additional assertion that final cause is of no use for understanding physical things (Ibid.: 164). Garber's treatment of the passage from The Principles dwells on how Descartes' God acts as the sustainer of the universe, now that "universe" has been redefined in purely mechanistic terms. Gone is Aquinas' picture of God upholding the order of the universe through "mediating causes" that must be understood telelogically. For Descartes, God is now "the direct cause of motion and change" (Garber 1992: 274-275). This is seen in the description of God as the efficient cause of things.

There are a few things to emphasize in these passages. The first is that the meaning of final cause has changed. In Aristotle's definition, final cause is intrinsic to each particular thing 
in question. The final cause is the end or purpose of the change or motion, and the direction of such change is always determined ${ }^{150}$ by the nature of the thing in question. The final cause, or end, of an acorn is different from an embryo because they are different substances; this implies that the nature of a particular final cause of a change is partially contingent upon the kind of thing in question. We can call this an internalist view of final cause, in which the final cause of a change is internal to the thing changing. Descartes, however, makes use of an externalist ${ }^{151}$ view of final cause. In his work the final cause is whatever purpose God had for imposing on nature the laws that he did. That is, the final cause operating on an acorn really has nothing to do with the nature of acorns, but only with whatever laws of nature govern the behavior of the acorn. The acorn itself is completely passive, and awaits the action of the laws of nature, which are the real drivers of change and motion. The possibility that there may be some intrinsic relationship between the nature of an acorn and an oak tree is ignored; it just so happens that God designed the laws of nature such that acorns grow into oak trees.

Implicit in this reinterpretation of final cause is an elevation of efficient causality. The only real causes that directly influence the behavior of matter are the laws of nature, which become Descartes' sole efficient causes. Even if final causes did exist, he implies, they would be two degrees removed from the behavior of matter, and therefore scientifically useless. They would only be the reason for the laws' being what they are, but would not themselves offer any additional explanation or understanding. Descartes is aware of this implication, and writes that "the species of cause termed final, finds no useful employment in physical things" (Ibid.: 164).

\footnotetext{
${ }^{150}$ Change is never completely determined by the end of the thing, because it occupies a world of other things with various potencies. There is an interlocking network of essential and accidental causes.

${ }^{151}$ We can define an externalist view of causality as one in which all causal power resides outside of the thing moved or changed. Helen Hattab argues that the laws of nature themselves are the causal agents commissioned by God to move matter in particular ways: "Descartes does not designate bodies but the laws of nature as secondary causes" (Hattab 2000: 108).
} 
The second important point in these passages is that the reality of final cause is never actually refuted. On the contrary, Descartes assumes that God does indeed have a reason for imposing the laws that he does; he simply places them beyond the bounds of science. There are reasons that fire is hot and objects tend to move in a straight line, and these could in theory be traced back to the conscious purposes of God, insofar as a good God presumably designed nature for our benefit. Whether or not men can know why or how, it is surely better for the universe to be governed by the laws it is currently under. No such claim is made, but it is required by the description of final cause as "the ends of God" (Ibid.: 164), who has already been demonstrated to be supremely good, beneficent, and truthful. There is thus an implicit recognition that there are final causes behind everything in nature; Descartes' only interest is in getting the reader to ignore them. ${ }^{152}$

The importance of these points can hardly be overstated, in light of their direct relevance to the overall argument of this dissertation. In the two most explicit discussions of final cause two reasons are presented against its inclusion in science, neither of which amount to even an attempted refutation of its existence. It is part of God's incomprehensible plan for the universe, implying that we cannot know it, and it offers no real explanatory power, implying that we need not know it. In either case, we are better off "regarding [God] as the efficient cause of all things" and to focus our attention on studying causes and effects (Ibid.: 288).

Descartes argues against the scientific utility of formal cause in a similar manner. His complete case against it will be made clear in his discussion of the nature of body, but his

\footnotetext{
152 Thomas Lennon draws a similar conclusion from this passage: "Final causes are proscribed not because they are unintelligible, or vacuous (the upshot of the New Science), or because God has no purposes (Spinoza's later view), but because they cannot be known, at least not by reason alone" (Lennon 2014: 182).

The only difference between Lennon's view and mine is one of emphasis: Lennon sees final cause as being beyond the realm of reason whereas I emphasize Descartes' placing final cause outside of natural science specifically.
} 
discussion of the ball of wax in the second meditation reveals his attitude toward forms and formal causes. The first half of the meditation consists of the inference from the cogito to the belief that man is a thinking substance, and therefore that what the mind perceives is more reliable than what the senses or imagination perceive. He illustrates this with the mental image of a ball of wax. We imagine the physical and sensible qualities of this wax, its sound, odour, solidity, etc., and are forced to admit that as the wax melts all of the above physical qualities which Descartes calls forms, interestingly - disappear. However, the same wax remains, albeit in a different physical form and appearing different to our senses.

The immediate import of this illustration is that our senses cannot be trusted. All of our senses report a different substance after the melting, but our mind knows that the same substance remains under a different form. So far this is standard Aristotelianism, reminiscent of the argument of Metaphysics book IV that attributes are ontologically dependent on an underlying thing that more truly is (Metaphysics, 1003b). However, the precise way in which the implications of the illustration are cashed out reveals a fairly explicit repudiation of Aristotelian formal cause. Matter is here described as appearing in the mode of certain forms, as opposed to actually taking on forms that are ontologically distinct. Cartesian form is treated as a mode of the appearance of matter, not an ontologically distinct entity. Matter may have certain perceptible qualities at one time and not at another, but this is not due to the presence of separate forms, but a change in the material composition of the matter alone. "What remains," he asks, of the melted wax stripped of its former modes of appearance? "Certainly nothing remains excepting a certain extended thing which is flexible and moveable" (Descartes 1997: 145). That is, the visible appearance of the wax, or form, is simply the illusion of our senses. What $i s$ the wax most truly, is extended substance, or geometrical matter. 
He further separates matter from form. Recall that the Aristotelian view was that matter itself is pure potency, or the capability of taking on various forms. Different types of matter are distinguished by the specific forms they are capable of taking on, that is, by their potencies. This was precisely how form became a scientifically useful concept, namely that it helped explain why certain types of matter behave one way while others behave in an entirely different manner. In other words, it is Aristotle's way of explaining why horses do not give birth to dogs (Physics, 191b).

Descartes briefly considers this theory: "Is it not that I imagine that this piece of wax being round is capable of becoming square and of passing from a round to a triangular figure [i.e. the Aristotelian practice of defining matter with respect to its potencies or capabilities]" (Descartes 1997: 145; my emphasis)? He rejects it because matter - according to his definition of it as extension - is capable of infinite changes and variations. ${ }^{153}$ In other words, matter does not have any inherent capabilities, tendencies, or potencies; it is thus scientifically useless to refer to formal cause, if by it is meant the ends to which certain types of matter are naturally drawn by their nature. Again, it is not that forms or formal causes have been disproved by a metaphysical or ontological argument, but simply that matter has been defined in such a way as to render formal cause scientifically useless. In The Discourse he is more candid about his approach: "I even went so far as expressly to assume that there was in it none of these forms or qualities which are so debated in the schools" (Ibid.: 98; my emphasis).

Charles Larmore succinctly states the anti-Aristotelian motive of the Meditations:

In teaching us to detach our mind from its dependence on the senses, the Meditations, he believed, would not only establish the metaphysical truths listed in their subtitle - the existence of God and the real distinction between mind and body - but also serve to validate thereby another anti-Aristotelian component of his thought, namely his

\footnotetext{
${ }^{153}$ Rozemond's analysis is useful here. She highlights the importance of "changeability" to the definition of matter derived from the wax example (Rozemond 1998: 93).
} 
mechanistic physics, which no longer attributed to bodies quasi-mental powers or 'substantial forms' (Larmore 2012: 51).

The third Aristotelian scientific category that Descartes openly attacks is motion. Recall that in a previous chapter Aristotle's definition of motion was presented as the core of his physics. His definition attempted to go beyond the usual circular definition of motion as movement in favour of an ontological understanding of what truly takes place at the level of material, formal, and final causes. Beneath his admittedly confusing definition is the insight that any motion is always toward a definite end, or that it is what potency does that makes it a potency, namely, reach out towards a certain end. This is a fleshing out of, among other categories, formal and final cause. It is not surprising, then, that Cartesian physics, having rejected formal and final cause, goes on to reject the definition of motion that Aristotle derives from them.

Descartes explicitly discusses Aristotle's definition of motion in two places, proposition twelve of Rules for the Direction of the Mind and chapter seven of The World. As he explains his method in Rules, it involves distinguishing between what is known by intuition and what is known by deduction from intuitive knowledge. He calls the truths of intuition "simple natures," and they include things such as figure, extension and motion (Ibid.: 44). It is noteworthy that he selects motion as the simple nature on which to elaborate, and ridicules Aristotle's attempt to define it. The attempt to go behind, as it were, simple natures, instead of treating them as mere brute facts to be observed is misguided from the start. Descartes argues that "in order to know these simple natures no pains need be taken, because they are of themselves sufficiently well known" (Ibid.: 50).

He begins by citing Aristotle's definition of place as “the surface of the body surrounding us" (Ibid: 50; cf. Physics, 212a) and makes two comments on it. The first is that this definition 
obscures the intuitive clarity of place by attempting to define it by more complex categories. The second is a simple refutation of it: "[surface] can so move along with me that, although it continues to surround me, I am nevertheless no longer in the same place" (Descartes 1997: 50).

Descartes then addresses Aristotle's complicated definition of motion, asking whether his readers can understand the definition and, if not, whether they nonetheless understand what motion is, implying that we all understand what motion is despite not being able to make heads or tails of Aristotle's attempt to go behind it. However, unlike the discussion of place, the discussion of motion contains no refutation of the definition, but only the assertion that it is a simple nature, behind which human knowledge cannot reach. This is the familiar pattern of excluding important elements of Aristotelian science on the basis of methodological concerns rather than on the basis of logical or metaphysical proofs.

This passage contains a subtle redefinition of motion, away from the end-directedness of Aristotle. The refutation of Aristotelian place is noteworthy because Aristotelian place is absolute and end-laden. Each thing has a place at which it is at rest, and toward which it strives; fire, for example, has a different natural place than earth. Rejecting absolute place is hand in hand with the overall rejection of the central categories of Aristotle's teleological science. Moreover, by tying motion so strongly to place, Descartes effectively reduces motion to local motion, to the exclusion of the kinds of motion Aristotle allowed for: motion with respect to form, magnitude, etc. (Ibid.: 26).

Finally, immediately after rejecting Aristotelian motion and implying that all motion is local motion, he writes that "the whole of human knowledge consists in a distinct perception of the way in which those simple natures combine in order to build up other objects" (Descartes 1997: 50-51). In other words, it is impossible to provide a definition of motion by reference to 
ends, absolute place, or category which might shed light on the final cause of individual motions. All that we can do is study "the way in which" these simple natures tend to behave. Those wishing to discover "the real nature" of a magnet, for example, must observe all of its effects, or "the way in which" it acts on other bodies (Ibid.).

The discussion of Aristotle's definition of motion in The World occurs in the formulation of the first law of nature, which is that "each particular part of matter always continues in the same state unless collision with others forces it to change its state" (Descartes 1998: 25). This is of course contrary to Aristotelian motion, in which the efficient cause was internal to the thing being moved, not contingent upon the presence or absence of external forces. ${ }^{154}$ Natural things are moved because of a potency intrinsic to the kind of things they are, and they move until they reach their end, at which point they stop and are at rest. Knowing that the law he has posited contradicts the popular Aristotelian definition, he turns to it again. He prefaces this rejection of Aristotle's definition with the claim that no one in the world of common sense would disagree with his stated law of nature, implying his common refrain that Aristotle took what was simple and made it incomprehensible. Once again he mocks the complexity of Aristotle's definition: "[t]hese terms are so obscure to me that I am compelled to leave them in latin because I cannot interpret them" (Ibid.: 26). ${ }^{155}$ He repeats the criticism from Rules For the Direction of the Mind that such a confusing definition is unnecessary because anyone who considers the matter clearly knows what motion is. There is, however, a new element in this passage: he suggests not that Aristotle's definition is wrong, but simply that it must be referring to something other than what Descartes has in mind by motion. "Do not think," he warns, "that I intend to contradict [scholastic philosophers], though; the motion that they speak of is so very different from that

\footnotetext{
${ }^{154}$ This is an idealized depiction. Aristotle grants that outside forces and conditions play a role, but only an accidental one.

${ }^{155}$ Perhaps the $17^{\text {th }}$ century equivalent of "You can't make this stuff up!"
} 
which I conceive that it can easily happen that what is true of the one is not true of the other" (Ibid.: 26). He then makes explicit what he implied in Rules, namely that "I know of no motion other than that... by which bodies pass from one place to another and successively occupy all the spaces in between" (Ibid.: 27). Following this, rest is defined in its turn as "merely a privation of motion" (Ibid.: 26). Recalling Remi Brague's argument discussed in the previous chapter that defining motion as change of place is circular, we see that Descartes falls into that trap, though he would not recognize it as such. Indeed Garber suggests that Descartes' primary problem with Aristotle's definition of motion was that it was a definition at all. "What I would like to call attention to," he writes, "is what Descartes substitutes for the Aristotelian definition of motion: nothing. Once again, he suggests that motion is a basic notion, indefinable" (Garber 1992: 158).

The fact that Descartes goes on to explain all physical phenomena without reference to the Aristotelian theory of motion indicates that he does indeed mean to supplant, rather that supplement, that theory. The discussion below of the laws of nature will go into more depth, but for now let it be said that he rejects Aristotle's theory that motion is teleological and based on the potencies of certain kinds of material for certain forms, and replaces it with a theory of local motion according to which all motion is movement of material from place to place, caused not internally by the potency of the material but externally by laws of nature that God imposes upon purely passive matter. Moreover, not a single argument is given against the Aristotelian view; it is simply ignored for methodological reasons and effectively forgotten. Descartes dismisses Aristotle's views on formal cause, final cause, or the end-directedness of all motion because they fail to provide utility, not because of any metaphysical or empirical shortcomings. 


\section{Descartes' Veiled Attack on Ancient Philosophy}

Now that we have in mind Descartes' open rejection of the ontological claims of Aristotelian physics, we are in position to better understand the significance of the content of Cartesian physics. Immediately after summarizing his metaphysical conclusions in The Discourse, Descartes makes the interesting claim that once he turned his attention from metaphysics to nature he discovered "many truths more useful and more important than all I had formerly learned or even hoped to learn" (Descartes 1997: 97). This admission should give pause to the interpretation of Descartes as being primarily a metaphysician. On the contrary, after summarizing the metaphysical method and conclusions for which he is famous, he claims that his scientific discoveries are in fact more useful and more important. This should not come as a surprise once we take seriously his architectural or tree analogies; a foundation is only useful insofar as an edifice can be constructed on it, and one does not grow a tree for its roots, but for its fruit - in this case, the results of the technological mastery of nature. His metaphysical and epistemological arguments, then, were never his primary concern. He engaged in them in order to advance his project of improving man's estate.

The principal interlocutor to this point in the chapter has been the approach to Descartes that takes the metaphysics of God, the soul, and certainty as the most important aspects of his thought, of which E.M. Curley (1978) and Harry Frankfurt (2008) are examples, as are the popular historical accounts by Copleston (1994), Russell (1975), Scruton (1984), and Kenny (2012). This theme will remain throughout the chapter, but we can now formally introduce a new question, namely “Does Descartes' metaphysically grounded science aim for mastery or reliability?" This is important because not all scholars who stress the relationship between metaphysics and science agree on this. The studies by Garber (1992) and Gaukroger (2002), for 
example, are very thorough but depict Cartesian science as reliability-seeking, and ignore the themes of utility and mastery. The primary focus of the remainder of this chapter will be to demonstrate the inadequacy of this interpretation.

Precisely what in his scientific knowledge was so useful? The laws of nature "which God has so established" (Descartes 1997: 97). This gives us a glimpse of the role his metaphysics plays in supporting his natural science: God is the guarantee that the laws of nature are stable and that we are correct in deducing them. The knowledge of God, in other words, is useful insofar as it grounds the laws of nature. Indeed, John Henry's study of Descartes' use of the laws of nature argues that Descartes' primary purpose for engaging in metaphysical speculation in the first place was to provide sufficient ground for the laws of nature. After calling attention to what he takes to be scholarly silence on the centrality of the laws of nature to Cartesian thought, Henry writes that

it would not have taken Descartes long to realize that he could not claim causal efficacy for his laws without invoking God, and hence his turn to the theology of providence, and a thorough concern with the metaphysical underpinning of his natural philosophy (Henry 2004: 99).

The precise utility of the laws of nature is not given here, but this statement marks an explicit departure from the ancient link between science and wisdom, and replaces it with the modern link between science and utility. The laws of nature become the efficient causes, and “the nature of material objects" (Descartes 1997: 98) refers to Descartes' distinct conception of material cause; together they constitute the extent of Cartesian science. As alluded to above, his science retains two of Aristotle's four causes while dismissing the other two as being explanatorily useless.

The Discourse's summary of The World provides additional clues to what Descartes sees as its important conclusions and implications. There is his assumption - methodological, not 
metaphysical - that there are no forms in nature. Moreover, his executive summary sheds light on the type of explanation he seeks; the only knowledge he seems to have found is of the "how" variety. His approach could be called behavioralism, in that it is concerned with the behavior of matter, bodies, and people, and ignores whatever formal or final causes are behind it. He claims to have shown "how... [the parts of the earth] did not fail all to gravitate exactly to its centre," "how" the tides and oceanic currents are put in motion, "how" the mountains were formed, and no less than nine other processes including the comprehensive "how all bodies, called mixed or composite, might arise" (Ibid.: 99). Clearly, Descartes' summary of his discoveries in the language of processes, behavior, and efficient cause and effect demonstrates his opinion regarding the importance of this knowledge.

Another important point, mentioned above, is the deduction of the laws of nature from the unchanging nature of God. ${ }^{156}$ This does more than simply connect his metaphysics to his physics. The fact that the laws of nature derive from God, when combined with the premise that God is unchanging, produce the conclusion that the laws of nature must be the same in all possible worlds. Not only are the laws that govern matter in this world stable and predictable, they must necessarily be stable and predictable in any world that God might choose to create. This is part and parcel of Descartes' so-called "rationalism," according to which all truth can effectively be deduced from clear first principles, with observation playing a minimal role. The behavior of matter, understood as geometrical figures, can be understood according to mathematical laws that, in principle, do not need to be observed to be known with certainty. At one point in The World, Descartes goes so far as to say that even observations contrary to his geometrical laws of behavior would not dissuade him of their truth, on account of the strength of the reasoning that led him to deduce them (Descartes 1998: 28).

\footnotetext{
${ }^{156}$ More will be said below about the relationship between divine immutability and the laws of nature.
} 
The immediate relevance of the uniformity of natural laws across all possible worlds is that it allows for the introduction of the rhetorical device at the heart of The World. Descartes claims to say nothing specific about the character of our world, but only of a hypothetical world. Any scientific truth that obtains in this hypothetical world would obtain in our own as well, since both are constructed out of the same kind of matter and are governed by the same laws.

Nevertheless, this new world gives him a degree of plausible deniability regarding controversial claims about our world, and it induces readers to lower their guard. As we will see, this new world was created by God as a formless collection of matter that, when initially moved by God, organized itself into something identical to our own world. Knowing that such an evolutionary account of the origin of stars, planets, and life would push the bounds of orthodoxy, he admits that our world may indeed have been created in its current state roughly 6,000 years ago.

That is, he is not interested in origins - presumably because knowledge of origins does not facilitate manipulation of nature - which allows him to concede on the controversial issue of the date of creation. All that matters is the laws that currently govern the behavior of the world, and whether God created the world in its current state 6,000 years ago or as formless matter 6 billion years ago is immaterial to that purpose. The necessary point is that the same laws that govern his imaginary world govern ours. Using the new world as a heuristic device, he can better understand the laws that governed the way in which it took shape, and therefore the laws that govern matter in our world today.

The following discussion of The World will examine the three categories Descartes uses to explain and account for all natural phenomena, namely motion, matter, and the laws of nature, before looking to some of the explanations themselves to see precisely what role those categories play and how they lend themselves to the goal of mastery. 


\section{Chapters 1-3: Local Motion Accounts for All Change and Behavioral Traits}

The first chapter is a prologue of sorts. The primary subject of The World is light, and Descartes knows that his conclusions, which include the view that light is caused by the action of matter upon our eyes, are counterintuitive. In order to prepare the reader for the novelty of his discoveries, he had to pre-empt the objection that an effect, light, could not be different than its cause, matter. In order to cast reasonable doubt on this claim he makes use of the phenomenon of language. Words are nothing but sounds in the air, created by the action of our mouths upon exhaled air. However, when received by our ears, the motions are sent to our brains by purely mechanical means and translated into ideas of things entirely different than the air itself. If causes and effects can be different in the phenomenon of speech, Descartes asks, "why could not nature also have established some sign which would make us have a sensation of light, even if that sign had in it nothing that resembled this sensation" (Descartes 1998: 4). He brings the chapter to a close by insisting that he does not pretend to have settled the matter, but only to have removed the bias in favour of the opposing view and made the reader more susceptible to accepting his own.

Chapter two is an explanation of fire by local motion alone. The argument begins by distinguishing between the categories Aristotle used to explain the behavior of fire, namely form, quality, and action, on the one hand, and local motion on the other. Descartes then asks which of these is essential for the actual burning that the fire accomplishes, suggesting that the form of fire, the quality of heat, and the action of burning, in the absence of the actual agitation of the matter, will accomplish nothing. These Aristotelian categories, he argues, are nothing but 
useless suppositions superimposed on the essential causal factor, namely the motion of matter. ${ }^{157}$ Although Descartes does not highlight his opposition to Aristotle at this point, his argument is essentially that forms accomplish nothing on their own. The physical effects in nature, understood by him to be the movement of corpuscles, are brought into being by matter alone, and can be accounted for without reference to forms or qualities. Again, his argument here is not sufficient to produce the conclusion that the forms do not exist, but only that we can understand the patterns of physical change without worrying about them.

Fire is now to be conceived of as resulting solely from the rapid motion of its corpuscles. The burning action it accomplishes consists of a violent separating out of the wood - or whatever it is that is being burned - into those parts that offer more and less resistance. The less resistant parts are sent up as smoke and the more resistant parts are left behind as ash.

In addition to the primary disagreement with Aristotle, namely the reduction of all motion to local motion, this chapter contains a subtle rejection of the Aristotelian doctrine of natural places to which matter is intrinsically drawn. ${ }^{158}$ Hoping to avoid the doctrine of material potencies, Descartes explains the upward tendency of fire with something resembling the law of least resistance. Bodies, he posits, follow the path of least resistance, and rise when the air above gives less resistance than whatever is beneath. The exact meaning of this law is not yet clear, as Stephen Gaukroger points out in his note on the text (Ibid.: 7n13). Since light is treated as the same type of phenomena as the local motion of corpuscles, the literal meaning of Descartes' law of least resistance would imply that light would reflect off opaque surfaces, at least on the reasonable assumption that air provides less resistance than glass. However, what Descartes

\footnotetext{
${ }^{157}$ Cf. Clarke (1982: 87): “[Descartes] cannot claim to know that there are no such entities as 'the form of fire' or 'the quality of heat'; therefore he relies on the principle of not postulating unnecessary entities in our attempts to explain natural phenomena" (Original emphasis).

${ }^{158}$ Gaukroger rightly points out how Descartes' theory of matter entails disagreement with “Aristotle's doctrine of natural place" (2002: 98).
} 
intends here is clarified by his later suggestion that matter is increasingly rarified at higher elevations. In the example of fire, the highly agitated corpuscles are driven upwards towards the rarified, and therefore less resistant, corpuscles above.

Chapter three continues this mode of explanation and applies it to the solidity and fluidity of all bodies. In another subtle reversal of Aristotle, he writes that "there is nothing anywhere which is not changing" (Ibid.: 9), from which he infers that each body is composed of miniscule parts in continuous motion, beyond the reach of our senses. He passes over the Aristotelian question of first causes, even allowing his readers to assume the existence of "some prime mover...rolling around the world at an incomprehensible speed" (Ibid.), because all that matters to his purposes is that matter is currently in motion.

Anticipating contemporary theories, Descartes argues that solidity is a result of the corpuscles of a body touching, "with no space remaining between any two and none of them in the process of moving" (Ibid.: 10). Fluidity is likewise explained by distance and movement between the primary corpuscles of the body in question. ${ }^{159}$ Adjacency and rest cause solidity, and distance and motion cause fluidity, due to a crude version of the law of conservation of motion according to which all change in motion can only be given to an object from another, from which the motion is transferred. In other words, nothing moves or stops of its own accord, but must be pushed or stopped by another. The corpuscles of a solid body, then, have no inclination to move apart, and will resist separation until pushed by a strong enough force. Corpuscles that are already in motion require less force to be moved in a certain direction, which accounts for their fluidity. The claim that corpuscles do not move unless moved by something external to them is a reversal of Aristotle's causal explanation of motion which, as we have seen,

\footnotetext{
${ }^{159}$ I specify “... between the primary corpuscles” because, as we see later on, there is never any purely empty space. Even the corpuscles that constitute a body of water, being relatively far apart, have more fine and rarified corpuscles between them.
} 
points to the potency internal to the thing moved. In addition to the relative distance and speed of the corpuscles, their size plays a role in determining the nature of the bodies they constitute. Generally speaking, he claims, smaller corpuscles make up fluid bodies while larger corpuscles make up solid bodies. Fire's extraordinary power to separate bodies comes from its combination of large corpuscles with rapid movement. The small corpuscles of air and water do not have the same power to dissolve because they do not collide with the same force as the larger fire corpuscles do. As corroborating evidence of the size of fire corpuscles he points to the fact that fire needs more than air to remain aflame. It requires an additional fuel source with large enough corpuscles to agitate and incorporate.

This kind of explanation is central to modern science, insofar as it explains macro level phenomena as resulting from micro level motions. ${ }^{160}$ The effect that a particular body has on another, for example fire acting upon wood, does not derive from the nature of the body taken as a whole, since that would involve something akin to Aristotelian forms. Instead the macro behavior of the fire is explained by the micro behavior of the corpuscles that comprise it. Neither can final cause be of any use, for it makes no sense to speak of the motion of the fire as having a single end, since it is not the fire qua fire that does anything, but only qua corpuscles. To this end, a single body is defined simply as a grouping of corpuscles "joined together and...not in the process of separating" (Ibid.: 12). In addition to the action of bodies, sight and heat are explained by micro level phenomena. Descartes anticipates Hobbes' dismissal of the ancient and scholastic view that objects send forth "a visible species...the receiving whereof into the Eye, is Seeing" (Hobbes 1987: 86). They both agree, contra Aristotle, that what we see or

\footnotetext{
${ }^{160}$ This distinction recalls the distinction between primary and secondary qualities that Curley notes in the Meditations, where primary qualities like size, motion, and shape, are the causal explanations of secondary qualities like colour and smell (Curley 1978: 208-209).
} 
feel is not the body qua single object, but rather the combined effect of many corpuscles acting on our sense organs.

The example of light points to the second revolution in scientific explanations, namely the fact that causes and effects, though mechanistically linked, are of different categories. The sensations of heat and light are caused by motion, and only translated into sensations by our brain. There is nothing intrinsically bright or colourful about things that appear so to our eyes; such brightness or colour is merely the result of motion sending signals to our brains.

\section{Chapters 4-5: All Matter Essentially the Same}

So far Descartes has accounted for a wide variety of effects on the basis of local motion. The fact that sensations, directional and even compositional change have been explained by local motion alone implies that the characteristics of the matter being moved are secondary, in keeping with his externalist theory of motion. However, in the third chapter he claims that the relative size of corpuscles may have some explanatory power. This leads into his discussion of matter itself and its variations.

Descartes begins the fourth chapter by asking how it can be that, if there is no vacuum, we do not perceive the air around us. He uses the idea of a vacuum as a heuristic device by which to introduce important elements of his theory of matter. He does not claim to decisively prove the non-existence of vacuums, but only that his theory of matter can explain our inability to perceive matter everywhere. ${ }^{161}$

\footnotetext{
${ }^{161}$ Clarke suggests that the purpose of this chapter is to support the thesis that there can be no vacuum in nature (1982: 89). However, this likely results from his downplaying of the relationship between metaphysics and science. My approach holds them together and is thus more attuned to metaphysical implications. See also (Ibid.: 112): "So far in this section I have ignored questions about the relationship between physical hypotheses and metaphysics, and have avoided the troublesome grey area where an explanans is no longer unambiguously a physical hypothesis" (Original emphasis).
} 
He begins his answer by stating an outright rejection of the ancient view of matter: "all bodies, whether hard or fluid, are made from the same matter" (Descartes 1998:13). All that distinguishes the characteristics and behavior of bodies, we know from the previous chapter, is the size and velocity of the corpuscles. Descartes now introduces the idea that the spaces between the larger corpuscles are filled with smaller ones, such that there is absolutely no empty space in nature. The universe is, thus, of a definite size, and is filled with a definite amount of matter. The tendency of nature to avoid a vacuum is not due to any inclination or desire on the part of matter, Descartes writes in a shameless misrepresentation of Aristotle, but to the fact that there simply is not enough room in the universe to allow for empty spaces (Ibid.: 15). Liquids remain in inverted casks, not because a vacuum would be formed in the cask, but because the space outside the cask is already full. The same cause explains rainfall and the operation of water pumps. It is noteworthy that every phenomenon explained here pertains to rising and falling, which Aristotle explained by natural tendencies of different types of matter.

He returns to the ostensible question of the chapter by asking how it is, if all space is equally full of matter, that we do not feel the air. His answer is that it is not pressure itself that registers as sensation in our minds, but changes in the amount of pressure we feel. The corpuscles of the air are constantly pressing on our skin, but we do not feel them until a gust of wind increases their pressure. This answer gives a plausible account of the question he has posed, although there is another, equally important question that he does not ask and only hints at an answer, namely the lack of resistance we feel in the air. It is unclear why he does not explicitly raise this problem, although an answer can be easily gleaned from his theory. He has already differentiated hardness and fluidity according to the distance and motion of corpuscles, and in this chapter he uses circular motion to account for the filling up of vacated spaces: as a 
body moves from one space to another, the surrounding corpuscles are pushed into a circular motion that fills up all spaces. ${ }^{162}$ Air's relative lack of resistance can be explained by its relative fluidity and the smaller amount of force required to move its corpuscles and initiate circular movement to fill all the spaces. The final paragraph points to the upshot of the chapter, by using the scholastic concept of rarity to describe his depiction of nature as a jar filled with different sized corpuscles. He defines a rare body as one in which "there are many small gaps between the parts of which [it] is composed" (Descartes 1998: 16).

Chapter five, which in the original 1664 publication was entitled "The reduction of the four Elements to three, with an explanation and establishment of them," accomplishes two objectives. First, it confirms his classification of matter, although it would be just as accurate to describe the elements as one, not three, due to their essential similarity in all things except size and rarity. Second, Descartes uses his taxonomy of elements to consolidate his case for a reductive materialism, according to which all qualities and traits are epiphenomena of matter.

The three elements are fire, air, and earth. Fire, by which he means simply the most rarified substance in the universe, not literal flames, ${ }^{163}$ is composed of the smallest and fastest moving corpuscles, whose speed allows them to be divided and contorted in order to fill up any space and pass through the smallest openings. Air corpuscles are slightly larger and therefore require smaller fire corpuscles to fill the gaps. Earth is larger and slower moving, and thus more prone to a solid state.

In describing these elements according to physical characteristics alone, many qualities are omitted. That is because all other qualities are determined by matter. They can all, Descartes

\footnotetext{
${ }^{162}$ In the familiar Cartesian pattern, this use of circular motion reverses Aristotle's causal logic. In the Pysics, Aristotle explains a body's continued movement after it has left the object that pushed it (i.e. the phenomenon now explained by the law of inertia) by circular movement of the air that continued pushing the body from behind (215a, 267a). For Descartes, the circular movement is effect, not cause, of the body's movement.

${ }^{163}$ Descartes will later make a distinction between the element of fire and "everyday fire" (Ibid.: 19).
} 
writes, "be explained without the need to suppose anything in their matter other than motion, size, shape, and the arrangement of its parts" (Ibid.: 18). All bodies, therefore, are composed of some combination of these types of corpuscle, and all qualities and tendencies can be explained by said combination. The tendency of solid bodies to fall and rare bodies to rise, for example, is explained by the tendency ${ }^{164}$ of matter to reduce itself to its pure form and unmix itself, as it were, with other elements. In other words, solid bodies tend toward other solid bodies, and vice versa for rare bodies. No argument is given for why or how bodies have this tendency, although it is unambiguously a rejection of the Aristotelian doctrine of natural places to which objects are drawn. Earth has no natural tendency down, or fire up, but simply tends toward other bodies of the same elements. It is unclear why Descartes would simply assert such a tendency without argument, although it appears that its purpose was to pacify his Aristotelian readers. He claims not to reject the doctrine that things have natural places, but simply to be "offering a more economical account of the elements," as Gaukroger puts it (Ibid.: 19n37). However, the fact that his defense of natural place is entirely without argument casts doubt on the extent to which Descartes himself believed it. A possible explanation is simply that he framed his reductive materialism as an alternative account of traditional theories in order to render it more acceptable.

\section{Chapter 6-7: Laws of Nature}

The first five chapters have established the materialist assumptions required to explain the character of the physical world according to laws of matter in motion. Although Descartes does not explicitly offer an externalist account of motion, he has laid all the necessary groundwork. The difference between internalist and externalist explanations of motion, referred to throughout this chapter, is expressed by Garber in the following manner:

\footnotetext{
${ }^{164}$ Of course, this "tendency" is simply imposed on it by God.
} 
For the schoolmen, each kind of substance had its characteristic behavior, determined by its substantial form; water tends to be cool, fire hot, air tends to rise, and earth fall. Descartes, of course, cannot appeal to such characteristic behaviors. For him, the characteristic behavior of body as such, corporeal substance, is given by a series of laws of nature. Since, as noted above, all change is grounded in local motion, these laws of nature are, in essence, laws that govern the motion of bodies (Garber 1992a: 310).

The Aristotelian and scholastic doctrine that "each kind of substance had its characteristic behavior" implies the teleological view of nature that Descartes rebuked as useless. It relies on the potency of different types of material, and thus the Cartesian replacement gave sole agency to external laws of motion acting upon purely passive matter.

Recall Helen Hattab's claim that laws of nature are themselves the causes of the motion of bodies (Hattab 2000: 108). This interpretation is consistent with Descartes ontology, according to which matter is nothing but passive extension. Bodies themselves have no power to do anything on their own, owing either to the material nature or inherent potencies, but can only act if acted upon by external agents. Hattab recognizes that this conception of laws as causal agents seems strange, since "laws are not normally thought to possess any agency and, at most, are said to describe the forces in matter" (Hattab 2007: 49). However, she maintains that hers is the only statement of Cartesian natural laws that is consistent with his metaphysics. However, Tad Schmaltz has argued, contra Hattab, that "the internal bodily forces and inclination... are themselves responsible for changes in the distribution of motion" (Schmaltz 2008: 115). Hattab's interpretation is born out of her explicit wish to take Descartes' materialist ontology of matter as pure extension seriously (Hattab 2000: 95-97, 116; 2007: 49, and in passim), whereas Schmaltz is evidently more willing to modify it when it conflicts with Descartes' scientific explanations. Hattab does not refer to Schmaltz by name, though she accuses some interpreters who introduce causal powers into matter as "amending Descartes' metaphysics" (Ibid.: 50). 
The question is whether causal power lies in bodies or laws. For Hattab, the laws of nature possess all causal power, and bodies are purely passive. For Schmaltz, bodies possess some causal power. My argument aligns with Hattab, insofar as it is attuned to the ways in which Descartes metaphysics paves the way for his natural science. However, even Schmaltz' position is consistent with the fact that the content of laws of motion is not entailed by type of body. He insists on the necessity of bodily force in order to make sense of Descartes' scientific explanations, though the precise effect that the force of one body has on another body - even if we give causal power to bodies themselves - is still not determined by the nature of the body in question but imposed on it from God. That is, even Schmaltz' view makes the behavior of bodies arbitrary, in that it could have been otherwise of God intended it to be. He summarizes his view in the following manner:

For Descartes the bodies in motion that God continuously conserves have as modes of their duration various forces that determine the outcomes of collisions, just as the motion that he conserves has as modal features of itself various inclinations that determine not only how it would proceed if unimpeded, but also certain effects that a moving body actually does have (Schmaltz 2008: 121).

So the power to move and behave in particular ways resides in bodies, but there is nothing in this account that explains how or why particular kinds of body have the forces they do, rather than other forces. In the final analysis, the modes are still determined by an external source, namely God.

With the sixth chapter Descartes turns directly to his primary aim, namely the creation of an imaginary world in which to present the laws of nature. We can infer that this is his primary aim from the fact that his summary of The World in part five of The Discourse begins at this point. The importance of the fact that he describes an imaginary world has been mentioned above; also worth mentioning is that he admits here that he simply assumes the non-existence of forms. Having taken the liberty of "imagining this matter as fancy" (Descartes 1998: 22), he can 
easily assume that this world has no forms or ontologically separate qualities over and above the matter he has described.

In the process of describing this new world we see key elements from The Discourse. He methodologically excludes forms and qualities for the familiar reason that he wished to give to the imaginary world "nothing that everyone cannot know as perfectly as possible" (․ㅏid.). Further on, he writes that the initial chaotic state in which God created the world "contains nothing which you do not know so perfectly that you could not even pretend to be ignorant of it" (Ibid.: 23). Whether or not his scientific theories truly satisfy his criteria of indubitability, he apparently believed they did. He ends the chapter by suggesting that everything it contains can be "imagined distinctly" (Ibid.: 24).

Moreover, he defines body in geometrical terms, at one point claiming that the very "form and essence" of body is extension in length, breadth, and depth. This is a direct result of the metaphysics of The Discourse, and provides a strong link between his metaphysics and physics.

Finally, the importance of motion and its laws is said to be derived from the supremacy of God, so central to the metaphysics of The Discourse. The strongest statements of the causal efficacy of the laws of motion are framed in such a way that they are derived directly from God:

Let us think of the differences He creates within this matter as consisting wholly in the diversity of the motions He gives to its parts....For God has established the laws in such a marvellous way that even if we suppose that He creates nothing more than what I have said, and even if He does not impose an order or proportion on it but makes it of the most confused and muddled chaos that any of the poets could describe, the laws of nature are sufficient to cause the parts of this chaos to disentangle themselves and arrange themselves in such a good order that they will have the form of a most perfect world (Ibid.: 23).

Grounding the nature of matter and the efficacy of the laws of nature in God's activity allows him to assign a high degree of stability to natural processes; God, being unchanging, will not arbitrarily change the laws of nature. He explicitly does this in the seventh chapter, at the 
beginning as well as throughout the exposition of the laws of nature. Its purpose is to describe three of the "principle rules by which we must believe God to cause the nature of this new world to act" (Ibid.: 25), although he admits there are others.

The first law is that "each particular part of matter always continues in the same state unless collision with others forces it to change its state" (Ibid.). This is a clear statement of the externalist theory of motion: motion or change never originates from within a thing itself, but is always imparted to it from an external source. Matter was originally moved by God, and now all things in motion are moved by other bodies in ways determined by external laws. Because this theory requires that Aristotle's internalist theory of motion be rejected, Descartes immediately mocks Aristotle's definition of motion and claims to be describing something entirely different. He does not reveal why he must pre-empt the Aristotelian objection at this juncture, but the reason is clear. Aristotelian motion is directly at odds with Descartes' law, in that by defining motion as the being-at-work of a potency of the material, it makes bodies themselves the cause of motion. Even in the case of objects clearly pushed by others, Aristotle gives the capability or potency - of being moved a causal role. This entails that the source of movement is completely or partially within the objects themselves, and particularly so in the case of coming to rest. Cartesian motion does not come to an end when objects reach their perfection or natural place because they have no inherent perfect or natural place. They move until they come up against another object, at which they impart some or all of their motion to it.

The second law is a clarification and fleshing out of the implications of the first, and can be called the law of the conservation of motion. There must always be a constant amount of motion taking place at any one time. Objects can only receive as much motion from other objects as those objects themselves lose on impact. This furthers the externalist account of 
motion, for objects can only come to rest if they impart their motion to others. Motion and rest are hence understood purely in geometrical terms as movement, or lack thereof, between two neutral points.

The third law is that bodies tend to move in a straight line unless impeded by an external force. There is some debate in the literature regarding whether this refers to the law of inertia or something different. Kennington and Gaukroger use "inertia" to describe it, but Garber points out some important differences between this law and Newton's law of inertia, preferring instead the language of "persistence."(Garber 1992: 224-230). An important aspect of this law is that it considers motion according to the particular direction at each instant, rather than as a whole which can be comprehensively understood. That is, at each "determinable instant" (Descartes 1998: 30) the body is moving in a particular direction, and has a tendency to remain moving in that direction. At the risk of repeating the point ad nauseum, this is another direct reversal of Aristotle, who argues in Book V of Physics that motions can only be understood as continuous wholes. The continuous wholeness of each motion follows from end-directedness, in that each motion is governed at every moment by a single goal; the breaking up of motions into instants, and the attributing to matter of particular tendencies at each instant, removes from consideration a particular goal of the motion as a whole. Just as behavior at the macro level of bodies is determined by behavior of the micro level of corpuscles, complete or macro motions are abstractions based on the combination of many micro motions.

Of interest to relation between metaphysics and physics, Geoffrey Gorham sees strongest the link to divine immutability in this law:

But unlike the other laws the proof of [the law of rectilinear motion] seems to depend essentially on a metaphysical assumption about the temporal immediacy of God's operation. According to Descartes, it is somehow because God only conserves motion in the precise form in which it is occurring "at the very moment when he preserves it" and 
without "taking account" of earlier motions, that his immutability constrains him to produce only rectilinear motion" (Gorham 2005: 432).

What all three laws have in common is the importance of stability and persistence.

Things do not move or stop unless moved or stopped by something external to them, and objects tend to move in a straight line, only to change directions when impeded or redirected. Although these natural tendencies correspond to everyday observations, these laws are not discovered by observation. Indeed Descartes goes so far as to claim that he would accept them even in the face of contrary observations (Descartes 1998: 28). These laws are derived from the immutability of God, who always acts in the same way and thus "always produces the same effect" (Ibid.: 29); that is, he wrote the laws of nature in such a way as to conserve everything in the same state unless externally impeded or acted upon.

It must be pointed out that grounding laws of nature in the nature of God does not clearly establish their content. ${ }^{165}$ This is consistent with Descartes' earlier words about the impossibility of grasping God's purposes in imposing on geometrical matter the laws he did. The primary function, rather, of divine immutability being the foundation for the laws is to provide assurance that patterns of behavior will not change. This is crucial for ensuring the manipulability of nature, in our world as well as Descartes' imaginary one, for God's immutability entails that the same laws must obtain in our world. Natural processes can only be understood, predicted, and therefore exploited, if they behave according to intelligible patterns. After making his case for the third law, he returns to the theme of God being the originator: "God alone is the author of all the motions in the world in so far as they exist and in so far as they are straight" (Descartes 1998: 30). He then hints at the use to which stable laws of nature can be put. These laws, as well as

\footnotetext{
${ }^{165}$ See Clarke (1982: 92) on this point: "The earlier discussion of God's immutability does no work, so far, in explaining the rules which follow."

Geoffrey Gorham, cited above, would likely object to this claim, at least concerning the law of rectilinear motion (2005). He evidently does not think that the other two laws can be so directly inferred from God's nature.
} 
the others that could be deduced from them, help us determine how best to divert, increase, or decrease motions, and in general to know effects from causes (Ibid.: 31-32; my emphasis). In other words, since motion accounts for everything in the universe, these laws will give us insight into every natural process and how each can be manipulated.

To summarize the theoretical portion of The World: nature consists of nothing but matter. Forms are epiphenomena of various constellations of matter, effects rather than causes with ontological reality. Purposes are ignored out of existence, under the guise of belonging to Aristotelian motion and therefore a different phenomenon than the one Descartes calls by that name. However, a careful reading reveals that Descartes is, in fact, explaining the same phenomena as Aristotle, but wishes to hide that from his less careful readers. All variations in appearance and behavior, consequently, can be explained by the motion of corpuscles. Finally, the laws that govern corpuscles have been imposed by God, and can therefore be reliably predicted and therefore controlled. It is no accident that the exposition of his theory of nature concludes with the implications for manipulating it by understanding causes and effects.

The primary takeaway from the first seven chapters of The World, therefore, is that change can be understood and explained according to the physical properties of matter, and any explanation that attempts to be scientific must appeal solely to such causes. Moreover, all material is said to follow stable, and therefore predictable, laws of behavior, the stability of which guarantees the reliability of judgements and the efficacy of attempts to manipulate nature.

\section{The Role of Metaphysics in Descartes' System}

Having given an account of central themes in Descartes' metaphysics and science, we are in a position to address their relationship head on. The above analysis attempted to draw 
connections between the content of his metaphysics and his scientific methods and conclusions. However, this relationship is highly contested, with scholarly opinion ranging from the view that Descartes did not believe any of the claims at the heart of his Meditations to the view that those claims were central to his project. The truth, as in many areas, lies somewhere in the middle; the following section will briefly examine the arguments behind the disparate positions and stake out a middle ground between the extremes. This section will put the finishing touches on the argument that Descartes' metaphysics provides a foundation for his new conception of science. The next section will extend this claim by arguing that Cartesian metaphysics grounds science in such a way that facilitates mastery rather than reliability, per se.

Laurence Lampert's Nietzsche and Modern Times: A Study of Bacon, Descartes, and Nietzsche provides the clearest exposition of the view that Descartes did not believe in his metaphysics. Following Leo Strauss, Lampert attributes an esoteric style of writing to Descartes, according to which what appear to be central claims of the text may in fact be window dressing for other, hidden teachings. Lampert shows that Descartes is at least aware of the "Socratic style [of] speaking ironically" (Lampert 1993: 161) from Notes Directed Against a Certain

Programme. The "certain programme" to which Descartes is responding is that of his follower Regius. Descartes criticizes Regius for, among other things, being too forthcoming about the irrelevance of God in the Cartesian system. He would later write in the preface to The Principles of Philosophy that Regius "denied certain metaphysical truths upon which the whole of physics ought to rest" (Descartes 1997: 273). Lampert infers from this that Descartes was aware of the dangers of exoterically denying the existence of God, even though his primary concern - physics - did not hinge on the existence or non-existence of God. He summarizes Descartes' esoteric style: 
[T] he most controversial implications of Descartes' method are expressly not drawn by Descartes. Knowing full well that his principles contradict the old ones, Descartes leaves it to his reader to see the contradictions and draw the appropriate conclusions (Lampert 1993: $163)$.

This observation fits with what we have seen in The World, in that Descartes implies that his physics contradicts and is intended to supersede Aristotle's physics without ever clearly stating that Aristotle's view is incorrect. However, the extent to which Lampert reads Descartes esoterically is revealed in a discussion of a central passage of part four of The Discourse. After arguing for the existence of God and the immortal soul, Descartes pre-empts the objections by those who remain unconvinced. There are two types of certainty - metaphysical and moral. Metaphysical certainty refers to the indubitable, beyond-a-shadow-of-doubt certainty, and requires one to presuppose the existence of a truthful God. Moral certainty, which refers to the high probability that the world is as it appears, requires no such presupposition (Descartes 1997: 95, 336). ${ }^{166}$ Lampert takes this concession as tantamount to an admission that Descartes' socalled metaphysical foundations are not in fact necessary to ground and legitimize the new science. On the contrary, this is a clever way of saying that traditional metaphysical standards of certainty require an ungrounded supposition - namely that a certain sort of God exists - whereas his method can proceed without requiring such certainty. In other words, Descartes "emphasizes absolute certitude and shows what is necessary to produce it, [and] he shows that he lacks it" (Lampert 1993: 239).

His purpose here, according to Lampert, is to reveal the prejudice - i.e. unfounded supposition - that underlies traditional metaphysics and theology, in order to replace it with the more modest goal of working with "useful probabilities" (Ibid.: 241). In another passage Lampert describes Descartes' metaphysical package in the following manner:

\footnotetext{
${ }^{166}$ Moral certainty is discussed in Part four of The Discourse as well as Part 4, section 204 of The Principles of Philosophy.
} 
Or are [the metaphysical reflections] a more serviceable mask, one befitting a knower, a mask that permits the radical discoverer of a new method for knowing the world to come forth as one who can provide "foundations" for the new world that look so much like the foundations of the old world that they could seem not to threaten it? (Ibid.: 177)

The real foundation of Cartesian science, Lampert claims, is not the metaphysics of God and the soul, but the mathematical method contained in the four rules discussed above. ${ }^{167}$ The mathematical method for discovering rules of behavior is more important than metaphysical theorizing, and can be carried out independently of it. ${ }^{168}$ The role of Descartes' metaphysical claims, Lampert concludes, was simply to provide a cover for his subversive project to manipulate and control nature. Only by appearing orthodox could he expect his profoundly unorthodox claims to receive a fair hearing.

The strength of Lampert's interpretation is that Descartes does clearly prioritize his physical claims over his metaphysical ones. In a passage quoted above he describes his physical discoveries as "more useful and more important than all I had formerly learned" (Descartes 1997: 97). He told Princess Elizabeth to spend no more than "a few hours a year on those [thoughts] which occupy the pure intellect" (quoted in Lampert 1993: 164). Moreover, Descartes does seem acutely aware of his precarious position as an anti-scholastic philosopher. It does not seem too far-fetched to suppose that Descartes would feel that such an elaborate cover was needed, given the politico-religious tension of his age. However, Lampert's reduction of the entirety of Cartesian metaphysics to lip service ignores the many ways in which its subtleties and details set the stage for his physics. We would do well to remain attuned to the political purposes behind Descartes' presentation of his metaphysics, but it cannot be said that it all serves

\footnotetext{
${ }^{167}$ I.E. The rules of certainty, division, order, and enumeration.

168 This point assumes that the four methodological rules can be divorced from the methodological doubt that leads from the cogito to absolute knowledge. It is not clear that such a distinction can be sustained. On the contrary, as suggested above, the best way to frame the process of methodological doubt is as an execution of the four methodological rules.
} 
negative or reputational purposes. Some of these metaphysical claims fulfill important logical requirements of Cartesian science, over and above serving to hide his intentions, which entails that they must in fact be true, not simply believed. ${ }^{169}$ Some of the ways in which its content is relevant for scientific inquiry have been discussed above, including the elevation of geometrical thinking, the de-divinization of matter, and the reduction of Aristotle's four causes to two.

Descartes must believe these and other metaphysical claims to be true in order to pursue and justify his scientific project.

On the other hand, much Cartesian scholarship tends toward a purely exoteric interpretation of his metaphysics according to which his principal goals were to establish with absolute certainty the existence of God and the reliability of pure reason. Harry Frankfurt and E.M. Curley have been discussed above as commentators who work from within this framework. The appeal of this position is that it takes Descartes at his word, insofar as he claims to be devoted to philosophic and theological truth and thus hopes to establish a firm foundation for such knowledge. ${ }^{170}$

The weakness of this interpretation, according to Lampert, is that treating Descartes as a logician and metaphysician requires the reader to come to terms with an elementary fallacy at the heart of his system, namely the aforementioned Cartesian circle. This circle was noticed by his first readers, and pointed out in early written objections, particularly the second set of objections to The Meditations on First Philosophy, compiled by Marin Mersenne (Descartes 1997: 196), and the fourth set, written by Antoine Arnauld (Ibid.: 223). Much ink has been spilled in the

\footnotetext{
${ }^{169}$ I here specify that "some of the metaphysical claims." We will see that not all of Descartes' explicit metaphysical claims need be true, or metaphysically certain, in order to ground his new science.

${ }^{170}$ However, it should be pointed out that even Descartes' own explicit words throw this simplistic view into question. There is the paragraph in part four of the Discourse that introduces moral certainty, and there is his admission that the physical discoveries were more useful than his metaphysical discoveries, for example.
} 
attempt to save Descartes from such an obvious error, ${ }^{171}$ despite Descartes' own admission that his introduction of God is an unjustified presupposition (Ibid.: 95). ${ }^{172}$

Since Descartes himself describes God as a presupposition, and admits that without this supposition we are left with useful probabilities, ${ }^{173}$ it is difficult to sustain the position that Descartes insisted on behalf of all of his theological and metaphysical claims. He does not seem to be placing traditional beliefs regarding God and the soul upon an indubitable foundation, but to read him as dismissing his metaphysical positions in their entirety as lip service to the prevailing politico-religious authorities seems just as simplistic. A more appropriate depiction of the relationship between Cartesian metaphysics and science would be attuned to the way in which the metaphysics paves the way for the physics, while at the same time using careful language and avoiding explicitly heterodox conclusions. Moreover, at least some of the conclusions that we might call metaphysical must be true in order for the scientific system to work, even if not the ones usually supposed. In other words, Descartes does not mean everything he writes on the surface, but the metaphysical claims he does intend to make, though often hidden beneath the surface, are as important as anything in his physical system. It is this via media approach that this chapter has taken. In particular, the important metaphysical implications of his philosophical meditations include the definition of body as mere passive extended material, the attribution of creative willing to immaterial minds, and the overall denigration of Aristotelian forms, ends, and teleological motion. All of these, Descartes is

\footnotetext{
${ }^{171}$ Recall the above discussion of the epistemic and psychological solutions to the problem of the Cartesian circle (Loeb 1992). In addition, Harry Frankfurt suggests that we escape the circularity if we take Descartes, not as attempting to simultaneously deduce God from reason and reason from God (which would undoubtedly be circular), but as positing the validity of reason as a provisional hypothesis "whose tenability is itself to be tested by the investigation he undertakes" (Frankfurt 2008: 41). For other treatments that attempt to solve the logical problem see the following: (Curley 1978: 96-124; Williams 2005: 175-189).

172 That is, according to the distinction between metaphysical and moral certainty in part four of the Discourse.

173 "Useful probabilities" is Lampert's repackaging of the following Cartesian phrase: "a certainty which suffices for the conduct of life" (Lampert 1993: 241).
} 
saying, can be known with a moral assurance that is sufficient to provide "a certainty which suffices for the conduct life" (Descartes 1997: 336), even if the existence of God is not known with metaphysical certainty.

This approach is similar to the one taken by Richard Kennington. In "Descartes' Discourse on Method" (2004: 105-122), he examines the gap between what Descartes claims to prove and what his arguments actually prove, and finds that in every case the theological and apologetic results give way to the revolutionary understanding of man and nature. For example, the argument for the independence of mind from body - namely from the premise that mind is knowable distinct from body - does not lead to the apologetic conclusion of the metaphysical independence of mind from body. It only proves that mind is epistemologically distinct from body. This is crucial for the Cartesian project of conquering nature. The nuanced mind-body, or mind-world, relationship that epistemological independence allows solves an important problem: "the knowing or thinking of mind must be pure of influences on the mind, without the being of mind being hopelessly separated from the world" (Kennington 2004: 117). That is to say, mind must be in the world but not of it: part of the world and able to influence it, but sufficiently removed so as to act on its own. This revolutionary mind-world relationship is deftly hidden under the guise of what has been often thought to be Descartes' intended, safe conclusion.

Similarly, the arguments for the existence of God, while appearing scholastic and friendly to authority, hint at a new understanding of nature that renders it manipulable. Kennington reminds the reader that whereas Aquinas moved from nature to God, Descartes moves from ideas in the mind to the existence of God (Ibid.: 118). As already stated, Cartesian metaphysics desacralised nature and turned it into the site of man's creative, technological purposes. His apologetic arguments ratify this change by admitting that nature cannot lead us to knowledge of 
God. Laws of nature are not teleological or instructive of divine purposes, they are simply mechanistic patterns of behavior, beyond which human knowledge cannot pass. This is a central Cartesian metaphysical truth, and the importance of this for Cartesian physics is clear.

It is these nuanced metaphysical principles that make his physical project possible, and to which he was likely referring in the following passage in a private correspondence to Mersenne:

I may tell you, between ourselves, that these six meditations contain all the foundations of my physics. But please do not tell people, for that might make it harder for supporters of Aristotle to approve them. I hope that readers will gradually get used to my principles, and recognize their truth, before they notice that they destroy the principles of Aristotle (quoted in Garber 1992: 24).

\section{$\underline{\text { Technological Mastery or Explanatory Power? }}$}

We have already shown how the natural philosophy of The World described nature in a way that rendered it predictable and manipulable. We can now strengthen this aspect of the argument by explicitly comparing it with alternative views in the commentary and examining other Cartesian passages that shed light on this issue.

Some readers of Descartes who pay particular attention to the way his metaphysics grounds science see him as trying to establish reliability alone, rather than mastery. The question can be posed in the following terms: Was Descartes' purpose in composing his natural philosophy to describe reality as accurately as possible or to facilitate control of it?

Many commentators incline toward the former possibility. Even John Henry, who as we have seen correctly notes the priority of physics over metaphysics to Descartes, nevertheless construes his scientific aims in terms of reliability and correspondence to nature (Henry 2004: 99). Stephen Gaukroger, a scholar of the philosophy of early modern science, also affirms that Descartes' purpose was the accurate description of reality. He nowhere denies the goal of mastery but instead describes Descartes' findings as if being accurate descriptions of reality 
exhausted their significance. A characteristic passage occurs in his introduction to Descartes' The World: "These laws of nature are designed to describe the collisions of corpuscles" (Gaukroger 1998: xvii). It is doubtful whether Gaukroger meant this as anything but an uncontroversial description of the laws of nature, but it suggests that Descartes' purpose was the description of reality as such rather than the ability to understand and manipulate its processes. For the purpose of comparison, a believer in the "mastery thesis" might write the same sentence in the following manner: "These laws of nature are designed to allow men to study nature's regular behavior in order to predict and control it in the future." Gaukroger expands his treatment of Descartes' laws of nature in Descartes' System of Natural Philosophy; although the discussion is very thorough, it treats Descartes' natural science as an alleged description of reality, but nothing more. Of particular note is Gaukroger's theory of why Aristotle's forms are omitted from Descartes' natural philosophy. Whereas this study argues that forms and ends were neglected because they offered no practical use, Gaukroger writes that " $[\mathrm{t}]$ he traditional Aristotelian forms and qualities are excluded because they could not form part of a properly mechanist explanation. Indeed, if we strip the world of the traditional forms and qualities, what we would be left with would, in Descartes' view, be its genuine properties" (Gaukroger 2002: 13). That is, Descartes abandoned Aristotle for the simple reason that Aristotle's theories were explanatorily inadequate. Gaukroger treats Descartes as if his aim were to accurately describe nature and natural processes, and insofar as Aristototelian forms do not provide any explanatory value they are scientifically useless.

Daniel Garber is more explicit in his denial that Descartes was a proponent of mastery. In addition to his implicitly treating Cartesian natural philosophy as if description of nature exhausted its meaning, he writes the following in an endnote: "However, unlike Bacon, 
Descartes is not thinking of technological success but of explanatory success" (Ibid.: 337n33). We will return to Garber's claim below, after a review of some variations on the mastery thesis. For now we can say that the view articulated by Gaukroger and Garber depicts Cartesian science as aiming for reliable explanations of natural process, not mastery, and that if mechanistic laws of nature prove themselves as more accurate descriptions of nature then they should be treated as part of the scientific lexicon. This entails, importantly, that the move from forms, matter-aspotency, and teleological motion to mechanistic laws of cause and effect signals the falsity of the former group of explanans. In other words, if Descartes' scientific method was primarily meant to produce accurate descriptions of reality, then the abandonment of these Aristotelian concepts is effectively a refutation of them. However, the other possibility, introduced by the mastery thesis, is that their abandonment signals nothing but Descartes' belief that they provide no knowledge that is technologically useful. This allows, in principle, for their being true at the same time as Descartes' useful explanans.

Among the Thomist proponents of the mastery thesis are Étienne Gilson, celebrated scholar of medieval and Cartesian philosophy, and Leon Kass, bioethicist and physician. Gilson's study of final causality and modern science, From Aristotle to Darwin and Back Again: A Journey in Final Causality, Species, and Evolution, was translated into English three years after the publication of Alasdair MacIntyre's After Virtue in 1981, and makes similar claims on behalf of ancient philosophy against trends in modern thought, though Gilson is more concerned with changes in the conception of science than was MacIntyre in After Virtue. Gilson's depiction of modern science, originated by Bacon and Descartes, is similar to that of this dissertation.

He writes that Descartes shared with Bacon the following core beliefs: "their taste for knowledge that is practical and useful, and their indifference concerning philosophical notions 
which, though perhaps true in themselves, do nothing to increase our power over nature" (Gilson 1984: 21). "The author of the Discourse on Method," continues Gilson, "saw the most certain proof of the truth of his own philosophy, and its greater merit, in its utility. Scholasticism was practically useless; therefore it was false" (Ibid.: 22). Gilson notices that a famous passage in part six of The Discourse (Descartes 1997: 110-11; discussed below) specifies that his practical philosophy is "instead of," rather than "beyond" the speculative philosophy of the schools, indicating that the criteria of usefulness requires replacing instead of merely building on preexisting thought (Gilson 1984: 23). Finally, Gilson notes that the Cartesian discarding of final cause was due to its uselessness to a "science whose end is to make us masters and possessors of nature" (Ibid.). His interpretation of Descartes as being a proponent of mastery was thus grounded in explicit statements as well as the logic of the Cartesian system, for example in his interpretation of the relationship between final cause and utility.

Kass' Toward a More Natural Science: Biology and Human Affairs is primarily concerned with ethical problems raised by the technological capabilities made possible by modern science, rather than with uncovering the philosophical origins of those possibilities. As the title suggests, the problem is not due to some form of technological perversion of science, but with the very nature of so-called "natural" science itself. The position he stakes out is, like Gilson's, similar to that of this project:

Ancient science had sought knowledge of what things are, to be contemplated as an end in itself satisfying to the knower. In contrast, modern science seeks knowledge of how things work, to be used as a means to the relief and comfort of all humanity, knowers and nonknowers alike (Kass 1985: 130).

He puts Descartes at the vanguard of this change, as when he justifies his new knowledge on the grounds that it will help to procure "the general good of all mankind" (Ibid.). Throughout the book, Kass makes repeated references to a famous passage in the sixth part of The Discourse 
(Ibid.: 130-131, 300). ${ }^{174}$ His argument throughout is that the Cartesian goal of complete mastery of nature may not carry the unqualified good that it promises, and that Aristotelian questions concerning the nature of community and of the good man should be given renewed emphasis (Ibid.: 17-18).

Whereas Gilson and Kass challenge the goals and assumptions of modern science with a view to rehabilitating an Aristotelian conception of science, Antonio Negri takes the mastery thesis in a completely different direction. Instead of exposing the underlying goals of Cartesian science and metaphysics for the purpose of reviving an older tradition of thought, Negri hopes to expose the bourgeois conception of self at the heart of the aspiration to control. He points out that as a young man and budding philosopher Descartes was drawn to the Renaissance-Humanist ideal of possessing and transforming nature (Negri 2007: 36-37). His early writings, during the composition of which he was forming the outlines of his scientific project, form for Negri "perhaps the best commentary to it [i.e. the Cartesian project]" (Ibid.: 45). A common theme in these writings is the possession of the world and "the possibility of reconstruction" (Ibid.). The eradication of doubt and the overcoming of scepticism emerge in these pages, Negri argues, as the means by which to possess and reconstruct the world (Ibid.: 46-47).

By the year 1629, after writing Rules For the Direction of the Mind but before The World and The Discourse, Negri suggests that Descartes had realized the importance of introducing a radical separation between subject and world, what he calls "a metaphysics of separation" (Ibid.: 106). This separation construed the world as opposed to the human subject just as it is opposed to its creator; moreover, the arbitrariness of nature qua created by God remains in its relation to man: "What is this world then? A phantom over which looms the incomprehensible will of the

\footnotetext{
174 There is an extended discussion of this passage below.
} 
sovereign" (Ibid.: 112). The metaphysics of separation forms the basis of what Negri calls "the

Cartesian ideology" (Ibid.: 130):

It is on the basis of this separate being that the world is to be reconstructed....In the superimposition of the productivity of ideology onto the passivity of mechanist science, [Descartes] succeeded in clearly revealing to the epoch its own specificity: a world in which the bourgeoisie, condemned to separate existence, needed to salvage, develop, and impose its own essence (Ibid.: 241-242.)

In Empire, Negri, along with co-author Michael Hardt, clarifies the ideological effect of

Cartesian mastery:

With Descartes we are at the beginning of the history of the Enlightenment, or rather bourgeois ideology. The transcendental apparatus he proposes is the distinctive trademark of European Enlightenment thought. In both the empiricist and the idealist currents, transcendentalism was the exclusive horizon of ideology, and in the successive centuries nearly all the major currents of philosophy would be drawn into this project. The symbiosis between intellectual labor and institutional, political, and scientific rhetorics became absolute on this terrain, and every conceptual formation came to be marked by it: the formalization of politics, the instrumentalization of science and technique for profit, the pacification of social antagonisms (Hardt and Negri 2000: 80).

Negri's analysis of Descartes is taken in a radically different direction than this project, in that he implicates Cartesian mastery in class oppression and exploitation, but he nevertheless stands as an insightful representative of the mastery thesis. ${ }^{175}$

Garber's denial of the mastery thesis, quoted above, is helpful on account of its succinctness. It nicely contrasts the alleged difference between technological and explanatory success, while placing Descartes in opposition to Bacon on the grounds of that difference. For this reason, his statement shall be the point of departure for the argument that Descartes is indeed a strong proponent of mastery. Garber's statement is inaccurate for two reasons. First, it assumes that there is no inherent link between mastery and explanation, as if mastery does not require a certain method of explanation. Second, it is demonstrably false to claim that Descartes

\footnotetext{
${ }^{175}$ It is not my contention that Negri's "bourgeois ideology" argument is necessarily mistaken, but simply that it is beyond the scope of this project. I remain methodologically agnostic on the question of whether the technologization of nature was intended to serve mankind in its entirety or specific class interests.
} 
"is not thinking of technological success" (Ibid.: 337n33). We will address the second problem first, before turning to the general question of the relationship between mastery and modes of explanation.

There are some explicit textual evidences for the claim that Descartes is "thinking of technological success," with one in particular that recommends close attention. In addition to the many references to utility in The Discourse, the clearest statement of purpose occurs in part six. After indicating his intent to follow the divine law "which obliges us to procure, as much as in us lies, the general good of all mankind," he describes his project in the following terms:

It is possible to attain knowledge which is very useful in life, and that, instead of the speculative philosophy which is taught in the schools, we may find a practical philosophy by means of which, knowing the force and action of fire, water, air, the stars, heavens and all other bodies that environ us, as distinctly as we know the different crafts of our artisans, we can in the same way employ them in all those uses to which they are adapted, and thus render ourselves the masters of possessors of nature (Descartes 1997: 110-111).

He then clarifies his meaning, telling the reader that by this he means "the preservation of health" as well as enabling mankind to enjoy the fruits of the earth. In sum, his science has the goal of relieving man's estate, by explaining the behavior of natural bodies in terms of their causes and effects.

The first thing to note regarding this passage is that it proves that Descartes had technological success in view. It would be hard to interpret this passage as anything other than as a statement of his organizing principle. He is motivated by a pious desire to benefit mankind, and the character of his knowledge is defined by its technological ambition. Second, he reverses the contemplative-productive hierarchy of pre-modern science. Speculation alone - what Garber might call "explanatory success" - is not a sufficient goal of philosophy, Descartes says. The aim of all philosophy must be productivity or use, not contemplation or wisdom. Reversing the ancient hierarchy also entails that the agenda, so to speak, is set by the requirements of 
productivity. In other words, the types of knowledge that are pursued will be those that lend themselves to greater technological success.

The Cartesian organizing principle is usefulness, as evidenced by his desire to procure the good of mankind and his ultimate goal of rendering men the "masters and possessors of nature." This leads him to investigate the "force and action" of natural bodies in order to manipulate their behavior. Compare this with the organizing principle of Aristotelian philosophy, which was wisdom defined as knowledge of the good of each thing. The end of all human activity is, or at least ought to be, knowledge for its own sake (Metaphysics, 980a21). Rather than designing his inquiries around the ideal of empirical observation, with its increased promise of certainty and therefore control, Aristotle inquired into whichever causes bore the most responsibility for the change in question. This, as has been shown, led him to treat order and purpose as the most fundamental causes of the natural and human worlds. The fact that such wisdom does nothing to reduce the material conditions of human existence speaks to the central contrast with which this project is concerned: the ancient scientific emphasis on wisdom versus the modern emphasis on control.

Third, the attunement of modern science, namely the "force and action" of bodies, is here plainly shown to follow from its goal of mastery. The reason for paying attention to laws of behavior is that it allows him to procure the good of mankind. "We could be free of an infinitude of maladies both of body and mind," he writes, "if we had sufficient knowledge of their causes" (Descartes 1997: 111; my emphasis). In other words, he reduces nature to matter in motion in order to more efficiently achieve his purpose, not because he has any logical or ontological reason for so doing. His conception of science is therefore consistent with the view that there is more to nature than his practical philosophy cares about. 
The reference to the "fruits of the earth" (Ibid.) being one result of his practical philosophy is reminiscent of the tree analogy in the preface to The Principles of Philosophy. This analogy subtly expands on the above Discourse passage by strengthening the logical relationship between all areas of knowledge from the roots to the fruits. Metaphysics and physics are the roots and trunk, respectively, and the applied sciences are the branches (Ibid.: 269). He does not name the specific fruits, although because medicine, mechanics, and morals are singled out as the principal applied sciences we can reasonably infer that the fruits include health, technological innovation, and social and political stability. Moreover, since the fruit is the most useful part of the tree the main use of philosophy is to strengthen and support the branches that bear fruit. This reiterates what has been said before, namely that the character of the metaphysical and physical reflections is determined by the anticipated fruits. At any rate, in this passage as well as The Discourse, Descartes clearly indicates his desire for technological success and the way in which he framed his investigations in pursuit of his goal.

However, in addition to these explicit statements, which could conceivably be written off as attempts to present his project in a positive light, there is what could be called an esoteric signal of his goal of mastering nature. The Discourse depicts his journey from received opinion to indubitable knowledge by way of radical doubt. In part three he provides the provisional moral code to be adopted for the journey, for the same reason that we "provide ourselves with some house where we can be comfortably lodged during the time of rebuilding" (Ibid.: 85). The most striking fact about these four maxims is their moderate character. For a radical reformer like Descartes, such moderation and willing acceptance of received opinions is noteworthy.

The first maxim is to "obey the laws and customs of my country." This includes conducting his opinions in a "moderate" and "judicious" manner and following the wisdom of 
"people on whose judgment reliance could be placed" (Ibid.). In other words, his first rule is to follow those around him and not dare to question the truth or wisdom of his countrymen; this is after he has already undermined the wisdom of received opinion.

The second maxim is to be "as firm and resolute in my actions as I could be, and not to follow less faithfully opinions the most dubious, when my mind was once made up regarding them" (Ibid.: 86). Again, this is after extoling the virtue of following the argument wherever it leads, even to the point of denying the most seemingly obvious truths.

The third maxim is to "try always to conquer myself rather than fortune, and to alter my desires rather than change the order of the world" (Ibid.: 87). The fourth is simply to reject this provisional code at the appropriate time, namely when he has arrived at a more satisfactory set of beliefs. However, for the current discussion the third maxim is revealing. The first two maxims exhibit a particular pattern: each is directly opposed to what we know Descartes' ultimate views to be. Unthinking acceptance of local custom and received opinion is the very problem that his epistemology is supposed to combat. Similarly, the refusal to re-evaluate one's beliefs in the face of new evidence is the foil against which radical doubt was set. The problem, both socially and philosophically, is that people are too resolute in their thoughts and actions.

It thus seems clear that the principle behind the provisional moral code is that each maxim is the opposite of what Descartes really thinks is appropriate behavior. There are two purposes for this tactic. The first is rhetorical; this section will give most readers the impression that Descartes has an appreciation for custom and moderation in social and intellectual life. The second purpose is to indicate the difference between received opinions, which the provisional moral code replicates, and his final set of principles that survive radical doubt. By placing 
received opinion in the sphere of the provisional, to be replaced by his considered principles, its inferiority is illustrated.

This brings us to the third and final maxim. ${ }^{176}$ In it he accepts the limits placed upon him by nature, and limits his aspirations to accustoming his thoughts and character to the world and its troubles. He aligns himself with ancient philosophers who "were able to free themselves from the empire of fortune, or, despite suffering or poverty, to rival the gods in their happiness" (Ibid.: 88). Nature, in other words, has imposed natural limitations on humans such that the appropriate response is to bring ourselves into conformity with nature, rather than bringing nature into conformity with our desires.

However, given the pattern of the first two maxims it is evident that Descartes' actual goal is diametrically opposed to the ancient practice of conforming oneself to nature. Rather than conforming his will to nature, it seems that Descartes' ultimate rule is to make nature conform to human will. Likewise, rather than siding with ancient philosophy, as he appears to do in his provisional code, in truth he could not be more opposed to its project of conforming oneself to the constraints and standards given by nature. We thus have, in the provisional code, good textual evidence for the proposition that he is interested in technological success, defined as mastery of nature in order to make it fit human purposes.

The incongruousness of the provisional morality has been noticed by scholars. Kennington rightly points out that while allegedly praising the Stoics, Descartes is in fact mocking them, insofar as their position entails not wishing to be cured of sickness, or freed from jail, whenever these are impossible (Kennington 2004: 116). The satirical element leads Kennington to the interpretation that the third maxim raises the possibility that what is currently

\footnotetext{
176 The fourth maxim is not really a moral code, per se, but a "sunset clause" permitting him to put these maxims aside in the future.
} 
within human power is "not identical with what can ever come within the limits of human power" (Ibid.). In other words, the third maxim hints at the possibility of a human mastery of nature, and thus at the reversal of its literal meaning. Lampert also refuses to take Descartes at what appears to be his word. He interprets the third maxim as assuming the conditional principle that "will tends naturally to desire only what intellect presents as possible" (Lampert 1993: 233). According to this approach, even the nuanced letter of the third maxim is consistent with the overall goal of mastery. As soon as men attain sufficient knowledge of the "forces and causes" of nature (Descartes 1997: 111), the range of possible actions will increase.

Not all interpretations of the provisional code are open to this implication. Gail Fine (2000) and Adam Kadlac (2007) argue that Descartes continued to accept the letter of these provisional codes throughout his life. However, such interpretations fail to do justice to the revolutionary aspect of Cartesianism and the centrality of mastery in his system. His ultimate project to transform nature compels us either to modify his direct claims, as Kennington and Lampert do, or to treat them as misdirection and rhetorical ploys, as my interpretation does. To say that they are misdirections and ploys is not to accuse Descartes of explicitly lying, however, insofar as Descartes never depicts them as absolutely authoritative. He himself presents them as provisional, which implies that he intends to move beyond them at the appropriate time. In fact, the unmistakable contradiction between the maxims and what we know him to truly believe should be taken as a strong textual clue that they should not be taken seriously as statements of his considered moral views or political project. This entails, in turn, that he is indeed a proponent of mastering and controlling nature in order to render it susceptible to human purposes. 


\section{Technological Mastery versus Knowledge of Nature?}

The discussion of Descartes' conception of science can be brought to a close with a few remarks on the relationship between technological and explanatory success. By framing the debate as between the contrasting goals of explanatory success versus technological success, a new way forward is opened up that can partially mediate between them. One need not choose between "Descartes the reliable explainer of nature" and "Descartes the manipulator of nature," because there is a necessary causal relationship between the two. We are now in a position to shed more light on how this is so.

Reliable knowledge of the behavior of bodies is required by the technical ability to manipulate natural processes. In order to bring about the desired effects, one must have sufficient knowledge of the precise causes of those effects. ${ }^{177}$ Repeatable laws of behavior are said to be the central attunement of Cartesian science. His statement of purpose in part six of The Discourse is clear on this, as are the scientific conclusions themselves as presented in The World. Recall that the laws he describes are explicitly laws of behavior that determine how "the motion of each body can be diverted and increased or decreased by colliding with others" (Descartes 1998: 31).

Moreover, it seems that certainty regarding some of his metaphysical claims is necessary, too. The laws of nature are the source of his science's utility, and these depend on important metaphysical departures from Aristotle, which have been discussed above. Matter must be stripped of any inherent causal powers, it must be possible for men to conceive of themselves

\footnotetext{
177 This section will clarify this claim. It is not true that exact knowledge is a prerequisite for manipulation of natural processes. However, incorrect knowledge can only provide technological use in particular circumstances. See below for Descartes' example of an incorrect but consistent use of the alphabet to accurately convey meaning. It is this notion of accuracy, understood through the concept of moral certainty, that Descartes is concerned with.
} 
and their interests in isolation from, or even opposition to, the material world, and Aristotelian forms, ends, and purposive motion must be eliminated from scientific explanations.

All of this tends toward the conclusion that, at least some, accurate knowledge is required for technological success. This is obvious enough, as the example of medicine illustrates. The explanatorily inadequate belief that diseases are caused by divine displeasure limits the ability of doctors to bring about health. It is only when men understood the true causes of bacterial diseases that they could cure them.

On the other hand, we have seen that Descartes also refers to the concept of moral certainty, and appears to prefer it to metaphysical, or absolute, certainty (Descartes 1997: 95-96, 336-7. Moral certainty refers to useful probabilities, or predictive successes, which he implies are possible even in the absence of metaphysical certainty. In The Principles of Philosophy he uses the example of a reader who mistakes the alphabetical order of the letters, albeit in a perfectly consistent manner. Such a reader would connect words to ideas and objects just as reliably as any other reader; "e-p-h" would signify dog just as reliably as "d-o-g” brings the same idea to our minds. His point with this illustration is that scientific theories can bring about technological success even if they are not absolutely correct, and moreover that that would not constitute a problem for his project (Descartes 1997: 336-337). Such moral certainty "suffices for the conduct of life" (Ibid.: 336). In contemporary terms, Descartes is articulating an early vision of scientific instrumentalism. The core of scientific instrumentalism is that scientific theories and assumptions need not be true, as long as they prove useful. ${ }^{178}$

An implication of the distinction between moral and metaphysical certainty is that two Cartesian themes are less important than might appear on the surface: the existence of God and

\footnotetext{
${ }^{178}$ Cf. Kenneth Waltz: “A theory contains at least one theoretical assumption. Such assumptions are not factual. One cannot legitimately ask if they are true, but only if they are useful" (Waltz 1979: 117-118).
} 
the absolute certainty with which we can treat the results of geometrical reason. Recall that this distinction is drawn in the context of the Cartesian circle, which implicates both the existence of God and the indubitability of reason. ${ }^{179}$ Descartes' unexpected concession that God must simply be presupposed in order to ground his system would indicate that metaphysical certainty in these areas is not a prerequisite for his science of mastery, so long as we have moral "certainty which suffices for the conduct of life" (Descartes 1997: 336).

The question, then, is how to reconcile this apparent downplaying of explanatory success with the previous discussion regarding the importance of explanatory success. This reconciliation can begin with the following observation: the boundaries of explanatory success must be modified to include predictive power. In other words, whether a specific scientific theory is metaphysically or absolutely true is secondary to the question of whether it is useful. Two textual examples of this will illustrate the use to which moral certainty is put. First is the fact that his laws, interpreted literally, imply that the world and its inhabitants evolved from a primitive and undifferentiated state, but he remains agnostic on the metaphysical question of how the world actually originated. ${ }^{180}$ In other words, it does not matter for his purposes whether his theory is metaphysically true; all that matters is that it accurately describes - or rather predicts the behavior of bodies in the present. Second, his rejection of Aristotle's definition of motion stems from a concern with repeatable behavior, and a corresponding lack of concern with metaphysical subtleties. An ontological description of the relationship of potency to end adds nothing to the empirical knowledge of how bodies tend to move, and is thus unnecessary.

\footnotetext{
179 This does not necessary mean that Descartes cannot make use of God as the primary cause of motion and author of the laws of nature, but it does mean that he can no longer claim metaphysical certainty for those laws. However, so long as Descartes is primarily concerned with useful probabilities, this does not seem to constitute a problem for his project.

180 "I did not at the same time wish to infer from all these facts that this world has been created in the manner in which I described" (Descartes 1997: 100).
} 
Thus, explanatory success is important to Descartes, if by explanatory success we mean explanations that allow us to predict behavior. This is not the pure scientific realism of a theoretician who wishes to understand intricate details for their own sake. His goal of technological mastery requires explanatory success of a certain type, or rather to a certain extent. When it comes to conflicting theories that offer the same predictions, Descartes is agnostic on principle, as we see in the example of the creation of the world. In the terminology of this study, the aim and attunements of Cartesian science induce him to adopt a certain explanatory requirement, namely moral certainty. This refined notion of explanatory success is able to account for the relationship between explanatory and technological success without requiring absolute certainty. This in turn allows him to bypass the questions to which final and formal cause are the answers, which effectively renders them unscientific. In other words, since the doctrine of natural right is in the domain of final and formal causality, it is Descartes' reliance on prediction and moral certainty that puts natural right outside the purview of his conception of science.

The argument of this chapter has been twofold. First, Descartes' metaphysics was not intended to stand alone as a contribution to academic debates with skeptics, but was designed in order to ground a new method of science. Second, the method of science with a view to which his metaphysics was constructed aimed at mastery of nature, over and above the ability to more accurately describe it. To this end we began with an examination of some approaches to Descartes that tend to treat his metaphysics of certainty as foundational and saw that placing Descartes in his proper historical context as an anti-scholastic philosopher brings to light certain metaphysical transformations that make his new science possible. 
The focus was then shifted to interpretations of Cartesian science that downplay, or completely ignore, the importance of mastery. His metaphysics was shown to have set the stage for his science in a way that facilitates mastery of nature, primarily by way of the predictable laws of nature. Moreover, his introduction of moral certainty indicates that he is interested in certainty, even if not the kind that Frankfurt et al. supposed. The metaphysical certainty with which the skeptic can be definitively refuted does not seem attainable (Descartes 1997: 95), but it also does not appear to be Descartes' main concern. His project of scientific mastery only seems to require the moral assurance, or useful probability, that bodies behave according to predictable laws.

If the above is true, then the philosophical importance of Descartes lies not in his solution to certain logical problems regarding the existence of God and the indubitability of natural reason, but in his articulation of a project to predict natural processes and make them serve human interests. This amounts to a reversal of the ancient scientific approach in which the mind was brought into accordance with nature by grasping the ultimate causes. For Descartes, the new aim of mastery attunes scientific inquiry to the predictable natural laws that facilitate manipulation of natural processes. 


\section{BACONIAN MASTERY AND OBSERVATION}

The main question with which the previous chapter dealt is not at issue in the literature on Bacon. There is no question about the aim underlying Baconian scientific method. Even Gaukroger, whose analysis ignored the themes of mastery and utility in Descartes, writes of the centrality of practical benefits to Bacon's intention:

At the heart of this reform is the production of useful knowledge. The practical nature of knowledge is a particularly pressing issue for Bacon - as we shall see, he denies the title 'truth' to anything unless it is 'productive of new works' - so it is important that we understand what is at stake in this question (Gaukroger 2003: 14). ${ }^{181}$

All of this is to say that what lies partially concealed in Descartes is shown in Bacon for the world to see. In keeping with his goal of reversing the harmful effects of the Fall of Man, Bacon is not ashamed of the nakedness of his technological ambitions. ${ }^{182}$ In fact, the openness of Bacon's intention is the reason for his being discussed after Descartes, despite the fact that his work appeared first. The reason for this is expository: the aim of mastery can be more clearly shown by considering Descartes before Bacon. Because it is not obvious to all readers of Descartes that his conception of science sought the ability to control natural processes, the discussion of his scientific thought required my making this explicit. There is a certain counterintuitiveness to any conception of science that does not set accuracy as its guiding light; the hope is that this could be overcome by explicitly addressing the theme of mastery in Descartes before

\footnotetext{
${ }^{181}$ Though we will see in what follows that many commentators, including Gaukroger, pay insufficient attention to the way Bacon's interest in mastery shaped his scientific method.

${ }^{182}$ Cf. Genesis 3:10: "I heard the sound of You in the garden, and I was afraid because I was naked; so I hid myself" (New American Standard Version).
} 
turning to Bacon's more candid presentation. This decision should not be taken to imply that Descartes played a more important role in the history of modern science, or that he is more of an originator than Bacon on that front. Descartes chose to keep his goal hidden from plain view, so we had to begin by uncovering the assumptions behind his metaphysical system to see how they contributed to his project of mastery. Bacon, we will see, is more open about his intentions, but his conception of science shares Descartes' aims and attunements. Furthermore, one of the central techniques of Cartesian dissimulation was to write without reference to previous proponents of mastery, most notably Machiavelli and Bacon. His wish to avoid the presumption of mastery required an interpretation untainted by prior consideration of Bacon. Finally, despite both having similar scientific aims and attunements, there is no clear evidence of direct causal influence from Bacon to Descartes. ${ }^{183}$ The similarity can, in large part, be attributed to certain attitudes being "in the air," so to speak, as evidenced by the very real philosophical differences between how each thinker arrived at the same aims and attunements. The obvious example is the rationalism of Descartes versus Bacon's emphasis on sensory experience. It is safe to say that had Descartes thought of himself as being primarily a student of Bacon he would not have allowed such distrust of the senses.

\section{The Machiavellian Roots of Mastery}

Though Bacon does not go to the same metaphysical lengths as Descartes in order to ground his scientific method, he unabashedly unites himself with the Machiavellian project of controlling nature. This political project was grounded in an ontology of nature that both

\footnotetext{
${ }^{183}$ This does not mean that Descartes was not aware of Bacon, as he surely was. The point is that Descartes developed his ideas sufficiently independently of Bacon such that considering him first is justifiable.
} 
redefined and rebuffed central categories in the classical view of nature. ${ }^{184}$ In order to provide some context to Bacon, we will begin by outlining some of the key components of Machiavelli's ontology of nature.

Two of the most important categories in The Prince are fortuna and virtù. ${ }^{185}$ The relationship between them sheds important light on Machiavelli's teaching, and particularly his ontological departures from classical philosophers like Plato and Aristotle. The seemingly innocuous observation that some statesmen leave things to chance while others take matters into their own hands forms the basis of a reinterpretation and rejection of central elements of the classical view of nature. ${ }^{186}$ Fortuna, which Harvey Mansfield translates simply as "fortune," becomes Machiavelli's stand-in for nature itself, with the implication that nature is ruled by chance, and is therefore variable, unreliable, and capricious. Compare this to Aristotle's argument in Physics book II that chance itself is not a cause of anything, but is simply the sum total of unintended side effects of final causes (Physics, 197a). Similarly, for Plato what most truly is - i.e. nature in the fullest sense - is not the changing world of experience but rather the unchanging world of the forms. Nature, for these two, was orderly and worked towards the

\footnotetext{
${ }^{184}$ Machiavelli is sometimes read as an anti-metaphysical thinker, who ignored metaphysical and ontological themes in favour of "practical politics." For example, the entry on Machiavelli in the online Stanford Encyclopedia of Philosophy contains no instances of "metaphysics" or "ontology," and justifies an entry on Machiavelli simply because "succeeding thinkers who more easily qualify as philosophers of the first rank feel compelled to engage with his ideas." In other words, he is not himself a philosopher or ontologist, but only a writer on politics who happens to be interesting to real philosophers (https://plato.stanford.edu/entries/machiavelli/). Peter Kreeft's Socrates Meets Machiavelli, an imagined conversation between the two thinkers in purgatory, admits that Machiavelli's writings made metaphysical assumptions, even if Machiavelli did not intend to (Kreeft 2003: 112120). However even this interpretation is unfaithful to the systematic way in which Machiavelli redefines central ontological categories that provide the theoretical basis for his political prescriptions. Kreeft's Socrates is correct in identifying metaphysical assumptions behind Machiavelli's overt political claims, but he is incorrect in characterizing them as haphazard or unintentional assumptions. On the contrary, Machiavelli has a clear metaphysical program.

${ }^{185}$ I will use the original Italian to designate the Machiavellian understanding of these categories, in order to avoid confusion with the typical meanings of fortune and virtue.

186 This analysis of Machiavellian virtue and fortune is indebted to Waller Newell (2013), especially p. 274-296.
} 
fulfillment of determinate ends. Not so for Machiavelli; it is pure chance. From this he draws the practical lesson that complete reliance on it is risky.

Virtù, or simply "virtue" in Mansfield's translation, despite the apparent similarity to Aristotelian virtue, is a repudiation of it. The classical virtues were based on conformity to nature; Machiavellian virtù is the ability to skillfully manipulate nature. In central passages in the $25^{\text {th }}$ and $26^{\text {th }}$ chapters of The Prince, the same idea is expressed by the phrase "libero arbitro," rendered as "free will" or "freedom," by Mansfield, depending on context (Machiavelli 1998: 138-139). The implication of this understanding of virtù is that freedom from nature depends on opposing it and taking matters into one's own hands. The conflation of virtù and free will is used to give men control over half of their actions while reducing fortune's share to the other half.

The positive lessons in chapter six, from those who acquired principalities through their own virtù, have broad applicability. Moses, Cyrus, Romulus, and Theseus were given the opportunity by fortuna, but it was up to them to skillfully make the most of the situation. ${ }^{187}$ The opportunity is the "matter" on which they could introduce any "form" they pleased (Ibid.: 23). The use of Aristotelian language is intentional, and points to the reinterpretation of the classical physical categories. Recall that for Aristotle matter was defined as potency for certain forms, such that there were natural relationships between matter and form that could not be altered. Virtue was defined as the ability to cultivate oneself (matter) and develop the appropriate dispositions (form). Each matter had potencies for some forms and not others, and the virtue of a

\footnotetext{
${ }^{187}$ Bacon's list of political founders in essay \#55, "Of Honour and Reputation," included Caesar, Ottoman, and Ismael but excluded Moses (Bacon 1973: 160-161). Howard White argues that the omission of Moses suggests Bacon's reticence to mix the human and the divine (White 1968: 46). Perhaps another way to put this is that Bacon was reluctant to rely on divine aid, which would explain his project to restore men's dominion over nature by the work of their own hands. More will be said about this below.
} 
thing was to reach the form appropriate to it. ${ }^{188}$ Now, virtù means the ability to manipulate matter into whichever form suits one's purposes.

The practical political lesson is that acquiring a principality by virtù requires much trouble and effort, but once it is so acquired it is easier to maintain. In the next chapter Machiavelli argues that the opposite is the case for those who rely on fortuna to attain their ends. Because nature is capricious and unreliable, the blessings it bestows on you one day can be revoked the next. Better to lay the appropriate foundations for lasting order, just as a tree must establish deep roots in order to endure inclement weather and other vagaries of fortune (Ibid.: 26). The "nature" that princes must manipulate is human nature, which is "variable" (Ibid.: 24). People can be easily persuaded, but not easily kept in that state without force. Virtù-ous princes therefore must be willing to manipulate human nature by coercing people into a continuous state of persuasion, thus ensuring that they "remain powerful, secure, honored, and happy" (Ibid.: 25). An interesting example of the importance of virtù mastering fortuna is the treatment of Cyrus (Ibid.: 23). Machiavelli here takes his lead from the account of Cyrus given by the historian Herodotus rather than that given by Xenophon in The Education of Cyrus. An important difference, as pointed out by Newell, is that Xenophon's Cyrus relies too heavily on fortune, whereas Herodotus' version fits Machiavelli's model of an “armed prophet” (Newell 2013: 235236). The subtle lesson here is that in order for Cyrus to be an example worthy of emulation, he must be presented as relying on his own virtù, rather than fortuna.

To the inattentive reader, Machiavelli's examples of successful and unsuccessful statesmen might obscure the ontological implications of these new categories. On the surface

\footnotetext{
${ }^{188}$ This is a simplification of Aristotelian hylomorphism, the nuanced version of which is discussed above in the section on the Metaphysics.
} 
they read like a simple list of political methods that have either worked or failed. ${ }^{189}$ However, we can extract from these lessons in political strategy some more general teachings concerning man's relationship to nature - that is, to fortune. The lessons concerning how princes can attain and consolidate their power over other men contain the ontological transformations necessary to help mankind as it seeks to increase its power over nature. This is implied throughout The Prince, but stated more explicitly in chapter 25 where Machiavelli admits that what he has said so far concerns "opposing fortune in general" (Ibid.: 99; italics mine). The following discussion of Bacon's conception of science will bring this into focus, though we can say for now that Bacon indicates his debt to Machiavelli several times in his works. ${ }^{190}$

The lessons concerning "opposing fortune in general" are that men must be aware of its tendencies and behavioral patterns in order to channel it in the preferred direction. From the behavioral fact that men react more reliably to fear than to love, Machiavelli draws the lesson that virtù-ous princes must rule by fear in order to produce the desired form in the matter of their subjects. My use of "channel" to describe virtù's relation to nature is intentional, since Machiavelli himself symbolizes fortuna with a river. Rivers can overflow their banks if left to themselves, bringing people to ruin. This is important insofar as it suggests that Machiavelli intends his lessons to apply to non-human nature as well. ${ }^{191}$ Skillful planning and construction

\footnotetext{
189 The interpretation of Machiavelli is primarily a strategist of realpolitik is dominant within the Realist tradition in the field of International Relations. For example, see Kenneth Waltz (1959: 212): "That Machiavelli was the theorist of Realpolitik makes it easy to assume that to have a general understanding of Realpolitik is to have an adequate understanding of Machiavelli himself."

Also, Michael Doyle (1997: 95): "Machiavelli's great contribution is to provide historical depth, beginnings and endings, dynamics to the analysis of the state of war. He tells how individual political entrepreneurship makes states as well as how states expand and why they fail."

${ }^{190}$ Cf. Harvey Mansfield (1998: 121): "These authors fill out and develop Machiavelli's enterprise - for example, Bacon and Descartes - so that they can be understood as his captains."

${ }^{191}$ Roger Masters (1996) argues that beneath Machiavelli's specific political prescriptions is a coherent philosophical theory of nature, due in large part to the analogy between fortune and a river. Some of his claims will be explored below.
} 
can channel the river away from villages towards, say, fields in need of irrigation. ${ }^{192}$ The point is that nature is a powerful force that men cannot afford to ignore. It is capricious and unreliable, ${ }^{193}$ so the classical approach of mirroring it or deriving standards of moral and political life from it leaves men insecure. However, its power can be repurposed and redirected if one knows the rules of its behavior.

Another crucial, and related, Machiavellian notion is his famous repudiation of classical idealism. Instead of uselessly contemplating imaginary republics based on how men ought to live, he begins by observing how men actually live. The reason for this is that political success in the real world depends on knowing how best to control and manipulate human nature, regardless of the justice or injustice of such methods. This requires knowledge of how men behave, what animates and motivates them, and how they can be manipulated and brought into a state of constant persuasion and obedience.

This distinction between is and ought points to the central difference between ancient and modern science. Bacon's explicit development of Machiavellian principles into a rejection of Aristotelian science is foreshadowed by Machiavelli himself. Ancient political philosophy is Machiavelli's target, insofar as it contemplated politics from the perspective of the human good; his new political science begins from the perspective of patterns of human behavior. For example, in a famous passage, he writes the following:

And many have imagined republics and principalities that have never been seen or known to exist in truth; for it is so far from how one lives to how one should live that he who lets go of what is done for what should be done learns his ruin rather than his preservation (Ibid.: 61).

\footnotetext{
${ }^{192}$ The point about channeling rivers in favourable directions is my addition to the example, though I take it to be in the spirit of Machiavelli.

${ }^{193}$ In the river analogy, Machiavelli curiously goes beyond attributing unreliability to nature, and implies that she actively seeks out weakness and exploits them: "fortune...demonstrates her power where virtue has not been put in order to resist her and therefore turns her impetus where she knows that dams and dikes have not been made to contain her" (Ibid.: 98-99).
} 
This parallels the importance ancient science gave to final causes as opposed to modern science's interest in efficient causes. ${ }^{194}$ The new political science is superior to the old, Machiavelli claims, because success in the world requires knowledge of how men act. Similarly, and as Bacon will explicitly argue, the new natural science is superior because the behavioral patterns it studies allow men to better protect themselves from the capriciousness of nature. This political and scientific realism ${ }^{195}$ is related to the ability of men to control fortuna, in that the only way for them to reliably do so is by understanding natural processes. ${ }^{196}$ Machiavelli does not formulate universal laws of the behavior of human or non-human nature, nor does he rely on a method in the manner of Descartes or Bacon. However, his political science is based on knowledge of behavior. ${ }^{197}$ It is this behavioral focus which provided the foundation for Bacon's methodical science and formulation of law-like generalizations. ${ }^{198}$

Bacon, as will be argued in what follows, accepts the general thrust of Machiavelli's ontology of nature, fortuna, and virtù. However, it is too simplistic to portray Bacon's relationship to Machiavelli as one of repurposing, as Richard Kennington seems to do. In "Bacon's Humanitarian Revision of Machiavelli," Kennington begins with the insight that Bacon's humanitarianism signifies a meaningful difference from Machiavelli (Ibid.: 57-77). On the surface level, it is true that Bacon's framing of the scientific mastery of nature as serving

\footnotetext{
194 See, for example, Bacon's summary of Machiavelli's teaching on this point, found in The Advancement of Learning: "So that we are much beholden to Machiavel and others, that write what men do, and not what they ought to do" (Bacon 1952: 2.22.9).

195 This formulation should not be confused with "scientific realism," as used in philosophy of science literature to denote the theory that scientific theories are true, and not mere useful concepts.

${ }^{196}$ Leo Strauss makes the connection between Machiavelli and contemporary social science, though largely in passing (Strauss 1999: 3-4). Harvey Mansfield argues in more depth that Machiavelli is indirectly the founder of the fact-value distinction in political science: "We will not find the fact-value distinction in Machiavelli, for he passes value judgments right and left with unmethodical abandon. But we do find a realism that was ancestor or parent of the fact-value distinction in Machiavelli's famous call, in chapter 15 of The Prince, not to depart from what is done for what ought to be done" (Mansfield 1981: 293).

197 At one point, Mansfield refers to Machiavelli's “behavioral political science” (Mansfield 1981: 299).

${ }^{198}$ Cf. Mansfield (1998: 21): "Machiavelli adumbrates the modern scientific understanding of nature that, with Bacon, abandons natural beings and begins the search for natural laws, but he does no more than adumbrate."
} 
mankind anticipates Descartes far more than it echoes Machiavelli. This framing was primarily a rhetorical move, however, insofar as it made the radically new conception of science palatable to a world still largely under the influence of Christian ideas. Both Bacon and Descartes justified their projects as following the divine imperative to seek the good of all men. Yet this by itself is no meaningful departure from Machiavelli. Indeed, it takes no real imagination at all to justify the proposals in The Prince in humanitarian language: if statesmen would follow Machiavelli's advice Italy would enjoy a long period of stability and peace. ${ }^{199}$ As he might have put it, it was actually the ancients' insistence on modelling politics on "imagined republics and principalities" (Machiavelli 1998: 61) that was to blame for the state of disorder it was experiencing in his day. ${ }^{200}$ Thus it seems that no substantive change is signified by framing mastery of nature as a project that will benefit people.

Kennington then points to a deeper meaning of humanitarianism that does signify a real departure from Machiavelli (Kennington 2004: 57). Humanitarianism, understood as placing one's allegiance with universal humanity over and above the local political community, does seem foreign to Machiavelli. Bacon's utopian humanitarianism, argues Kennington, is different than Machiavelli's political realism. This utopianism, he argues, points to the essential difference between the two thinkers. As he puts it, Machiavelli was a realist through and through, and only coaxed statesmen to master fortuna for political goals; Bacon was a utopian who coaxed scientists to master nature for the physical good of men everywhere. Central to this modification of Machiavelli is a new application of the goal of mastery beyond the sphere of

\footnotetext{
199 "Having considered... whether there is matter to give opportunity to someone prudent and virtuous to introduce a form that would bring honor to him and good to the community of men..." (Machiavelli 1998: 101-102; my emphasis).

${ }^{200}$ Harvey Mansfield makes a similar point on the "Conversations with Bill Kristol" podcast: "[Machiavelli] thinks that it would be good for mankind to have a greater display of virtue, and that this will come about by following his advice. Therefore he's a kind of master conspirator, advising everybody else to conspire against each other, but he himself uses their counteraction for an end which is above them, and that's for the general improvement of mankind" (Kristol 2014).
} 
politics. Writes Kennington: "Bacon universalizes the range of mastery to 'lordship over the universe' and locates the means in science or the method of science" (Ibid.: 60). Related to this is the claim that "inventions and arts are more benevolent than even the supreme political actions, and that the arts or, rather, the method that can discover the arts, also has greater power" (Ibid.: 61). In other words, Kennington's Machiavelli was solely interested in controlling fortune in political life, and Bacon transplanted this Machiavellian interest into the more general sphere of non-human nature.

The limitation of this interpretation is its claim that Machiavelli himself did not already intend for his teachings on mastering fortuna to be generalized to non-human nature. But as we have seen, that is already entailed by his ontological categories. Nature itself, of which human nature is a part, is variable and capricious. Nature is a source of immense power which can and ought to be understood and redirected in ways that improve human life. Roger Masters provides an insightful commentary on the role of technology and natural science in Machiavelli, based on his knowledge of and work with Leonardo da Vinci. Masters argues that Da Vinci's work as an inventor and engineer inspired Machiavelli. For instance, they were both involved in the Florentine project to redirect the Arno River in 1503-1504 (Masters 1996: 57). It is worth recalling that Machiavelli's own comparison of fortune to a river is in the context of generalizing nature-as-fortune to "opposing fortune in general" (Machiavelli 1998: 99). Masters takes this as plausible textual evidence that Da Vinci's technological use of nature is present in Machiavelli as well. Masters' thesis is summed up in the following manner:

While this attempt to use technology failed, it symbolizes not only Leonardo's other plans to rechannel rivers and control water for peaceful political ends, but the broader potential of harnessing science and technology to the goals of human action (Masters 1996: 209).

Latent in Machievelli's thought, Masters therefore claims, "is the proposal that humans use natural science and technical expertise to imitate the creative power of the Judeo-Christian God" 
(Ibid.). The difference between Machiavelli and Bacon is primarily one of emphasis, not repurposing, as Kennington claims. Bacon accepted the main thrust of Machiavelli's ontology of nature, and focused on ways to understand and redirect non-human nature.

That said, there are very real differences beyond this shared emphasis. Travis Smith astutely points out that "a man can have Machiavelli as a teacher without having him as a master" (Smith 2009: 184n46; my emphasis). Another of Bacon's anticipations of Descartes is the importance given to method. Whereas Machiavelli relies on limited observations of political practice which may be open to selection bias, Bacon seeks to buttress observation with a strict method of observation and enumeration of facts. This is based on the assumption that the human intellect, unaided by tools, is incapable of attaining reliable knowledge. In fact, Machiavelli's "method" of observing politics, and therefore human nature, might be condemned by Bacon as exemplifying the worst excesses of pre-modern science, namely by hastily jumping to generalizations from a few examples. More will be said below about Bacon's use of method as a restraint on the intellect's natural wanderings and biases. The result is that Bacon is not simply Machiavelli repurposed against non-human nature. He is well within the Machiavellian understanding of nature, albeit with the aid of a method for meticulously observing and recording natural phenomena.

\section{Baconian Ends and Attunements}

The central claim of this chapter is that Bacon conceived a scientific method whose aim was mastery of non-human nature for the benefit of mankind. In itself, this is not a new claim. However, in the course of its presentation, new light will be shed on the link between this aim and the specifics of his scientific method. Much has been written on Bacon's project of mastery 
-aims- and as well as on the technical aspects of his scientific method -attunements. Gaukroger (2003), Malherbe (1996), Sargent (1996), and Butterfield (1965) offer insightful interpretations of Bacon's scientific method but generally refrain from explaining how this method facilitates mastery. John Henry's study of Bacon is a clear illustration of this tendency (Henry 2002). He rightfully stresses Bacon's interest in deriving benefits from knowledge, citing Bacon's virtual unification of truth and utility (Ibid.: 42). However, the relationship between knowledge and utility in Henry's account is such that objective knowledge is sought and then put to use. On the questions of whether the goal of utility conditions the ways in which truth is sought or the criteria by which truth is distinguished from falsehood, Henry is silent. Bacon emerges from this account as an objective observer of nature who turns the results of his clear-eyed search for knowledge into practical benefits. The possibility, overlooked by Henry, that the goal of mastery might indeed determine what is taken to be scientific, will be pursued in this chapter.

On the other side, there have been some insightful studies of Bacon's socio-political aims, including White (1968), Weinberger (1985), Lampert (1993), and Minkov (2008). They point to the goal of relieving man's estate and rightfully suggest that his new scientific methods were the means to that end. However, not much is said about the precise way in which Baconian methods facilitate mastery. Extended discussion of some of them will follow, but for now we can say that this study accepts the main thrust of their conclusions, but compliments them with a further investigation of how Bacon changed the meaning of science to serve his novel end.

Richard Kennington (2004) has drawn some connections between Bacon's method and his aims. Note, for example, the question by which he frames his essay on Bacon's ontology: “Is there a real link between Bacon's end - call it power and utility - and Bacon's means to that end, the new method of natural science?" (Ibid.: 34). He goes on to argue against the view we noted 
above in Henry according to which it is possible to draw a clear line of separation between pure science and the applied results of that science, suggesting instead that the very meaning of modern science, beginning with Bacon, was determined by the goal of applicable knowledge.

This chapter will attempt to advance this line of inquiry by further demonstrating how Bacon's method serves his project of mastery. Using the terms of the organizing framework of this dissertation, it will clarify how Bacon's end - mastery of nature - played a role in determining the things his scientific method was attuned to.

This technological project had social and political implications; the human mastery of nature signified a new political project. ${ }^{201}$ The means were carefully selected in the service of this end, namely knowledge of the laws of cause and effect according to which all matter behaves. Knowing the combination of causes and initial conditions allows men to bring about the desired effects at will. To this extent, Descartes shares much with Bacon, although some important philosophical differences remain, the largest of which is the absence of clear political goals in Descartes. He does not foresee or describe a radically new political order based on the mastery of nature, but rather a "smoothing out," as it were, of the existing order once metaphysical and theological disputes could be peacefully settled.

Despite their aforementioned epistemological differences, their conceptions of science were remarkably similar in aims and attunements. Bacon's mature thoughts on scientific inquiry are found in his magnum opus, The Great Renewal, although he died before it could be completed. The theoretical core, however, was contained in the second part, The New Organon, named in direct reference to Aristotle's Organon. The preface to The New Organon, as well as the general introduction to The Great Renewal, entitled "Plan of the Work," contain helpful

\footnotetext{
${ }^{201}$ Bacon provides an outline of what a politics enlightened by technology might look like in The New Atlantis. The details of his specific political programme are not important to the argument of this dissertation, but a brief description is given in the sixth chapter below.
} 
summaries of the aims and attunements of Baconian science. The exposition of Bacon's conception of science will therefore begin with these writings before turning to the body of The New Organon itself for clarification. Together, these introductory writings emphasize three related themes: the goals of inquiry, the importance of method, and the difference between Bacon's approach and the ancient one he hoped to overcome.

The goals of inquiry encompass the other themes. Bacon writes that his method differs from existing science by its "end, its order of demonstration, and in the starting points of its inquiry" (Bacon 2000: 15). His description of the end is worth quoting in full:

For the end we propose for our science is the discovery of arts, not of arguments, of principles and not of inferences from principles, of signs and indications of works and not probable reasonings. Different results follow from our different design. They [i.e. ancients] defeat and conquer their adversary by disputations; we conquer nature by work (Ibid.: 15-16).

The first point made here is that his method is useful (arts, not arguments). The subtext of his new organon is that it is a refutation of the old organon, and hence every word in the text should be understood within the context of the ancient science it is replacing. Bacon anticipates Descartes' claim that his predecessors pursued arguments and sophistical subtleties rather than results, and he orients his inquiry towards tangible benefits. He then makes "principles...signs and indications" an end, rather than "inferences from principles... [and] probable reasonings" (Ibid.). These all seem to be indicators of certainty, or at the very least reasonable sources of reliability. Again, we see a similarity to Descartes in this bringing together of certainty and utility. True utility requires certain knowledge of laws of cause and effect.

The second sentence quoted above indicates that Bacon is aware of what is the central contention of this dissertation, namely that his new method will produce a different set of conclusions than the ancient scientific approach. That is, in fact, the raison d'etre of his new method. The results are his ultimate goal; the "different design" is secondary to them and has 
been chosen precisely because it will produce results of a specific kind. In other words, the result - i.e. the ability to conquer nature - is the governing principle in Baconian science.

The closing comparison between ancient science and his own reiterates what has been said so far: ancient scientists and logicians did not accomplish anything of use, but only increased discord and instability. At the risk of being repetitive, this also parallels Descartes' assessment of the ancients. The adversarial nature of ancient thought was due to its focus on disputation at the expense of works of tangible benefit, and therefore Bacon's opposite emphasis will avoid dividing men into adversarial groups and instead unite men against that which must truly be conquered: nature. That the adversary is nature rather than other men requires him to adopt a new design. The opposition between man and nature, as we have seen from the discussion of Descartes, is required in order to treat it as an object of manipulation. ${ }^{202}$

The end having been clearly stated, Bacon then defines his rigorous inductive method, or what he calls the "order of demonstration" (Ibid.: 16). He takes issue with deduction as well as induction as it is commonly practiced. The problem with deduction could be called the problem of first principles, and Bacon's complaint here would not surprise his primary interlocutor, Aristotle. Bacon grants that the rules and axioms of deductive reasoning are valid, but the problem arises with the introduction of first principles or definitions. The meaning of words, or the material on which deduction operates, is arbitrary and admits imperfection, bias, and confusion. Although the deductive syllogism appears to be objective and mathematically certain, the arbitrariness of starting definitions makes it an "underlying fraud" where "everything falls to pieces" (Ibid.: 16). This is a noteworthy difference between himself and Descartes, who purports

\footnotetext{
${ }^{202}$ The subtitle of the preface to The Great Renewal contains an illustrative depiction of the man-nature relationship: "On the state of the sciences, that it is neither prosperous nor far advanced; and that a quite different way must be opened up for the human intellect than men have known in the past, and new aids devised, so that the mind may exercise its right over nature" (Ibid.: 6; my emphasis).
} 
to have developed a completely syllogistic system derived from indubitable first principles and definitions. Even he, though, was shown to answer this Baconian objection with difficulty, in that his solution to the arbitrariness of his first principle was to introduce the infamous Cartesian circle. The problem of first principles ultimately means he has to rely on moral, rather than, metaphysical, certainty.

Bacon's concern was not whether deduction entails logical fallacies, but whether or not it remains faithful to nature and produces results. Since deduction allows for deviations from nature, depending on the set of primary definitions, it is not worthy of his end; "[f]or we regard induction as the form of demonstration which respects the senses, stays close to nature, fosters results and is almost involved in them itself" (Ibid.).

His method of induction, too, is more demanding than others. He complains that most practitioners of induction note a few examples and hastily derive general principles that do not reflect the complexity of nature. It is not the mere quantity of observations justifying the inductive inference that is at issue, however. Anthony Quinton points out that the problem with previous methods of induction was that they generalized from only favorable instances (Quinton 1980: 51). Bacon does not name names, although something like Aristotle's method of deriving ontological truths from common sense observations of nature seems to be the target. We will see that Bacon avoids this error by seeking out falsifying instances, which is why many commentators refer to the Baconian method as "eliminative induction" (Gaukroger 2003: 138; Lane 1999: 181). Bacon's inductive method shares Aristotle's respect for the senses, contra Descartes, but avoids hasty generalizations. Instead, "by our method, axioms are gradually elicited step by step, so that we reach the most general axioms only at the very end" (Bacon 2000: 17). The effect of such a rigorous method is stated nicely in Fulton Anderson's influential 
study of Bacon: "The understanding, therefore, is not to be supplied with wings but rather is to be hung with weights" (Anderson 1948: 188).

His discussion of the "starting points" of inquiry makes the typical modern point that he will accept nothing on the basis of authority or tradition, but intends to discover everything on his own and compel all principles "to give an account as to what extent they are firmly established" (Bacon 2000: 17). This insistence on escaping the influence of pre-rational or prescientific judgements is indeed central to the identity of modern thought, as we see in Descartes too. It is a clear negation of the classical approach of beginning with opinions, as in Plato, or common sense observations of the material world, as in Aristotle. Two essays in Leo Strauss's What Is Political Philosophy? And Other Essays draw out this difference. “On Classical Political Philosophy" describes the classical relationship between philosophical and prephilosophical knowledge in the following manner: "Yet there is a straight and almost continuous way leading from the pre-philosophic to the philosophic approach” (Strauss 1988: 81). By contrast, Hobbes' distinctly modern approach is this: "Hobbes attempts to replace that 'common sense' understanding by a scientific understanding of man" (Ibid.: 181). Ancient natural and political science treated opinions and common sense as the material for philosophy to clarify, whereas modern thought tends to treat them as sources of confusion and error that must be replaced by scientific truths. Insofar as Bacon examines all starting points on their own merits he fits nicely into this pattern.

Thus, there is a clear connection between his goal of conquering nature, the true inductive method, and rationally examining all principles and observations, insofar as verifiable observations and proper induction from them to intermediate and eventually general principles produces the knowledge that his end requires. The other themes of the introductory writings, 
namely method and the difference between ancient and modern scientific inquiry, have emerged in the discussion of his goals. A few further clarifications remain. His teaching regarding method is not simply that he has devised a new one, but that inquiry must always be guided by a clear method in order to prevent the mind from going astray. In a sense, the problem with other forms of induction is that they had no method. Machiavelli's use of historical observations is perhaps guilty of Bacon's charge here.

For Bacon, a method is a tool used by the mind to better understand the world, and is analogous to physical tools used by the body. They are necessary because the senses by themselves are weak and prone to deception. There are some things that are beyond their grasp, and there are some things within their grasp that they nevertheless misapprehend. In an interesting anticipation of Nietzschean perspectivism or post-positivist philosophy of science, he writes that "the evidence and information given by the senses is always based on the analogy of man not of the universe; it is a very great error to assert that the senses are the measure of things" (Bacon 2000: 18). ${ }^{203}$ Where Bacon departs from these sceptical positions is his insistence that the weakness of the senses can simply be corrected with the proper tools. He compares his position to the ancient Greek sceptics:

In its initial positions our way agrees to some extent with the method of the supporters of lack of conviction; but in the end our ways are far apart and strongly opposed....They thereupon proceed to destroy the authority of sense and intellect; but we devise and provide assistance to them (Ibid.: 1.37).

The weakness of the senses necessitates an instrument to guide them and prevent them from going astray and jumping to generalizations. The function of his method is to channel the activity of the intellect and serve as an intermediary between it and the world. The method is

\footnotetext{
${ }^{203}$ This point is worth comparing with Weinberger's suggestion that Bacon was aware of the limitations of his method that would later be exploited by Nietzsche and Heidegger, and was able to warn of such excesses (Weinberger 1985: 19-20). Weinberger presents Bacon as a moderate defender of modern science who was aware of the dangers of a utopian approach to politics and society.
} 
essentially a plan for controlling experiments and itemizing their results. The experiments observe and record natural behavior, and the scientist observes and records the tabled results without having to bother with attempting to directly observe nature itself, "and therefore little is left to the power and excellence of the intelligence" (Ibid.: 11). The paradoxical secret behind the increase of man's power over nature, Bacon claims, is to limit the role of the individual's intelligence. ${ }^{204}$ Put differently, in order to unleash the full human potential, he greatly restricts the role of the intellect. By constraining the intellect "we have made the senses...sacred high priests of nature and skilled interpreters of its oracles" (Ibid.: 18). Although not as explicit about this paradox, Descartes assumes a similar dynamic. Method plays a similar role in his thought, insofar as it constrains the individual's capacity for personal judgement.

Michael Oakeshott observes that the centrality of method is the primary distinctive of modern rationalism. ${ }^{205}$ Method consists of the reduction of thinking to following rules; it is a “consciously formulated technique of research" (Oakeshott 1991:18). "The doctrine of the Novum Organum," he writes, "may be summed up, from our point of view, as the sovereignty of technique" (Ibid.: 20-21). It is worth noting that Oakeshott sees Bacon and Descartes as the founders of modern rationalism because of their emphasis on method.

Bacon's goal and method are directly opposed to earlier methods of inquiry, though he is guarded in his acknowledgment of this fact. The comparison of his method to physical tools brings to mind the image of attempting physical labour without the required tools: "would not a sensible spectator regard it as an act of utter lunacy?" (Bacon 2000: 28). He reminds the reader that if his analogy holds, this is indeed the state of science in his day. The "naked intellect" is left attempting tasks for which it is not fitted and for which it now has a helpful tool (Ibid.: 29).

\footnotetext{
${ }^{204}$ Recall Anderson's metaphor of hanging weights on the intellect, cited above.

${ }^{205}$ By "rationalism" Oakeshott refers to the modern faith in the human mind to solve problems, not merely the rival of empiricism. His rationalism includes Bacon as well as Descartes.
} 
Such "lunacy," being a "systematic and methodical act of insanity," would appear damning to the proponents of such misguided intellectual activity, but here Bacon softens his attitude toward the ancients. He frames the issue as one of different methods with different goals so as to minimize the appearance of conflict. ${ }^{206}$ With all modesty he admits that he claims more results than the ancients but, importantly, not by the same methods as they used. To claim better results by doing the same thing is to assert one's superiority, which he explicitly avoids. He merely claims to be engaging in an entirely different practice than ancient physicians and metaphysicians (Ibid.: 28). Ancient philosophy is extolled for its usefulness in "fueling disputations, adorning discourses and being successfully employed in academic instruction and

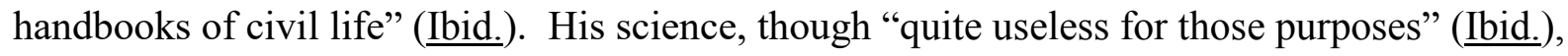
has the potential to reduce human suffering and ease the labour required to produce the means of commodious living. According to this framing, two different methods for two different goals. He is not better than them at their own game, he is playing an entirely different game.

This framing of the relationship obscures several important points. First, even granting his claim that the methods and goals are entirely different, he still implies the superiority of his method. The modesty of his claim, that achieving better results through a different method does not imply intellectual superiority, is offset by the only remaining possibility that his method is superior insofar as it is conducive to better results. Moreover, his method aims at the alleviation of human suffering. Implied in this discussion is that he cares more about reducing suffering than the ancients did. If Bacon can be described with some justice as one of the great "partisans of humanity," due primarily to his method, what does that make Aristotle (Rahe 1994: 47)? This

\footnotetext{
206 This is slightly humorous given that the title "New Organon" quite literally implies a replacement of the old approach.
} 
apparently innocent presentation of the two different methods implies a subtle but damning moral critique of the lack of humanitarian concern implicit in the ancients.

Farrington's classic study of Bacon goes even further, using textual evidence to highlight the explicit moral judgment of the ancients. Accordingly, Bacon's disgust with Aristotle was "not intellectual but moral," due to the fact that his writings were "barren of the production of works for the benefit of the life of man" (Farrington 1964: 30). Bacon saw them as "morally indifferent to the plight of mankind" and lacking in charity, which Bacon defined as "meeting people's needs, not quarreling with their opinions" (Ibid.: 20, 30). Farrington derives these conclusions from Bacon's private words spoken to his chaplain; it is not hard to understand why he might have kept his true thoughts concealed from the general public, given the importance he attached to giving his project the appearance of conforming to, or at least not conflicting with, the prevailing orthodoxies of his day.

Second, it conceals the fact that the old method did purport to provide knowledge of nature. Indeed, Bacon himself speaks of the old methods of deduction and hasty induction as attempting and failing to provide knowledge of nature. Deduction provides no knowledge of nature because it depends on arbitrary definitions, and lazy induction makes generalizations without observing all of the relevant particulars and counterexamples. He refers to ancient practice as "anticipation of nature" as opposed to his own "interpretation of nature" (Bacon 2000: 1.26). The problem with ancient science was that it "anticipated," by arbitrary deduction or hasty generalization, without the appropriate amount of care. So it seems that Bacon intentionally overstated the difference in goals. Ancient science was not limited to disputations and academic instruction; it sought knowledge of nature and, according to Bacon, its poor methods limited its success. 
Finally, Bacon will go on to treat ancient philosophy as one of the idols standing in the way of scientific progress. His amicable presentation in the preface must be regarded as an attempt to get potential pre-modern reactionaries to let their guard down. In order for his project to take hold, it must not seem threatening.

To that end, the introductory writings refer to the biblical wisdom literature, ${ }^{207}$ and plead with critics to be patient before criticizing his results (Ibid.: 30-31). The book of Ecclesiastes is replete with repudiations of human ambition and wisdom, and would thus seem a strange ally for Bacon. An illustrative example is his choice of Ecclesiastes 1:14: "I have seen all the works which have been done under the sun, and behold, all is vanity and striving after wind" (New American Standard Bible). In order to avoid this glaring rebuke of his project, he interprets this passage as referring to human works outside of God's design, and not to human activity that accords with divine ends. "If we labour in your works," he writes, "you will make us to share in your vision and in your Sabbath" (Ibid.: 24). The reference to the Sabbath hints at the eschatological nature of the Baconian project. ${ }^{208}$ Throughout the old and new testaments, sharing in God's Sabbath rest is, among other things, shorthand for heaven, referring to the reversal of the curse placed upon humanity in the Garden of Eden. ${ }^{209}$ Bacon intends for his new method of science to give men the means of overcoming the struggle of existence that resulted from original sin. It need hardly be said that his immanentist vision of God's Sabbath rest

\footnotetext{
${ }^{207}$ Proverbs 25:2: "It is the glory of God to conceal a matter, But the glory of kings is to search out a matter" (New American Standard Bible).

${ }^{208}$ John Henry emphasizes Bacon's Millenarianism (2002: 93-103), with specific reference to the way in which his natural scientific method was to help overturn the results of the Fall.

${ }^{209}$ For example, Hebrews 4: 1-3: "Therefore, let us fear if, while a promise remains of entering His rest, any one of you may seem to have come short of it. For indeed we have had good news preached to us, just as they also; but the word they heard did not profit them, because it was not united by faith in those who heard. For we who have believed enter that rest, just as He has said, 'As I swore in my wrath, they shall not enter my rest,' although His works were finished from the foundation of the world" (New American Standard Bible).
} 
occurring in time and as a result of human activity was a radical departure from traditional interpretations of the biblical vision.

Farrington, interestingly, denies this claim, suggesting instead that Bacon was firmly within the biblical tradition. His aptly named chapter, "Out with Aristotle and In with the Bible," says much on its own. Using various pieces of textual evidence, from the name of Bacon's island utopia (Bensalem $=$ Son of Peace) or its scientific institution $($ The College of the Six Days' Works), to the general framing of his project in the language of dominion over creation, Farrington concludes that Bacon "found within the bible a world-outlook in which his new conception of science could take root and grow" (Farrington 1964: 25-26). With the Fall man lost his innocence and dominion over creation, and Farrington suggests that while religion can restore man's innocence, Baconian science can restore dominion over creation (Ibid.: 29).

Farrington is right to notice the themes of creation and salvation in Bacon's work, but he makes the mistake of confusing any solution to the Fall with the specifically biblical solution to the fall, thereby ignoring the hubristic nature of replacing Christ with human scientific endeavor. ${ }^{210}$ Bacon's method indeed permits one to stop relying on salvation from Christ, since men would be given the tools to overcome the curse of Fall without recourse to divine grace. Indeed, rather than falling within the faithful biblical tradition, one can say with some justice that Bacon's approach has more in common with the builders of the tower of Babel ${ }^{211}$ than with the virtues of Christian humility and dependence on God. David C. Innes makes this point in more depth in "Bacon's New Atlantis: The Christian Hope and the Modern Hope” (Innes 1994).

\footnotetext{
${ }^{210}$ More recently, Stephen McKnight (2006) has argued that Bacon's Christianity was more than rhetorical. McKnight specifically opposes his thesis to the view, presented here, that Bacon's appeals to Christianity served the primarily rhetorical function of making Bacon's anti-christian project appear less so. Travis Smith is more open to the possibility of rhetoric, admitting only that Bacon must "appear" to be pious, and that "any 'arch-heretic' sharing his circumstances would do likewise" (Smith 2009: 176, 170).

${ }^{211}$ Cf. Genesis 11:1-9 (New American Standard Bible).
} 
Overall, the rhetorical purpose of the introductory writings is to make his revolutionary project appear traditional and, therefore, reconcilable to the philosophical and theological authorities of his day. It is in the body of The New Organon that he reveals the extent to which he means to overthrow those authorities and replace them with his new scientific method. Despite his words here, he sees ancient philosophy as a threat to his project, and therefore must replace it, not just supplement it as one of many possible methods.

\section{Bacon's Refutation of Ancient Science and Philosophy}

Before presenting the details of his method, Bacon must undermine the existing approach. He does this by exposing the four "idols" that have led men astray: idols of the tribe, cave, marketplace, and theatre (Ibid.: 1.29-30). ${ }^{212}$ The doctrine of the idols should not be thought of as a mere preliminary to the exposition of the method. As with Descartes, the initial means of purging false opinions from the mind are just as philosophically interesting as the means whereby true opinions are reached. Indeed, in Truth and Method Gadamer writes that the doctrine of the idols is a more significant achievement than the inductive method itself (Gadamer 2004: 344). This claim occurs in the chapter devoted to analyzing "historically effected consciousness" (Ibid.: 336-382), which for Gadamer is a component of the "ontological structure of understanding" (Ibid.: 294) and the very thing that modern scientific method seeks to overcome. This refers to the fact that all understanding, thinking, and interpreting takes place within a historically-constructed framework of meaning, or set of prejudices. The idols Bacon exposes are the various prejudices that make objective interpretation of nature impossible, some of which he recognizes to be the products of historically-contingent linguistic and conceptual

\footnotetext{
${ }^{212}$ All citations to the body of The New Organon will note the book and aphorism, not page number.
} 
prejudices, or what Gadamer calls the "historicity of experience" (Ibid.: 342). ${ }^{213}$ The fact that Bacon attributes the previous failures of science to such idols makes him a textbook example of Gadamer's claim that "the fundamental prejudice of the enlightenment is the prejudice against prejudice itself" (Ibid.: 273). It is only by unmasking these prejudices as prejudices that we can overcome them and achieve an unprejudiced view of natural operations, Bacon believes.

He organizes these prejudices into four groups: idols of the tribe, cave, marketplace, and theatre. Idols of the tribe are the elements of human nature and intellect that impede the mind's access to truth. That is, the mind is not a passive recipient of truth, but allows its tendencies and preferences to corrupt discovery. As noted above, this is the basis of his partial agreement with ancient sceptics, namely that the mind sees what it wants to see and cannot be trusted to faithfully apprehend the world as it is. Some examples of this natural tendency are the mind's inability to be content with uncaused brute facts, its desire to impose order and regularity on everything it observes, and to impose human purposes on nature (Ibid.: 1.45-50). In short, it is human nature for men to see what they want to see, and thus the unaided intellect is not a reliable guide to truth. This develops his earlier point about the weakness of the senses themselves; here the problem is how the mind interprets sensory data and imposes an unnatural and arbitrary order on the world. The result is that "the human understanding is carried away to abstractions by its own nature, and pretends that things which are in flux are unchanging (Ibid.: 1.51).

\footnotetext{
${ }^{213}$ Among the idols are the effects of education, language, and mistaken philosophies. Of the four idols, Bacon directly attributes one to objective - and hence not historically contingent - facts about human nature, though there is debate about the extent to which the other three can be traced to human nature as well. More will be said about this ambiguity below. Gadamer, however, would be suspicious of the attempt to describe anything, including what we take to be objective facts, as objective and beyond history. For example: "If we are trying to understand a historical phenomenon from the historical distance that is characteristic of our hermeneutical situation, we are always already affected by history. It determines in advance both what seems to us worth inquiring about and what will appear as an object of investigation, and we more or less forget half of what is really there-in fact, we miss the whole truth of the phenomenon—when we take its immediate appearance as the whole truth" (Ibid.: 300).
} 
These tendencies are common to men and universal in their effects. Idols of the cave, by contrast, are those particular influences on each individual that stand in the way of an accurate understanding of nature. Some people are affected by education, upbringing, or chance events (Ibid.: 1.53) so as to develop a taste for either novelty or tradition, logic or observation, or become attuned to either differences or similarities. The susceptibility to be carried away by particular effects is only made possible for the nature common to all men, so the idols of the cave should be classified as particular effects of the universal idols of the tribe. Since the idols particular to each individual are driven by preference and inclination, the solutions to them are careful observation coupled with an awareness of the danger of following one's inclinations: "every student of nature must hold in suspicion whatever most captures and holds his understanding" (Ibid.: 1.58).

The idols of the marketplace ${ }^{214}$ are the results of communication and life together, specifically language. Words, which are the primary means of understanding nature, can never accurately reflect it, and thus lead us astray. The paradox here is that words are necessary for human life, and even Baconian scientific inquiry, but inevitably introduce errors. Harmful words are those that refer to things that do not exist or misrepresent the nature of things. "First mover" is given as an example of the first kind, and "wet" as an example of the second (Ibid.: 1.60). More careful observation, again, is the solution to these errors.

The fourth set of idols, those of the theatre, explicitly refers to mistaken philosophies and rules of proof, but a careful look shows that these philosophies are effects of the first three idols. Our desire for neat and orderly systems, our individual preferences and inclinations, and the vagaries of language result in poor abstractions from nature in the guise of systematic

\footnotetext{
214 Jardine and Silverthorne point out in a textual note that "marketplace," despite being the traditional translation, obscures the meaning. A more literal term would be "forum" or "townsquare": "the place where men meet and talk and reinforce each others' 'idols"' (Ibid.: 48n20).
} 
philosophies. He divides false philosophy into three groups: sophistic, empirical, and superstitious (Ibid.: 1.62). Sophistic and empirical philosophy mirrors the deductive-inductive distinction, and Aristotle is the representative of the first. Bacon here does not so much refute Aristotle as dismiss him, but the aspects of Aristotelianism that he deems worthy of dismissal are telling. He accuses Aristotle of making his mind up before conducting experiments, and relying on them as post hoc justifications of his dialectical conclusions. The "unilluminating distinction between act and potentiality," the claim that each body has a motion particular to it, and his theory of the human soul are all impositions on nature resulting from his usage of words (Ibid.: 1.63). More Aristotelian notions are labelled superstitious, including forms, final causes, and first causes (Ibid.: 1.65).

Bacon's largest complaint against Aristotle is that he directs his gaze beyond observables and combines observation with what we might today call metaphysics. This is precisely the problem associated with the idols of the tribe. Our unceasing desire for order compels us to go beyond brute facts to look for ultimate causes. It is worth noting that Bacon's discussion of this phenomenon uses distinctly Aristotelian language to describe what we tend to seek: things "better known in nature" (Ibid.: 1.48, 44n13). ${ }^{215}$ Similarly, our natural desire for simplicity and order leads us to suppose that heavenly bodies move in circles and that all things move towards specified ends (Ibid.: 1.45, 1.47). This is to say that Aristotle's problem was that he failed to protect himself against the idols of the tribe. Instead of refuting Aristotle's physics, Bacon shows how Aristotle's mode of thinking can be explained by the inherent weaknesses of the human intellect. Naturally, the solution to Aristotle's faulty thinking is the Baconian method, which is designed to mitigate the effects of the idols. Bacon admits that Aristotle's intellectual

\footnotetext{
${ }^{215}$ Compare with Aristotle at Physics 184a: "The natural road is from what is more familiar and clearer to us to what is clearer and better known by nature" (My emphasis).
} 
powers surpass those of everyone else, ${ }^{216}$ but without a proper method to mitigate these tendencies Aristotle's entire undertaking was hopeless. Even a mind as brilliant as his was prone to the influence of the idols of the cave, tribe, and marketplace.

Bacon is unclear about the extent to which human nature is responsible for the influence these idols have had on previous philosophies. Only the first idol is explicitly attributed to "human nature itself" (Bacon 2000: I.41). Farrington takes this downplaying of human nature at face value, and sees in it a connection with what he calls Bacon's "doctrine of the sociological distortion of truth":

The impediments which have been in the nature of society and the policies of state. That there is no composition of estate or society, nor order nor quality of persons, which have not some point of contrariety towards true knowledge (Farrington 1964: 40).

While it should be noted that Farrington does not explicitly advocate for eradicating human nature from our account of the idols, it remains true that as a matter of emphasis his interpretation tends toward a sociological, or structural, explanation of error. Fulton Anderson notes as well Bacon's decision to only attribute the first idol to human nature, but qualifies this by pointing out that the first three are "inherent" in human nature. He does not specify what is meant by "inherent," though the immediate context implies that he means something like unavoidable. The fourth idol, which for Anderson is not inherent in human nature, is primarily differentiated insofar as its "entrance into the mind can be prevented" (Anderson 1948: 104). False philosophies are historically contingent, meaning they could possibly have not arisen; they are for that reason classified as avoidable, and hence unnatural.

Whether one or three idols arise out of human nature thus turns out to bear similarities to the timeless question of whether individuals or social structures are responsible for the course of

\footnotetext{
${ }^{216}$ Although this must be weighed against his charge of lunacy against those who work without appropriate tools.
} 
human events. ${ }^{217}$ The second and third sets of idols - idols of the cave and marketplace - are either particular to each individual's upbringing or result from the intersubjective nature of language; in either case it is easy enough to see how Farrington might make connections with Bacon's more explicit sociological explanation of error. However, going as far as only attributing the first idol to human nature potentially obscures the way in which even the educational and intersubjective nature of the second and third idols are only possible because human nature is as it is. That is, we can justifiably represent the particular biases each person has, different though they may be, as products of human nature. Similarly, the mistaken terminology and definitions of the idols of the marketplace are derived from human nature. It is arguably the universal tendency to see what we want to see - i.e. the idols of the tribe combined with the vagaries of individual influences that renders the language so detached from nature. Similarly, the fact that humans use complex languages to communicate derives from human nature and is what makes the idols of the marketplace so troublesome. This is all to say that Farrington's reduction of the natural idols to one is mistaken; we can at least attribute the first three to human nature. ${ }^{218}$

Moreover, it makes sense to think of even the final set of idols, those that Anderson treated as unnatural due to their avoidability, as being derived from human nature. What are the manifold false philosophies but the products of the first three sets of idols? If we are to describe the idols of the tribe, cave, and marketplace as either directly resulting from or deriving from human nature, then we must go even further than Anderson and classify the philosophies that

\footnotetext{
${ }^{217}$ The classic formulations of the individual and social explanations are found in Hobbes and Rousseau, respectively. In contemporary social science this takes the form of the agent-structure problem. See Clark (1998), for one of many accounts of this problem.

${ }^{218}$ The naturalness of these hindrances to accurate observation of nature is corroborated by recent work in forensic science that appeals to Bacon's idols as ever-present obstacles to be overcome. Dror (2009) argues that using Bacon's doctrine of the idols to point to potential vulnerabilities in forensic science as currently practiced, it can be made increasingly scientific and objective.
} 
result from them as being similarly derived from human nature. Though Aristotle's philosophy was mistaken and avoidable, Bacon seems to suggest that it was nevertheless a product of the natural tendencies inherent in all human thinking and communication. This enigmatic claim is consistent with Bacon's portrayal of method as a type of constraint on the intellect that would direct it away from its natural habits.

It is worth recalling at this point that Bacon does not directly challenge the truth of Aristotle's natural philosophy. Svetosar Minkov notes that Bacon's refutation of the classical belief in final causes is "pragmatic" not "theoretical": "he appears to reject these traditions because of their bad effects" (Minkov 2008: 266). Some of Bacon's criticisms of Aristotle do accuse him of using arbitrary definitions and imposing order on things that are inherently disordered, but these criticisms are incidental to Bacon's intention. He sets out to bring utility, not simply a better understanding of nature. To that end, he proposes judging philosophies by their effects rather than their truth, or more specifically that the truth of a philosophy is proven by its utility:

For the discovery of products and results is like a warranty or guarantee of the truth of a philosophy....In religion we are taught that faith is shown by works; and the same principle is well applied to a philosophy, that it be judged by its fruits and, if sterile, held useless; the more so if instead of the fruits of the vine and the olive, it produces the thistles and thorns of disputes and controversy (Ibid.: 1.73).

The actual errors of Aristotelianism are secondary to the main problem of its uselessness. Its abstract claims may or may not be true - Bacon suspects they are not - but it provides no benefit and is therefore as good as false anyway. In this sense, Bacon anticipated the philosophical schools of pragmatism and scientific instrumentalism, in which theories are to be accepted if they possess predictive or explanatory power.

Though I have so far spoken of Bacon's opposition to ancient philosophy, such a formulation requires one important qualification. He opposes Socrates, Plato, and Aristotle, to 
be sure, as well as the greek sceptics, but he admires the materialist Presocratics. The Presocratics' ideas and discoveries are largely lost to history, Bacon argues, because of their relative solidity and substantiality. Democritus, in particular, is singled out for his emphasis on dissecting nature rather than abstracting from it; in so doing he "penetrated more deeply into nature than the others (Ibid.: 1.51). The river of time has carried the weightless thoughts of Plato and Aristotle while, like an actual river, leaving the solid to sink to the bottom and remain lost (Ibid.: 1.71). ${ }^{219}$ That Bacon understands himself as reviving aspects of a philosophical tradition pre-dating Socrates himself is no accident. William Sessions suggests that Bacon held as a "cosmic principle" that "in the deepest past can be found the future" (Sessions 1990: 247). Bacon derived this principle both from the content of Presocratic ideas themselves and from the very presence of their ideas in his new method for the future. ${ }^{220}$

It should not be assumed that Bacon offered a complete endorsement of the Presocratics, insofar as they lacked his method. His treatment of them is more positive than his treatment of Aristotle because of the continuing influence of Aristotle, but contra Anderson we can say that he does not intend to simply revive Democritean natural science. ${ }^{221}$ Anderson's claim is rooted in a prioritization of the metaphysics of materialism shared by the two thinkers, ${ }^{222}$ but fails to take into account the very real methodological differences. For example, Bacon hints at a

\footnotetext{
${ }^{219}$ It is beyond the bounds of this project to cross-examine in depth the theory of history implied here, although it seems to undermine the possibility of progress. If weightless and useless ideas have are more easily passed to posterity, the progress that Bacon is instigating will face an uphill battle and will not be nearly as automatic as often assumed.

${ }^{220}$ This can be compared to the remark by Nietzsche, who himself thought philosophy took a wrong turn with Plato, in Beyond Good and Evil: "'Bad! Bad! What? Is he not going - backwards?' Yes! But you ill understand him if you complain about it. He goes backwards as everyone goes backwards who wants to take a big jump" (Nietzsche 1994: Aph. \#280).

${ }^{221}$ For example: "Nevertheless, it is Bacon's bold design to announce a revival of the theories of Democritus" (Anderson 1948: 49).

${ }^{222}$ Anderson summarizes what Bacon approvingly saw in Democritus: "Democritus rejects final causes, leaves mind out of nature, avoids abstract forms, and accepts positively formed matter as the source of all things and their activities" (Anderson 1948: 48).

Richard Kennington, though, will even point to differences in the ontologies of Bacon and Democritus: "Bacon was always a materialist, but never an atomist" (Kennington 2004: 10).
} 
criticism of Democritus in 1.57: there Democritus "is so concerned with the particles of things that he almost forgets their structures." That is, in his noble inquiries into the material constitution of things, he neglects knowledge of the constituted things themselves, which a science that aims for utility must possess.

This look at Bacon's verdict against unaided intellectual activity and ancient science revealed that previous scientific errors were not simply the result of inferior minds or lack of effort; the wisest men cannot help but fall into error - which, as we have seen, is almost synonymous with uselessness - if they rely on their own wisdom, just as the strongest men cannot move a heavy obelisk with their bare hands (Ibid.: 28). This is not to denigrate the intellects of Plato or Aristotle or the strength of the mover, but it does point to the need for appropriate tools. The human intellect falls into a number of errors when left to its own devices, outlined by the four idols of the mind and put on display by Aristotle himself. The solution is not to retreat into scepticism, but to provide such tools. The Baconian method, by using controlled experiments as an intermediary between mind and world, provides a means for men to gain useful knowledge of nature. The experiment observes nature, insofar as it directly measures or quantifies a natural process or event, and the scientist simply observes the results of the experiment. The method acts as a constraint on the scientist, limiting his role to the meticulous recording of objective facts. The specifics of this experimental method will be discussed below, but for now it has sufficed to show how the need for it follows from Bacon's analysis of previous thinkers and traditions of scientific inquiry.

\section{Bacon's Ontology of Nature}

A complete exegesis of Bacon's ontology is beyond the scope of the present argument, 
but a few important concepts must be clarified in order to show the relationship between the experimental method and technological control. Understanding the meaning of these concepts is made all the more difficult by Bacon's insistence on using Aristotle's terms to refer to completely different categories. ${ }^{223}$ Richard Kennington is atypical among the commentators on Bacon in paying attention to the reinterpretation of nature that was required in order to bring about his social and political purposes. His analysis of Bacon's ontology focuses on Bacon's novel conception of laws of nature, and the ways in which this new conception made mastery of nature possible (Kennington 2004: 8-12, 33-56). The present analysis accepts the main lines of Kennington's interpretation, and seeks to deepen it by pointing out other ontological moves made in the service of securing control of nature and contextualizing them within broader themes in Bacon's thought.

\section{Nature}

The first ten aphorisms of book I restate the main lessons to be drawn from the introductory writings, namely that nature is something to be conquered. It can be mastered only by discovering its laws of behavior and harnessing the effects of those laws for human purposes. There is, in other words, a strict dualism between man and nature, in which man sets himself against nature as an object to be studied and manipulated. Nature is simultaneously the cause of human suffering and the source of its relief. It follows purposeless laws of behavior, but men, in their separateness from nature, can manipulate it to their purposes. ${ }^{224}$

\footnotetext{
${ }^{223}$ Cf. Bacon's words in The Advancement of Learning: "It seemeth best to keep way with antiquity usque ad aras; and therefore to retain the ancient terms, though I sometimes alter the uses and definitions" (Bacon 1952: 2.7.2; original emphasis).

${ }^{224}$ Cf. 2.2: "The final [cause] is a long way from being useful; in fact it actually distorts the sciences except in the case of human actions" (My emphasis).
} 
Using the language of men being "set against" nature as "object" to describe modern science is not new. George Grant points to the literal meaning of the german word for object (gegenstand) - i.e. that which stands against - to uncover what is implied by the modern emphasis on objective knowledge. Modern, which for Grant means technological, knowledge is objective knowledge, which is in turn knowledge of a nature that stands against us as an object of study and control (Grant 1986: 36). Grant takes the "against" in "that which stands against" in an oppositional sense, such that nature is treated with suspicion and interrogated as if it were a defendant in court. ${ }^{225}$ This attitude can be traced back to Bacon and Machiavelli. Heidegger's description of nature under technology as "standing-reserve" makes a similar point, although with the opposite connotation given to object: "whatever stands by in the sense of standingreserve no longer stands over us as object" (Heidegger 1977: 17; my emphasis). Despite the apparent disagreement over whether nature is object or not, Heidegger's point is the same as Grant's. He contrasts "standing-reserve" with "object," in that an object has independent ontological status whereas standing-reserve is simply "standing by" waiting to be called on in such a way that its ontological status depends on human purposes. ${ }^{226}$ Heidegger and Grant agree that under technology, nature is defined by its utility, not by anything that it objectively is on its own.

That we see the same conception of nature in the opening pages of The New Organon is illustrative of the centrality of technology to modern science from the very beginning. As Heidegger and Grant, among others, rightfully point out, at the core of the technological project is a radical redefinition of nature as the site of human activity and the source of man's power.

\footnotetext{
${ }^{225}$ Grant speaks of experimental research in the following terms: “...the summoning of something before us and the putting of questions to it, so that it is forced to give its reasons for being the way it is as an object" (Grant 1986: 36). ${ }^{226}$ Of course, Grant and Heidegger call attention to the way in which the technological imperative might usurp conscious human purposes in a way that Bacon did not foresee. Cf. Grant: "[Technology] is a destiny which enfolds us in its own conceptions of instrumentality, neutrality and purposiveness" (1986: 32).
} 
The inverse is also true: man is understood according to his power over nature. The opening aphorism begins: "Man is nature's agent and interpreter" (Bacon 2000: 1.1). Insofar as man understands natural processes, he is its interpreter; insofar as he acts on and through nature, he is its agent. The central themes converge in the third aphorism:

Human knowledge and human power come to the same thing, because ignorance of cause frustrates effect. For Nature is conquered only by obedience; and that which in thought is a cause, is like a rule in practice.

Nature is something to be conquered by men, who for the present purpose are not considered part of nature, and it must be conquered by imitating or obeying its regular processes. Knowledge of these processes allows men to harness nature's power by redirecting $\mathrm{it}^{227}$ and letting it do the work. The fourth aphorism clarifies the meaning of obedience in this context: "All man can do to achieve results is to bring natural bodies together and take them apart; Nature does the rest internally." Knowledge of causes and their effects allows men to bring the necessary bodies together for the end they have in view. There is a certain tension between men being set against nature in an oppositional relationship and being forced to play nature's game, so to speak. Men must obey nature in order to subdue nature and mitigate the suffering it causes.

\section{Natures}

In addition to nature as a whole, Bacon speaks of simple and compound natures. Simple natures are attributes 228 and compound natures are substances, or combinations of many simple natures. Gold, for example, is a compound nature consisting of the simple natures "tawnycoloured," "heavy with a certain weight," "not volatile," and so on (Bacon 2000: 2.5). That is, compound natures are nothing but collections of attributes. The "what-it-is-to-be" gold, to use

\footnotetext{
${ }^{227}$ Recall Machiavelli's analogy of fortuna-as-river, that the virtuous man will channel and redirect.

${ }^{228}$ Kennington describes them as "generic physical properties" (Kennington 2004: 41).
} 
Aristotelian language, is simply a list of the attributes that gold possesses. A thing is a collection of qualities. This has important implications. The first is that this signals a much different ontology of substance and attribute than Descartes'. Descartes' rationalism necessitated an intelligible substance behind all perceptible qualities, and it was this geometrical aspect of bodies that was truly knowable. Bacon, with his instrumentalism and empirical focus, is content to have the perceptible qualities exhaust the meaning of substances. A purely geometrical body behind the sensible qualities cannot be discovered by empirical experimentation and is for that reason excluded from Bacon's ontology. At 1.73 he writes that technological results are a guarantor of truth; he might also have said that they are a guarantor of being itself.

A compound nature, or single body, being a "combination of simple natures" (Ibid.: 2.5), is brought together by laws of act, which Bacon awkwardly equates with forms. The occurrence of a given simple nature is due to a specific form that caused it. From this it follows that any compound nature can be produced once one knows the causes of each simple nature. He infers from this that whosoever knows how to produce the required simple natures and can combine them in a single body can therefore produce gold.

His use of gold is certainly intentional, with its connotation of alchemy. Alchemy and the various magical arts sought the ability to transform nature in ways suitable to human purposes; Bacon is announcing that he can finally provide what the alchemists are after. For example, in 1.5 his criticism of the "alchemist and magician" is simply that they do not know how to produce results. He shares their goal, but criticises their haphazard approach to nature. On the relationship between Bacon and alchemy, Paolo Rossi writes in more oppositional terms:

"Bacon condemned magic and alchemy on ethical grounds. He accused them of imposture and of megalomania. He refuted their nonparticipatory method and their intentional unintelligibility, their attempt to replace human sweat by a few drops of elixir. But he 
borrows from the magico-alchemical tradition the idea that man can attempt to make himself the master of nature (Rossi 1996: 31).

While the end result is the same in Rossi's analysis and mine, it is important to stress the importance of Bacon's borrowing from the magical and alchemic traditions in a way that Rossi does not. Because the primary aim of Baconian science was the ability to transform nature and impose new natures on bodies, its borrowing from those traditions should be seen as vital.

Frances Yates argues for a closer relationship between Bacon and what she calls the "Renaissance magus ideal" (Yates 1984: 61). The thrust of her rebuttal to Rossi is that whereas Rossi presents Bacon as opposed to the pride of that tradition on moral grounds, Bacon can in no way be perceived as particularly humble about the aims of his method. Yates presents Bacon's method in the following manner:

By this process, eventually, the innocent communion with nature which Adam had before the Fall will be restored. Bacon's 'Great Instauration' of the sciences was intended to lead to this millennium, perhaps in a very short time (Ibid.: 62).

Even though the particularities of Bacon's method have an element of humble submission to and imitation of the latent processes of nature, the end result is no more humble than that of magic and alchemy.

John Henry's study of Bacon goes yet further, pointing out methodological and ontological similarities between magic and Baconian science. Important writers in the magical tradition like Giambattista Della Porta and Cornelius Agrippa describe the magical method, so to speak, as combining or separating certain substances based on the occult powers belonging to each. Della Porta suggests that bodies are either sympathetic or antipathetic to others; particular effects can be enhanced by combing sympathetic bodies and certain effects can be weakened or eliminated by the presence of an antipathetic body (Henry 2002: 43-45). We can compare this to Bacon's own summary of his method at I.4: “All men can do to achieve results is to bring natural 
bodies together and take them apart; Nature does the rest internally." Nature herself seems endowed with causal powers, and the role of the scientist-as-technician is merely to give her the proper materials with which to work. Once the correct bodies have been satisfactorily arranged, nature's power takes over. In this light, the "latent processes" at work in these transformations seem remarkably similar to the "occult powers" of Della Porta and Agrippa. Neither of them are empirically observable yet they mysteriously bring about changes in material bodies. These commonalities lead us to the conclusion that Bacon was heavily indebted to the magical and alchemical traditions. ${ }^{229}$

The ontology of simple and compound natures clarifies the opening sentence of book II: "The task and purpose of human power is to generate and superinduce on a given body a new nature or new natures" (Ibid.: 2.1). We must begin by discovering the form, or cause, of the desired nature, and continue by replicating the conditions that bring the form about, such that it can be produced at will. Bacon calls this approach the first axiom of the transformation of bodies. This axiom treats the physical world as consisting of bodies containing numerous simple natures in combination. One can produce any compound nature by simply introducing the causes of the desired simple natures. "This mode of operation," he concludes, "proceeds from what is constant, eternal and universal in nature, and affords vast opportunities to human power" (Ibid.: 2.5).

\section{Latent Processes and Structures}

There is, however, a second "axiom," or approach, to manipulating nature. It begins by distinguishing between simple natures, on the one hand, and latent processes and structures, on

\footnotetext{
${ }^{229}$ Henry writes that "By introducing pragmatism and experimentalism from magic into natural philosophy, Bacon radically changed natural philosophy and made it potentially far more fruitful" (Henry 2002: 67).
} 
the other hand. The latent structure refers to the elementary particles that compose bodies, the epiphenomena of which are the observable simple natures. These structures, though, are imperceptible by virtue of being too small to observe; they are, however, material, and thus in principle observable and perceptible.

Instead of conceptualizing nature as consisting of isolated bodies taking on various combinations of simple natures, this approach attempts to understand, in order to replicate or manipulate, these latent processes. The latent process refers to the behavior of the elementary particles that produce the desired simple natures. These processes are more general than individual simple natures, such that understanding them will grant knowledge of how to generate multiple natures at once. This axiom would create gold not by imposing many simple natures on a given body, but would learn the process by which nature itself generates gold out of its elementary substances - that is, the specific molecular transformations bodies undergo to become gold. The emphasis here is on the elementary particles that become the base for the superstructure - i.e. the simple natures of colour, weight, solidity, etc. - rather than the epiphenomenal simple natures themselves. Bacon suggests that this axiom offers more hope than the first, which is not surprising given his belief that nature can only be conquered by obedience or imitation. The second axiom, with the importance it gives to nature's way of working on elementary particles to produce bodies with given simple natures, is more obedient than the arbitrary imposition of qualities on pre-existing bodies.

For since every natural action is transacted by means of the smallest particles, or at least by things too small to make an impression on the senses, no one should expect to master or modify nature without taking the appropriate means to grasp and take note of them (Ibid.: 2.6).

As we will see from the specifics of the experimental method itself, Bacon's final approach adopts elements of both axioms. Since he does not adopt one at the expense of the 
other, they might best be thought of as ideal types or heuristic devices intended to illustrate what is at stake in his project of mastering nature. A dogmatic application of the first axiom would consist of the alchemical attempt to make non-gold bodies gold simply by giving them the appropriate qualities. For example, at 2.9 the first axiom is explicitly linked with magic. The second axiom's emphasis on elementary particles underlying such changes is really an elaboration of the first axiom, or an account of what must be done in order to accomplish the aims of the first. That is, in order to "superinduce on a given body a new nature"230 (Ibid.: 2.1), one must manipulate nature on the level of elementary particles and processes. This relationship of elaboration or building-upon might explain Bacon's curious use of “axiom" to refer to methods of manipulating nature. In other places The New Organon uses "axiom" in a more typical way as "proposition" or "claim." Axioms are truths that are built upon via further deductions and elaborations, but never fully replaced or negated. Here, too, the axioms can be built upon or elaborated by increasingly specified axioms or methods.

In 2.9 the first axiom, inquiry after forms, is called metaphysics and related to magic, whereas the second axiom, "inquiry after the efficient and material causes, the latent process and latent structure," is called physics and related to mechanics. Recall that Bacon's opposition to magic is on the basis that it fails to attain its noble ends. In other words, Bacon's second axiom, physics, is just a more effective way of superinducing new natures on given bodies, namely by discovering the latent processes and structures underlying all physical change.

We can sum up Bacon's ontology of nature in the following manner: man is distinct from nature in such a way that he is able to impose his desires on it; nature exists as passive material

\footnotetext{
${ }^{230}$ This summary of his project, given at the outset of book II, is framed in the language of the first axiom. This is telling insofar as it demonstrates that even though the first axiom has been abrogated by the second, Bacon still sees fit to use its terminology in the central description of his aims. This is solid textual evidence in favour of the claim that the second axiom is an elaboration of the first rather than a replacement.
} 
awaiting the ordering of the scientist as technician. This is related to Bacon's downplaying of final causes or any notion of purpose, Aristotelian or otherwise. To the extent that natural processes have a purpose, that purpose begins and ends with what is good for mankind. This view of nature serves as a moral sanction for the modern project of mastery.

Mastery of nature for human ends requires making nature do things it does not do of its own accord; it requires, in other words, "superinduc[ing] on a given body a new nature or new natures" (Ibid.: 2.1). At first glance, it might seem that this can be done by discovering the causes, or forms, of each simple nature in order to manually instantiate them in objects at will. However, as Bacon reminds us, this is the short-sighted and unmethodical approach taken by magicians and alchemists. A more promising approach would be to discover the changes and causes that take place on the level of elementary particles in order to produce the variety of simple natures. This approach, or axiom, will necessarily pay more attention to the types of bodies on which it attempts to superinduce natures. For example, introducing redness in a metallic body is fundamentally different than doing the same with a piece of wood. Metal can be heated until it turns red, but wood will ignite under the same treatment. The first axiom has a difficult time accounting for that, as it treats simple natures as universally the same and caused by the same things. The second axiom, by focusing on the latent structure and process of redness will be more attuned to the material differences between metal and wood and avoids the fallacy of treating redness as an abstract quality that can be applied uniformly to any body as if it were a blank canvass. ${ }^{231}$ Each simple nature has a particular cause at the level of latent process and

\footnotetext{
${ }^{231}$ This might seem Aristotelian, in that different types of material have different capacities, or potencies, for different forms. The main difference between Bacon's view here and Aristotle's is noticed by Kennington (2004: 9). Bacon construes simple natures (predicates) is properties rather than as separately subsisting entities. That is, a Baconian simple nature does not have the ontological status that Aristotle grants to forms. Lacking any sort of ontological status on their own, simple natures have no causal power, and thus material is not intrinsically drawn toward them in the way that Aristotelian material is drawn toward that for which it has potency.
} 
structure. One off-hand remark equating latent process and structure with efficient and material cause, respectively, indicates that all qualities can be explained according to material composition and natural laws. ${ }^{232}$ Baconian nature, thus, can be reduced to matter in motion. There is no form to which matter is inherently drawn and consequently no final cause that governs or would allow the observer to evaluate a given set of material conditions.

\section{The Experimental Method}

The final task that remains is to determine how the experimental method supported and was conditioned by the Baconian project of mastery. It is worth noting that Bacon died before having the chance to ever carry out his method in great detail. What we have instead is a demonstration of his method regarding the phenomenon of heat. The basic principle behind the method is to sort out each instance of a desired nature in order to discover its necessary and sufficient conditions; that is, its cause or causes.

Keeping his second axiom in mind, he is particularly attuned to elementary particles and the material conditions for change. However, because the second axiom pertains to unobservable phenomena, latent structures and processes, there is a tradition of interpreters who for this reason reproach Bacon of straying from his empiricist presuppositions. Lisa Jardine sketches what she takes to be one of the two dominant traditions of Baconian commentary, beginning with Robert Hooke and including no less of an authority than John Stuart Mill:

[T] he crucially original feature of Baconian method, in their view, was its acknowledgement of the centrality to scientific endeavor of carefully tabulated and collated descriptions of the external qualities of natural phenomena....The goal of Baconian science, on this account, was well-confirmed, rigorously tested generalizations about those external qualities (Jardine 1990: 47).

${ }^{232}$ That is, at 2.9: “...inquiry after the efficient and material causes, the latent process and latent structure.” 
The reading of Bacon as a collector of observations is hard to reconcile with particular elements of his methodology and ontology of nature, which gave rise to an alternative tradition that sees Bacon as a system-builder in search of first principles. ${ }^{233}$ Pierre Gassendi thus describes Bacon's desire, ala Descartes, to build a new philosophy from the foundation up (Ibid.: 49). Jardine correctly notes that elements of each tradition are present in Bacon's writing, such that the search for the latent processes underlying all visible phenomena must be sought out by way of the empirical inductive method (Ibid.: 50). She goes on to suggest that the reason the opposing traditions remain at odds with each other has to do with the relation between sense data and theory. To see Bacon as a pure observationalist or as a pure deductive system-builder is to unnecessarily posit an "unbridgable gulf between the two activities" (Ibid.: 51-52). Jardine interprets the scientific methodology of the New Organon in a way that has induction naturally lead the observer to what she refers to as "the essential natures of which our senses detect only the external symptoms" (Ibid.: 49). ${ }^{234}$ The following discussion of Bacon's method is in general agreement with Jardine on this point, as well as Gaukroger's analysis (Gaukroger 2003: 132$148){ }^{235}$

In what follows we see that Bacon's method involves rigorous enumeration of instances of the presence or absence of individual natures like heat, light, colours, and the rest. ${ }^{236}$ The goal is to find the necessary and sufficient causes of each, and to eliminate spurious causes. ${ }^{237}$ Bacon presents his method by a demonstration of how it would proceed with reference to heat, and

\footnotetext{
${ }^{233}$ Anderson also refuses to group Bacon among the empiricists, due to his methodology (1948: 2).

${ }^{234}$ She does not use the terminology of latent structures or processes, though it appears that is what she has in mind.

${ }^{235}$ For example: "His [i.e. Bacon's] method revolves around the notion of going beyond merely surface appearances to get to the underlying reality" (Gaukroger 2003: 134).

${ }^{236}$ In The New Organon Bacon applies his method to the simple nature "heat," though in Valerius Terminus: Of the Interpretation of Nature he does the same with the simple nature "colour." Gaukroger analyzes that demonstration in (Gaukroger 2003: 143-145). The demonstrations are essentially the same, though as Gaukroger notes, The New Organon's account is more elaborate (Ibid.: 145).

${ }^{237}$ The terminology of "necessary and sufficient causes" is not Bacon's own, but is taken from Gaukroger's exposition (2003).
} 
begins by meticulously enumerating every known natural occurring instance of heat; this is called the "table of existence and presence" (Bacon 2000: 2.11). There are 27 specific instances, including the sun's rays, flame, and friction, as well as a $28^{\text {th }}$ entry designating "other things" (Ibid.). His next step is to enumerate a list of instances that are similar to those above but which do not produce heat; this is the "table of divergence, or of closely related absences" (Ibid.: 2.12). The first such instance is a helpful example of what he has in mind. Whereas the table of existence and presence includes the sun's rays, the second table makes note of the fact that the moon's rays, while similar to those of the sun in some ways, do not provide heat. From this he is able to narrow down the source of heat, knowing that not all rays of light from heavenly bodies are hot.

He generally refrains, at this point, from interpreting or explaining the difference between these instances, though he does occasionally allow current opinion to creep into his explanations. For example, although the moon, comets, and stars do not provide the earth with any heat, he admits that the larger fixed stars can increase the heat of the sun "when it goes under them or approaches them; as happens when the sun is in Leo and in the dog days" (Ibid.). It is common knowledge in the $21^{\text {st }}$ century that the constellation Leo is not what increases the power of the sun in mid-summer, but rather the angle at which its rays hit upon the earth. Other related absences, too, are given false explanations. However, that should not detract from the legitimacy of the instances themselves. As will be seen, the results of the method speak for themselves, and are not logically related to his own interpretations at this point in the process.

The third table - the "table of degrees" (Ibid.: 2.13) - contains instances in which the nature is present either potentially or to a certain degree. Bacon's reason for enumerating these instances is that "a nature is not accepted as a true form [i.e. cause] unless it always decreases 
when the nature itself decreases, and likewise always increases when the nature itself increases" (Ibid.). For example, he distinguishes between the extreme heat of fires and the mild warmth of living creatures, though even animals and people get warmer "from movement and exercise" (Ibid.). Enumerating greater and lesser degrees of a given nature provides even greater specificity in correlating it with prior causes. These three tables constitute the first stage of Bacon's method, or the "presentation of instances to the intellect" (Ibid.: 2.15). ${ }^{238}$ They indicate that he is looking for things, events, or conditions that are perfectly correlated with heat. The three tables together enumerate the instances of heat, the closely related absences of heat, and conditions of greater and lesser heat. To this point in the procedure, the goal has simply been to provide as many relevant observations as possible to serve as the data for the induction to come.

The next task is to "exclude" all natures or instances that do not correlate with the nature under investigation. This exclusion, or elimination, of all spurious causes is the basis of Gaukroger's term “eliminative induction":

The procedure [Bacon] elaborates, eliminative induction, is one in which various possibly contributory factors are isolated and examined in turn, to see whether they do in fact make a contribution to the effect. Those that do not are rejected, and the result is a convergence on those factors that are truly relevant. (Gaukroger 2003: 139).

Because the goal is exact correlation, natures that increase when the given nature decreases, or vice versa, are to be excluded. For the effect "heat," he rejects natures such as heavenly nature, light, texture, and rarity, since there is at least one falsifying instance of heat being present when each of these is not.

\footnotetext{
${ }^{238}$ The latin "comparentia" for "presentation" was a legal term denoting the presentation of documents to the court. Throughout The New Organon Bacon uses legal terms and analogies to describe his investigation and interrogation of nature. This is not surprising, since Bacon held a variety of legal and prosecutorial roles, including learned counsel to Queen Elizabeth and King James I, Attorney General, and Lord Chancellor (Bacon 2000: xxx-xxxi, $110 \mathrm{n} 4)$.
} 
The goal, as throughout The New Organon, is knowledge of forms, understood as laws of act or behavior. Bacon is here inferring causality from perfect correlation, and at one point he claims that a single falsifying instance is enough to disprove a causal law (Ibid.: 2.18). Precise knowledge of each and every instance that has a correlative relationship with a given nature is as good as knowledge of the causes of that nature.

This is an interesting but expected difference between himself and Descartes. Descartes' rationalism allowed him to conceive of natural laws as being imposed on matter by an immutable God. Bacon's empirical method does not allow him to infer any metaphysical relationship between natures that are observed in conjunction, even if such conjunction is perfect and constant. This does not necessarily constitute a problem for Bacon's project for, as has been argued in this chapter, his intention was not to discover nature for its own sake, but to learn how to harness nature's power for human ends. He makes the connection between correlation and human action in 2.17: "And so when we say (for example) in the inquiry into the form of heat, Reject rarity, or, rarity is not the form of heat [i.e. the nature that is perfectly correlated with heat], it is the same as if we said, Man can superinduce heat on a dense body, or on the other hand, Man can take away heat or bar it from a rare body" (Original emphasis).

Bacon's technological goal is not hampered by the objection that he has no certain knowledge of causality, metaphysical or otherwise. The precise nature of the relationship between cause and effect is unimportant. It may be that God generates the effects whenever the requisite causes come together, ${ }^{239}$ or it may be the case that Aristotelian potencies naturally strive for certain ends. So long as cause A perfectly correlates with effect B, technological

\footnotetext{
${ }^{239}$ Occasionalism was the view that causes do not directly cause their effects, but that God brings them about, almost arbitrarily. Daniel Garber provides the following definition: "On this view, the changes that one body appears to cause in another upon impact, the changes that a body can cause in a mind in producing a sensation or a mind can cause in a body in producing a voluntary action, are all due directly to God, moving bodies or producing sensations in minds on the occasion of other appropriate events" (Garber 1992: 299).
} 
manipulation of nature is possible. Bacon does not use anything like Descartes" "moral certainty," though the idea is similar. According to his own version of scientific instrumentalism it is useful probabilities of constant conjunction, not metaphysical certainty of causality per se, that allow for manipulation of nature.

Finally, after rejecting every falsifying instance, he affirms a certain instance that is perfectly correlated with heat with no falsifying or contradictory instances. In this, the "first harvest of the form of heat," he suggests that motion might be the perfect correlate: "In each and every instance, the nature of which heat is a limitation seems to be motion....it is quite obvious that in the internal parts of a body, heat causes tumult, agitation and fierce motion which gradually brings it to dissolution" (Ibid.: 20). Moreover, heat is an expansive motion of the elementary particles of a body that has a tendency to rise. To reiterate the practical benefit of the "first harvest," he writes that whoever could produce similar agitation in a body would in so doing be able to produce heat.

He devotes the remainder of The New Organon (2.21-52) to examining "privileged instances" of heat, in order to tease out more behavioral discoveries (Ibid.: 2.21). "Privileged instances" is a specific legal term that indicates how Bacon intended these instances to be interpreted. It was originally used in reference to the centuria praerogitiva, the 100 aristocratic voters of the comitia of the Roman Republic. They were given the chance to vote first and thereby indicate to the other members how to vote (Ibid.: 136n23). There are 27 categories of such instances, and they serve to further isolate the precise cause of the given nature or show how best to bring it about at will: "The use of these instances, in which they surpass ordinary instances, tends in general either to the direction of information or in the direction of operation, or both" (Bacon 2000: 2.52; original emphasis). 
The problem to which Bacon's method is the solution was that investigation of nature was beholden to the fancies of individual men, and was thus led astray. He sought to overcome this difficulty by providing an experimental method as a go-between for man and nature. It was to be a tool for the organization of experience, with such detail that bias, memory, or preference had no impact on the result. Men would provide neutral and repeatable observations, and the rules and methodological strictures would force them to arrive at the inductive conclusions permitted by the observations. There are two specific ways in which this method is conducive to control of nature. First, in avoiding the four idols by which men had previously been led astray the method provides reasonable assurances of reliability, even if only of the instrumentalist sort. Second, by narrowing in on exact causes ${ }^{240}$ of phenomena and formulating such instances as universal laws of nature, his method gives men the tools to imitate natural laws by channelling their power and uniform outcomes.

Bacon's example of heat shows the method in action with some success. ${ }^{241}$ His rigorous enumeration of facts, instances, and falsifications allowed him to arrive at the reasonable conclusion that heat is caused by the motion of elementary particles. Indeed, he arrived at this

\footnotetext{
${ }^{240}$ Technically, Bacon has only established correlation, not causation, but for his purposes correlates are treated as if they are causes.

${ }^{241}$ Gaukroger expresses some doubt about eliminative induction's ability to provide a complete account of necessary and sufficient causes, suggesting that when eliminative induction appears to point the way to causes, the real work of discovery is being done by other methods and procedures. The utility of eliminative induction can only emerge when the insightful and creative scientist is able to identify possible explanations or counter-instances (Gaukroger 2003: 150-153). Robert Lane makes the more forceful argument that the very logical structure of the method of eliminative induction prevents it from producing infallible conclusions (Lane 1999). These points are well taken, especially in light of the twentieth-century responses to scientific positivism from Kuhn, Polanyi, and others. Gadamer makes a point of saying that Bacon's method "produced little, especially when applied to the study of nature" (Gadamer 2004: 343-344). However, it is not clear whether this truly weakens the accuracy of Bacon's method. The fact remains that when presented with enough possible instances of heat, the method of eliminative induction was able to isolate motion as the exact correlate. This may fall short of contemporary understandings of thermodynamics, but it was clearly on the right track, and Bacon never claimed finality for any of his discoveries, but only to point the way for future experimentation and discovery.

Over and above the adequacy of the content of Bacon's investigations, we must note the importance of exclusion in the development of modern scientific method. Georg Henrik von Wright has found Bacon's lasting influence in the method itself rather than his own conclusions from it (Wright 1951: 151-156).
} 
conclusion despite his own inability to avoid speculating and relying on assumptions of his day, as we saw in his guess that the dog days of summer are hottest because the sun passes in front of certain constellations of stars. Despite this, his method forced him to stay on track and arrive at the proper correlate of heat. There are, of course, legitimate criticisms to be made of his implied definition of nature as a collection of objective facts waiting to be discovered by a neutral and dispassionate observer of nature, though an exhaustive study of these is beyond the purview of this project. ${ }^{242}$ It nevertheless remains the case that his method, in practice, is a faithful embodiment of his intention, and contributes to its fulfillment. At every turn it is attuned to repeatable laws, or instances of correlation, and he brings its results to bear on questions of technical mastery.

Two final observations must be made regarding Bacon's experimental method. The first is that despite his insistence that he is merely observing nature at work, his method really involves making nature do things it would not do of its own accord. ${ }^{243}$ In The Advancement of Learning he writes that "the passages and variations of nature cannot appear so fully in the liberty of nature as in the trials and vexations of art" (Bacon 1952: 2.1.6). Letting nature be at liberty is not as successful a method of discovery as placing it under the unnatural vexations of human art. A similar distinction is made in the Outline of a Natural and Experimental History: nature can be "free and unfolding in her own ordinary course," or "constrained and shaped by

\footnotetext{
${ }^{242}$ Thomas Kuhn's The Structure of Scientific Revolutions (2012) is the classic argument against this positivistic view of facts, and Michael Polanyi's Personal Knowledge (1974) persuasively rebuts the idealization of the scientist as a dispassionate recorder of facts.

${ }^{243}$ There is irony in the fact that nature refers to things that happen of their own accord. For example, see Aristotle's definition of physis as having "in itself a source of motion and rest" (Physics, 192b). See also C.S. Lewis' word study of "nature": "This, as it is one of the oldest, is one of the hardiest senses of nature or natural. The nature of anything, its original, innate character, its spontaneous behavior, can be contrasted with what it is made to be or do by some external agency.... The natural here is the given" (Lewis 1967: 43).
} 
human art and agency" (Ibid.: 223-224). ${ }^{244}$

Carolyn Merchant, drawing on Bacon's day job as a crown prosecutor, persuasively interprets Bacon's "vexation" in light of the torture used to extract confessions from accused witches and heretics: "[b]eyond imprisonment, the causal relationship between vexation and understanding was present in Inquisitional torture" (Merchant 2015: 88). Like nature, the accused cannot be expected to divulge secrets willingly. Torture as vexation was used, accordingly, to reveal or uncover an already existing truth, not to create truth or the appearance of truth. Bacon himself, who was no doubt aware of the Inquisition and its practices, referred to scientific investigations as "inquisition[s] of nature" (Bacon 2000: 2.47).

Modern experimental science has long been recognized as combining neutral observation with active intervention. Ian Hacking argues that one of the uses of scientific experiments is to create the phenomena to be studied:

I suggest, in contrast, that the Hall effect does not exist outside of certain kinds of apparatus. Its modern equivalent has become technology, reliable and routinely produced. The effect, at least in a pure state, can only be embodied by such devices.

That sounds paradoxical. Does not a current passing through a conductor, at right angles to a magnetic field, produce a potential, anywhere in nature? Yes and no. If anywhere in nature there is such an arrangement, with no intervening causes, then the Hall effect occurs. But nowhere outside the laboratory is there such an arrangement (Hacking 1983: 226).

Heidegger makes a similar claim in "The Question Concerning Technology.” Modern technology, he writes, is “a revealing” (Heidegger 1977: 14). However, it is not a neutral revealing of natural secrets, but a revealing that has the characteristics of "a challenging" and "an expediting” (Ibid.: 14-15). Heidegger, admittedly, goes beyond both Bacon and Hacking in arguing that technological "expediting” fashions a truth instead of objectively discovering a pre-

\footnotetext{
244 There is a middle option too, though it is not important for the present point: the apparent irregularities or grotesque exceptions to natural patterns.
} 
existing one, insofar as nature is revealed under technology as "standing-reserve" instead of as a river or forest:

What kind of unconcealment is it, then, that is peculiar to that which comes to stand forth through this setting-upon that challenges? Everywhere everything is ordered to stand by, to be immediately at hand, indeed to stand there just so that it may be on call for a further ordering (Ibid.: 17).

Even if we avoid Heidegger's conclusion by maintaining that every phenomenon Bacon's experimental method creates is an accurate representation of nature, we are left with the following question: Are the results truly reflective of how nature acts if they can only be ascertained by the artificial prodding and arrangement of perfect conditions? The problem with the torturous vexation of nature can be seen when applied to accused witches: coerced confessions do not always reflect the truth of the matter. ${ }^{245}$

A Baconian resolution of this problem must come from his distinction between the two axioms of the transformation of bodies (Bacon 2000: 2.5). Because Bacon is trying to discover the laws that govern the latent structures of things, not simply the visible epiphenomena, unnatural vexations are useful. An artificial set of conditions may not mimic natural processes, understood as "what simple or complex natures do on their own," but it will in fact put the latent structures in such a position that they react to a controlled set of causes. Knowing the particular effects that certain causes have on the latent structures is a kind of knowledge of nature, insofar as the discovered law of act can be generalized beyond the specific situation of the experiment itself. For example, the discovery that material A reacts in such and such a way to material B is indicative of the natural law of behavior that stipulates that material A reacts in such and such a way to material B. At the level of latent structures and processes, this knowledge of natural laws

\footnotetext{
${ }^{245}$ Recent studies have shown that information received by means of torture is less reliable than when freely given (Schiemann 2012; O’Mara 2015; Morgan, et al. 2006). This may not be a direct refutation of Bacon's approach to nature, but it illustrates the potential problem.
} 
is knowledge of how nature behaves.

By way of a final comment of the role of vexation, Merchant notes some obvious gendered dimensions to the relationship between man and nature. Nature is something to be conquered, and this conquering takes place by forcing it to divulge its secrets. Machiavelli's infamous description is worth comparing:

[F]ortune is a woman; and it is necessary, if one wants to hold her down, to beat her and strike her down. And one sees that she lets herself be won more by the impetuous than by those who proceed coldly. And so always, like a woman, she is the friend of the young, because they are less cautious, more ferocious, and command her with more audacity (Machiavelli 1998: 101).

Merchant, drawing on Bacon's history as King James I's Attorney General and prosecutor, alleges a direct causal relationship between witch trials, which were themselves a social, cultural, and political statement regarding the status of women, ${ }^{246}$ and the discourse surrounding modern science. Bacon himself uses sexual imagery and the language of inquisition: "[n]either ought a man to make scruple of entering and penetrating into these holes and corners, when the inquisition of truth is his whole object" (quoted in Merchant 1983: 168).

The object here, as discussed above, was to portray nature as worthy of control and mastery. Whether nature was feminized because femininity was thought to be passive, or whether nature and femininity were pacified together is not important for the present purpose; the point is that there are sexual connotations to nature being portrayed as coy to reveal its secrets unless held down and forced, and such connotations are intentional. As discussed in various contexts above, it was necessary to provide the modern technological project with a moral sanction. This is accomplished by de-divinizing and feminizing nature such that, rather than being the world over which God has given humanity the responsibility of stewardship, it

\footnotetext{
${ }^{246}$ Merchant draws parallels between the witch trials and the general opposition to women upending traditional gender norms (1983: 165-168).
} 
was an open-ended site of conquest and imposition of human purposes. Merchant summarizes

this transformation, with her characteristic provocativeness: ${ }^{247}$

The constraints against penetration associated with the earth-mother image were transformed into sanctions for denudation. After the Scientific Revolution, Natura no longer complains that her garments are being torn by the wrongful thrusts of man....From an active teacher and parent, she has become a mindless, submissive body" (Ibid.: 189190).

\section{Science, Politics, or Both?}

The focus of this chapter has been the details of Bacon's scientific methodology, and the manner in which they are conducive to useful knowledge. However, this dissertation has also described the emergence of modern science as the rise of a new socio-political framework, according to which the relationship between man and nature would be transformed. Bacon scholars disagree about the extent to which social and political transformation was part of Bacon's concern, as opposed to the more limited goal of reducing labour and suffering on an individual basis. We can pose this question in the following way: Is there any social, moral, or political significance to Bacon's conception of science?

The position that science and political matters are essentially unrelated in Bacon's thought is expressed separately by Markku Peltonen and Paoli Rossi, from the points of view of political philosophy and natural science, respectively. Peltonen evaluates Bacon's political views essentially independently of his concern for the rise of science. Whether discussing Bacon's support for James I against Catholics who asserted the rights of the people against the King (Peltonen 1996: 285-286), or his waffling on the question of whether the King is subservient to law or vice versa (Ibid.: 287-288), no connection is made between his explicit

\footnotetext{
${ }^{247}$ Henry resists these sinister implications, claiming that "vexation" should be understood in Bacon's work as merely "agitation or disturbance," with none of the connotations of rape or torture (Henry 2002: 133-135).
} 
political views and the implications or prospects of the new science. As we will see below, the fact that he changed positions on this seemingly crucial question ${ }^{248}$ is telling, and hints at another explanation.

At best, Peltonen sees the promotion of science as one of many political issues, not the architectonic one. He does not see Bacon promoting any particular political system as more or less conducive to the advancement of science (Ibid.: 292). Indeed, Peltonen's presentation of Bacon's political philosophy is as if Bacon had not been at the vanguard of a new conception of science at all.

Paoli Rossi operates under the same assumption as Peltonen, insofar as he treats the significance of Bacon's scientific thinking in isolation from his larger social or political goals. It concerns, he writes, "that which today we would call an ethics of scientific research" (Rossi 1996: 26). His account of the ends of scientific knowledge is fairly standard, so far as it goes, though it lacks a deeper account of what the possibility of productive knowledge would mean for human society and political order in general, as if the two were unconnected in Bacon's mind.

Gaukroger's study of Bacon's natural philosophy falls into this group as well. Other than a discussion of the institutional requirements of his new science (Gaukroger 2003: 160-165), very little is done to relate the dominion of nature to any overarching political project. The scientific basis of the utopian city of The New Atlantis is mentioned only to highlight the alleged lack of consideration put into how it might be brought about (Ibid.: 165).

Against this backdrop the significance of Howard B. White's Peace Among the Willows: The Political Philosophy of Francis Bacon (1968) is that it rightly emphasizes the political in Bacon's philosophy, specifically as it relates to the scientific. White's Bacon is concerned with

\footnotetext{
${ }^{248}$ Bacon was King James I's Solicitor General at this time, so the matter would have been of professional interest to him, if nothing else.
} 
political questions, the most important of which is "What kind of regime is required in order for science to flourish?" If science will bring about the relief of man's estate, as Bacon thought it must, then White rightly suggests that the possibility of "this relief...demands a serious philosophical effort to reconsider the goals of the political life" (White 1965: 4).

The political framework of White's Bacon is generally Machiavellian, except that inventors rather than founders of regimes are the heroes. In other words, the principal political project is the relief of man's estate (Ibid.: 104-105). It is not the political cunning and courage of the prince that will master fortune in human affairs, but the fruits of technological science. Every aspect of Bacon's thought, according to White, was subservient to the realization of scientific politics, including his explicit political statements, some of which have been briefly discussed above in the analysis of Peltonen's essay. Bacon, argues White, was a monarchist, an Anglican, and an imperialist because he thought they were the positions most conducive to his utopian vision. Echoing Descartes' provisional morality, White refers to this as Bacon's "provisional politics" (Ibid.: 58-92). Like its Cartesian analogue, the claims are not held absolutely; rather Bacon saw fit to "use political conservatism as a protection for scientific expansion" (Ibid.: 58). This might explain Bacon's ambivalence towards over-specifications of the theory of Monarchy, discussed above.

Bacon's provisional politics clears the path for what White calls his "definitive politics" (Ibid.: 223-251). This political vision concerned the relationship between man and his world, and took the utopian form outlined in The New Atlantis. More will be said about The New Atlantis in the pages that follow, but it suffices to say here that it is a utopian political community made possible by Baconian science. The upshot of White' interpretation is that it draws a strong connection between science and politics in Bacon's philosophy. The present 
study accepts this relationship in broad outline, but seeks to interrogate it from the opposing side.

That is, White rightly shows how Bacon's theory of politics was subservient to his goal of promoting science, but his analysis does not sufficiently examine how what Bacon meant by science might itself have been subservient to the goal of mastering nature. This chapter has sought to supplement White's account by clarifying how Bacon consciously devised a particular scientific method that would facilitate control.

Weinberger shares White's emphasis on Bacon's political theory, as his study looks to The Advancement of Learning to shed light on his political project. A contribution from Weinberger is that the utopianism of Bacon should be understood as the moderate utopianism of classical political philosophy, and that Bacon indeed intended to warn against an overly-zealous interpretation of the modern scientific project (Weinberger 1985: 34-35). His analysis makes reference to many of the ontological innovations Bacon effects, including the separation of man from nature and the dismissal of final causes (Ibid.: 244-259). Noting, as I have above, that Bacon retains final cause in human affairs, Weinberger infers that this requires a form of selfknowledge that is unattainable in "the present charitable age" (Ibid.: 257).

Weinberger's exposition of the relationship between science and politics is more limited in scope than others, due in part to his interpretation of the significance of the fundamental transformations in the meaning of nature and causality. ${ }^{249}$ Svetosar Minkov's recent work on Bacon explores this tension from another angle. He brings together the moral and scientific elements of his thought, in his concern with the moral foundations of the Baconian scientific

\footnotetext{
${ }^{249}$ Another way to put this is that Weinberger minimizes the importance of Bacon's scientific thoughts themselves. See for example Mark Neustadt's, admittedly unfavorable, review of Weinberger: "In confining himself to Bacon's concealed utopian political philosophy, Weinberger tends to ignore Bacon's more explicit intentions in the Advancement. Weinberger does not appear to have examined the immediate intellectual background to Bacon's text, and seems to miss many central issues at play in the work. He fails adequately to discuss Bacon's own program for the reform of natural philosophy, although this is crucial to his discussion, limiting himself to a few general, quaintly Whiggish remarks about Bacon being the father of modern science” (Neustadt 1987: 450).
} 
project. In "The Human Good and the Problem of Bacon's Intention” (2008), he supplements Bacon's scientific aims with an analysis of the undergirding moral philosophy. That is to say that the moral and political aspects of Bacon's thinking are inseparable from his scientific project. In fact, argues Minkov, there is such a relation between a moral understanding of the human good, on one hand, and scientific method, on the other, that the potential tension between them points to "a very penetrating criticism of Bacon" (Ibid.: 274). It is hard to reconcile the materialism of Bacon with the view that human suffering is a moral evil that ought to be redressed by means of technology. Minkov quotes Robert Faulkner's charge: it is doubtful “whether Bacon's insistence on knowing through method is consistent with his reliance on a premethodical psychology and a 'universal philosophy' of nature.... The gravest difficulty is a reliance on notions of human quality that Bacon's critical epistemology would exclude" (Ibid.: 273-274). Minkov's point is neither to definitively resolve nor to reify this tension, but to articulate what is at stake in this question. ${ }^{250}$ One implication is that serious questions of moral and socio-political concern undergird the Bacon scientific project. Relieving man's estate is a moral and political activity that cannot be relegated to questions of scientific methodology; scientific questions for Bacon were ultimately bound up with moral and political questions. In other words, for Bacon, science was done for the sake of a broader moral and political

\footnotetext{
${ }^{250}$ Neither is it necessary for the present argument to fully resolve this tension, but a welcome by-product of the argument of this chapter is that once we conceive of Bacon's attunements - that is, his scientific assumptions and methods - as tools meant to serve his socio-political aims, the force of Faulkner's critique is weakened. It may be that the humanitarian impulse and separation of human needs and desires out of the non-human world are incompatible, strictly speaking, with a full-fledged materialist metaphysics. But I have argued that what is important for Bacon are the moral and political claims underlying his project, for which he has adopted certain scientific assumptions and methods as instruments. He need not commit himself absolutely to the truth of the results of his method, so long as they prove useful. This is why the instrumentalist and behaviorist character of modern science has been stressed in these pages.
} 
objective. $^{251}$

The debate whether Bacon's new science had any political import or was merely a means of remedying particular ills without changing the relationship between man and nature is a matter of relative emphasis. Virtually no interpreters of Bacon ignore the role of utility in his conception of science, though not all draw the same socio-political conclusions from it. Gaukroger is a prominent representative of the group devoted to analyzing Bacon's philosophy of science at the expense of exploring the political implications, while the opposite approach discussed above tends not to relate Bacon's political project to the technical details of his methodology. My approach has attempted to draw from both groups in order to add depth to our understanding of how Bacon's new science facilitates the political project of controlling nature. We have seen how Bacon's ontology of nature and method of investigation permit - morally as well as epistemologically - investigation into the necessary and sufficient conditions of any nature or form that men wish to manipulate. Taking these observations together with the above considerations into Bacon's moral and political intentions, we can say that his scientific methodology - attunements - was put together under the guidance of his broader socio-political project of mastery.

Graham Howell discusses much of this literature, noting that the implications of Baconian science emerge only in the context of his political aims, which cannot be reduced or explained on empirical grounds. It is thus "in Bacon as philosopher, not as 'son of science,' that the meaning of Baconian science comes to light" (Howell 2008: 187). This perspective, shared by Weinberger, White, Minkov, and others, is a helpful corrective to the overly positivist interpretation of Baconian science that ignores moral or political things, but it must not lead us to

${ }^{251}$ This is not in contradiction with White's suggestion that Bacon proposed provisional moral and political arrangements to allow the flourishing of science, which science would then usher in the final political transformation. 
the opposite error of downplaying what Bacon as "son of science" truly did say and how he sought to investigate nature in the service of his political project. This aspect has received insufficient attention in the literature to date, ${ }^{252}$ and for this reason I have attempted to bridge the gap by bringing the "Bacon as political philosopher" commentators into dialogue with the "Bacon as son of science" commentators. The former rightly emphasize Baconian ends while the latter, also correctly, emphasize Baconian attunements. However, a proper understanding of Bacon requires interpreting each through the eyes of the other, even while recognizing that the aim is causally prior to the attunements.

\section{Concluding Remarks on Cartesian-Baconian Science}

Descartes and Bacon have so far been treated as important theorists of the modern scientific project. It is therefore worth bringing them together for a thorough comparison. The first obvious similarity pertains to the goal of scientific inquiry, namely mastering nature. It is not possible or necessary here to take a definitive position on the true motives behind the words of Bacon and Descartes, though there is a range of scholarly opinion. For example, some critics have accused them of attempting to control nature for the exclusive benefit of privileged gender or class interests. ${ }^{253}$ On a sympathetic reading, however, they sought to master nature for the benefit of the entirety of mankind. Descartes suggests that the three practical benefits of his science are "medicine, mechanics, and morals" (Descartes 1997: 269). Bacon, similarly, hopes that his methods might spur inventions that are conducive to commodious living and national

\footnotetext{
${ }^{252}$ With the notable exception of Richard Kennington (2004).

${ }^{253}$ See, for example, Negri (2006) and Merchant (1983). Even C.S. Lewis, who could not be accused of having Marxist or other critical sympathies, writes of the unequal distribution of benefits from modern science: "In what sense is Man the possessor of increasing power over Nature?....From this point of view, what we call Man's power over Nature turns out to be a power exercised by some men over other men with Nature as its instrument" (Lewis 2001: 54-55).
} 
prosperity. His repeated references to gold, with its obvious connotations of wealth and prosperity, points to his hope that economic prosperity can be added to the Cartesian trio of the benefits of technology. ${ }^{254}$ Bacon's vision of a scientific utopia is characterized by social tranquility, material comfort, and endless financial surpluses. Minkov is struck by "the fact that Bacon seems to have devoted an enormous amount of effort to being a benefactor" (Minkov 2010: 12).

The aim of mastery gave rise to similar attunements in both thinkers. They each claim that mastery could be attained through the discovery of repeatable, and therefore in principle controllable, laws or patterns of behavior. Descartes' The World culminates in three laws of nature that are purported to explain the behavior of corpuscles in his imaginary universe; similarly, Bacon's extensive experimental method is designed to reveal the laws of act that produce the various simple natures. One of the overriding themes of this chapter and the previous one has been the relationship between aims and attunements, and more specifically how the attunements - or scientific methods - contribute to achieving the aims - mastery of nature.

These aims and attunements have proven to be important, and constitute the strongest locus of agreement between Bacon and Descartes. Despite strong differences in their epistemology, theology, and intellectual background, they are united in their proposal that nature be conquered by the discovery and manipulation of natural laws that govern inanimate matter. For reasons that have been discussed above, this theme is explicit in Bacon and somewhat veiled in Descartes, though the brief passages in which Descartes lowers his guard suggest that he is as much a proponent of mastery as Bacon. We have seen that Bacon feminizes nature in order to

\footnotetext{
${ }^{254}$ For example, Paul Rahe connects Bacon to the spirit of innovation and entrepreneurship that characterized early capitalism: "Bacon was to reserve for 'the authors of invention' - men whose discoveries had extended 'benefits... to the whole race of man.' It was, he suggested, both more wholesome and more noble for men to labor 'to establish and extend the power and dominion of the human race itself over the universe' than for them to engage in similar exertions merely 'to extend the power of their country and its dominion among men"' (Rahe1994: 113).
} 
render it passive. Descartes similarly reduces all matter to passive receptivity to control and influence by mind. This moral sanctioning of the control of natural processes is part and parcel of the technological project.

An implication of the causal or logical relationship between aims and attunements - that is, between mastery and laws of nature - is that science, as articulated by Descartes and Bacon, is inherently technological. There is no meaningful distinction between theoretical and applied science because even so-called theoretical science utilizes a method that was designed to elicit useful information. The only kinds of information about nature that are scientific, in the Baconian or Cartesian sense, are those that pertain to how matter obeys repeatable laws of behavior. Because those laws became the subject of science out of applied purposes, nothing they reveal is purely theoretical. An individual scientist utilizing Bacon's method of eliminative induction might personally only care about knowledge for knowledge's sake, but the method he or she uses - i.e. the discovery of repeatable laws that matter obeys - is an expression of the will to mastery.

The necessary relationship between aims and attunements entails that the attunements can never truly be isolated from the project of mastery. In addition to the prolonged discussions of Descartes and Bacon that demonstrated the necessity of this relationship, Grant and Heidegger's insights have been brought in as corroborating evidence. Grant interprets modern science as being based on a novel combination of making and knowing - indicated by the bringing together in technology of techne and logos - in which what is made and what is known are mutually reinforcing:

We close down on the fact that modern technology is not simply an extension of human making through the power of a perfected science, but is a new account of what it is to know and to make in which both activities are changed by their co-penetration (Grant 1986: 13). 
Heidegger, for his part, argues that modern experimental science consists of a "preconception" or predetermination of the facts that guides experimentation (Heidegger 1993: 272). Modern science, he continues, is mathematical. This is not in itself controversial, indeed Descartes' suggests that the mathematical and deductive nature of his method is its strongest feature. Heidegger, however, points beyond the immediate conception of mathematics as having to do with numbers and emphasizes the meaning of the greek ta mathemata as "the things insofar as we take cognizance of them as what we already know them to be in advance" (Ibid.: 275). Modern mathematical science, then, is not simply an open-ended receptivity to the facts as they present themselves. Its methods are instead devised in such a way as to bring about desired results, namely mastery.

Heidegger takes this, admittedly controversial, interpretation of mathematical science to the work of Newton, Galileo, and Descartes, arguing in all three cases that nature had to be experienced in a particular way before the so-called mathematical laws of motion could be conceivable. By this he is referring to the gestalt shift from seeing objects as moving "according to their nature," to moving in accordance with external laws of motion (Ibid.: 284). This is akin to what Kuhn calls a scientific revolutions (Kuhn 2012). A fundamental reorientation of the mind, or of the way in which it experiences the world, had to take place before the new scientific laws could be formulated. Modern science is mathematical, for Heidegger, in the sense that its discoveries follow from a prior experience of things as being governed by external laws:

Both Galileo and his opponents saw the same 'fact.' But they interpreted the same fact differently and made the same happening visible to themselves in different ways....Both thought something along with the appearance but they thought something fundamentally different, not only about the single case, but fundamentally, regarding the essence of a body and the nature of its motion (Heidegger 1993: 290).

The things are then transformed into objects - a transformation Heidegger claims is completed by Descartes - which brings us into the realm of technology. 
There is one potential minority report that is worth discussing as regards the technological character of modern science: Michael Polanyi. Polanyi could be characterized as a post-positivist with respect to science, insofar as he was critical of Bacon's naïve depiction of the dispassionate scientist merely observing and recording facts. The major thrust of Polanyi's Personal Knowledge is that scientific discovery is a deeply personal endeavour in a way unaccounted for by objectivist and positivist philosophies of science. However, despite this departure from a distinctly modern conception of science, he appears at first glance to adopt one of the central assumptions against which this dissertation is arguing, namely the distinction between theoretical and applied science in modernity.

He delves into the logical structures of science and technology and argues that they have different bases of originality: "in science originality lies in the power of seeing more deeply than others into the nature of things, while in technology it consists in the ingenuity of the artificer in turning known facts to a surprising advantage" (Polanyi 1974: 178). He makes a distinction between knowing and acting, such that each is self-contained. We can see more deeply into nature, which seeing is not oriented toward future discoveries, and we can take pre-existing facts and turn them into advantages. He uses this distinction to justify the familiar language of certain activities and disciplines being "the application of pure science to practical problems: (Ibid.: 179).

Leaving off here would give the false impression that Polanyi believes modern science, as colloquially understood, is conceptually distinct from technology. However, Polanyi's goal in this book and others was to defend science from the ideological control exercised over it by the USSR. ${ }^{255}$ That is, the problem to which he was reacting was a science that was too beholden to

\footnotetext{
255 "But since the rise around 1930 of the Neo-Marxian theory of science, which became within the decade the official doctrine of the U.S.S.R. and gained widespread influence outside it, the distinction between science and
} 
predetermined goals and aims, which helps to explain his emphasis on science for science's sake. ${ }^{256} \mathrm{He}$ hopes to save the true value of science from the "ideological utilitarianism of the modern revolutionary movement" (Ibid.: 182).

Behind this theoretical separation between pure science and applied technology, Polanyi lays the groundwork for the conclusion that the Cartesian-Baconian conception of science ${ }^{257}$ is somewhere in between. Two middle forms of inquiry are "systematic technology" and "technically justified science" (Ibid.: 179). The first refers to areas like aerodynamics where a systematic set of laws and knowledge claims is intimately tied to specific uses. The second refers to areas of science that are particularly useful and thus worthy of study. Though Polanyi makes no such connection, it seems that this describes Descartes and Bacon closely enough. The area, or aspect, of nature that their scientific methods put into focus were such because of their expected utility.

To put Bacon and Descartes' conceptions of science in the category of technically justified science leaves the space of pure science unoccupied. Polanyi extols the virtue of practicing pure science for its own sake, writing that the very possibility of scientific discovery rests on the belief that science is important for its own sake (Ibid.: 183). He had earlier distinguished between two kinds of knowledge: knowledge derived from an express purpose and knowledge pursued with no such purpose (Ibid.: 175). This corresponds to the different aims of ancient and modern science, insofar as Plato and Aristotle had no utilitarian purpose for scientific inquiry, but simply the desire for wisdom of ultimate causes. It thus appears that

technology, even when still upheld in practice by the continued operation of these institutions, is violently challenged in principle" (Ibid.: 180).

${ }^{256}$ A complete justification of this claim would require a separate chapter. The following will simply point to a few textual hints.

${ }^{257}$ This term should not be taken to wash over their differences, but rather as pertaining to their shared aims and attunements. 
behind Polanyi's distinction between science and technology is an argument that the PlatonicAristotelian conception of science is pure science and the Cartesian-Baconian conception is more akin to technically justified science. ${ }^{258}$

The point of this excursus has been to demonstrate that the technological instinct has been latent in modern science from the beginning, whether one takes a more benign positivist view or a critical view such as that of Heidegger or Kuhn. ${ }^{259}$ On this, Descartes and Bacon agree with each other and with a variety of commentators. The relative merits of these and other interpretations of the relation between ancient and modern science will be considered in the concluding chapter of this dissertation.

Beyond these important similarities, Descartes and Bacon highlight the importance to scientific success of a strict method, and they have similar criticisms of the ancients. These have already been discussed above, so only a brief summary is needed here. Each of them is aware of the danger of the peculiarities of the individual philosopher or scientist infecting, as it were, the thought process and inhibiting the search for truth. For this reason, they each strove to go back to first principles and begin anew, rejecting received opinion along the way. Descartes is famous for his radical doubt and retreat into the cogito, and Bacon follows a similar process. In language indistinguishable from Descartes, he writes that "one cannot count on the unaided power of men's judgement; one cannot count on succeeding by chance.... We need a thread to guide our steps; and the whole road, right from the first perceptions of sense, has to be made with a sure method" (Bacon 2000: 10). That all received wisdom is tainted by aimless wandering and reliance on chance requires that "the entire work of the mind be started over again" (Ibid.: 28).

\footnotetext{
${ }^{258}$ It needs to be stressed that Polanyi makes no attempt to overlap his kinds of knowing onto periods in the history of scientific thought.

${ }^{259}$ It should be noted that this is different from the claim that all modern scientific work is concerned with mastery, which claim we have not been concerned with here. This project makes the more modest claim that the conception of science developed by Descartes and Bacon was conditioned by the aim of mastery.
} 
The very title of The Great Renewal implies a new beginning: at 1.31 Bacon writes that "a new beginning ${ }^{260}$ has to be made from the lowest foundations, unless one is content to go around in circles for ever" (Ibid.: 1.31). Although Descartes' method begins from rationalist first principles, whereas Bacon begins with basic sense perceptions, both agree that first principles of some sort are required in order to avoid the accrued opinions that make the search for truth impossible.

Related to the importance of a method to avoid the errors of the past is the similar critique of ancient philosophy and science. A common theme in each of their critiques is that ancient and medieval thinkers wasted time on irresolvable disputes. The old criteria of truth did not include absolute certainty, which meant that debates in physics and metaphysics created more disputes than they settled. Bacon and Descartes also make the explicit connection between certainty and utility in the context of criticizing ancient philosophy. The lack of certainty, or worse, the lack of concern with certainty, condemned ancient thought to perpetual uselessness.

Moreover, and central to this project, final cause was rejected by Descartes and Bacon for being a useless category, not for being false. There is decent enough reason to believe that neither Descartes nor Bacon themselves believed in final cause as an operative principle in the natural world, but it is important to note that no decisive argument against it is so much as attempted. Rather, it is rejected for not offering any technological use. Moreover, as I have suggested, the categories of aims and attunements suggest a way of reconciling the possibility of final cause with modern laws of nature. For now it is worth reiterating that the technological aspirations of each thinker rendered final cause, even if true, unnecessary. Remember Descartes’ claim that "the species of cause termed final, finds no useful employment in physical things"

\footnotetext{
260 The latin word for "beginning" is instauration, which is usually rendered as "renewal," as in the title of the work (Ibid.: 39n7).
} 
(Descartes 1997: 164). Similarly, from Bacon: “[b]ut of these [causes] the Final is a long way from being useful" (Bacon 2000: 2.2).

The above notwithstanding, there are some meaningful disagreements that form the basis of real scientific differences. The most immediate is the relative importance given to perceiving with the senses versus with the mind. Descartes' radical distrust of his senses constitutes a strong objection to Bacon, whose method would have no hope of withstanding Cartesian skepticism. Sense perceptions, however neatly organized and enumerated, could always be the product of Descartes' evil demon, for example. While Descartes is squarely within the rationalist tradition of modern philosophy, it is anachronistic to unequivocally call Bacon an empiricist, and commentators as diverse as Fulton Anderson and Richard Kennington have refrained from so doing. Anderson unambiguously writes that "Bacon was no empiricist," and that "the assumption of empiricists, then, that 'the sense of man is the measure of all things' must be rejected" (Anderson 1948: 2, 188). Kennington, for his part, calls John Locke "the founder of empiricism," implying that Bacon is not within that philosophical camp, strictly speaking (Kennington 2004: 256). The difference between Locke and Bacon, as recounted by Kennington, is that despite Bacon's emphasis on empirical observation, his knowledge is not restricted to ideas, but extends to natures themselves (Ibid.: 256-258). Nevertheless, it remains true that Descartes and Bacon fundamentally disagreed on the trustworthiness of sensory data. Moreover, the importance given to it by Bacon influenced later empiricists in their eventual restriction of the sphere of knowledge to the sensible. ${ }^{261}$

This epistemological difference is responsible for further substantive disagreements. First, Descartes begins from a theory and works out from it, so to speak, while Bacon attempts to

\footnotetext{
${ }^{261}$ Even Anderson is willing to grant that empiricists such as Locke and Hume are philosophical descendants of Bacon (1948: 303).
} 
derive so-called theoretical explanations from appropriate sensory observations. Descartes' theory of matter, namely that everything is composed of corpuscles and should be understood in terms of geometrical extension alone, is derived from what he "conceived to be" (Descartes 1997: 94; 1998: 22). The laws of nature he derives from his conception of God and matter are not based on observation but on making proper deductions from his initial premises. Bacon, as we have seen, painstakingly enumerates every conceivable instance of a simple nature before venturing to posit a law of act or theory regarding its latent structure. That is, they serve as extreme cases of deductive and inductive method, respectively. Butterfield accurately depicts the contrast between the two methods:

Experiment, therefore, only had a subordinate place in the system of Descartes, and in the later part of the seventeenth century the famous scientist Huygens, who criticised Bacon for his lack of mathematics, complained that the theories of Descartes were not sufficiently confirmed by experiment (Butterfield 1965:126).

Butterfield goes on to note that the reliance on metaphysics in Descartes' system allowed to it be overshadowed by experimental methods coming out of England in the seventeenth century. ${ }^{262}$ However, there were strengths to be gained from basing physics on the foundation of metaphysics, of which Bacon proved unable to avail himself. The first is that Descartes could claim knowledge of causation in addition to correlation. Once he justified the premise that he could not be deceived in any of his clear and distinct perceptions, the inference from correlation to causation was easier to defend. Moreover, his access to an immutable God who has imposed all of the laws of nature on material objects further justifies his knowledge of causality itself. ${ }^{263}$

\footnotetext{
${ }^{262}$ Cf. J.R. Milton on Descartes' limited influence as a result of his rationalism: "The result of this was that the collision rules were effectively immune from any kind of empirical test, either direct or indirect. Unsurprisingly, therefore, few of Descartes' successors outside the ranks of the most committed Cartesians were inclined to follow him on this issue. Mathematicians such as Huygens, Brouncker, and Wren applied the collision rules directly to macroscopic bodies and were quite ready to compare Descartes' predictions with results gained from experiment" (Milton 200: 689).

${ }^{263}$ This point, however, must be qualified by Descartes' own recognition that God can only be known by presupposition with moral certainty. However, as we saw in the previous chapter, this seems good enough for him
} 
Bacon has no such knowledge, nor does he claim to need it. Experiments, though able to provide reliable sensory data pertaining to natural patterns of behavior, provide none of the metaphysical justifications of causality. Whereas Descartes sometimes retreats to a scientific instrumentalism, Bacon has no choice but to be an instrumentalist because he has no basis for treating his laws as anything but useful theories. He does not know that his laws of act really describe cause as well as correlation, but he only needs correlation to satisfy his aim of inquiry. In other words, there was an epistemological cost to go along with the benefit of relying on experiments alone, namely the inability to truly attain knowledge of the world. However, since the goal common to both was the ability to manipulate nature, not to know it as such, Bacon deemed the cost acceptable. That later developments in scientific method have echoed his emphasis on experiment indicates that others have as well. ${ }^{264}$ A recent book by historian Yuval Noah Harari notes the importance, and lasting influence, of this instrumentalist understanding of science. Harari writes that,

Scientists usually assume that no theory is 100 per cent correct. Consequently, truth is a poor test for knowledge. The real test is utility. A theory that enables us to do new things constitutes knowledge (Harari 2014: 259).

Harari goes on to relate this instrumentalist idea to the unification of science and technology, which he traces to Bacon (Ibid.: 259-264).

Read against the backdrop of the ancient conception of science, with its aim of wisdom, the similarities between Descartes and Bacon are put into sharp relief. Without minimizing their epistemological differences, we can nevertheless maintain that they shared a vision of a useful science that would benefit mankind by providing it with the tools to subdue nature and make it

to derive useful probabilities. The extreme skeptical challenge, namely that his clear and distinct perceptions may nevertheless be false, only affects metaphysical certainty, not moral certainty (Descartes 1997: 336-337).

264 This is further indicated by the persistence of scientific instrumentalism and anti-realism in the natural and social sciences to this day (Waltz 1979; Van Fraassen 1980). 
serve human interests. 


\section{CONCLUSION}

This project has sought to understand the relationship between modern science and natural right. Specifically, the issue under consideration is why natural right is often thought to be incompatible with modern science. One widespread answer to this question is given by the character "Ranger" in Owen Barfield's dialogue Worlds Apart. Ranger is described as "a young man employed at a rocket research station" (Barfield 2006: 7) who has wholly bought into the triumphalist story of modern science eradicating superstition by the force of its superior observations:

What I do know is, that three or four hundred years ago for some reason or other the human mind suddenly woke up. I don't know who started it - Bacon, Copernicus, Galileo or someone - and it doesn't seem to me to matter. The point is, that for some reason people began to look at the world around them instead of accepting traditional theories, to explore the universe instead of just sitting around and thinking about it. First of all they discovered that the earth wasn't flat...

[At this point a medievalist registers his objection.] ....and that it was not the centre of the universe, as they had been dreaming, but a rapidly evolving and whirling speck of dust in empty space. Almost overnight about half the ideas men had had about the universe and their own place in it, turned out to be mere illusions (Ibid.: 13-14).

Ranger is not primarily discussing natural right in the quoted passage, but he does hint at its relation to modern science. He implies that the main difference between premodern and modern science is that modern scientists actually looked at the world instead of merely thinking about inherited theories. The difference between geo- and helio-centrism, in other words, is not one of perspective, or methodological and epistemological orientation, but simply one of 
thinking about the world versus looking at the world. Naturally, as they looked at the world for the first time scientists immediately discovered that they had been wrong all along. ${ }^{265}$

Moreover, his inclusion of man's "place in the universe" among the illusions dispelled by careful observation takes us to the heart of the issue. The role of man in the universe is the question to which natural right was the answer. It suggests that men and their social, moral, and political concerns are not artificial islands created in the midst of impersonal nature, as Hobbes might have it. On the contrary, political life is natural - indeed it is how Aristotelian man was most fully himself. ${ }^{266}$ Men are not so much "in" the universe (or cosmos) but part of it, and their responsibilities therein are determined by their relative place within it.

According to Ranger, this understanding of man's place in the universe was proven false by the observations of modern scientists. The intention of this dissertation has been to reopen this conversation by proposing a way of thinking about modern science that does not prematurely dismiss the possibility of natural right. It has attempted to go beyond the obvious fact that it is not clear what observations could really justify such a reversal, and instead articulated the core aims and methods of modern and premodern science.

This study has not necessarily proven the full compatibility of natural right with the entirety of modern scientific knowledge, but I hope to have made some progress toward the possibility of such a reconciliation as well as having shown how it might be accomplished. Conceptualizing ancient and modern science in terms of their respective aims and attunements provides a possible way out of the positivistic framework according to which more sophisticated

\footnotetext{
${ }^{265}$ Barfield exaggerates the naiveté of Ranger's position for dramatic effect, but there is some truth in this description of the triumphalist view. Bertrand Russell writes that one of the characteristic merits of modern science is "immense patient observation," which led to "the recognition that much of what had been believed since ancient times might be false" (Russell 1975: 514). Moreover, Barfield's exaggeration notwithstanding, there is real naiveté in supposing modern science to be characterized by pure observation and ancient science to be completely devoid of it, as the previous chapters have pointed out. Ranger is perhaps not as much of a caricature as it might appear.

${ }^{266}$ See Aristotle's Politics (1252b, 1275b) and Nicomachean Ethics (1097b).
} 
discoveries alone are responsible for the emergence of modern science. The goal has not been to provide a definitive statement concerning the viability of natural right but, as the title of this dissertation indicates, to clarify the manner in which it is in conflict with modern science. To that end, this work has drawn attention to the way in which Descartes and Bacon, as representatives of modern science, saw themselves as departing from the Platonic-Aristotelian tradition of natural science. This difference has been articulated in terms of competing sets of aims and attunements.

So, if the story told by Owen Barfield's Ranger is false, as I believe it is, what story better accounts for the rejection of natural right? The story given here, if accurate, suggests a way of thinking about modern scientific discoveries that is both compatible with classical natural right and faithful to the conception of science held by two of its prominent modern founders. Thinking about the difference between ancient and modern science in terms of different sets of questions and concerns allows us, I suggest, to consider the possibility that the self-imposed methodological constraints of modern science - effective as they have been for promoting empirical and technical knowledge - have made us too quick to dismiss the possibility of natural right entirely.

Bringing these four thinkers together emphasizes important points of disagreement, and thus suggests the possibility of a way forward. The major disagreement between the ancient and modern thinkers explored in these pages pertains to the aim of scientific inquiry and the way in which different aims contributed to different attunements. The possibility I want to suggest is that it was not new or improved observations that rendered natural right untenable, but a new conception of what it meant for beliefs to become part of the scientific enterprise. Modern scientific claims, at least according to the principal subjects of this study, must pertain to 
impersonal matter and the laws governing its behavior. This new conception of science was born out of the desire to control nature.

Descartes and Bacon, in other words, did not claim that natural right has been made unscientific by way of further scientific discovery, but rather by a conscious effort to reorient science in a different direction. Their methods of science were unconcerned with natural ends or what might be naturally good for its subjects; they were more interested in discovering how matter behaves so they could manipulate it for the benefit of humankind. Any other concerns were dismissed as unimportant, or at the very least, unscientific. Recall Descartes and Bacon each writing off final causes as outside the purview of science without actually proving, empirically or otherwise, their falsehood:

The species of cause termed final, finds no useful employment in physical [or natural] things (Descartes 1997: 164).

It is also not bad to distinguish four causes: Material, Formal, Efficient, and Final. But of these the Final is a long way from being useful (Bacon 2000: 2.2).

To recap the aims and attunements of the two conceptions of science, ancient science pursued wisdom - that is, knowledge of the first causes of things - and therefore attuned itself to whatever bore responsibility for things being as they are. Plato and Aristotle, each in their own way, made the Good the cause of all that is. Plato's form of the Good was the cause of the being and intelligibility of everything, such that nothing could be fully understood without reference to it. Socrates' discussion of "the Good-and-Binding" at Phaedo 99c illustrates its causal role in natural phenomena. The cause of beauty in a flower is the Beautiful, and so on for every other particular instantiation of each form. The Good-and-Binding, however, seems to govern the entire structure of instantiations, and is the cause of this particular object becoming beautiful instead of that one. So while the forms are the causes of individual things, the Good-andBinding exercises causality over everything. Nothing is fully known, Plato concluded, unless 
normative causes are invoked. Similarly, Aristotle argues that every scientific explanation must refer to the final cause of each thing, even suggesting that motion itself requires a teleological framework. Platonic and Aristotelian inquiry into nature, then, entails pursuing the ends or natural goods of each thing. That is another of way of saying that natural right fits neatly into the practice and purposes of ancient science.

In contrast, Descartes and Bacon provide a conception of science that aims at the ability to manipulate and control nature, and is therefore attuned to repeatable laws of cause and effect. Knowledge of the good, the reason for things being the way they are, and natural ends are completely irrelevant to the goal of controlling natural processes.

At this point, two questions remain: one concerns the relationship between ancient and modern science and the other concerns the origin of modern science. Although each has been evoked by the body of this study, neither can be fully resolved in what follows. In what follows they are treated as much to suggest directions for future research as to buttress the argument of this dissertation.

\section{The Relationship Between Ancient and Modern Science}

Exploring the similarities and differences between ancient and modern science forces us to confront the question of their precise relationship. The answers to this question can be grouped into three broad categories: progress, incommensurability, and compatibility. The relationship of progress is expressed by Barfield's Ranger, quoted above. Modern science represents an objective improvement over ancient science in that its claims about the universe are more accurate. Both ancient and modern science were attempts to understand the causes of natural phenomena, and modern science's explanations are simply better explanations. More 
careful and sophisticated observations have allowed recent scientists to better answer the same questions asked by Aristotle and his followers. This view has been the main foil for this study, against which I have argued for a more complex understanding of the conflict between modern science and natural right. Instead of providing better answers to the same questions as ancient science, modern science can be seen as asking fundamentally different questions and therefore bringing new goals to bear on its study of nature.

That modern science asks fundamentally different questions raises the possibility that it is incommensurable - or at the very least incompatible - with its precursor. Thomas Kuhn articulates the incommensurability thesis in The Structure of Scientific Revolutions. Science is the interpretation of nature, and for Kuhn all interpretation takes place via paradigms. Paradigms serve as criteria for appropriate scientific practice, define the relevant facts, provide ontological presuppositions, and determine what sort of explanations will be acceptable. It is difficult to ascertain with any precision exactly what Kuhn's paradigms are and how they function, since he provides no single authoritative definition. Indeed, one commentator counts as many as twentyseven different meanings of paradigm (Masterman 1970: 61). "Paradigm" is used to refer to exemplars of scientific research (Kuhn 2012: 186-190), received answers to fundamental questions (Ibid.: 5), and epistemological approaches (Ibid.: 121). Masterman distills Kuhn's twenty-seven definitions down to three categories: metaphysical paradigms, sociological paradigms, and artefact paradigms (Masterman 1970: 65).

What is common to Kuhn's many uses of the term, however, is that they serve as criteria by which scientific explanations are judged. Metaphysical and epistemological presuppositions obviously serve this function, but classic texts in a field or individual experiments are paradigms insofar as they serve as guides to other scientists. In other words, whenever Kuhn is thinking 
about paradigms, and with regard to the many different things he calls by that name, the central idea is that they determine the questions scientists ask, the types of things that count as relevant facts and the types of explanations that are scientifically acceptable.

Kuhn's central insight is that because paradigms are the criteria for choosing between competing claims, there is no trans-paradigmatic way of rationally choosing between paradigms. Each paradigm assumes its own criteria and is unable to answer other paradigms in the terms that would be acceptable to them. This is why change between scientific theories takes the form of revolutions, in which one paradigm is replaced by another. There is no rational or empirical evidence to support the new; this is impossible because the paradigms themselves disagree about what would constitute appropriate rational or empirical evidence. The title of his tenth chapter is illustrative: "Revolutions as Changes of Worldview." The language of one paradigm is meaningless to the language of another, hence the incommensurability between them.

There is a tension in Kuhn's thought between realist and anti-realist views of scientific theories. It is easy enough to draw perspectivist conclusions from paradigmatic incommensurability: if there is no rational method for determining which paradigm is true or most in accord with the objective world then everything becomes a matter of authority, will, or preference. Kuhn resisted this subjectivist conclusion that paradigms hopelessly removed all scientific theories from the objective world:

I was talking to a...friend and colleague whom I knew, from a published review, to be enthusiastic about my book. She turned to me and said, "Well, Tom, it seems to me that your biggest problem now is showing in what sense science can be empirical." My jaw dropped and still sags slightly (Quoted in Gutting 2009: 152).

There is a sense in Kuhn's thought that the movement from one paradigm to another might be more than mere preference. A paradigm will hold sway as long as few anomalies are found. But as more and more observations prove difficult to reconcile with the prevailing 
paradigm a crisis occurs, the result of which is that a new paradigm is adopted that is able to contain what its precursor could not. This interpretation of the history of science succeeds in avoiding subjectivism and perspectivism, although it does so by providing a distinctly unKuhnian way to judge between competing paradigms: i.e. which one is able to account for the most anomalies? If we are to take seriously Kuhn's description of the nature and function of paradigms, even the answer to this question depends on a paradigm. That is, what it means to "account for an anomaly" might be different in each paradigm. In the last analysis, despite Kuhn's insistence to the contrary, the perspectivist implications seem unavoidable, given what he says about the role of paradigms. ${ }^{267}$

In the context of this study, Kuhn's approach would imply that ancient science operated within a particular paradigm that was replaced by a modern scientific paradigm. Modern science cannot truly judge the claims made by the previous paradigm except to say that it gave rise to some anomalies. It also cannot incorporate claims made by it, since those claims took on meaning under a different set of criteria that no longer obtains. Finally, there can be no rational choice between ancient and modern science, since any choice would presuppose the criteria of one or the other. This would technically save natural right from the danger of refutation by modern science, but at the cost of relegating it to a chapter in history in which a now rejected paradigm was predominant. At any rate, a natural right that survived only in the sense that it could be asserted as a single perspective with no legitimate claim on the contemporary scientific community or body politic does not seem worth maintaining. This study has avoided the Kuhnian implications of perspectivism for this reason. The logic of competing aims and attunements need not imply Kuhnian incommensurability, but rather the objective choice between wisdom and mastery and the methodologies that follow from them.

${ }^{267}$ For other relativist interpretations of Kuhn see Shapere (1964), Doppelt (1978), and Sankey (1997). 
Kurt Riezler depicts ancient and modern science as incompatible but avoids Kuhn's incommensurability. His Physics and Reality depicts a resurrected Aristotle addressing a congress of scientists in 1940 to rebuke their methods. Riezler's Aristotle sets up a dichotomy between his and their approaches to natural inquiry, and argues that while they are incompatible with each other there are rational criteria by which they can be judged and compared. The defining fact of modern science is that it treats man as set apart from nature rather than as being part of a complete whole. The world described by modern science excludes subjective experiences and is limited to what can be measured and quantified - as his Aristotle puts it:

Eskimos and Negroes disagree about heat and cold, but read the same number on the thermometer. In your mind the intersubjective is the objective. By limiting yourself to the measurable you think you feature objectivity (Riezler 1940: 10).

The so-called "anonymous observer" (Ibid.: 11) of gauges and needles, Aristotle continues, is a myth. The world it describes is not the world in which we actually live. Motion, for example, is experienced by living men in the world as movement and change from one position or state to another, whereas the "robot observer" (Ibid.) of modern science describes it as the replacement of variables in the four dimensional space-time continuum, without any of the experienced movement that defines motion as we know it. Similarly, colour is determined by the number value of electromagnetic waves, and so on (Ibid.: 8-9). Riezler's critique of modern science is that the world it describes is not the one in which we actually live, and that when we insist that our scientific theories do refer to the world of our experience we are deluding ourselves:

You use the word force and, when queried, you define it by law, field, and vector; but what you really have in mind is the force you feel in commanding your muscles. Do not imagine, however, that you are united these two: you mix up unconnected notions, surreptitiously exchanging one for the other (Ibid.: 11-12). 
The two different, and according to Riezler's Aristotle unconnected, worlds suggest the central difference between his science and the modern instantiation. Aristotelian science began with everyday experience and made sense of the world in light of it. His was not a world of neutral and impersonal pointer readings and numerical values, but a world filled with purpose and intentionality, just as we experience it. Implicit throughout Riezler's critique is that the worlds of ancient and modern science are incompatible: the insights gained through modern mathematical methods are incompatible with the claims of ancient science, because they make contradictory claims about reality. Modern science, in this view, restricts itself to "the order in which everything perceivable is connected - the relations and laws linking our observations" (Ibid.: 8), and in so doing denies the importance of experience to concepts like motion, colour, and heat.

In Aristotelian terms, we might say that modern science eliminates formal and final causes to study only the material and efficient. Riezler's argument is that by restricting itself to the measurable - i.e. material and efficient causes - it has fundamentally changed the meaning of the measurable such that it does not merely offer an incomplete picture of the world, but a false one. That is, one cannot simply supplement the material and efficient causes of modern science with Aristotelian concepts drawn from experience. For Riezler the two sets of ideas describe completely different realities. Either motion is a change in numerical values of four dimensional variables or it is what we experience it to be, but it cannot be both. There is something to be said for Riezler's argument, especially given that Aristotle would agree that material only makes sense in light of final causality, since it only exists as potency for a circumscribed set of ends. Once material is reduced to neutral stuff that reacts to other neutral stuff, it does seem like a fundamentally different world than the one Aristotle described, rather than a partial description 
of the same world. For this reason Riezler claims that the world of modern science, including its many discoveries, cannot be reconciled to or combined with final causes or natural right.

Kuhn and Riezler argue that the new methods make it impossible to reconcile ancient beliefs about nature with modern ones, either because they are incommensurate or simply incompatible. This entails that an either-or decision faces us. According to Kuhn there are no trans-paradigmatic criteria by which we can choose, whereas Riezler argues that, objectively speaking, Aristotelian science better describes reality. In either case, ancient scientific theories regarding natural ends cannot be accepted along with the modern theory of motion. In other words, the revival of natural right would require the replacement of modern science with its Aristotelian precursor. As a purely historical or sociological possibility, that seems highly unlikely.

There is yet another possibility, hinted at by Eric Voegelin's criticism of scientism's reduction of the four causes to two. In "The Origins of Scientism" he lists the three characteristics of scientism, the second and third of which are relevant to the present discussion: “(2) that all realms of being are accessible to the methods of the sciences of phenomena; and (3) that all reality that is not accessible to sciences of phenomena is either irrelevant or, in the more radical form of the dogma, illusionary" (Voegelin 2000: 169). He recognizes the distinction between substances and phenomena, where substance refers to the essence of things, over and above their observable properties, and phenomena refers to the aspects of things that we can experience with the senses. Voegelin takes knowledge of substances to be superior to knowledge of phenomena, despite the tangible and empirically-verifiable nature of phenomenal knowledge. Moreover, the scientistic emphasis on phenomena over substance leads to the treatment of phenomena as if it were substantial, or the thing in itself. Through this conceptual 
process, the study of phenonema transforms into the (alleged) study of substantial reality, through the assumption that all that exists are the phenomena. Modern science is a science of empirically verifiable accidents and says nothing about the substances that underlie those accidents, and as Voegelin points out it often denies the reality of underlying substances altogether. In other words, it makes claims regarding the material and efficient causes - or at least the aspects of those causes that are empirically verifiable - but has nothing to say about forms or ends.

"Phenomenalism" expands on this definition of scientism as "the attitude that transforms the 'accidences of the accidences' into a science of the 'real' order of nature" (Voegelin 1999: 184). He retains Aristotle's distinction between substance and accident, and uses "phenomena" to refer to knowledge of accidents. Phenomenalism is his term for "the preoccupation of man with the phenomenal aspects of the world, as they appear in science, and the atrophy of awareness of the substantiality of man and the universe" (Ibid.: 178). Voegelin demonstrates the effect of phenomenalism on three scientific fields: biology, economics, and psychology. In the field of biology, which is most relevant to this dissertation, the phenomenal discovery that the current variety of species is a result of genetic mutations and natural selection was transmuted into a theory of the substance of man, according to which his place in the cosmos was radically altered. In Voegelin's words:

The case of biological theory is, furthermore, specifically important because it reveals in great clearness the peculiar problem of phenomenalism. A theory that in itself might contribute to our knowledge of the phenomenal unfolding of a substance is perverted into a philosophy of substance: the causal relationship of phenomena (always assuming the correctness of the theory) is understood as an explanation on the level of the substance of life (Ibid.: 185).

It is important for our purposes that the "phenomenalist" move from a description of accidents to a theory of nature is not entailed or permitted by the empirical evidence itself. 
Moreover, the new and improved description of the empirically accessible accidents does not necessarily refute or overturn the existing theory of substance. Voegelin's use of Aristotelian ontology divides reality into substance and accident with only the former being accessible to empirical scientific methods. The point is that we have not so much disproved the older substantial theories, but that as we emphasized knowledge of accidents we forgot about the empirically inaccessible substances that must underlie the accidents. Finally, Voegelin hints at a reconciliation between Darwin's theory of accidents and an ontologically robust theory of substance: "A theory that in itself might contribute to our knowledge of the phenomenal unfolding of a substance..." (Ibid.: 185). His point seems to be that the empirical claims of the theory of evolution could be reconciled to a theory of the substance of man. That is, Darwin's theory speaks to the material and efficient causes but says nothing about what the formal or final causes might be. On this Voegelin agrees with Riezler. He disagrees, however, about the impossibility of combining, or re-combining, the study of substance and accident.

To put it in the terms used throughout this study, the more accurate knowledge of the behavior of things - i.e. phenomena - can be combined with the knowledge of the ultimate causes of things - i.e. substance - to produce a fuller view of the whole. If modern biology is correct about the diversity of living things having come about through a gradual process of mutation and natural selection, then that should be treated as the way in which what we now recognize as the form of man historically originated. In fact, ethical naturalists at their best do exactly that. Allan Gotthelf, for example, suggests that DNA, as the mechanism by which traits are passed on, confirms and in a certain sense explains how material can have the potential for forms that it does not yet possess (Gotthelf 2012: 390). The modern discovery of DNA, which finally explained how Darwinian adaptations could have occurred, increases our knowledge of 
the material and efficient causes of man. It helps to explain the mechanism by which material becomes human, but it need not change our theory of the underlying substance of man.

This recalls the argument made in chapter three that Aristotle's ontological description of motion does not depend on the specific content of the material and efficient causes. The change from four to 118 elements has no bearing on the truth or falsity of the claim that motion is the being-at-work of potency. Similarly, the change from the eternality of species to their gradual emergence in history has no immediate bearing on the claim that certain ways of life are by nature better for members of the species homo sapiens than are other ways of life. ${ }^{268}$ More generally, the comparison of aims and attunements leaves open the possibility that the attunements leading to a modern theory - laws of nature - do not necessarily conflict with the attunements of ancient science that gave rise to natural right - namely ultimate cause.

This project has attempted to provide the conceptual categories by which the empirical knowledge pertaining to material bodies and their laws of motion could, in principle, be wedded to the fuller conception of science, and reintegrated into a system that includes formal and final causality, and therefore natural right. This should not be construed as a definitive demonstration of the complete reconcilability of natural right with every modern scientific theory, but as an indication of the form such a demonstration could take.

Descartes and Bacon restricted their conceptions of science to the phenomenal behavior of the material world, and there seems to be no good reason why such a description cannot coexist with the premodern emphasis on the goods intrinsic to each thing. This would allow us to welcome the discoveries of modern science, the benefits of which are undeniable, without denying the reality of purposes and ends that Plato and Aristotle used as the foundation of their inquiry into nature. At any rate, as this study has argued, it should be kept in mind that the

${ }^{268}$ This is in fact the central claim of Arnhart (1998). 
ancient belief in natural right and the modern denial of the same arise out of different concerns and motivating goals, rather than simply poor versus sophisticated observation of nature.

\section{The Emergence of Modern Science}

It might be said that my argument concerns the motivations of the early modern theorists of science. The exposition of Cartesian and Baconian science claimed that their social and political intentions influenced their scientific work. In other words, this study of competing conceptions of science could be said to be a study of the emergence of a new socio-political project, namely the expansion of man's power over nature. I have suggested that the modern scientific method was shaped by the desire for mastery over nature. Of the aims and attunements of modern science, the aims preceded and influenced the attunements.

However, the question must be asked whether it is not the other way around. For example, did new discoveries emerge that made further power over nature seem possible in the first place? The question is made even more complicated when we consider the fact that the supposed aims of modern science were bound up with broader themes in modern political thought. Freedom from the capriciousness of nature has scientific as well as political connotations, as we see in the similarities between Bacon and Machiavelli's intentions. We can ask this question in its strongest form in the following manner: which came first, the sociopolitical desire for control over nature or the type of knowledge required to achieve such control?

Without pretending to have definitively settled the issue, we can note that there are textual indications that Descartes and Bacon, for their parts, seemed to consciously make social and political aims the motivating force behind their scientific investigations. We have already had occasion to observe Descartes' complaints about the political problems of his age, and his 
belief that a more certain method of solving disputes would bring human affairs under control. It is evident that his epistemological and theological speculations, at the very least, were motivated by practical concerns. Moreover, there is the critical passage in part six of The Discourse on Method that explicitly reveals the aim underlying his scientific work. He recounts his discovery that useful knowledge is possible, after which he devoted his time to developing a "practical philosophy" by which to "render ourselves the masters and possessors of nature" (Descartes 1997: 111). The same point is made by his comparison of philosophy to a tree in the preface to The Principles of Philosophy, wherein the fruits are the useful arts of medicine, mechanics, and morals. Everything else in the tree exists for the sake of the fruits (Ibid.: 269). We have also shown how scientific practice itself, with its emphasis on stable laws of nature, was determined with a view to the aim of mastery.

We have seen similar statements from Bacon. On this point it is worth mentioning the utopian society envisioned in The New Atlantis. ${ }^{269}$ The small, unknown island nation of Bensalem is described to the European crew of a ship by its Governor. Among the details given is that its founding legislator, Solamona, established a society of natural science. "Salomon's House," as it is called, was the "pre-eminent" act of King Solamona, and continues to be the "foundation" and "lantern" of Bensalem (Bacon 1952: 206). The implication is that Bensalem is literally a society founded upon the principles of science and technology. The political importance given to the work of Salomon's House is illustrated by the royal procession by which one of the fathers of the House enters into the city. The fruits of Baconian science are on full

\footnotetext{
269 The details and political philosophy of The New Atlantis are discussed in detail by White (1968), Lampert (1993: 27-66), Whitney (1990), and Wheeler (1990). Whitney rejects the interpretation of Bensalem as representing a radical or utopian political vision, writing instead that "In the New Atlantis Bacon generally wishes to demonstrate to conservative, potentially sympathetic readers that science may not be disruptive, but may eliminate sedition and even increase both prosperity and national wealth" (Whitney 1990: 265).
} 
display in Bensalem. ${ }^{270}$ They have immense medical knowledge, including new medicines of which the Europeans are unaware, they are prosperous to the point of permanent budget surpluses, ${ }^{271}$ and they employ caves and towers for a variety of technological purposes.

One principal difference between Platonic and Baconian utopianism is that Bacon thought his society was desirable and possible. The lesson of The New Atlantis is that a society that is established on the foundation of modern science and uses it as its lantern will prosper. As David C. Innes correctly observes:

The literary function of the New Atlantis is to accomplish precisely the task with which, at the end of the story, the narrator is charged: to proclaim the possibilities, and thus the hope, of the new science. The excellence of the science is seen in the attractiveness of the island of Bensalem, where the fullness of the hope which it offers is showcased. Those who populate the island, like us, are modem people. They are "happy," widely enjoying as they do what is most important to them, the fruit of that largely triumphant science. Their virtue is their "humanity." This is primarily the disposition to provide others with these goods, the only goods which modem science equips us to provide. It also encompasses, however, the toleration and civility underlying the religious and civil peace which mark the island. This peace derives from the priority which the Bensalemites give to the comforts and security which science successfully provides (Innes 1994: 4).

This is all to say that Bacon had a clear purpose in articulating his experimental method.

Like Descartes, he envisioned a peaceful world undivided by competing religious or political beliefs. The absence of political strife in Bensalem is the implied result of the benefits of modern science, as Innes points out. A people devoted to peace, comfort, and security, in other words, would do well to turn to his science in order to satisfy their desires. In the context of the question at hand, Bacon consciously pursued scientific discoveries with a political goal in mind. He appears to have been looking ahead to a desirable political situation, in which men had

\footnotetext{
${ }^{270}$ That their science is distinctly Baconian is indicated by the Father of Salomon's House: "The end of our foundation is the knowledge of causes, and secret motions of things; and the enlarging the bounds of human empire, to the effecting of all things possible" (Bacon 1952: 210).

${ }^{271}$ Bensalem earmarks a certain amount each year for the care of visitors; because they have had no visitors for 37 years there remains an almost unlimited fund for such purposes.
} 
sufficient control over nature to meet their needs and live peaceably, the enabling of which was the purpose of his scientific methodology.

Baconian and Cartesian science does not seem to be value-neutral. On the contrary, the central attunements thereof, namely the focus on matter and the laws of nature, appear to be the expressions of determinate political goals. Bacon was not merely concerned with science for science's sake, but was a political thinker with political goals (White 1968). These goals are left under the surface by Descartes, but we have seen indications in The Discourse that point to the political motivations of his thinking. Though he does not foresee a radically new political order arising as a result of technological science, he is motivated by the desire to resolve political disputes and relieve human suffering. Therefore, an implication of my analysis of Descartes is that his epistemological and scientific work is driven by some of the same moral and political goals of the more explicitly political political philosophers of modernity. ${ }^{272}$

Moreover, the natural right framework that Descartes and Bacon hoped to supplant is itself politically important. It is important to return to this theme in order to emphasize the moral and political implications of this study, which has dealt with predominantly scientific themes. There are some specific policy issues that would directly benefit from the availability of the natural right framework, though Alasdair MacIntyre goes even further in suggesting that the loss of the classical moral framework has made virtually all moral and political debate interminable (MacIntyre 1984: 8). The loss of a shared moral horizon has reduced public debate to "assertion and counter-assertion" of arbitrary views (Ibid.). This is similar in implication to The President's Council on Bioethics' suggestion in 2003 that the difficulty in defining the concept

\footnotetext{
${ }^{272}$ In addition to what has been said in the above pages about Descartes, Bacon, and Machiavelli, it is worth pointing out that Hobbes and Locke explicitly defined politics in terms of material self-preservation (Hobbes 1987: 223; Locke 2002: 2). A theme, therefore, running through modern political philosophy is that bodily needs like health, security, and prosperity are of the utmost importance.
} 
of normal health leaves many bioethical questions without satisfactory answers (The President's Council on Bioethics 2003: 14-16). We noted at the outset that the difficulty with which opponents of unlimited genetic engineering can persuasively oppose the tempting promises of longevity and the alleviation of suffering is a consequence of the blurred boundary between therapy and enhancement (cf. Sandel 2009a and Habermas 2003). MacIntyre traces these difficulties to the problem of relativism, ${ }^{273}$ or what he calls emotivism:

the doctrine that all evaluative judgments and specifically all moral judgments are nothing but expressions of preference, expressions of attitude or feeling, insofar as they are moral or evaluative in character (MacIntyre 1984: 11-12).

For MacIntyre emotivism is not an academic problem, but a political and cultural one. ${ }^{274}$ It reduces all moral disagreement to incommensurable first principles between which rational dialogue is impossible. In the genetic engineering debate, the proponents of enhancement appeal to their first principle of autonomy, ${ }^{275}$ against which the claims of Sandel's ethic of giftedness has no obvious claim. MacIntyre's analysis suggests that once we are faced with the choice between the principles of autonomy and mastery, on the one hand, and Sandel's "openness to the unbidden" (Ibid.: 86), on the other hand, the contemporary moral framework has no resources with which we can make a rational decision. He illustrates this by way of the Rawls-Nozick debate regarding the role of the state in reducing inequality, arguing that behind the appearance of real debate is the appeal to the rival moral claims of entitlements or needs, neither of which could answer the questions of the other:

\footnotetext{
${ }^{273}$ See also Kass (1985: 280): "In fact - a second obstacle [to speaking about the body] - it seems that there may be no naturally and universally valid 'plain truths' about the body, since different cultures vary widely in their assessment of the nature and worth of what we call 'the body'."

${ }^{274}$ Peter McMylor puts it this way: "MacIntyre is not claiming that this philosophical theory is very widely accepted, although its emergence in the late nineteenth century and early twentieth century is not without significance. Indeed in his A Short History of Ethics, he pointed to several powerful critics of the view. But rather the point is that something very much like emotivism is, in fact, institutionalised and operational in a society like our own" (1994: 23-24).

${ }^{275}$ Michael Sandel discusses the "Autonomy Argument" in (2009a: 6-10).
} 
But our pluralist culture possesses no method of weighing, no rational criterion for deciding between claims based on legitimate entitlement against claims based on need. Thus these two types of claim are indeed, as I suggested, incommensurable, and the metaphor of 'weighing' moral claims is not just inappropriate but misleading (Ibid.: 246).

If one feels that needs are more important than entitlements, nothing that is said on behalf of entitlements will matter, and vice versa. In other words, there is no rational ground beneath our moral and political views, only the appeal to arbitrarily held convictions. Each side presents what appears to be arguments, but are simply private preferences for one incommensurable premise over another, presumably equally plausible, premise. Because no further rational grounds can be provided for such premises, they must ultimately be the result of choice or personal preference. MacIntyre will go on to describe this situation as Nietzschean, with some justice (Ibid.: 114-115). He traces contemporary relativism, however, not to Nietzsche or the postmodernist philosophers, but to the enlightenment project of overthrowing classical moral and political philosophy (Ibid.: 62-78).

Roughly three decades before the publication of After Virtue, Leo Strauss similarly diagnosed the cause of relativism (Strauss 1999: 1-3). The loss of natural right, he claims, has reduced all law to positive law and has removed any objective criteria by which the laws of any particular society may be judged. We noted in chapter one that Strauss was aware of two solutions on offer: either eradicate teleology from nature entirely or insist on a regional teleology governing human affairs (Ibid.: 8). In chapters two and three of this study the weakness of the second approach became evident, namely that it is impossible to maintain human goods if the natural world in which and out of which humans are made is purposeless matter in motion. If chance is prior to purpose in the realms of physics and chemistry, it is hard to see how biological end-directedness might emerge in a way that is immune to reductionism. Strauss blames the loss 
of natural right on the apparent victory of modern science, writing that "an adequate solution to [this problem] cannot be found before the basic problem has been solved" (Ibid.).

MacIntyre seems to agree with Strauss' claim that modern science has made natural right a difficult framework to maintain. Indeed, the purpose of After Virtue was to revive Aristotelian ethics in a form that takes for granted modern biology's refutation of natural ends (MacIntyre 1984: 162-163). ${ }^{276}$ Instead of deriving the virtues from human biology, MacIntyre looked to the inter-subjective nature of social life according to which roles, purposes, and meaning are assigned from without, so to speak. Ultimately, what he calls a "moral tradition" is the arena in which the virtues take on a shared meaning (Ibid.: 187). The merits of this approach do not need to be definitively settled here, but it is worth noting that the decision to locate the virtues in moral traditions re-opened the door to charges of relativism. ${ }^{277}$

The point of all this is that the scientific themes taken up in these pages have a clear connection to a contemporary political problem. Whether the problem is, a la MacIntyre, an emotivist culture that reduces moral and political debate to competition between arbitrary assumptions, or Strauss' legal positivism that makes it impossible to judge the competing moral claims of societies, ${ }^{278}$ it seems that the loss of natural right has had serious consequences. ${ }^{279}$

\footnotetext{
${ }^{276}$ Robert C. Bartlett significantly minimizes the importance of Aristotle in MacIntyre's ethical project: "MacIntyre's return to Aristotle (and Aquinas) is not without qualification and considerable complexity....For in the end, MacIntyre is less concerned with what Aristotle himself thought on any given question than with what the tradition of Aristotelianism came to think" (Bartlett 2011: 45-46).

${ }^{277}$ See Wachbroit (1983) for an early argument to that effect. Similarly, Bartlett suggests that MacIntyre's account of the virtues is unable to satisfactorily avoid the problem of historicism (2001: 51). MacIntyre himself has responded to these types of charges, and in later works has become more receptive to the role of biology in grounding morality (MacIntyre 1999).

${ }_{278}$ For two thoughtful analyses of the problem of relativism in international affairs see Nardin (1989) and Lawson (1998).

${ }^{279}$ This is not to ignore the fact that many see this as a positive development, in that mankind has once and for all shed itself of the moral authority of nature. This attitude is typical of modern philosophers who defined politics as an unnatural phenomenon; chapter 1 discusses Hobbes' creation of an artificial island of morality and order in the midst of the natural world. John Rawls provides a contemporary account of principles of justice arising from nothing but the free choice of autonomous individuals (Rawls 1971). The current project, however, takes the desirability of natural right as a working assumption.
} 
Moreover, Strauss, MacIntyre, and the regional teleologists whose work has been examined in this study all seem to think that modern science has made natural right more difficult, if not impossible, to maintain. This dissertation has focused on precisely this question in the philosophy of science in order to contribute to the political project of restoring the natural right framework as an available position. An assumption shared by many defenders and detractors of natural right is that modern science has disproved the claim that non-human nature can be understood as being end-directed - that is, as having particular goods (Hassing 1997: 5, 39-41; Wallace 1997: 70; Arnhart 1998: 242-245; Holloway 2009). The weakening of this assumption would serve to strengthen the case for natural right. This has been the purpose of the present study, and it is in light of these moral and political concerns that the above scientific arguments should be read.

To conclude, the primary objective of this project has been to articulate categories that might allow the now distinct fields of science and philosophy to work their way back to the classical natural right approach. By pointing to this possibility I hope to have justified and thus encouraged further analysis. The possibility of reconciling science and philosophy under the natural right model needs to be further pursued in at least the following two ways. First, the investigation of the aims and attunements of modern science could be expanded and corroborated by studies of the work of important modern scientists including Newton, Galileo, and others. These individuals are set apart from Descartes and Bacon by their emphasis on doing the work of scientific discovery itself, rather than philosophy of science. If the aims and attunements attributed to modern science by way of Descartes and Bacon are found to animate 
the work of scientists whose discoveries defined the modern scientific worldview then the reconciliation hinted at here would increase in likelihood.

Second, sorting out the implications for natural right of key scientific theories and discoveries themselves would strengthen the argument that natural right is still a live option in political philosophy. We have had occasion to discuss some of these in passing, including the discovery of DNA, modern chemistry's expansion from four to 118 elements, and the materialism at the heart of Cartesian and Baconian physics. However, since certain discoveries are often seen to be at odds with teleological explanations, and hence natural right, it might be fruitful to examine them directly and in more depth than this exegetical study allowed for. Candidates for such investigation might include Newton's gravitational theory of motion, Darwinian evolution, and possibly heliocentrism itself. The claim that modern science has not disproven natural right is a negative one and thus almost impossible to prove; however, it will become more and more plausible as problematical scientific theories are dealt with and their alleged refutation of natural right clarified. This study's chosen categories of aims and attunements, I suggest, may prove useful in such analyses in the ways hinted at above in the brief discussions of other discoveries. ${ }^{280}$

The upshot of the viability of natural right alongside modern science, if true, is that it would put us in a position to go beyond the mere regional teleology of Arnhart, et al. Their division of nature into the biological and non-biological realms rendered their revived versions of natural right incomplete at best and conceptually impossible at worst. If formal and final

\footnotetext{
${ }^{280}$ This is to say nothing of the possibility of quantum mechanics confirming, or at least moving in the direction of, Aristotelian categories. Thomas Pangle argues for something like this in his article entitled "On Heisenberg's Key Statement Concerning Ontology," which explores the implications of Werner Heisenberg's introduction of potentiality as a middle category between possibility and actuality (Pangle 2014). Riezler had similarly suggested that quantum physics was in need of something like Aristotelian potentiality (Riezler 1940). This avenue of research is promising, though beyond the scope of this dissertation or the research programme it entails.
} 
causality could again be thought of as live options, even in non-human nature, we would have the option of grounding natural right in the full cosmic teleology intended by Plato and Aristotle. In addition to addressing the aforementioned political problems of relativism and the interminability of moral disagreement, this possibility opens up two further directions for future research, one policy-oriented and one methodological. First, asking the "purpose" or "why" questions that natural right encourages could shed new light on a number of policy debates. Any policy issue that requires an answer to the question "What is $\mathrm{X}$ for?" is made very difficult by the modern reticence to derive moral principles from the nature of the world. Basing the answers to these questions on a firmer ground than convention might open up paths to fresh insight. Second, natural right contributes to methodological debates within political science regarding the value-neutrality of the discipline. Its implied criticism of positivist and behavioralist methods can offer a different perspective than the many poststructuralist and non-foundational approaches currently on offer. 


\section{Works Cited}

Alican, Necip Fikri (2012). Rethinking Plato: A Cartesian Quest for the Real Plato. Rodopi Press.

Allison, Henry (2004). Kant's Transcendental Idealism: An Interpretation and Defense, Revised and Enlarged Edition. Yale University Press.

Anderson, Fulton (1948). The Philosophy of Francis Bacon. University of Chicago Press.

Annas, Julia (1977). “Aristotle on Substance, Accident and Plato's Forms," Phronesis, 22(2), 146-160.

--------- (1981). An Introduction to Plato's Republic. Oxford University Press.

Anselm of Canterbury (1998). The Major Works. Oxford University Press.

Aquinas, Thomas (1998). Selected Writings, edited by Ralph McInerny. Penguin Books. (1999). Commentary on Aristotle's Physics. Translated by Richard J. Blackwell, Richard J. Spath, and W. Edmund Thirlkel. Dumb Ox Books.

Arendt, Hannah (1958). The Human Condition. University of Chicago Press.

Ariew, Roger (1999). Descartes and the Later Scholastics. Cornell University Press.

Aristotle (1924). Metaphysics, translated by W.D. Ross. Oxford University Press.

-------- (1933). Metaphysics, translated by Hugh Tredennick. Harvard University Press. (1970). Physics, Volume 1: Books 1-4, translated by Phillip H. Wicksteed and Francis M. Cornford. Harvard University Press. (1985). Politics, translated by Carnes Lord. University of Chicago Press. (1996). Nichomachean Ethics, translated by Harris Rackham. Wordsworth Editions Limited.

--------- (2002). Metaphysics, translated by Joe Sachs. Green Lion Press. 
Arnhart, Larry (1998). Darwinian Natural Right: The Biological Ethics of Human Nature. State University of New York Press.

(2000). “Defending Natural Right," Interpretation, 27(3), 263-277.

(2009). “A Darwinian Reading of Cropsey’s Plato,” [Blog Post]. Retrieved from http://darwinianconservatism.blogspot.ca/2009/07/darwinian-reading-of-cropseysplato.html.

Bacon, Francis (1952). Great Books of the Western World, Volume 30: Advancement of Learning/Novum Organum/New Atlantis, Edited by Robert Maynard Hutchins. Encyclopaedia Britannica.

(1973). Essays. Everyman Paperbacks.

(2000). The New Organon, Edited by Lisa Jardine and Michael Silverthorne. Cambridge University Press.

Barbour, Ian G. (1997). Religion and Science: Historical and Contemporary Issues. HarperCollins.

Barfield, Owen (2006). Worlds Apart: a dialogue of the 1960's. The Barfield Press.

Bartlett, Robert C. (2011). The Idea of Enlightenment: A Postmortem Study. University of Toronto Press.

Behe, Michael (2007). The Edge of Evolution: The Search for the Limits of Darwinianism. Free Press.

Benardete, Seth (1978). “On Wisdom and Philosophy: The First Two Chapters of Aristotle's 'Metaphysics' A," The Review of Metaphysics, 32(2), 205-215. (1989). Socrates'Second Sailing: On Plato’s Republic. University of Chicago Press.

Bird, Graham (2006). The Revolutionary Kant: A Commentary on the Critique of Pure Reason, Chicago and La Salle: Open Court.

Bolotin, David (1987). "The Life of Philosophy and the Immortality of the Soul: An Introduction to Plato's Phaedo," Ancient Philosophy, 7, 39-56.

--------- (1998). An Approach to Aristotle's Physics: With Particular Attention to the Role and Manner of Writing. State University of New York Press.

Brague, Remi (1990). “Aristotle's Definition of Motion and its Ontological Implications," Graduate Faculty Philosophy Journal, 13(2), 1-22.

Brooke, John and Geoffrey Cantor (1998). Reconstructing Nature: The Engagement of Science and Religion. Oxford University Press. 
Bruell, Christopher (2014). Aristotle as Teacher: His Introduction to a Philosophic Science. St. Augustine's Press.

Butterfield, Herbert (1965). The Origins of Modern Science, Revised Edition. Free Press.

Chamberlain, Tyler (2013)."Blaise Pascal as a Political Thinker: The Politics of the Knowledge of the Heart." Upublished paper presented at the Canadian Political Science Association Conference. University of Victoria, Victoria, BC: June 2013.

-------- (2014). "MacIntyre's Unsuccessful Aristotelianism: An Oakeshottian Critique of After Virtue." Unpublished paper presented at the Aristotle and the Peripatetic Tradition Conference. Dominican University College, Ottawa, ON: October 2014.

Charlton, William (1970). Aristotle's Physics. Books $1 \& 2$. Translated with introduction and notes by William Charlton. Clarendon Press.

Chávez-Arvizo, Enrique (1997). "Introduction," in Descartes, René. Key Philosophical Writings, Edited by Enrique Chavez-Arvizo, translated by Elizabeth S. Haldane and G.R.T. Ross. Wordsworth Editions Limited.

Clark, William (1998). "Agents and Structures: Two Views of Preferences, Two Views of Institutions," International Studies Quarterly, 42(2), 245-270.

Clarke, Desmond M. (1982). Descartes'Philosophy of Science. Manchester University Press.

Copleston, Frederick (1994). A History of Philosophy. Volume IV. Modern Philosophy: From Descartes to Leibniz. Image; Later prt. edition.

Corkum, Phil (2008). “Aristotle on Ontological Dependence,” Phronesis, 53(1), 65-92.

Cox, Robert (1981). "Social Forces, States, and World Orders: Beyond International Relations Theory," Millennium - Journal of International Studies, 10(2), 126-155.

Cresswell, M.J. (1987). “Aristotle's Phaedo,” Australasian Journal of Philosophy, 65(2), 131155.

Cropsey, Joseph (1995). Plato's World: Man's Place in the Cosmos. University of Chicago Press.

Curley, E.M. (1978). Descartes Against the Skeptics. Harvard University Press.

Darby, Tom (2016). "On Odysseys Ancient and Modern: An Excursus on Spiritual Crisis and Causal Explanation," in Sojourns in the Western Twilight: Essays in Honor of Tom Darby, Edited by Robert C. Sibley and Janice Freamo. Fermentation Press.

Darwin, Charles (1993). The Portable Darwin, Edited, with an Introduction, Notes and Epilogue by Duncan M. Porter and Peter W. Graham. Penguin Books. 
Descartes, René (1997). Key Philosophical Writings, Edited by Enrique Chavez-Arvizo, translated by Elizabeth S. Haldane and G.R.T. Ross. Wordsworth Editions Limited. (1998). The World and Other Writings, Edited and translated by Stephen Gaukroger. Cambridge University Press.

Doppelt, Gerald (1978). "Kuhn's epistemological relativism: An interpretation and defense," Inquiry, 21(1-4), 33-86.

Doyle, Michael (1997). Ways of War and Peace: Realism, Liberalism, and Socialism. W.W. Norton.

Dror, Itiel (2009). "How Can Francis Bacon Help Forensic Science? The Four Idols of Human Biases," Jurimetrics: The Journal of Law, Science, \& Technology, 50(1), 93-110.

Farrington, Benjamin (1964). The Philosophy of Francis Bacon. The University of Chicago Press.

Fine, Gail (1995). On Ideas: Aristotle's Criticism of Plato's Theory of Forms. Oxford University Press.

------- (2000). “Descartes and Ancient Skepticism: Reheated Cabbage?” Philosophical Review, 109(2), 195-234.

Frankfurt, Harry (2008). Demons, Dreamers, and Madmen: The Defense of Reason in Descartes' "Meditations." Princeton University Press.

Friedlander, Paul (1969). Plato: The Dialogues: Second and Third Periods. Princeton University Press.

Furley, David (1985). "The Rainfall Example in Physics ii 8," in Aristotle on Nature and Living Things: Philosophical and Historical Studies Presented to David M. Balme, ed. A. Gotthelf. Mathesis Publications, 177-82.

Gadamer, Hans-Georg (1980). Dialogue and Dialectic: Eight Hermeneutical Studies on Plato. Translated by P. Christopher Smith. Yale University Press.

--------- (1981). Reason in the age of science. Translated by Frederick G. Lawrence. MIT Press. (1986). The Idea of the Good in Platonic-Aristotelian Philosophy. Translated by P. Christopher Smith. Yale University Press. - (2004). Truth and Method, Revised Edition. Translated by Joel Weinsheimer and Donald G. Marshall. Continuum.

Garber, Daniel (1992). Descartes' Metaphysical Physics. University of Chicago Press. 
------- (1992a). "Descartes' Physics," in The Cambridge Companion to Descartes. Edited by John Cottingham. Cambridge University Press, 286-334.

Gaukroger, Stephen (1998). "Introduction," in René Descartes, The World and Other Writings. Edited by Stephen Gaukroger. Cambridge University Press.

(2002). Descartes'System of Natural Philosophy. Cambridge University Press.

(2003). Francis Bacon and the Transformation of Early-Modern Philosophy, netLibrary Edition. Cambridge University Press (Virtual Publishing).

Gilson, Étienne (1984). From Aristotle to Darwin and Back Again: A Journey in Final Causality, Species, and Evolution. Translated by John Lyon. Ignatius Press.

Gorham, Geoffrey (2005). "The Metaphysical Roots of Cartesian Physics: The Law of Rectilinear Motion," Perspectives on Science, 13(4), 431-451.

Gotthelf, Allan (2012). Teleology, First Principles, and Scientific Method in Aristotle's Biology. Oxford University Press.

Grant, George (1973). "Introduction to Plato," in The George Grant Reader. Edited by William Christian and Sheila Grant. University of Toronto Press, 207-210.

(1985). English-Speaking Justice. Anansi Press.

(1986). Technology and Justice. Anansi Press.

Gutting, Gary (2009). What Philosophers Know: Case Studies in Recent Analytic Philosophy. Cambridge University Press.

Habermas, Jurgen (2003). The Future of Human Nature. Polity Press.

Hacking, Ian (1983). Representing and Intervening: Introductory Topics in the Philosophy of Natural Science. Cambridge University Press.

Harari, Yuval Noah (2014). Sapiens: A Brief History of Humankind. McClelland \& Stewart.

Hardt, Michael and Antonio Negri (2000). Empire. Harvard University Press.

Hassing, Richard F. (1997). "Introduction," in Final Causality in Nature and Human Affairs. Edited by Richard F. Hassing. The Catholic University of America Press, 1-51.

Hattab, Helen (2000). "The Problem of Secondary Causation in Descartes: A Response to Des Chene," Perspectives on Science, 8(2), 93-118. - (2007). "Concurrence or Divergence? Reconciling Descartes' Physics with his Metaphysics," Journal of the History of Philosophy, 45(1), 49-78. 
Hegel, G.W.F. (1977). Phenomenology of Spirit. Translated by A.V. Miller. Oxford University Press.

Henry, John (2002). Knowledge is Power: Francis Bacon and the Method of Science. Icon Books.

(2004). "Metaphysics and the Origins of Modern Science: Descartes and the Importance of Laws of Nature" Early Science and Medicine, 9(2), 73-114.

Heidegger, Martin (1977). The Question Concerning Technology and Other Essays. Harper Torchbooks.

--------- (1993). Basic Writings, Revised and Expanded Edition. Edited by David Farrell Krell. HarperCollins.

Hibbs, Thomas S. (2017). Wagering on an Ironic God: Pascal on Faith and Philosophy. Baylor University Press.

Hobbes, Thomas (1987). Leviathan. Penguin Books.

(1994). The Elements of Law Natural and Politic. Edited with an Introduction and Notes by J.C.A. Gaskin. Oxford University Press.

Holloway, Carson (2009). "Strauss, Darwinism, and Natural Right," in The Human Person and a Culture of Freedom. Edited by Peter Pagan Aguiar and Terese Auer. Catholic University of America Press.

Howell, Graham R. (2008). Of Science and Civic Character: A Study of Plato, Bacon, and Hobbes. Ph.D Dissertation, Department of Political Science, Carleton University.

Innes, David C. (1994). "Bacon's New Atlantis: The Christian Hope and the Modern Hope," in Interpretation: A Journal of Political Philosophy. 22(1), 3-38.

Jardine, Lisa (1990). “Experientia literata or Novum Organum: The Dilemma of Bacon's Scientific Method," in Francis Bacon's Legacy of Texts. Edited by William A. Sessions. AMS Press.

Kadlac, Adam (2007). “Acceptance, Belief, and Descartes's Provisional Morality,” Ethical Theory and Moral Practice, 10(1), 35-52.

Kahn, Charles (1996). Plato and the Socratic Dialogue: The Philosophical Use of a Literary Form. Cambridge University Press.

------- (2002). “On Platonic Chronology,” in New Perspectives in Plato, Modern and Ancient. Edited by Julia Annas and Christopher J. Rowe. Center for Hellenic Studies.

Kant, Immanuel (1997). Critique of Practical Reason. Translated by Mary Gregor. Cambridge University Press. 
--------- (1992). Critique of Pure Reason. Translated by F. Max Müller. MacMillan \& Co.

Kass, Leon, R. (1985). Toward a More Natural Science: Biology and Human Affairs. The Free Press.

Kennington, Richard (2004). On Modern Origins: Essays in Early Modern Philosophy. Edited by Pamela Krauss and Frank Hunt. Lexington Books.

Kenny, Anthony (2012). A New History of Western Philosophy. Oxford University Press.

King, Gary, Robert O. Keohane, and Sidney Verba (1994). Designing Social Inquiry: Scientific Inference in Qualitative Research. Princeton University Press.

Kojève, Alexandre (1980). Introduction to the Reading of Hegel: Lectures on the Phenomenology of Spirit. Translated by James Nichols, Jr. Cornell University Press.

Kuhn, Thomas (2012). The Structure of Scientific Revolutions, $4^{\text {th }}$ ed. Chicago: University of Chicago Press.

Kristol, Bill (2014). "Harvey Mansfield." Conversations with Bill Kristol [Podcast].

Lampert, Laurence (1993). Nietzsche and Modern Times: A Study of Bacon, Descartes, and Nietzsche. Yale University Press.

Lane, Robert (1999). “Why Bacon's Method is Not 'Certain'," History of Philosophy Quarterly, 16(2), 181-192.

Lapid, Yosef (1989). "The Third Debate: On the Prospects of International Theory in a PostPositivist Era," International Studies Quarterly, 33(3), 235-254.

Larmore, Charles (2012). "The First Meditation: Skeptical Doubt and Certainty," in The Cambridge Companion to Descartes' Meditations. Edited by David Cunning. Cambridge University Press, 49-67.

Lawson, Stephanie (1998). "Democracy and the problem of cultural relativism: Normative issues for international politics," Global Society: Journal of Interdisciplinary International Relations, 12:2, 251-270.

Lennon, Thomas M. (2014). "The Fourth Meditation: Descartes' theodicy avant la letter," in The Cambridge Companion to Descartes' Meditations. Edited by David Cunning. Cambridge University Press, 168-185.

Lewis, C.S. (1967). Studies in Words, $2^{\text {nd }}$ ed. Cambridge University Press.

-------- (2001). The Abolition of Man. HarperCollins.

Lipton, P. (2001). "The History of Empiricism," in International Encyclopedia of the Social and Behavioral Sciences. Elsevier, 4481-4485. 
Locke, John (2002). The Second Treatise of Government and A Letter Concerning Toleration. Dover Publications.

Loeb, Louis E. (1992). “The Cartesian Circle," in The Cambridge Companion to Descartes, Edited by John Cottingham. Cambridge University Press.

MacIntyre, Alasdair (1984). After Virtue: A Study in Moral Theory, $2^{\text {nd }}$ ed. University of Notre Dame Press.

--------- (1999). Dependent Rational Animals: Why Human Beings Need the Virtues. Open Court Publishing.

Malherbe, Michel (1996). "Bacon's Method of Science," in The Cambridge Companion to Bacon, Edited by Markku Peltonen. Cambridge University Press.

Mansfield, Harvey C. (1981). "Machiavelli’s Political Science,” American Political Science Review, 75(2), 293-305.

-------- (1998). Machiavelli's Virtue. The University of Chicago Press.

Masterman, Margaret (1970). "The Nature of a Paradigm," in Lakatos, I. and Musgrave, A. (eds.), Criticism and the Growth of Knowledge. Cambridge University Press.

Masters, Roger D. (1989). The Nature of Politics. Yale University Press. (1990). "Evolutionary Biology and Political Theory," The American Political Science Review, 84(1), 195-210.

-------- (1996). Machiavelli, Leonardo, and the Science of Power. University of Notre Dame Press.

McCarthy, John C. (1994-1995). "Pascal on Certainty and Utility." Interpretation, 22(2), 247269.

McKnight, Stephen A. (2006). The Religious Foundations of Francis Bacon's Thought. University of Missouri Press.

McMylor, Peter (1994). Alasdair MacIntyre: Critic of Modernity. Routledge.

Menn, Stephen (1990). "Descartes and Some Predecessors on the Divine Conservation of Motion," Synthese, 82(2), 215-238.

Merchant, Carolyn (1990). The Death of Nature: Women, Ecology, and the Scientific Revolution. HarperOne. (2015). Autonomous Nature: Problems of Prediction and Control from Ancient Times to the Scientific Revolution. Routledge. 
Miljan, Lydia (2012). Public Policy in Canada: An Introduction, $6^{\text {th }}$ Edition. Oxford University Press.

Milton, J.R. (2000). "Laws of Nature" in The Cambridge History of Seventeenth-Century Philosophy. Edited by Daniel Garber and Michael Ayers. Cambridge University Press.

Minkov, Svetozar (2008). "The Human Good and the Problem of Bacon's Intention” Interpretation. 35(3), 265-282.

------ (2010). Francis Bacon's "Inquiry Touching Human Nature": Virtue, Philosophy, and the Relief of Man's Estate. Lexington Books.

Moravcsik, Julius (1974). “Aristotle on Adequate Explanations” Synthese. 28(1), 3-17.

Morgan, C.A., A. Doran, G. Steffian, G. Hazlett, and S.M. Southwick (2006). "Stress-Induced Deficits in Working Memory and Visuo-Constructive Abilities in Special Operations Soldiers," Biological Psychiatry, 60(7), 722-729.

Nagel, Thomas (1997). The Last Word. Oxford University Press.

-------- (2012). Mind \& Cosmos: Why the Materialist Neo-Darwinian Conception of Nature is Almost Certainly False. Oxford University Press.

Nardin, Terry (1989). "The Problem of Relativism in International Ethics," Millennium Journal of International Studies, 18(2), 149-161.

Negri, Antonio (2007). Political Descartes. Translated by Matteo Mandarini and Alberto Toscano. Verso.

Neustadt, Mark S. (1987). "Review of Science, Faith, and Politics: Francis Bacon and the Utopian Roots of the Modern Age by Jerry Weinberger," Political Theory, 15(3), 448451.

Newell, Waller R. (2000). Ruling Passion: The Erotics of Statecraft in Platonic Political Philosophy. Rowman \& Littlefield Publishers.

-------- (2010). "Did Plato Believe in His Own Metaphysics?" in Recovering Reason: Essays in Honor of Thomas L. Pangle. Edited by Timothy Burns. Lexington Books.

-------- (2013). Tyranny: A New Interpretation. Cambridge University Press.

Nietzsche, Friedrich (1994). "Beyond Good and Evil" in Great Books of the Western World, Vol. 43, Edited by Mortimer J. Adler, translated by R.J. Hollingdale. Toronto: Encyclopeadia Britannica Inc.

Nolan, Lawrence (2014). "The Third Meditation: causal arguments for God's existence," in The Cambridge Companion to Descartes' Meditations. Edited by David Cunning. Cambridge University Press, 127-148. 
O'Mara, Shane (2015). Why Torture Doesn't Work: The Neuroscience of Interrogation. Harvard University Press.

Oakeshott, Michael (1991). Rationalism in Politics and Other Essays. New and Expanded Edition. Liberty Fund.

Okasha, Samir (2002). Philosophy of Science, A Very Short Introduction. Oxford University Press.

Pangle, Thomas L. (2014). "On Heisenberg's Key Statement Concerning Ontology" The Review of Metaphysics. 67(4), 835-859.

Pascal, Blaise (1952). Great Books of the Western World, Volume 33: The Provincial Letters/Pensées/Scientific Treatises, Edited by Robert Maynard Hutchins. Encyclopaedia Britannica.

Peltonen, Markku (1996). "Bacon's Political Philosophy," in The Cambridge Companion to Bacon, Edited by Markku Peltonen. Cambridge University Press, 283-310.

Plato (1991). The Republic of Plato, second edition. Translated by Allan Bloom. Basic Books.

-------- (1998). Phaedo. Translated by Eva Brann, Peter Kalkavage, and Eric Salem. Focus Philosophical Library.

Plato \& Aristophanes (1998). Four Texts on Socrates, revised edition, translated by Thomas G. West and Grace Starry West. Ithica: Cornell University Press.

Polanyi, Michael (1974). Personal Knowledge: Towards a Post-Critical Philosophy. Chicago: University of Chicago Press.

Postman, Neil (1993). Technopoly: The Surrender of Culture to Technology. Vintage Books.

President's Council on Bioethics (2003). Beyond Therapy: Biotechnology and the Pursuit of Happiness. Harper Perennial.

Quinton, Anthony (1980). Francis Bacon. Oxford University Press.

Rahe, Paul (1994). Republics Ancient and Modern, Volume II: New Modes and Orders in Early Modern Political Thought. The University of North Carolina Press.

Rawls, John (1971). A Theory of Justice. Belknap Press.

Reiss, Timothy J. (1991). "Descartes, the Palatinate, and the Thirty Years War: Political Theory and Political Practice," Yale French Studies. 80, 108-145.

Riezler, Kurt (1940). Physics and Reality: Lectures of Aristotle on Modern Physics at an International Congress of Science. Yale University Press. 
Roseneau, Pauline Marie (1991). Postmodernism and the Social Sciences: Insights, Inroads, and Intrusions. Princeton University Press.

Ross, David (1964). Aristotle. Barnes and Noble Inc.

Rossi, Paulo (1996). "Bacon's Idea of Science," in The Cambridge Companion to Bacon, Edited by Markku Peltonen. Cambridge University Press, 25-46.

Rozemond, Marleen (1998). Descartes’ Dualism. Harvard University Press.

Russell, Bertrand (1975). History of Western Philosophy. London: George Allen \& Unwin Ltd.

Sachs, Joe (1995). Aristotle’s Physics; A Guided Study. Rutgers University Press.

-------- (n.d.). “Aristotle: Motion and its Place in Nature," Internet Encyclopedia of Philosophy, ISSN 2161-0002. http://www.iep.utm.edu/. Accessed May 16, 2016.

Sandel, Michael (2009). Justice: What's the Right Thing To Do. Farrar, Straus, and Giroux.

-------- (2009a). The Case Against Perfection: Ethics in the Age of Genetic Engineering. The Belknap Press of Harvard University Press.

Sankey, Howard (1997). "Kuhn's Ontological Relativism," in Issues and Images in the Philosophy of Science: Scientific and Philosophical Essays in Honour of Azarya Polikarov, Edited by Dimitri Ginev and Robert S. Cohen. Springer.

Sargent, Rose-Mary (1996). "Bacon as an Advocate for Cooperative Scientific Research," in The Cambridge Companion to Bacon, Edited by Markku Peltonen. Cambridge University Press, 146-171.

Sassen, Brigitte. (2000). Kant's Early Critics: The Empiricist Critique of the Theoretical Philosophy, Cambridge: Cambridge University Press.

Shapere, Dudley (1964). "The Structure of Scientific Revolutions," Philosophical Review, 73, 383-394.

Schiemann, John W. (2012). "Interrogational Torture: Or How Good Guys Get Bad Information With Ugly Methods," Political Research Quarterly, 65(1), 3-19.

Schmaltz, Tad (2008). Descartes on Causation. Oxford University Press.

Scruton, Roger (1984). A Short History of Modern Philosophy: From Descartes to Wittgenstein. London: Routledge.

Sessions, William A. (1990). "Francis Bacon and the Classics: The Discovery of Discovery," in Francis Bacon's Legacy of Texts, Edited by William A. Sessions. AMS Press. 
Smith, Steve (1996). "Positivism and Beyond," in International Theory: Positivism and Beyond. Edited by Steve Smith, Ken Booth, and Marysia Zalewski. Cambridge University Press, $11-46$.

Smith, Steve, Ken Booth, and Marysia Zalewski, ed. (1996). International Theory: Positivism and Beyond. Cambridge University Press.

Smith, Travis (2009). "Being Altogether Bad, Becoming Altogether Good," in The Arts of Rule, Edited by Sharon R. Krause and Mary Ann McGrail. Lexington Books.

Stark, Rodney, (2003). For the Glory of God: How Monotheism Led to Reformations, Science, Witch-Hunts, and the End of Slavery. Princeton University Press.

Strauss, Leo (1978). The City and Man. University of Chicago Press. (1999). Natural Right and History. University of Chicago Press.

Taylor, C.C.W. (2002). "The Origins of Our Present Paradigms," in New Perspectives on Plato: Modern and Ancient. Edited by Julia Annas and Christopher J. Rowe. Center for Hellenic Studies.

Taylor, Charles (2007). A Secular Age. The Belknap Press of Harvard University Press.

Thomson, Garrett (2000). On Kant. Wadsworth.

Turnbull, Robert G. (1958). "Aristotle's Debt to the 'Natural Philosophy' of the Phaedo." The Philosophical Quarterly. 8(31): 131-143.

Van Evera, Stephen (1997). Guide to Methods for Students of Political Science. Cornell University Press.

Van Fraassen, Bas (1980). The Scientific Image. Clarendon Press.

Van Inwagen, Peter (2015). Metaphysics, $4^{\text {th }}$ Edition. Westview Press.

Vlastos, Gregory (1991). Socrates: Ironist and Moral Philosopher. Cambridge University Press.

Voegelin, Eric (1978). "What is Nature?," in Anamnesis. Edited by Gerhart Niemeyer. University of Notre Dame Press, 71-88. (1978a). "Right by Nature," in Anamnesis. Edited by Gerhart Niemeyer. University of Notre Dame Press, 55-70. (1999). "Phenomenalism," in History of Political Ideas, Volume VII, The New Order and Last Orientation. Edited by Jurgen Gerhardt and Thomas A. Hollweck. University of Missouri Press, 178-192.

---- (2000). "The Origins of Scientism," in Published Essays: 1940-1952. Edited with an introduction by Ellis Sandoz. University of Missouri Press, 168-196. 
-------- (2000a). Order and History, Volume III, Plato and Aristotle. Edited with an introduction by Dante Germino. University of Missouri Press.

Wachbroit, Robert (1983). “A Genealogy of Virtues,” The Yale Law Journal. 92(3), 564-576.

Wallace, William A. (1997). "Is Finality Included in Aristotle's Definition of Nature?" in Final Causality in Nature and Human Affairs. Edited by Richard F. Hassing. Catholic University of America Press.

Walsh, W.H. (1963) Metaphysics. Hutchinson University Library.

Waltz, Kenneth (1959). Man, the State, and War: A Theoretical Analysis. Columbia University Press.

--------- (1979). Theory of International Politics. Addison-Wesley Publishing Company.

Weinberger, Jerry (1985). Science, Faith, and Politics: Francis Bacon and the Utopian Roots of the Modern Age. Cornell University Press.

Williams, Bernard (2005). Descartes: The Project of Pure Inquiry. Routledge.

Witt, Charlotte (1987). "Hylomorphism in Aristotle," The Journal of Philosophy, 84(11), 673679.

Wheeler, Harvey (1990). “Francis Bacon's New Atlantis: The 'Mould' of a Lawfinding Commonwealth," in Francis Bacon's Legacy of Texts. Edited by William A. Sessions. AMS Press.

White, Andrew Dickson (1897). A History of the Warfare of Science with Theology in Christendom, 2 vols. D. Appleton and Company.

White, Howard B. (1968). Peace Among the Willows: The Political Philosophy of Francis Bacon. Martinus Nijhoff.

Whitney, Charles C. (1990). "Merchants of Light: Science as Colonization in the New Atlantis," in Francis Bacon's Legacy of Texts. Edited by William A. Sessions. AMS Press.

Woodruff, Paul (1993). Justice, Power, and Human Nature: Selections from The History of the Peloponnesian War. Hackett Publishing Company.

Wright, G. H. von, (1951). A Treatise on Induction and Probability. Routledge and Kegan Paul. Ltd.

Yates, Frances A. (1984). "Bacon's Magic," in Ideas and Ideals in the North European Renaissance. Routledge, 60-66.

Zuckert, Catherine (2009). Plato's Philosophers: The Coherence of the Dialogues. The University of Chicago Press. 